$10 / 13.97950$

SANDIA REPORT

SAND97-8210 • UC-706

Unlimited Release

Printed December 1996

\title{
Butyl Rubber O-Ring Seals: Revision of Test Procedures for Stockpile Materials
}

Linda A. Domeier, Kevin R. Wagter

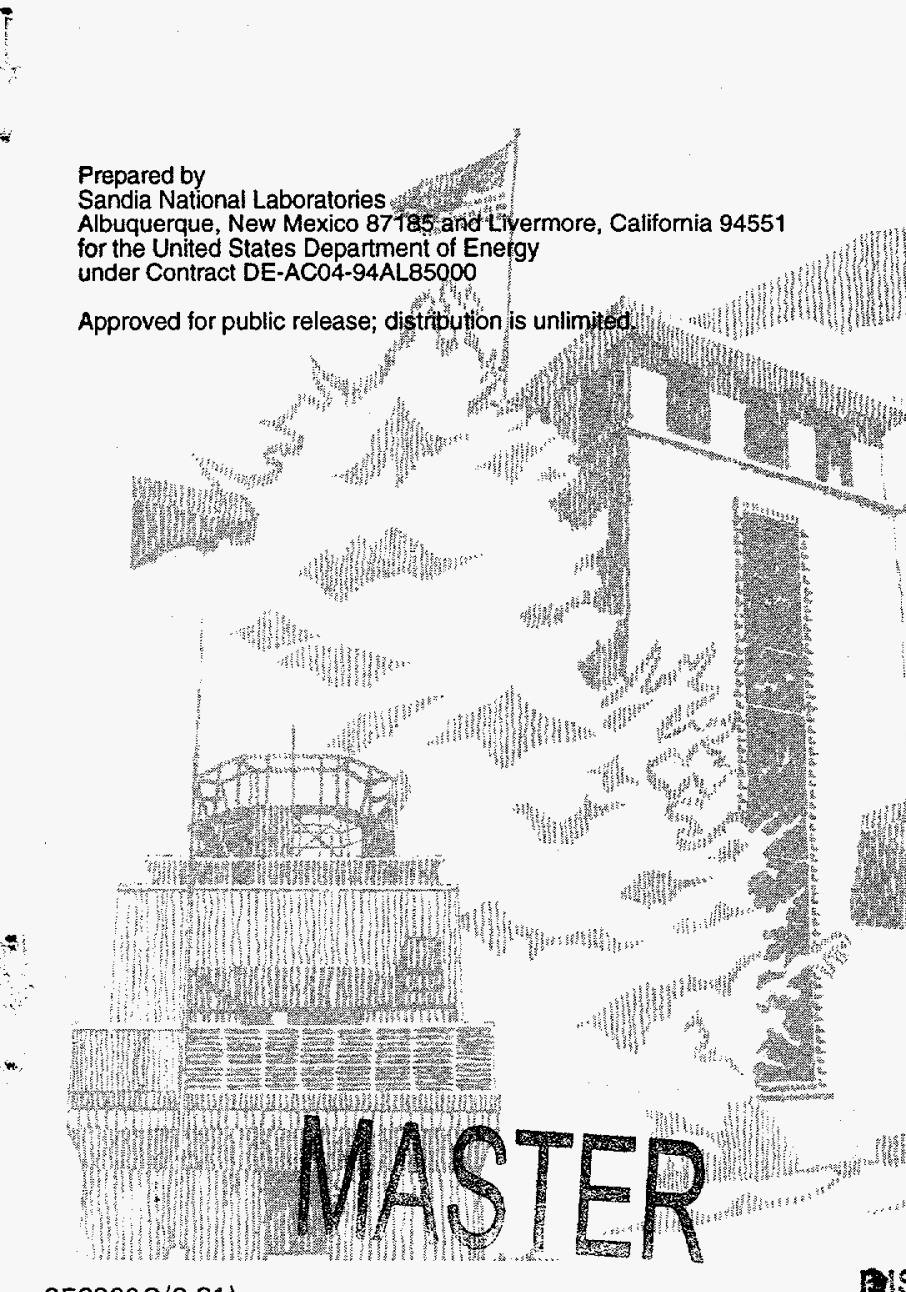


Issued by Sandia National Laboratories, operated for the Uniled States Department of Energy by Sandia Corporation.

NOTICE: This report was prepared as an account of work sponsored by an agency of the United States Govemment. Neither the United States Government nor any agency thereof, nor any of their employees, nor any of the contractors, subcontractors, or their employees, makes any warranty, express or implied, or assumes any legal liability or responsibility for the accuracy, completeness, or usefulness of any information, apparatus, product, or process disclosed, or represents that its use would not infringe privately owned rights. Reference herein to any specific commercial product, process, or senvice by trade name, trademark, manufacturer, or otherwise, does not necessarily constitute or imply its endorsement, recommendation, or favoring by the United States Government, any agency thereof or any of their contractors or subcontractors. The views and opinions expressed herein do not

necessarily state or reflect those of the United States Government, any agency thereof, or any of their contractors or subcontractors.

This report has been reproduced from the best available copy.

Available to DOE and DOE contractors from:

Office of Scientific and Technical Information

P.O. Box 62

Oak Ridge TN 37831

Prices available from (615) 576-8401, FTS 626-8401.

Available to the public from:

National Technical Information Service

U.S. Department of Commerce

5285 Port Royal Rd.

Springfield, VA 22161 
SAND97-8210

Unlimited Release

Printed December 1996

\title{
BUTYL RUBBER O-RING SEALS: REVISION OF TEST PROCEDURES FOR STOCKPILE MATERIALS
}

\author{
Linda A. Domeier and Kevin R. Wagter \\ Materials Processing Department \\ Sandia National Laboratories/California
}

\begin{abstract}
Revised test procedures have been defined for butyl rubber O-ring seals which characterize actual O-ring test specimens in place of the test slab specimens now evaluated. This program was initiated by the W87 system group (Org. 2266) due to concern over the extent to which such test slab evaluations reliably assess the quality and performance of O-rings being accepted for W87 warhead use. Butyl rubber O-rings, in particular, provide critical environmental protection from moisture and oxygen for various components in the W87 and other weapon systems. The program also identified an alternative vendor to the current supplier.

Extensive testing showed little correlation between test slab and O-ring performance. New procedures, comparable in ease to those used with the traditional test slabs, were defined for hardness, compression set and tensile property testing on sacrificial O-ring specimens. Changes in the target performance values were made as needed and were, in one case, tightened to reflect the O-ring performance data. An additional study was carried out on O-ring and slab performance vs. cure cycle and showed surprisingly little sensitivity of the material performance to large changes in curing time.
\end{abstract}

Further aging and spectral characterization of certain materials indicated that two sets of test slabs from the current vendor were accidently made from EPDM rather than butyl rubber. Random testing found no O-rings made from EPDM. As a result of these findings, an additional spectroscopic test will be added to the product acceptance procedures to verify the type of rubber compound used. 
(THIS PAGE INTENTIALLY LEFT BLANK) 


\section{DISCLAIMER}

Portions of this document may be illegible in electronic image products. Images are produced from the best available original document. 


\section{Table of Contents}

Introduction

Program Outline and Overview

Current Butyl Rubber Performance Requirements and Tests

Table 1. Current Butyl Rubber Physical Testing Requirements 10

O-Ring Hardness Testing

Figure 1. Shore M Hardness Testing Apparatus

Table 2. Hardness Data: Slabs and O-Rings

Plot 1. Hardness of Unaged and Aged O-Ring Samples

O-Ring Compression Set Testing

$\begin{array}{lll}\text { Figure } 2 & \text { Compression Set Apparatus and Laser Micrometer } & 18\end{array}$

Table 3. Compression Set Data: Slabs and O-Rings 19

Plot 2. Compression Set of O-Ring Samples 20

O-Ring Tensile Strength and Elongation Testing 21

Figure 3. Insert Mount and Split-spool Fixtures for Tensile Testing 23

Table 4. Tensile Strength Data: Slabs and O-Rings 25

Plot 3. Tensile Strength of Unaged and Aged O-Ring Samples 26

Table 5. Tensile Elongation Data: Slabs and O-Rings 27

Plot 4. Tensile Elongation of Unaged and Aged O-Ring Samples 28

Table 6. Preliminary O-Ring Tensile Strength and Elongation Requirements 28

O-Ring Tensile Modulus and Work Testing

Table 7. Tensile Modulus Data (0-25\% Elongation): Slabs and O-Rings 31

Plot 5. Tensile Modulus (0-25\%) of Unaged and Aged O-Ring Samples $\quad 32$

Table 8. Tensile Work Data (0-20\% Elongation): Slabs and O-Rings 33

Plot 6. Tensile Work (0-20\%) of Unaged and Aged O-Ring Samples 34

O-Ring Tensile Properties vs. Test Speed

Table 9. Tensile Strength, Elongation and Modulus vs. Crosshead Speed 36

Plot 7. O-Ring Tensile Properties vs. Crosshead Speed 37

O-Ring Properties vs. Cure Cycle

Plots 8-13. Test Data from O-Ring Samples with Different Cures

Figure 4. DSC Scans Of Butyl Rubber Samples with Different Cures

Rubber Composition Testing

Figure 5. Solid State NMR Spectra for Butyl and EPDM Rubber 48

Vendor Comparisons

49

Summary

Table 10. Test Data Summary for Materials from Different Vendors

49

Plot 14. Combined, Unaged O-Ring Test Values from Different Vendors

Table 11. Test Data Summary for RD Rubber Materials with Different Cures

Plot 15. Combined, Unaged O-Ring Test Values with Different Cures

Table 12. Proposed Butyl Rubber O-Ring Physical Testing Requirements Acknowledgments

53

54

55 
Table of Contents (continued)

page

Appendix A: $\quad$ Proposed Test Method for Rubber O-Ring Hardness 56

Appendix B: Proposed Test Method for Rubber O-Ring Compression Set 61

Appendix C: $\quad$ Proposed Test Method for Rubber O-Ring Tensile Properties 67

Appendix D: Current Butyl Rubber O-Ring Specification (SS453883) 75

1) Current W87 Butyl Rubber O-Rings 76

2) Copy of SS453883 $\quad 77$

Appendix E: Vendor Information $\quad 84$

1) Participating O-Ring Vendors $\quad 85$

2) Non-participating O-Ring Vendors 86

3) Equipment Vendors $\quad 87$

Appendix F: $\quad$ Hardness Test Data $\quad 88$

1) Hardness and Compression Set Data on O-Rings 89

2) Effect of Sampling Rate on Hardness and Compression Set Data 90

3-4) Plots showing Effect of Sampling Rate on Hardness \& Standard Deviation 91-92

5) Hardness Data from Single O-Rings Compared to Stacked O-Rings 93

6) Operator Sensitivity of Hardness Testing 94

7) Round-Robin Shore M Hardness Testing 95

8) Shore A vs. Shore M Durometer Hardness Data 96

9-15) Detailed Hardness Test Data on O-Rings and Test Slabs 97-103

Appendix G: Compression Set Test Data 104

1) see F-1. Hardness and Compression Set Data on O-Rings

2) see F-2. Effect of Sampling Rate on Hardness and Compression Set Data

3-4) Plots showing Effect of Sampling Rate on Compression Set \& Std. Dev. 105-106

5) Thickness Measurements and Standard Deviations Summary 107

6) O-Ring Thickness vs. Time After Compression Aging 108

7-13) Detailed Compression Set Test Data on O-Rings and Test Slabs

Appendix H: Tensile Strength and Elongation Test Data 116

1) Tensile Data vs. Fixture Parameter and Test Speed 117

2) Tensile Strength and Elongation Data on O-Rings 118

3-11) Detailed Strength and Elongation Test Data on O-Rings and Test Slabs 119-127

Appendix I: $\quad$ Tensile Modulus and Work Test Data 128

1-2) Tangential Tensile Modulus Data (all elongation ranges) 129-130

3-4) Plots showing Unaged and Aged Tensile Modulus Data (all elong. ranges) 131-132

5) Plot showing Unaged and Aged Tensile Modulus Data (average values) 133

6) Tensile Work Data 134

7) Linear Modulus Data 135

8-12) Detailed Modulus (0-25\% elongation) Test Data on O-Rings and Test Slabs 136-140

Appendix J: $\quad$ Properties vs. Cure Cycle Data 141

1) Hardness and Compression Set Data $\quad 142$

2) Tensile Strength and Elongation Data 143

3-4) Tensile Modulus Data $\quad$ 144-145

5) Tensile Work Data 146

6-7) Plots showing Unaged and Aged Tensile Modulus Data (all elong. ranges) 147-148

Appendix K: DSC Scans on Rubber Materials 149

1) O-Rings and Slabs from Different Vendors 150

2) Stockpile Aged W76 and W87 O-Rings 151

Appendix L: $\quad$ Drawings for Tensile Test Fixtures $\quad 152$

1) Angle Mount Drawing 153

2-6) Mount Inserts for Different Ring Cross Sections 154-158 


\section{Introduction}

Traditional acceptance testing methods for O-rings, within DOE and industry, have often relied on the testing of companion test slabs (typically $6 \times 6 \times 0.072$ in.) rather than testing of the actual O-rings. The test slabs are cut into either discs for hardness and compression set testing or into dog-bone specimens for tensile testing. Concerns have persisted, however, over the extent to which such slab testing reliably assesses the quality and performance of O-rings, often over a wide range of sizes, made from the same batch of rubber.

The W87 group initiated a program in 1994 to investigate the testing of butyl rubber O-ring samples in place of test slab samples, to determine the extent to which O-ring and slab test results correlated, and to define appropriate procedures and target test values for the product acceptance testing of O-ring samples. Butyl rubber O-rings, in particular, provide critical environmental seals within the W87 and other weapon systems. Revised test procedures developed for these particular Orings should also be applicable to O-ring seals made from other elastomeric materials.

A second goal of the program was to identify alternate vendors whose butyl rubber O-rings would provide performance equivalent to or better than that now provided. The current W87 specification (SS453883 in Appendix D) requires the use of Parker Seals proprietary B612-70 butyl rubber formulation, effectively excluding all other vendors. Difficulties with Parker and the quality of their materials have made it desirable to qualify at least one additional vendor for these seals and to switch the specification to a performance basis rather than one restricted to a specific formulation.

\section{Program Outline}

The program involved several stages including

1) a survey of potential vendors to identify those capable of providing suitable materials

2) procurement of O-ring and test slab materials for testing

3) procurement of testing equipment

4) preliminary testing to define procedures, to determine the sensitivity of the test data to various parameters, and to modify the procedures and equipment as needed

5) definition of proposed test procedures and equipment

6) procurement of additional batches of rings and test slabs from the vendors

7) complete testing of multiple batches of materials

8) definition of revised test procedures for incorporation into new material specifications.

A total of 19 vendors (see details in Appendix E) were contacted including the current vendor, Parker Seals. Only two vendors other than Parker were able to supply non-halogenated butyl rubber O-rings in sizes close to those requested. Those vendors were RD Rubber Technology Corp. and Precision Associates. RD Rubber is already a supplier of other O-ring seals to the DOE.

The W87 uses butyl O-rings ranging in size from $0.116 \times 0.038$ in. to $16.339 \times 0.103$ in. (inner diameter, ID, of O-ring $x$ cross section, CS, diameter or thickness of rubber cord). Most of the rings are close to one inch in inner diameter with only two significantly larger (details in Appendix D). Four representative sizes, including the two larger sizes, were selected for testing. Vendors other than Parker were allowed to supply O-rings of similar dimensions if custom tooling would be required to produce the exact dimensions requested. Later tests were also conducted on the smallest O-rings currently supplied by Parker $(0.116 \times 0.038$ in.) and on a smaller ring size from RD Rubber. Test slabs were also requested of each vendor and were to be prepared from the same batch of rubber used to fabricate the O-rings. The dimensions of the rings initially obtained from each vendor are shown below. 


$\begin{array}{ccc}\text { Parker Seals } & \underline{\text { RD Rubber }} & \underline{\text { Precision }} \\ 0.301 \times 0.054 \mathrm{in} . & 0.551 \times 0.070 \mathrm{in} . & 0.301 \times 0.054 \mathrm{in.} \\ 1.364 \times 0.070 \mathrm{in.} & 1.114 \times 0.070 \mathrm{in} . & 1.364 \times 0.070 \mathrm{in} . \\ 7.688 \times 0.070 \mathrm{in} . & 7.185 \times 0.103 \mathrm{in.} & 7.739 \times 0.070 \mathrm{in} . \\ 16.339 \times 0.103 \mathrm{in} . & 11.196 \times 0.103 \mathrm{in} . & 16.995 \times 0.139 \mathrm{in} .\end{array}$

Existing ASTM methods were identified which describe procedures and equipment broadly suitable for the testing of $\mathrm{O}$-ring samples. Commercial instruments and fixtures for hardness and compression set testing of rings were ordered. Tensile testing equipment was assembled including commercial fixtures as well as Sandia designed fixtures. Details of this equipment are discussed within each test section and vendor information is included in Appendix E.

O-rings of the sizes noted above were procured from each vendor and used in preliminary evaluations of the test equipment and probable test procedures based on the above ASTM procedures and equipment vendor recommendations. The sensitivity of the data to a range of test variables, including different operators, was investigated and appropriate changes in the equipment and procedures were made until robust procedures had been defined. Additional lots of O-rings were then procured from each vendor for additional testing and comparison to the initial results.

The data presented in the following discussions of each test therefore consists of two sets of data from two different lots of each O-ring size. A total of eight lots (4 ring sizes $x 2$ lots each) were thus evaluated from each vendor. In addition, single lots of two smaller ring sizes were examined, one from Parker and one from RD Rubber, providing a total of nine lots from those vendors. Standard tests were run on companion test slabs made from the same rubber batches, except in those cases where slabs were unavailable, for comparison to the O-ring data.

As a result of these multiple rounds of testing, proposed procedures (Appendices A-C) were developed for hardness, compression set and tensile acceptance testing for a wide range of O-ring sizes. Test values obtained during the program indicated a need to modify the test target values in several cases. No correlation was found throughout the program between test slab results and corresponding O-ring results.

An additional evaluation was carried out in cooperation with one vendor, RD Rubber Technologies, in which O-rings and test slabs were deliberately cured about 3-4 minutes rather than the normal $10 \mathrm{~min}$. Undercuring has been a suspected cause of poorly performing materials and this test series was expected to define the sensitivity of the acceptance tests being used/proposed to such cure deviations. The surprising results showed comparable test behavior for materials cured for reduced periods and cured for the standard period. Subsequent DSC studies indicated that nearly complete cure was obtained with extremely short cure cycles, consistent with comments made by the vendor. While none of the performance tests could reliably distinguish materials processed with such varying cure times, it was, conversely, a desirable feature that O-ring properties appeared to be relatively insensitive to large process variations.

Aging tests being carried out at Allied Signal (Kansas City) on some of the study test slabs suggested unusually good compression aging behavior for a recent butyl rubber batch from Parker Seals. Further analysis on this sample showed, very unexpectedly, that it was prepared from EPDM, not butyl, rubber as ordered and labeled. Random analysis of other samples showed at least one additional Parker test slab to be prepared from EPDM rubber. No O-rings were found to be made from EPDM. As a result of this finding, an additional test is being proposed for the material specification to identify the type of rubber used, butyl vs. EPDM or others. 


\section{Current Butyl Rubber Performance Requirements and Tests}

Current Kansas City acceptance tests for butyl rubber O-rings, as detailed in Appendix D, call for hardness, compression set and tensile testing of samples cut from test slabs prepared from the same batch of rubber as the O-rings being evaluated. Tests are carried out according to ASTM procedures. The only testing now carried out on the rings is a detailed dimensional and visual inspection per MILSTD -413 which would be continued regardless of changes made in the physical test procedures.

Table I summarizes the current W87 physical test requirements, methods and samples used for butyl rubber materials. Density testing can be carried out on any suitably sized sample and no test method revisions were required. No measurement of tensile modulus is currently required and the possibility of adding such a requirement was included in the O-ring method development program. Neither are any measurements of oxygen or moisture permeability currently carried out in acceptance testing although experimental studies in this area have been conducted at Sandia, NM by Ken Gillen.

An extensive literature search revealed no systematic comparisons of rubber test methods using test slab vs. O-ring samples. Hardness testing, in general, has been criticized as a measure of material performance whether in rubber materials, polyurethanes or other polymers. Even the ASTM-D2240 method for hardness testing cautions that no simple relationship exists between hardness values and any fundamental rubber property. One paper suggested the use of tensile work (integration under the stress-strain curve) between 0-20\% elongation as a useful parameter in elastomeric dog-bone samples and such testing is discussed in a following section.

General methods for testing rubber O-ring samples rather than test slab samples have been published as ASTM-D-1414. These procedures are typically vague and merely suggest the use of suitable Oring specimens in the existing ASTM procedures listed in Table I. These procedures served as a starting point to evaluate O-ring testing, but did not provide the detailed procedures eventually needed to insure reproducible results. The ASTM-D-1414 recommendations are discussed in the following sections on hardness, compression set and tensile test method development. 


\section{Table I. Current Physical Testing Requirements for Butyl Rubber Test Slabs***}

\section{Property}

Specific gravity

Hardness

Compression set**

Tensile strength

Tensile elongation
Requirement

$1.14 \pm 0.02$

65-75 Shore A pts before aging. Maximum change of 10 pts after aging*.
$15 \%$ maximum after aging 22 hours at 158 hours under $25 \%$ compression.

1600 psi minimum before aging. Maximum $\pm 15 \%$ change after aging*.

$200 \%$ minimum before aging. Maximum $\pm 15 \%$ change after aging*.
Test Method

ASTM-D-297 (pycnometer or hydrostatic)

ASTM-D-2240

ASTM-D-395 Method B

ASTM-D-412

ASTM-D-412

dog-bone samples cut from test slab

\author{
any suitable piece of \\ test slab (or O-ring)
}

stack of 4-7 discs

(1 in. diameter) cut from test slab or dog-bone end tabs)

stack of 4-5 discs

(1 in. diameter) cut from test slab dog-bone samples cut
from test slab

* Hardness and tensile aging conditions: 70 hours at $212^{\circ} \mathrm{F}$.

** $15 \%$ compression set maximum corresponds to a maximum reduction in original thickness of $15 \% \times 25 \%=3.75 \%$.

*** Test slab dimensions were typically 6 in. $\mathrm{x} 6$ in. with thickness ranging from about 0.077 to 0.100 inches. 


\section{Q-Ring Hardness Testing (Additional tables and plots in Appendix F)}

The blunt, heavily weighted Shore A durometers used to measure hardness on quarter inch stacks of discs cut from test slabs, as noted in ASTM-D-1414, are unsuitable for testing of O-rings. Shore (now a division of Instron) sells a micro-indentor and durometer, the Shore M, specifically for O-ring testing. This durometer is mounted on a hydraulic stand with holding fixtures to position the O-rings, features recommended by ASTM. Both dial and slightly more expensive digital models are available. The micro-indentors, unlike the blunt Shore A probes, actually puncture the O-ring with a needle surrounded by a collar which rests on the O-ring surface. The Shore $M$ durometer is not identical in operation to that currently specified in ASTM-D-1414 and Shore is apparently working on a revision of that specification. Zwick, a German manufacturer, offers a durometer said to conform exactly to the ASTM standard. Difficulties in even obtaining information from Zwick, however, led to the early selection of Shore $M$ durometers which are already widely recognized and used.

In comparing Shore A tests on stacked discs to Shore $M$ tests on O-rings (see Table 2), there is a shift of approximately 5 hardness points. Slabs giving Shore A hardness values of 65-75 are prepared from the same rubber batch as O-rings giving Shore $M$ hardness values of 70-85. Direct comparisons between the Shore A and M durometers (Table F-8 in the Appendix) on similar samples (flat calibration blocks and test slabs) did not show this large shift, indicating good correlation between the two durometer types, and suggest that most of the difference is due to the change in sample geometry (thickness and curvature) and possibly differences in the degree of cure. Later studies on variably cured samples showed little correlation of hardness with cure time and point to the change in sample geometry as the key factor.

In the direct comparisons of Shore $\mathrm{A}$ and $\mathrm{M}$ dial-type durometers on flat blocks and slabs, it was also found that Shore $M$ durometers were much less sensitive to either changes in sample thickness or the time delay between durometer impact and hardness reading (Table F-8). Shore M digital durometers, unlike the dial durometers, are designed to automatically take a reading one second after impact and eliminate any operator influence on the time from impact to reading. The heavier weight $(1 \mathrm{Kg}) \mathrm{used}$ with Shore A durometers would account for the greater sensitivity of Shore A readings to sample thickness and time delay. As discussed below, there were small changes noted in Shore $M$ hardness values when two stacked O-rings were compared to single O-ring samples.

Initial O-ring tests utilized a dial durometer (Shore Model 714) mounted on a hydraulic stand. This was eventually replaced with an automated digital durometer (Shore Model 2000, see Fig. 1) to increase resolution (from 0.5 to $0.1 \mathrm{pts}$ ) and to eliminate operator variables such as reading time after contact and dial position judgments. The hydraulic stand eliminates operator differences in lowering the durometer and impacting the O-rings and also insures correct positioning of the ring so that it is impacted near its midpoint. It was important to exercise the hydraulic stand about ten times immediately before taking a series of readings to insure reproducible operation and hardness values. The platform area of the hydraulic stand can readily support smaller O-rings but left the larger 7 and 16 inch rings drooping over the edges. Difficulties in reproducibly positioning these rings for measurement led to the use of an adjacent "Lab-Jack" stand covered with cardboard which allowed the larger rings to lay flat while being rotated through the double pin fixtures for measurement.

A series of double pin inserts were ordered to accommodate different ring thicknesses and these are easily interchanged according to the ring size being measured. Taller double pin inserts capable of holding two stacked O-rings are also available and suggested by ASTM-D-1414. As shown in Table F-5 in Appendix F, there was a reduction of about 2 hardness points, slightly less for the thinner rings, when a double ring rather than single ring sample was used. This difference was not significant enough to preclude adjusting the target values for ring hardness testing and also required far more care in positioning the samples for measurement. The increased difficulty of using two rings outweighed any partial benefits in matching Shore $\mathrm{A}$ and Shore $\mathrm{M}$ measurements and a single ring procedure was selected. This slight sensitivity of Shore $M$ hardness values to sample thickness was later seen during the testing of large numbers of single O-rings of varying thickness. A drop in 
hardness of 2-3 points was noted at higher thickness although the drop was neither large enough or consistent enough to warrant any change in hardness target values with different O-ring thicknesses.

Table 2 and Plot 1 summarize the hardness data obtained on a series of O-ring (Shore $\mathrm{M}$ ) and test slab (Shore A) lots obtained from the three vendors. Test slabs generally fell near the target of 65-75 points while ring samples made from the same rubber batches gave values of 70-85. As noted above, this higher range is attributed primarily to the change in sample geometry from flat discs to ring cross sections. There was no noticeable correlation of test slab data and $\mathrm{O}$-ring data made from the same batch of rubber. RD Rubber materials gave slightly lower hardness values than Parker and Precision, even after aging. Tables F-1 and F-9 through F-15 provide more detailed data on the Table 2 tests.

The sampling scheme used for this study was generally 2 points each on 5 separate rings (10 data points total) for smaller O-rings and 8 points each on 3 separate rings ( 24 data points) for the larger rings having inner diameters of about 7 and 16 inches. The same rings and sampling rates were used before and after aging although the measurement sites were offset to avoid re-puncturing of the ring. While the data reported here for the larger rings utilized 8 measurements per ring on 3 rings before and after aging, analysis of that data indicated that 4 measurements per ring on 3 rings provided equivalent precision. Table F-2 and Plots F-3 and F-4 in Appendix F show that no loss of precision was incurred by reducing the number of measurement points while clearly reducing the time required.

Using the current slab hardness criteria of 65-75 Shore A points, Sandia tests would have rejected one $\mathrm{RD}$ Rubber slab lot as too low (14810). The proposed ring criteria of 70-85 Shore M points would have rejected no O-ring lots. A tighter $70-80$ ring criteria would have rejected 3 Parker ring lots.

With one exception, all the materials gave higher hardness values after aging. Both the ring and slab samples generally showed a much smaller increase than the currently allowed 10 point variation. As discussed in the section on curing studies, there appeared to be a greater hardness change in less cured materials. A reduction of the allowed hardness change on aging from 10 points to 4 points would therefore help screen out undercured rings while having little total effect on the acceptance rate. Such a reduced aging variation should help insure somewhat greater uniformity in the rings being accepted.

A recognized contributor to uncertainty in hardness values is calibration of the individual durometers, a problem which has previously resulted in round-robin testing of Shore A durometers using test slab discs. Calibration by Shore of the durometers is stated to assure only that the durometer will measure within \pm 3 pts of the stated values on calibration blocks supplied by Shore. Round-robin testing amongst three Shore M digital durometers (two at Sandia, CA and one at Kansas City) showed surprisingly good agreement, only a 1-2 point spread, with one of the Sandia durometers consistently giving the highest value and the $\mathrm{KC}$ durometer the lowest value. The only exception was noted in tests on a large O-ring. An assortment of standard blocks and O-rings was also evaluated as shown in Table F-7. While the agreement found here was quite acceptable, the stated precision of the durometers suggests that an overly rigid specification on O-ring hardness would probably result in unnecessarily low acceptance rates. The recommended hardness target for O-rings is therefore a 15 point range (70-85) instead of the 10 point range (65-75) now used with the test slabs. The allowed change on aging, however, would be reduced from 10 to 4 points as discussed above.

In a related study, the same Shore $M$ dial and digital durometers were used by three different operators to measure the hardness of a set of O-rings. Measurement sites were systematically offset to avoid repuncture while still measuring in similar ring areas. Table F-6 shows some variation with operator, giving up to a 2 point spread in average value per ring. Uncontrolled sources of variation during this series included the ambient temperature and whether the hydraulic stand was properly "exercised" prior to taking readings. Generally good agreement was obtained even with the dial durometer although the digital version was clearly easier to use and provided higher precision.

The recommended procedure for hardness testing of O-rings is described in Appendix $\mathrm{A}$ and the recommended test values are summarized along with the other test changes in Table 12. 
Figure 1. Shore M (Model 2000) Hardness testing apparatus with digital durometer, hydraulic stand and interchangeable double-pin inserts to position the O-rings.
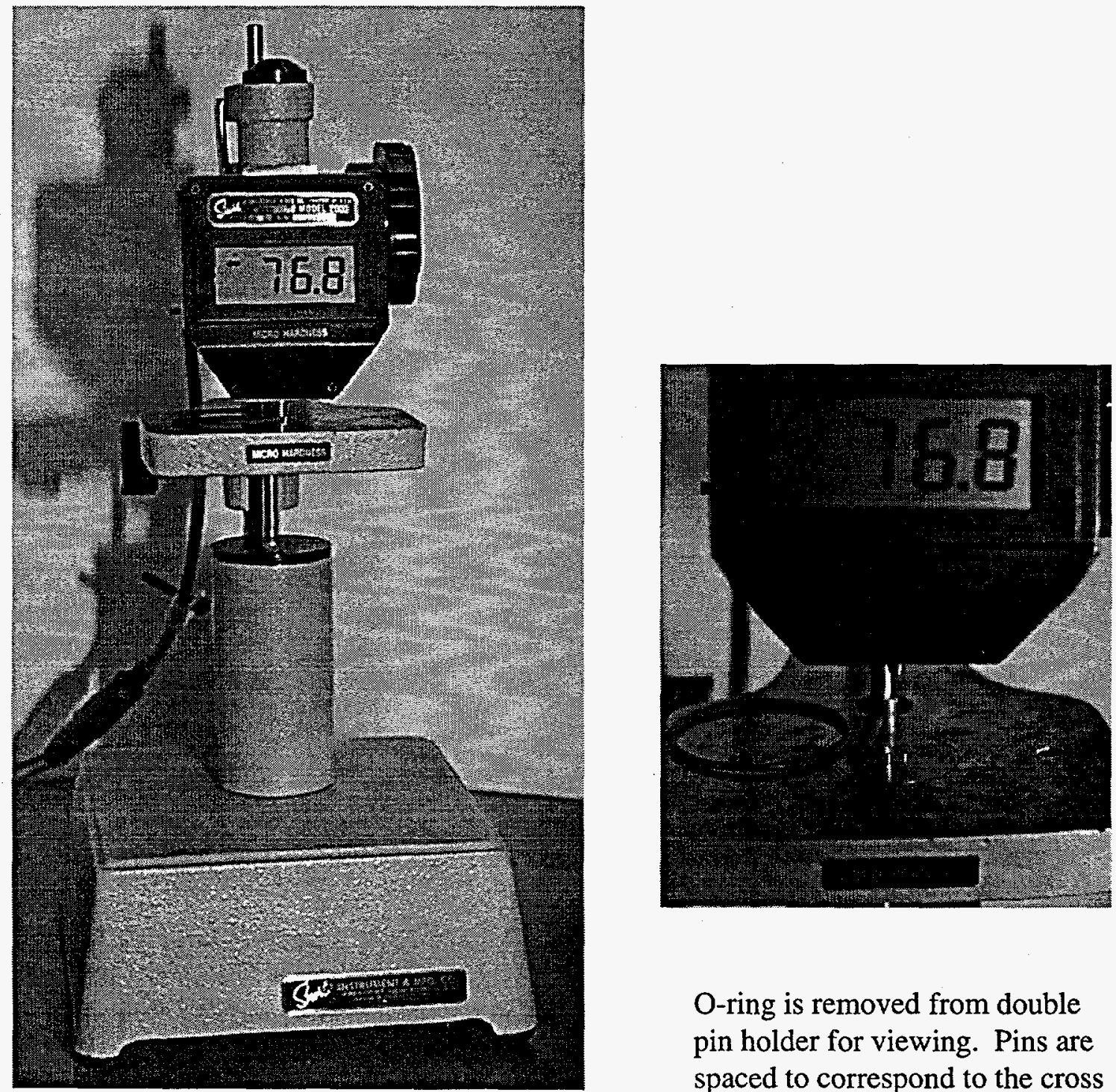

O-ring is removed from double pin holder for viewing. Pins are spaced to correspond to the cross section of the O-ring being tested. 
Table 2. Hardness Data: Slabs and O-Rings

\begin{tabular}{|c|c|c|c|c|c|c|c|c|c|c|}
\hline Vendor & Rubber & \pm Aging & Tes & Slab D & & O-Ring D & ata (Standarc & Deviations $f$ & om \pm 0.3 to \pm 1 & .8$, avg. \pm 0.7$)$ \\
\hline & Batch & & Vendor & $\mathrm{KCP}$ & Sandia & $0.116 \times 0.038$ & $0.301 \times 0.054$ & $1.364 \times 0.070$ & $7.688 \times 0.070$ & $16.339 \times 0.103$ \\
\hline Parker & 316104 & unaged & 72,75 & 65 & 72.3 & & 81.1 & $\begin{array}{l}79.7 \\
80.9\end{array}$ & $\begin{array}{l}80.8 \\
81.8\end{array}$ & $\begin{array}{l}79.6 \\
811\end{array}$ \\
\hline Parker & 316710 & unaged & 72 & & $\begin{array}{l}69.0 \\
70.3\end{array}$ & & $\begin{array}{l}81.3 \\
80.8\end{array}$ & & & $\begin{array}{l}77.8 \\
79.9\end{array}$ \\
\hline Parker & 317403 & unaged & 70 & & 72.8 & & & 77.5 & & \\
\hline Parker & 317851 & $\begin{array}{l}\text { aged } \\
\text { unaged }\end{array}$ & 67,69 & 73 & $\begin{array}{l}75.8 \\
73.0\end{array}$ & & & & 72.2 & \\
\hline & & aged & & 73 & 73.3 & & & & 75.3 & \\
\hline Parker & 318466 & $\begin{array}{c}\text { unaged } \\
\text { aged }\end{array}$ & & & $\begin{array}{l}72.8 \\
74.0\end{array}$ & $\begin{array}{l}74.9 \\
78.1\end{array}$ & & & & \\
\hline & & & & & & $0.301 \times 0.054$ & $0.551 \times 0.070$ & $1.114 \times 0.70$ & $7.185 \times 0.103$ & $11.196 \times 0.103$ \\
\hline RD & 14810 & unaged & 65,65 & 64 & 63.3 & & 75.1 & $\begin{array}{l}73.7 \\
75.7\end{array}$ & $\begin{array}{l}71.0 \\
72.4\end{array}$ & \\
\hline $\mathrm{RD}$ & 14936 & unaged & 66,66 & 68 & NA & & & & & 72.6 \\
\hline RD & 15107 & $\begin{array}{c}\text { unaged } \\
\text { aged }\end{array}$ & 70 & & $\begin{array}{l}65.5 \\
64.8\end{array}$ & $\begin{array}{l}76.1 \\
79.3\end{array}$ & $\begin{array}{l}74.6 \\
76.8\end{array}$ & $\begin{array}{l}75.2 \\
76.8\end{array}$ & $\begin{array}{l}74.2 \\
76.1\end{array}$ & $\begin{array}{l}72.8 \\
75.4\end{array}$ \\
\hline & & & & & & & $0.301 \times 0.054$ & $1.364 \times 0.070$ & $7.739 \times 0.070$ & $16.955 \times 0.139$ \\
\hline Precision & 17405 & unaged & NA & & NA & & & 76.9 & & \\
\hline Precision & 19052 & $\begin{array}{c}\text { unaged } \\
\text { aged }\end{array}$ & NA & & $\begin{array}{l}72.8 \\
74.8\end{array}$ & & $\begin{array}{l}74.6 \\
80.0\end{array}$ & & $\begin{array}{l}78.4 \\
80.9\end{array}$ & \\
\hline Precision & 19422 & $\begin{array}{c}\text { unaged } \\
\text { aged }\end{array}$ & NA & & NA & & & & & $\begin{array}{l}75.6 \\
78.1\end{array}$ \\
\hline Precision & 19895 & $\begin{array}{c}\text { unaged } \\
\text { aged }\end{array}$ & 73 & & $\begin{array}{l}71.5 \\
75.5\end{array}$ & & $\begin{array}{l}78.3 \\
79.4\end{array}$ & $\begin{array}{l}77.6 \\
79.2\end{array}$ & $\begin{array}{l}77.7 \\
80.6\end{array}$ & $\begin{array}{l}76.3 \\
79.1\end{array}$ \\
\hline Precision & 19921 & $\begin{array}{c}\text { unaged } \\
\text { aged }\end{array}$ & 73 & & NA & & & & & \\
\hline
\end{tabular}




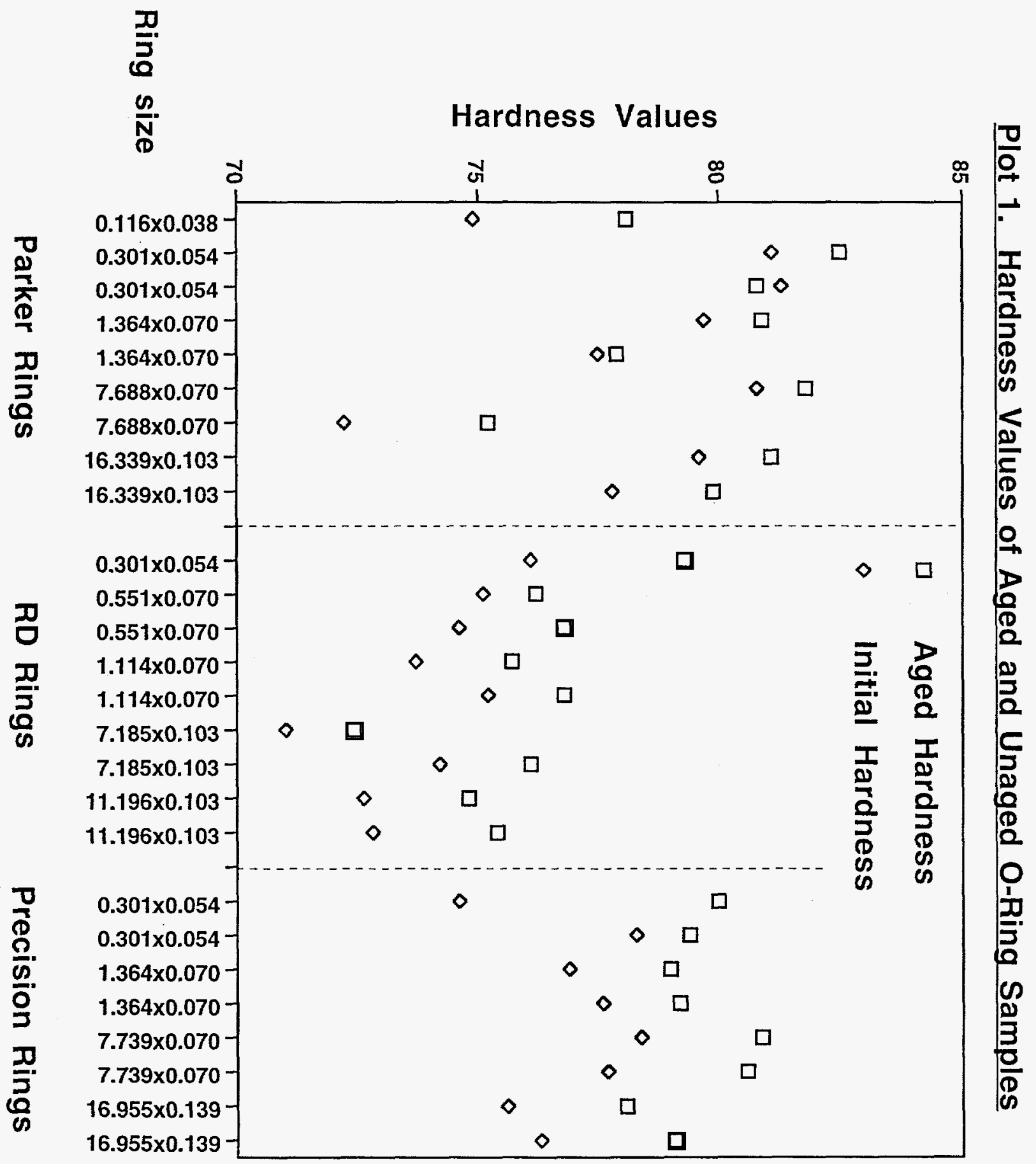




\section{O-Ring Compression Set Testing (Additional tables and plots in Appendix G)}

Compression set testing is probably the most important performance test carried out on O-ring sealant materials as it most closely approximates real performance requirements. The major challenge faced in compression set testing of O-rings vs. much thicker stacks of test slab discs was the higher precision needed in initial and final thickness measurements. The current specification calls for a $15 \%$ maximum compression set after aging under $25 \%$ compression. This translates to an overall loss of thickness of $15 \% \times 25 \%$ or $3.75 \%$ of the initial thickness. For ring thicknesses as low as 0.038 inches, the corresponding maximum thickness loss would be 0.0014 inches. Additional challenges were posed by the non-uniformity of thickness around typical rings and the need, therefore, to insure that the same cross section location, both around and through the ring, was being measured before and after aging.

The dial or spring micrometers specified in D-1414 were found to provide inadequate resolution and a laser micrometer, similar to one already used at Kansas City, was acquired. Both the precision and ease of operation were improved with the laser micrometer which is shown in Figure 2. Laser micrometers provide resolution of \pm 0.00001 inches, ten times that of the Shore micrometers, and the level of operator skill required was significantly reduced. Samples are simply placed on the fixture and the thickness measurement recorded.

The compression set aging apparatus, available from at least two vendors, is simply a set of chrome plated steel plates which are bolted together (see Fig. 2). The distance between the plates is fixed by using spacers of the desired thickness. The same apparatus used to compress the stacks of test slab discs is suitable for the O-ring samples and simply requires the use of thinner spacers. Compression tests typically call for the sample to be compressed $25 \%$ (i.e. to $75 \%$ of its initial thickness). Spacers were ordered corresponding to 75\% of each of the ring thicknesses to be evaluated and samples were compressed to $75 \%$ of their nominal thickness. No adjustments were made for variations from this nominal thickness as is done with the thicker stacks of discs.

Slices about 2 in. long from larger O-rings are suggested in ASTM-D-1414 as samples. Shorter segments, with less curvature, tended to roll more easily and were difficult to position reproducibly with exactly the same ring cross-section exposed for measurement and compression. For smaller rings it is suggested in ASTM-D-1414 that a 1/8 in. section be removed and the remainder of the ring used as a sample. D-1414 strongly recommends that whole O-rings not be used as samples due to trapped air and potentially different aging conditions on the inside of the ring. It was found convenient in the Sandia tests to simply slice smaller O-rings into halves, each of which could be used as a sample in the compression set test. Ring segments were conveniently marked on their outside circumference with dots of ordinary white correction fluid to allow measurement of the same cross section location before and after aging. This can be seen in the detail in Fig. 2.

Early testing pointed out the need for careful removal of the ring segments from the compression apparatus. Segments needed to be gently scraped from the metal surface using a sheet of paper or similar "blade" so as to avoid any peeling or stretching of the segment. Mold release on the metal surface assisted this process, especially on poorly plated or degraded surfaces.

Laser micrometer measurements were carried out to determine the rate at which compression set aged samples rebounded and whether the 30 minute delay currently specified between sample removal from the hot apparatus and thickness measurement was critical in any way. Ring segments were removed from the apparatus, immediately placed in the laser micrometer fixture, and analyzed for height vs. time. Cooling effects, leading to contraction, compete with rebound expansion during the initial measurements, especially in the larger rings. Plot G-6 in the Appendix shows the overall thickness recovery rate in the laser micrometer for two ring sizes. In both cases the data indicates that the 30 minute waiting period is adequate to reach a relatively stable thickness. Most of the rebound is virtually instantaneous and shorter or longer waiting periods, for example $20 \mathrm{~min}$. to $40 \mathrm{~min}$., would 
have no significant effect on the results. The recommended $30 \mathrm{~min}$. waiting period should be adhered to as closely as possible, especially with thicker ring sizes, to insure good reproducibility.

Table 3 and Plot 2 summarize the compression set data obtained on a series of O-ring and test slab lots obtained from the three vendors. Ring samples, in general, showed significantly lower compression set values $(5-12 \%)$ than the stacks of discs $(6-20 \%)$. There was again no correlation of ring and test slab data and there was no consistent trend of compression set with ring thickness. Precision rings and slabs showed higher compression set than Parker or RD Rubber materials. The compression set values on their test slabs were well above the current $15 \%$ allowed and would have been cause for rejection.

As a result of this testing it was decided that the allowable compression set, measured on ring samples in place of disc stacks, could be reduced from $15 \%$ to $10 \%$ with no significant decrease in acceptance rate. The lower allowed value should ensure greater uniformity in the rings accepted and perhaps better long term performance as well. Using this $10 \%$ maximum compression set criteria and rounding the hardness data to the nearest whole integer would have rejected 1 of the Parker ring lots, none of the RD ring lots, and 5 of the Precision ring lots.

Even with the more precise laser micrometer, there was concern over the magnitude of the standard deviation values relative to the actual change in thickness being measured. Table G-1 summarizes the standard deviations typically observed and also the change in thickness observed after compression set aging. The ring samples show an average change in thickness which is roughly 2-3 times the average standard deviation of the thicknesses being measured. This largely reflects the non-uniform thickness of the original rings and would not be improved by a more precise measuring instrument. Given that the ring samples, although non-uniform, are at least being measured in the same locations before and after, this is probably an acceptable situation and one which is inherent to testing real ring samples.

The sampling scheme used in these tests was, as in the hardness tests, generally 2 points each on 5 separate rings ( 10 data points total) for smaller O-rings and 8 points each on 3 separate rings ( 24 data points) for the larger rings having inner diameters of about 7 and 16 inches. The same rings and the same thickness measurement sites were used before and after compression aging. This is detailed in the procedure in Appendix B. While the data reported here for the larger rings utilized 8 thickness measurements per ring on 3 rings ( 24 data points) before and after aging, analysis of that data again indicated that the use of 4 measurements per ring provided equivalent precision. Table F-2 and Plots G-1 and G-2 in the appendices show that no loss of precision was incurred by reducing the number of measurement points while clearly reducing the time required.

The recommended procedure for compression set testing of O-rings is described in Appendix B and the recommended test values are summarized along with the other test changes in Table 12. 
Figure 2. Compression set apparatus and laser micrometer used for thickness measurements.
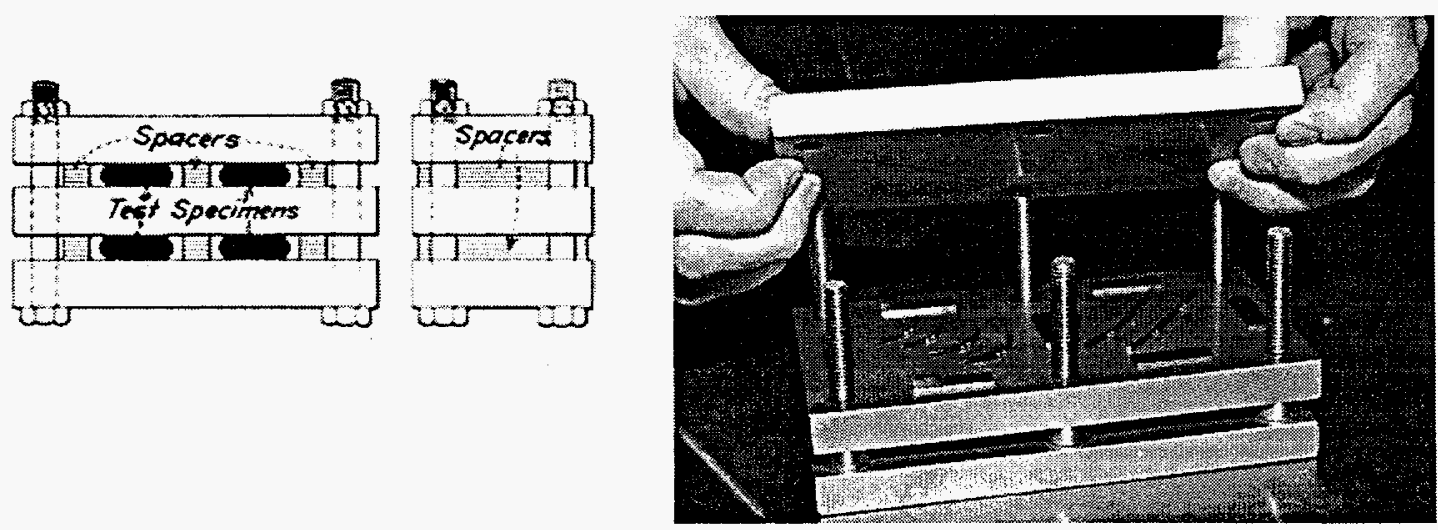

Compression set apparatus with spacers and O-rings.
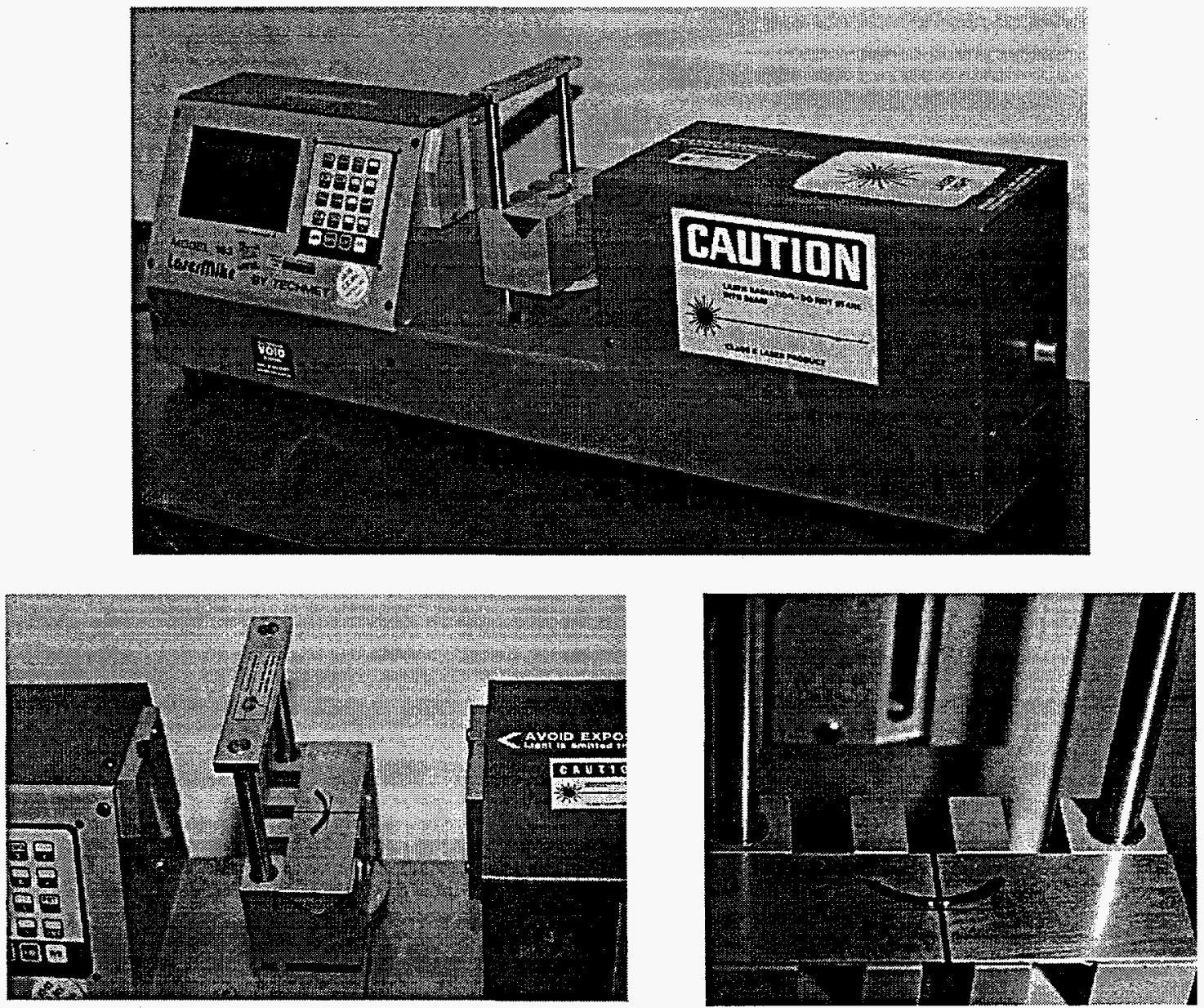

Laser micrometer (Model 183) with fixture insert and O-ring marked and positioned for thickness measurement. 
Table 3. Compression Set Data: Slabs and O-Rings

\begin{tabular}{|c|c|c|c|c|c|c|c|c|c|}
\hline \multirow[t]{2}{*}{ Vendor } & \multirow{2}{*}{$\begin{array}{l}\text { Rubber } \\
\text { Batch }\end{array}$} & \multicolumn{3}{|c|}{ Test Slab Data } & \multicolumn{5}{|c|}{ O-Ring Data } \\
\hline & & Vendor & KCP & Sandia & $0.116 \times 0.038$ & $0.301 \times 0.054$ & $1.364 \times 0.070$ & $7.688 \times 0.070$ & $16.339 \times 0.103$ \\
\hline Parker & 316104 & 11.0 & 14.5 & 11.0 & & 4.6 & 6.1 & 7.7 & 7.8 \\
\hline Parker & 316710 & & & 9.9 & & 9.7 & & & 8.7 \\
\hline Parker & 317403 & & & 10.4 & & & 10.1 & & \\
\hline Parker & 317851 & 10.0 & 9.8 & 15.9 & & & & 8.2 & \\
\hline Parker & 318466 & & & 18.9 & 10.7 & & & & \\
\hline & & & & & $0.301 \times 0.054$ & $0.551 \times 0.070$ & $1.114 \times 0.70$ & $7.185 \times 0.103$ & $11.196 \times 0.103$ \\
\hline RD & 14810 & 7.0 & 6.3 & 5.9 & & 5.5 & 5.6 & 5.0 & \\
\hline RD & 14936 & 6.3 & 8.7 & NA & & & & & 4.5 \\
\hline RD & 15107 & 10.5 & & 12.6 & 6.5 & 5.7 & 7.1 & 5.6 & 4.8 \\
\hline & & & & & & $0.301 \times 0.054$ & $1.364 \times 0.070$ & $7.739 \times 0.070$ & $16.955 \times 0.139$ \\
\hline Precision & 17405 & NA & & NA & & & 8.8 & & \\
\hline Precision & 19052 & NA & & 24.0 & & 9.5 & & 10.7 & \\
\hline Precision & 19422 & NA & & NA & & & & & 12.0 \\
\hline Precision & 19895 & 14.3 & & 22.8 & & 10.7 & 10.0 & 11.5 & 19.8 \\
\hline Precision & 19921 & 22.2 & & NA & & & & & \\
\hline
\end{tabular}




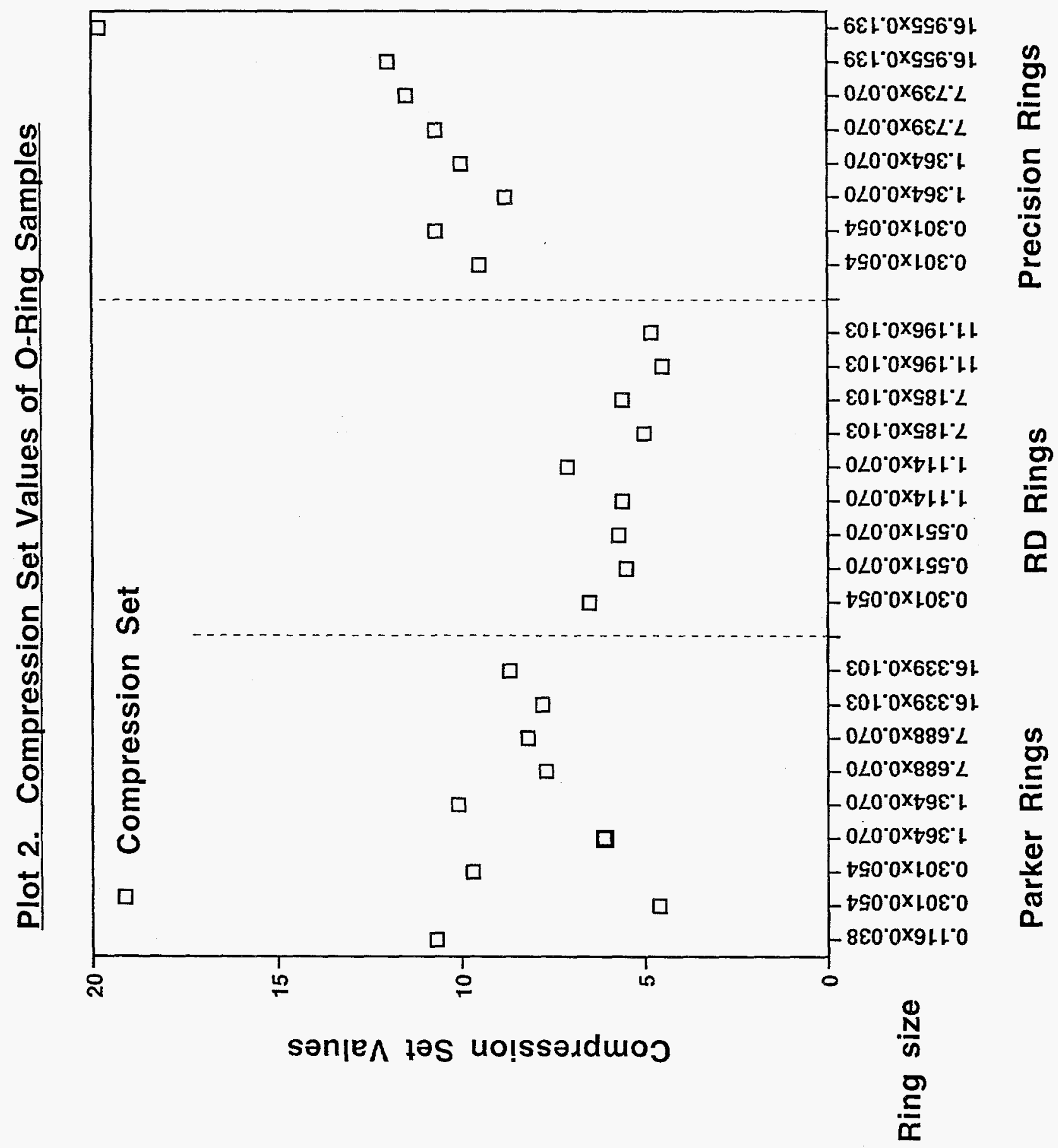




\section{O-Ring Tensile Strength and Elongation Testing (Additional tables and plots in Appendix H)}

ASTM-D-1414 recommends the use of whole O-rings for ring tensile testing along with the use of rotating ball-bearing spools and lubrication to minimize local stresses. A crosshead speed of 20 in./min. is suggested. All tests in this program were carried out on whole O-rings to avoid the inherent fixturing and stress localization problems associated with ring segment samples.

When the effects of such variables as fixture rotation, lubrication, multiple looping of larger rings, and test speed were evaluated there was little variation noted with any of these parameters. Table H-1 summarizes these early results. As part of this initial evaluation, a very simple set of grooved, splitspool fixtures was designed and fabricated. These non-rotating fixtures are shown in Fig. 3 and the design drawings are included in Appendix L. The interchangeable spools of different diameters can readily accommodate a wide range of O-ring sizes and were particularly suited for testing the very small rings typical of many W87 parts. Rod fixtures with optional rotation were obtained commercially. No significant differences in test values were noted among the three types of fixtures. While lubrication is still recommended and was used throughout this program, no significant effects were noted when it was not used with any of the fixture types evaluated. Similarly, no effects were noted when rings were fixtured with either 1, 2 or 3 loops. These initial looping tests utilized a rotating fixture. The non-rotating fixtures are probably more suitable for multi-looped rings as there is no potential interaction of the cross-over sites with the fixture.

Following these initial tests, the very simple, non-rotating split-spool fixtures in Fig. 3 were selected for further O-ring tensile testing. Similar fixtures can be fabricated and supplied to vendors and a set has already been provided to Kansas City. O-rings are simply slipped over the grooved top and bottom fixtures, the fixture gap is adjusted according to the O-ring and spool sizes to set the zero elongation point, and the ring is then stretched to failure. Tables in the proposed method in Appendix $\mathrm{C}$ detail the spool diameter to be used with each ring size and provide starting crosshead distances for the O-ring sizes used in the W87. Extensometers were not used and sample elongations were calculated from crosshead distances.

Test speeds in the initial studies above were varied between 10 and $20 \mathrm{in} . / \mathrm{min}$. and showed little effect on the data. Most of the data acquired during the program was taken at $20 \mathrm{in} . / \mathrm{min}$. as recommended by ASTM. A more detailed study of test speed effects was carried out near the end of the program and was motivated by potential difficulties noted in measuring modulus on smaller Orings. At $20 \mathrm{in} . / \mathrm{min}$. these rings are stretched and broken very quickly, sometimes within seconds. That evaluation of test speed is discussed in a following section, but Plots $\mathrm{H}-2$ and $\mathrm{H}-3$ illustrate the effects on tensile strength and elongation when test speeds were varied over a wider range. Strength increased about $10-20 \%$ over the 5-20 in./min. range while elongation was essentially unaffected.

Test speeds eventually recommended for ring acceptance testing were $5 \mathrm{in} . / \mathrm{min}$. for all the smaller W87 rings and 20 in./min. for the two larger rings with inner diameters of about 7 and 16 inches. This should increase the precision of the tests and also allow the use of strip chart recorders in place of computerized data systems if desired. All rings were also tested with only one loop except for the two larger rings which were tested with a triple loop. No rings were double looped.

Tables 4 and 5 and Plots 3 and 4 summarize the tensile strength and elongation data obtained on a series of O-ring and test slab lot obtained from the three vendors. Unlike the hardness and compression set results, there was a clear correlation of tensile strength and elongation with ring size. The lower strength and elongation seen in larger rings may simply reflect a higher number of potential defects with increasing volume as suggested in "Rubber Technology Handbook", W. Hofmann (Hanser Publishers, 1989). This variation with ring size led to wide overall ranges in both tensile strength (1100-2500 psi) and elongation (170-400\%). A range of tensile strength (1450-2300 psi) and elongation (150-250\%) were also noted for the test slab data, however, which was all gathered on samples with identical dimensions. There was again no significant correlation of slab and ring data 
from the same rubber batches. Slabs were cut with a stencil into dog-bone specimens, five per slab, for testing.

Both the initial strength and elongation decreased as ring size increased. A graduated range of minimal strength and elongation target values will therefore be required for ring testing in place of the single values now used with the test slabs. Final decisions on these targets will be made after additional testing at Kansas City, but a preliminary set of tensile strength and elongation requirements are shown in Table 6 . As future tests on all but the larger rings will be carried out at $5 \mathrm{in} . / \mathrm{min}$. instead of the $20 \mathrm{in.} / \mathrm{min}$. used in this study, the strength and elongation values on smaller rings are expected to decrease slightly and the values shown in Table 6 were selected with that in mind.

Using the current slab criteria, the Sandia tests would have failed all the Parker slab lots (either for strength or elongation or both) and none of the RD Rubber or Precision slabs. Kansas City tests on the slabs, where available, were all passing. Using the proposed ring criteria in Table 6, the Sandia tests would have failed 1 of the Parker ring lots (for strength), none of the RD Rubber ring lots, and 1 of the Precision lots (for strength). Strength values obtained at slower speeds may be 10-20\% lower and would increase the rejection rate, particularly of some of the Parker materials.

Aging of the samples gave roughly equal increases and decreases in tensile strength. Elongation decreased with aging in about $2 / 3$ of the tests. The allowable $\pm 15 \%$ percent change on aging, particularly of elongation, would have eliminated all but one lot of the O-rings received from Precision. All the Parker rings and all but one of the RD Rubber lots were within this $15 \%$ change on aging, however. No modification in the current aging specification appeared to be warranted.

Most of the tensile tests in this study utilized 8 rings for the initial properties and another 8 rings for the aged properties. Smaller numbers were used in some cases due to limited availability. A more convenient sample size for future acceptance testing would be 5 rings each before and after aging.

Based on discussions with the Kansas City personnel, it was decided that tensile testing on aged samples would probably not be required for acceptance of every O-ring lot received. Complete tensile testing (aged and unaged samples) would instead be required as a vendor qualification test on a regular interval to be decided. Factors in this decision were the absence of significant tensile stresses on the O-rings as used in compression and the large number of rings required for tensile testing.

The recommended procedure for tensile testing of O-rings is described in Appendix $\mathrm{C}$ and the recommended test values are summarized along with the other test changes in Table 12. 
Figure 3. Insert mount and split-spool, interchangeable fixtures for O-ring tensile testing. Insert and split spools fabricated according to Sandia drawings.

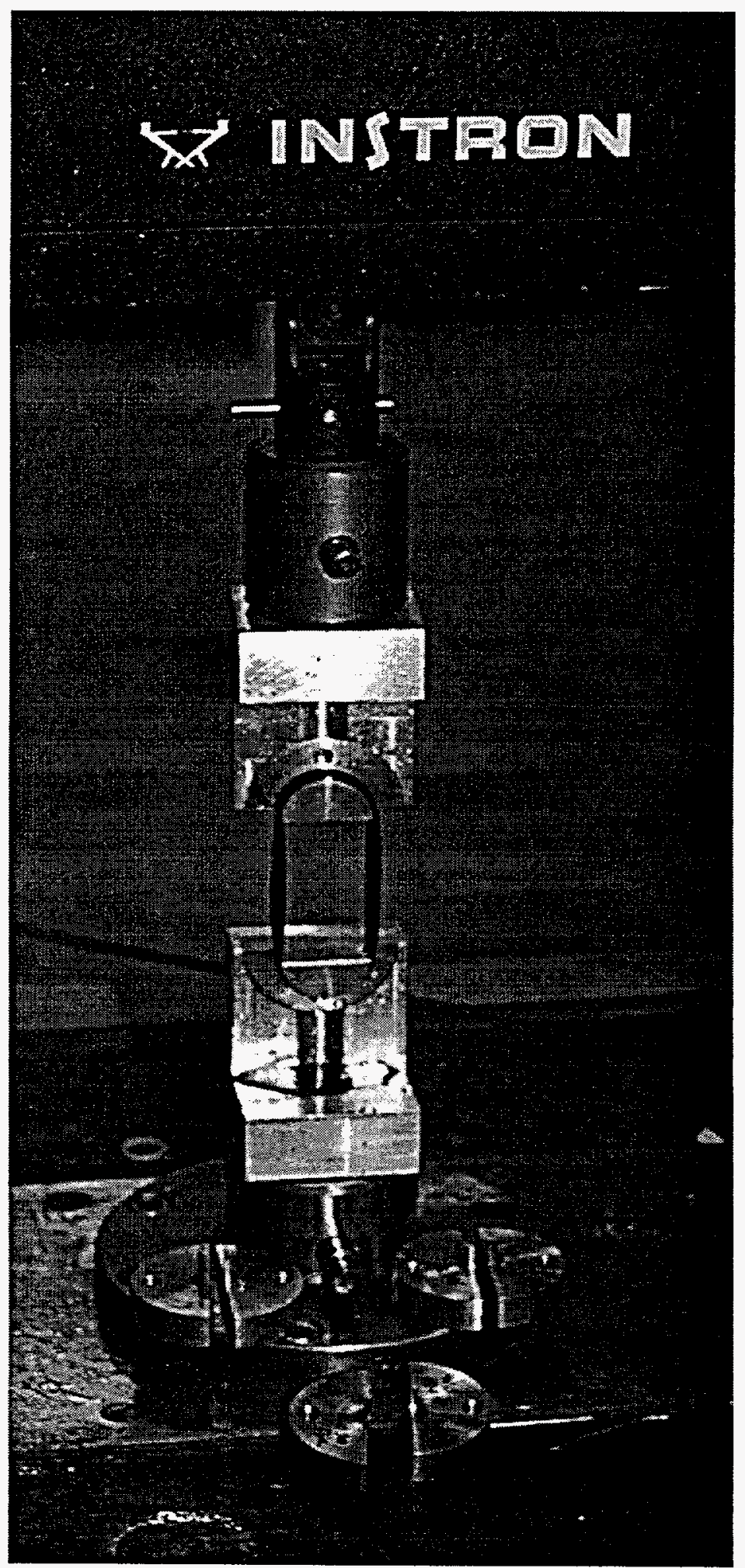


Table 4. Tensile Strength Data: Slabs and O-Rings

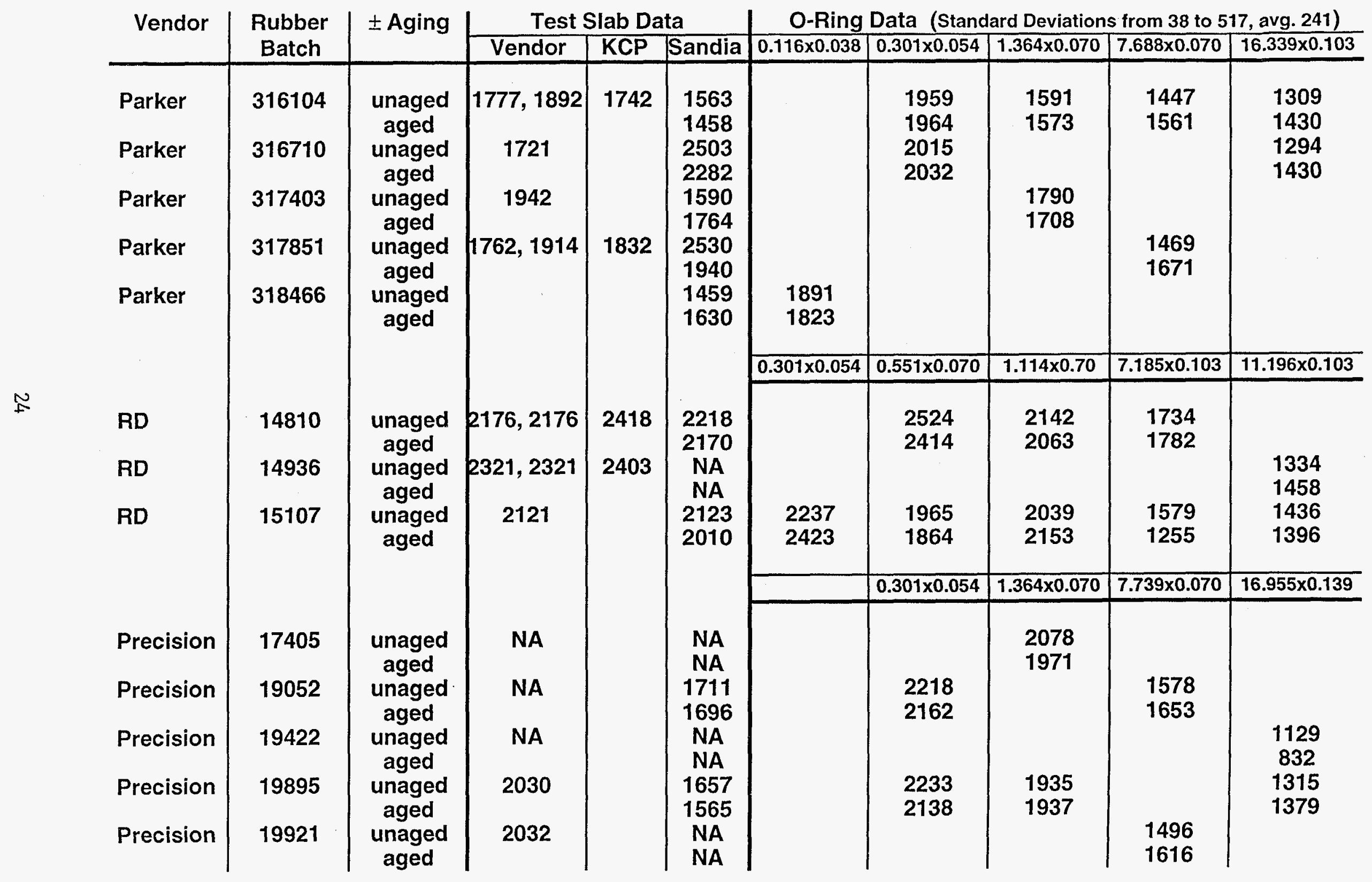


꼭

N

Tensile Strength (psi)

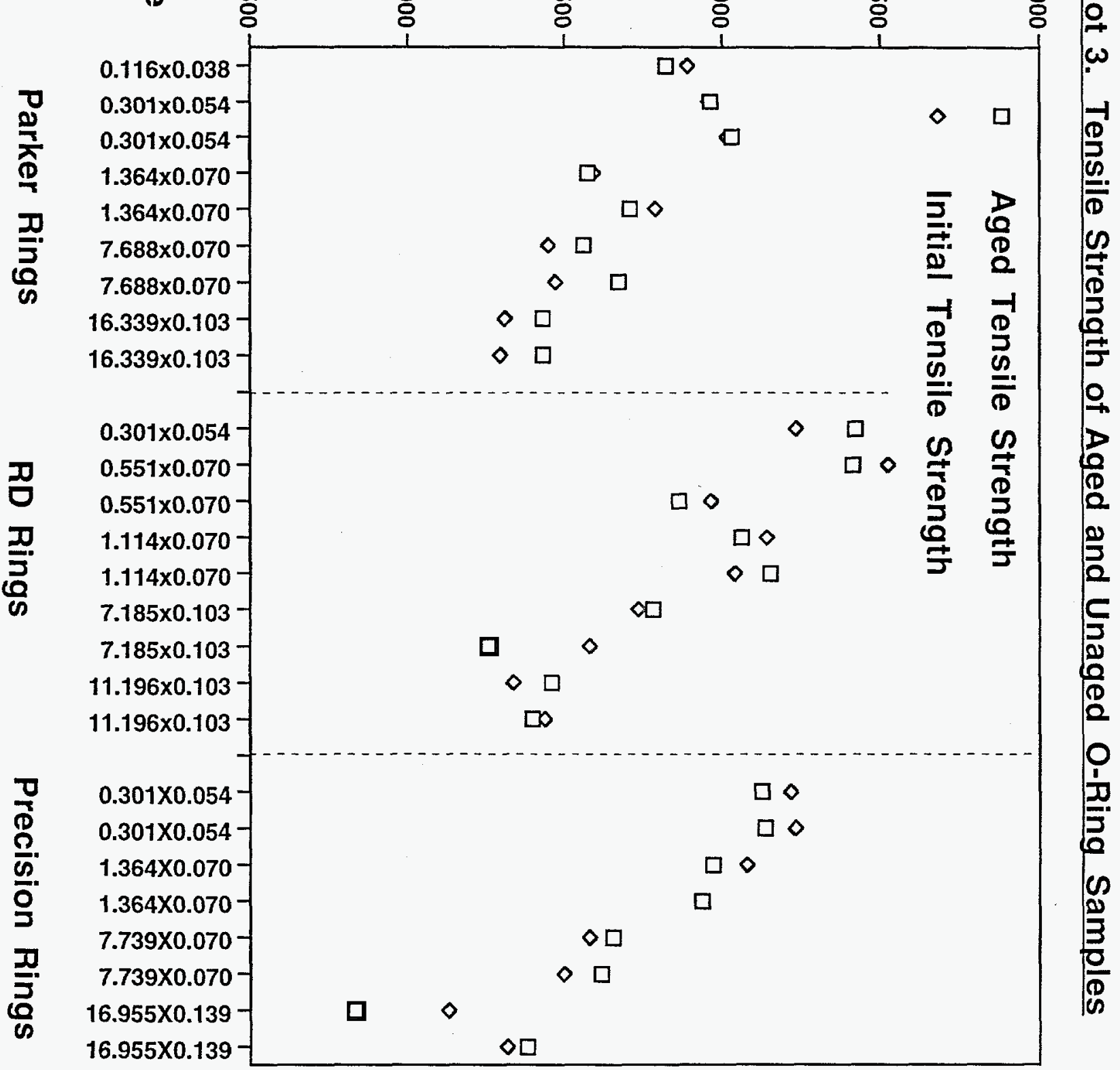


Table 5. Tensile Elongation Data: Slabs and O-Rings

\begin{tabular}{|c|c|c|c|c|c|c|c|c|c|c|}
\hline Vendor & Rubber & \pm Aging & Test & Slab D & & O-Ring I & Data (Stand & rd Deviations & from 4 to 85 , & avg. $30 \%$ ) \\
\hline & Batch & & Vendor & $\mathrm{KCP}$ & Sandia & $0.116 \times 0.038$ & $0.301 \times 0.054$ & $1.364 \times 0.070$ & $7.688 \times 0.070$ & $16.339 \times 0.103$ \\
\hline Parker & 316104 & unaged & 215,239 & 290 & 199 & & 259 & 209 & 178 & 168 \\
\hline & 316710 & $\begin{array}{c}\text { unaged } \\
\text { aged }\end{array}$ & 233,264 & 260 & $\begin{array}{l}160 \\
186 \\
172\end{array}$ & & $\begin{array}{l}261 \\
272 \\
271\end{array}$ & 210 & 188 & $\begin{array}{l}188 \\
203\end{array}$ \\
\hline Parker & 317403 & $\begin{array}{c}\text { unaged } \\
\text { aged }\end{array}$ & 286 & & $\begin{array}{l}221 \\
221\end{array}$ & & & $\begin{array}{l}281 \\
269\end{array}$ & & \\
\hline Parker & 317851 & unaged & $421 ?$ & & 178 & & & & 362 & \\
\hline Parker & 318466 & $\begin{array}{c}\text { aged } \\
\text { unaged } \\
\text { aged }\end{array}$ & & & $\begin{array}{l}152 \\
535 \\
588\end{array}$ & $\begin{array}{l}278 \\
264\end{array}$ & & & & \\
\hline & & & & & & $0.301 \times 0.054$ & $0.551 \times 0.070$ & $1.114 \times 0.70$ & $7.185 \times 0.103$ & $11.196 \times 0.103$ \\
\hline RD & 14810 & $\begin{array}{c}\text { unaged } \\
\text { aged }\end{array}$ & 372,372 & 300 & $\begin{array}{l}273 \\
247\end{array}$ & & $\begin{array}{l}402 \\
344\end{array}$ & $\begin{array}{l}314 \\
293\end{array}$ & 231 & \\
\hline RD & 14936 & unaged & 273,273 & 230 & NA & & & & & 180 \\
\hline $\mathrm{RD}$ & 15107 & $\begin{array}{l}\text { aged } \\
\text { unaged } \\
\text { aged }\end{array}$ & 320 & & $\begin{array}{l}\text { NA } \\
243 \\
220\end{array}$ & $\begin{array}{l}308 \\
303\end{array}$ & $\begin{array}{l}293 \\
261\end{array}$ & $\begin{array}{l}296 \\
300\end{array}$ & $\begin{array}{l}215 \\
171\end{array}$ & $\begin{array}{l}184 \\
175 \\
152\end{array}$ \\
\hline & & & & & & & $0.301 \times 0.054$ & $1.364 \times 0.070$ & $7.739 \times 0.070$ & $16.955 \times 0.139$ \\
\hline Precision & 17405 & unaged & NA & & NA & & & 313 & & \\
\hline Precision & 19052 & unaged & NA & & 276 & & $\begin{array}{l}380 \\
300\end{array}$ & & $\begin{array}{l}192 \\
152\end{array}$ & \\
\hline Precision & 19422 & unaged & NA & & NA & & & & & 188 \\
\hline Precision & 19895 & unaged & 312 & & 229 & & 369 & 275 & & 223 \\
\hline Precision & 19921 & $\begin{array}{c}\text { unaged } \\
\text { aged }\end{array}$ & 311 & & $\begin{array}{l}\text { NA } \\
\text { NA }\end{array}$ & & & & $\begin{array}{l}226 \\
181\end{array}$ & \\
\hline
\end{tabular}




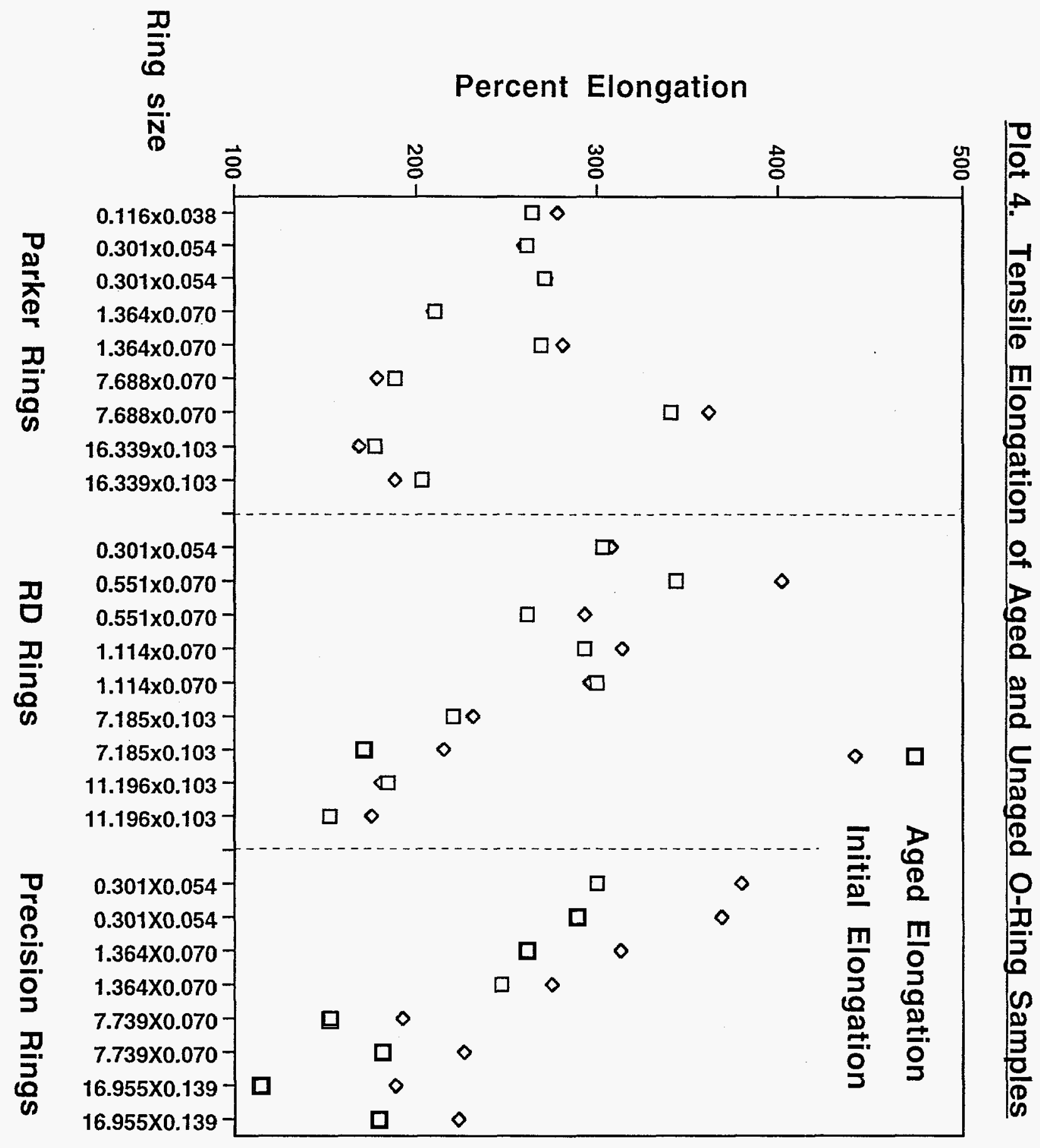


Table 6. Preliminary Tensile Strength and Elongation Requirements for O-Ring Testing

\begin{tabular}{c|c|c} 
Ring size & $\begin{array}{c}\text { Initial Tensile Strength } \\
\text { Minimum Value }\end{array}$ & $\begin{array}{c}\text { Initial Tensile Elongation } \\
\text { Minimum Value }\end{array}$ \\
\hline $\begin{array}{c}\text { less than } 0.5 \text { inch inner diameter } \\
\text { and less than } 0.060 \text { inch cross section }\end{array}$ & $1800 \mathrm{psi}$ & $225 \%$ \\
$\begin{array}{c}\text { between } 0.5 \text { and } 2.0 \text { inch inner diameter } \\
\text { and over } 0.06 \text { inch cross section }\end{array}$ & $1600 \mathrm{psi}$ & $200 \%$ \\
$\begin{array}{c}\text { between } 7 \text { and } 8 \text { inch inner diameter } \\
\text { and over } 0.06 \text { inch cross section }\end{array}$ & $1400 \mathrm{psi}$ & $175 \%$ \\
$\begin{array}{c}\text { over 10 inch inner diameter } \\
\text { and over 0.06 inch cross section }\end{array}$ & $1200 \mathrm{psi}$ & $150 \%$ \\
test slab dog-bones & $1600 \mathrm{psi}$ & $200 \%$
\end{tabular}




\section{O-Ring Tensile Modulus and Work Testing (Additional tables and plots in Appendix I)}

Tensile modulus is not currently measured as part of the test slab acceptance testing. While developing procedures for ring tensile strength and elongation testing, it was opportune to also measure modulus over a variety of elongations and to evaluate the possible value of including modulus as one of the acceptance tests. A literature report (C. Peacock, "Quality Control Testing of Rubber Shear Modulus," Elastomerics, p. 42-45, May 1992) suggesting that measurements of the integrated work up to $20 \%$ elongation might also provide a useful measure of elastomer performance led to inclusion of that parameter in the tensile test evaluation.

All the moduli were measured at a crosshead speed of $20 \mathrm{in.} / \mathrm{min}$. A study of tensile properties vs. test speed prompted by the rapid elongation and failure of smaller rings at this high speed is discussed in the following section. A modest increase in modulus (measured between 10-20\% elongation) was noted in that study as the test speed increased from about 5 to $20 \mathrm{in} . / \mathrm{min}$.(see Table I-1).

Tensile moduli were measured over 5 different elongation ranges: $5-10 \%, 10-15 \%, 5-15 \%, 10-20 \%$ and $0-25 \%$. These particular values were computer generated averages of the tangent to the stressstrain curve at each data point within that range. The highest moduli were generally observed in the 5$10 \%$ elongation range and the lowest moduli were generally observed in the 10-20\% elongation range, reflecting a slight bending in the stress-strain slope.

A more simple and preferred modulus calculation would be the linear modulus defined by the stress at a given elongation. Such measurements would not require the computerized data handling required in the initial Sandia tests and would be compatible with basic strip chart recorder instruments. Such modulus measurements were carried out at Kansas City and also at Sandia and this simple linear modulus or stress at $25 \%$ elongation calculation is recommended in the test procedure in Appendix C.

Comparisons of the linear modulus to the computer generated tangential modulus values showed close agreement with the smaller rings. The larger ring sizes, 7 in. ID and up, showed slightly higher moduli with the simple linear calculation.

ASTM-D-1414 also describes the measurement of tensile "moduli" or stress at a defined elongation for typically 100 or $200 \%$ elongation. A limited amount of such "modulus" data was obtained at 100 , 200 and $300 \%$ elongation during the initial trials with different fixtures as described in the preceding section. The highly non-linear nature of the stress-strain curves over these long elongations, however, led to the use of shorter elongation ranges in the present evaluations

Calculations of tensile work, over the $0-20 \%$ elongation range, were carried out by computer integration and summation of the rectangular areas under each data point in the stress-strain curve. Each rectangle was bounded by the stress at a given point and by the elongations midway between that point and its neighbors. Calculations of tensile work in units of absolute elongation (i.e. inch-lb. per square inch) reflected primarily the size of the O-ring and more meaningful results were obtained in units of percent elongation or percent-lb per square inch.

As described in the preceding section, tensile tests were carried out by setting both the force and elongation to zero at a starting crosshead distance calculated from the nominal ring diameter and the spool diameter. Tables in the proposed method in Appendix C provide these starting crosshead distances for O-ring sizes used in the W87.

Tables 7 and 8 and Plots 5 and 6 summarize the tensile modulus and work data obtained on a series of $\mathrm{O}$-ring and test slab lot obtained from the three vendors. The modulus table and plot show only the simple linear data obtained with the 0-25\% elongation range. All the tangential modulus data over different elongation ranges is detailed in additional tables and plots in Appendix I. Work, as noted above, was measured over the $0-20 \%$ elongation range. 
Unlike the tensile strength and elongation data, there was no significant correlation of tensile modulus or work with ring size. More detailed data is again included in the Appendix. These results suggest that modulus and work, like hardness and compression set, are more reflective of bulk properties and are less sensitive to defects than strength and elongation measurements. There was again no significant correlation of slab and ring data from the same rubber batches.

Linear modulus values for the RD Rubber rings all fell between about 360-510 psi before aging and 390-560 psi after aging. Parker and Precision rings showed much higher moduli and also greater variability. A minimum modulus of 350 psi before aging would accept all the rings tested. A maximum change on aging of $+15 \%$ (not $\pm 15 \%$ ) would have excluded two Parker ring lots, one RD Rubber lot and three Precision lots. All but one Parker ring lot and two slab lots showed a higher modulus after aging and suggests that a loss of modulus is not typical of most butyl rubber materials and is probably undesirable.

Future tensile measurements at $5 \mathrm{in} . / \mathrm{min}$. instead of the $20 \mathrm{in} . / \mathrm{min}$. used here may reduce the observed values about $10 \%$. None of the stiffer Parker or Precision ring materials would be rejected by a small reduction in the measured modulus. The lower modulus RD Rubber materials would be more borderline and may require adjustment of the tentative 350 psi minimum or perhaps an adjustment in the RD Rubber formulation. The RD Rubber materials also gave lower tensile work, hardness and compression set values than those from Parker and Precision. These lower RD Rubber values, clearly desirable in compression set, also tended to be more uniform than those from the other vendors. Overall, the RD Rubber formulation may provide a more desirable balance of properties.

Tensile work values (see Table 8 and plot 6) showed trends similar to those observed in the tensile modulus measurements and offered no particular insights into material quality. No unusual correlation with compression set results or other parameters was noted in either the lot to lot comparisons or the cure study comparisons. The results do not suggest any future use of tensile work measurements for acceptance testing.

As noted in the preceding section, it is anticipated that tensile testing would no longer be required for acceptance of each lot of O-rings but would instead be utilized in a periodic manner for vendor qualification.

The recommended procedure for tensile testing of O-rings is described in Appendix $\mathrm{C}$ and the recommended test values are summarized along with the other test changes in Table 12. 
Table 7. Linear Tensile Modulus (0-25\% Elongation) Data: Slabs and O-Rings

\begin{tabular}{|c|c|c|c|c|c|c|c|c|}
\hline \multirow[t]{2}{*}{ Vendor } & \multirow{2}{*}{$\begin{array}{c}\text { Rubber } \\
\text { Batch }\end{array}$} & \multirow[t]{2}{*}{ \pm Aging } & Test Slab Data & \multicolumn{5}{|c|}{ O-Ring Data (Standard Deviations from 6 to 96 , avg. 27 ) } \\
\hline & & & All Sandia results & $0.116 \times 0.038$ & $0.301 \times 0.054$ & $1.364 \times 0.070$ & $7.688 \times 0.070$ & $16.339 \times 0.103$ \\
\hline \multirow{6}{*}{$\begin{array}{l}\text { Parker } \\
\text { Parker } \\
\text { Parker } \\
\text { Parker } \\
\text { Parker }\end{array}$} & 316104 & unaged & $\begin{array}{c}761 \\
1120\end{array}$ & & $\begin{array}{l}754 \\
780\end{array}$ & 683 & 896 & 868 \\
\hline & 316710 & $\begin{array}{c}\text { unaged } \\
\text { aged }\end{array}$ & $\begin{array}{l}981 \\
956\end{array}$ & & $\begin{array}{l}812 \\
819\end{array}$ & & & $\begin{array}{l}819 \\
842\end{array}$ \\
\hline & 317403 & $\begin{array}{c}\text { unaged } \\
\text { aqed }\end{array}$ & $\begin{array}{c}922 \\
1056\end{array}$ & & & $\begin{array}{l}639 \\
675\end{array}$ & & \\
\hline & 317851 & $\begin{array}{c}\text { unaged } \\
\text { aqed }\end{array}$ & $\begin{array}{l}973 \\
958\end{array}$ & & & & $\begin{array}{l}489 \\
586\end{array}$ & \\
\hline & 318466 & $\begin{array}{c}\text { unaged } \\
\text { aged }\end{array}$ & $\begin{array}{l}569 \\
690\end{array}$ & $\begin{array}{l}527 \\
581\end{array}$ & & & & \\
\hline & & & & $0.301 \times 0.054$ & $0.551 \times 0.070$ & $1.114 \times 0.70$ & $7.185 \times 0.103$ & $11.196 \times 0.103$ \\
\hline \multirow{4}{*}{$\begin{array}{l}\mathrm{RD} \\
\mathrm{RD} \\
\mathrm{RD}\end{array}$} & 14810 & $\begin{array}{l}\text { unaged } \\
\text { aged }\end{array}$ & $\begin{array}{l}579 \\
589\end{array}$ & & $\begin{array}{l}358 \\
403\end{array}$ & $\begin{array}{l}369 \\
387\end{array}$ & $\begin{array}{l}418 \\
435\end{array}$ & \\
\hline & 14936 & $\begin{array}{l}\text { unaged } \\
\text { aged }\end{array}$ & $\begin{array}{l}\text { NA } \\
\text { NA }\end{array}$ & & & & & $\begin{array}{l}465 \\
496\end{array}$ \\
\hline & 15107 & $\begin{array}{c}\text { unaged } \\
\text { aged }\end{array}$ & $\begin{array}{l}641 \\
666\end{array}$ & $\begin{array}{l}447 \\
493\end{array}$ & $\begin{array}{l}367 \\
414\end{array}$ & $\begin{array}{l}389 \\
431\end{array}$ & $\begin{array}{l}507 \\
553\end{array}$ & $\begin{array}{l}477 \\
560\end{array}$ \\
\hline & & & & & $0.301 \times 0.054$ & $1.364 \times 0.070$ & $7.739 \times 0.070$ & $16.955 \times 0.139$ \\
\hline & 17405 & $\begin{array}{l}\text { unaged } \\
\text { aged }\end{array}$ & $\begin{array}{l}\text { NA } \\
\text { NA }\end{array}$ & & & $\begin{array}{l}577 \\
658\end{array}$ & & \\
\hline & 19052 & $\begin{array}{l}\text { unaged } \\
\text { aged }\end{array}$ & $\begin{array}{l}731 \\
823\end{array}$ & & $\begin{array}{l}554 \\
628\end{array}$ & & $\begin{array}{l}788 \\
919\end{array}$ & \\
\hline Precision & 19422 & $\begin{array}{c}\text { unaged } \\
\text { aged }\end{array}$ & $\begin{array}{l}\text { NA } \\
\text { NA }\end{array}$ & & & & & $\begin{array}{l}576 \\
660\end{array}$ \\
\hline Precision & 19895 & $\begin{array}{c}\text { unaged } \\
\text { aged }\end{array}$ & $\begin{array}{l}766 \\
803\end{array}$ & & $\begin{array}{l}516 \\
642\end{array}$ & $\begin{array}{l}585 \\
623\end{array}$ & & $\begin{array}{l}614 \\
729\end{array}$ \\
\hline Precision & 19921 & $\begin{array}{c}\text { unaged } \\
\text { aged }\end{array}$ & $\begin{array}{l}\text { NA } \\
\text { NA }\end{array}$ & & & & $\begin{array}{l}760 \\
834\end{array}$ & \\
\hline
\end{tabular}




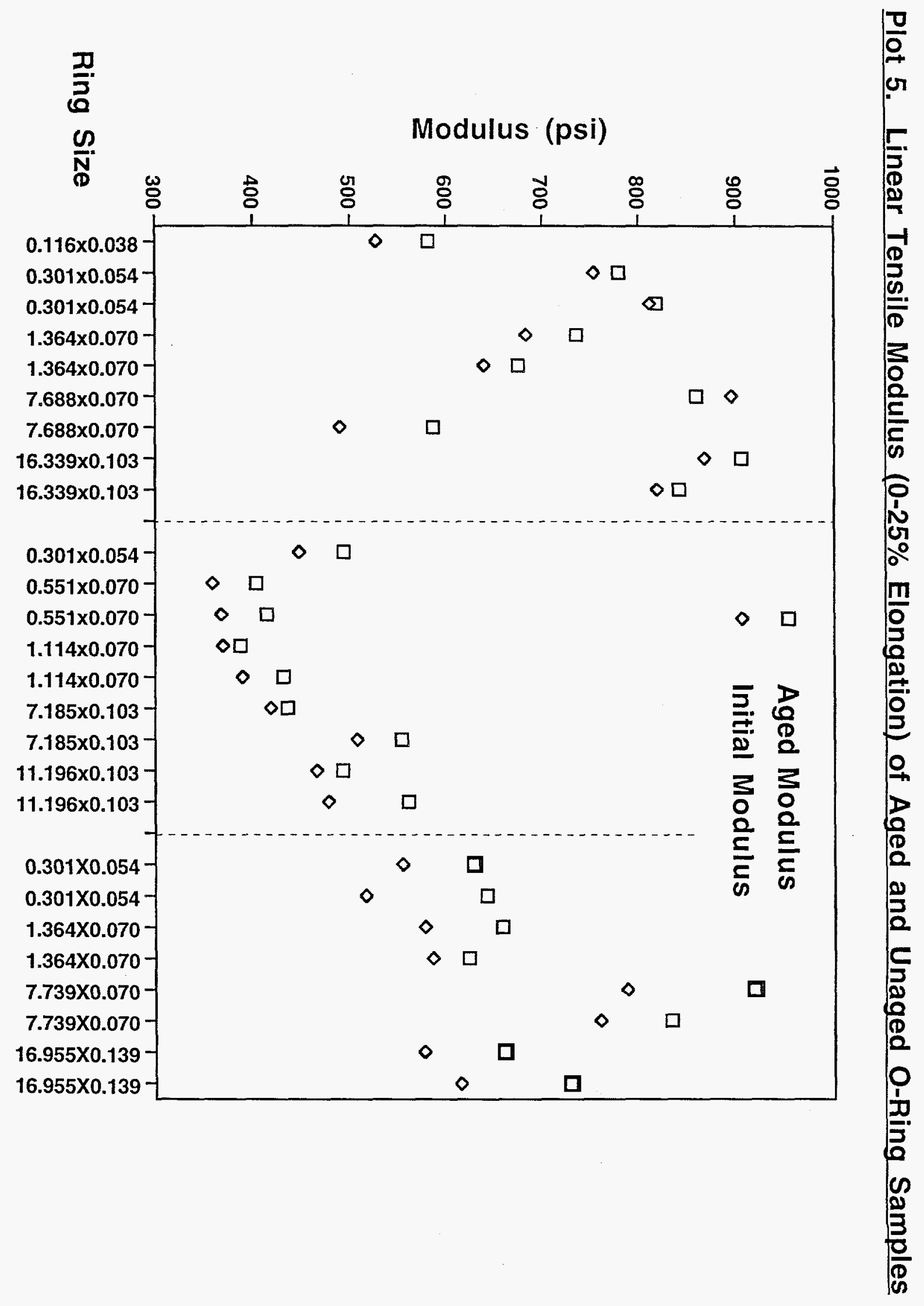


Table 8. Tensile Work Data (0-20\% Elongation): Slabs and O-Rings (Data in percent-lb/sq.in.)

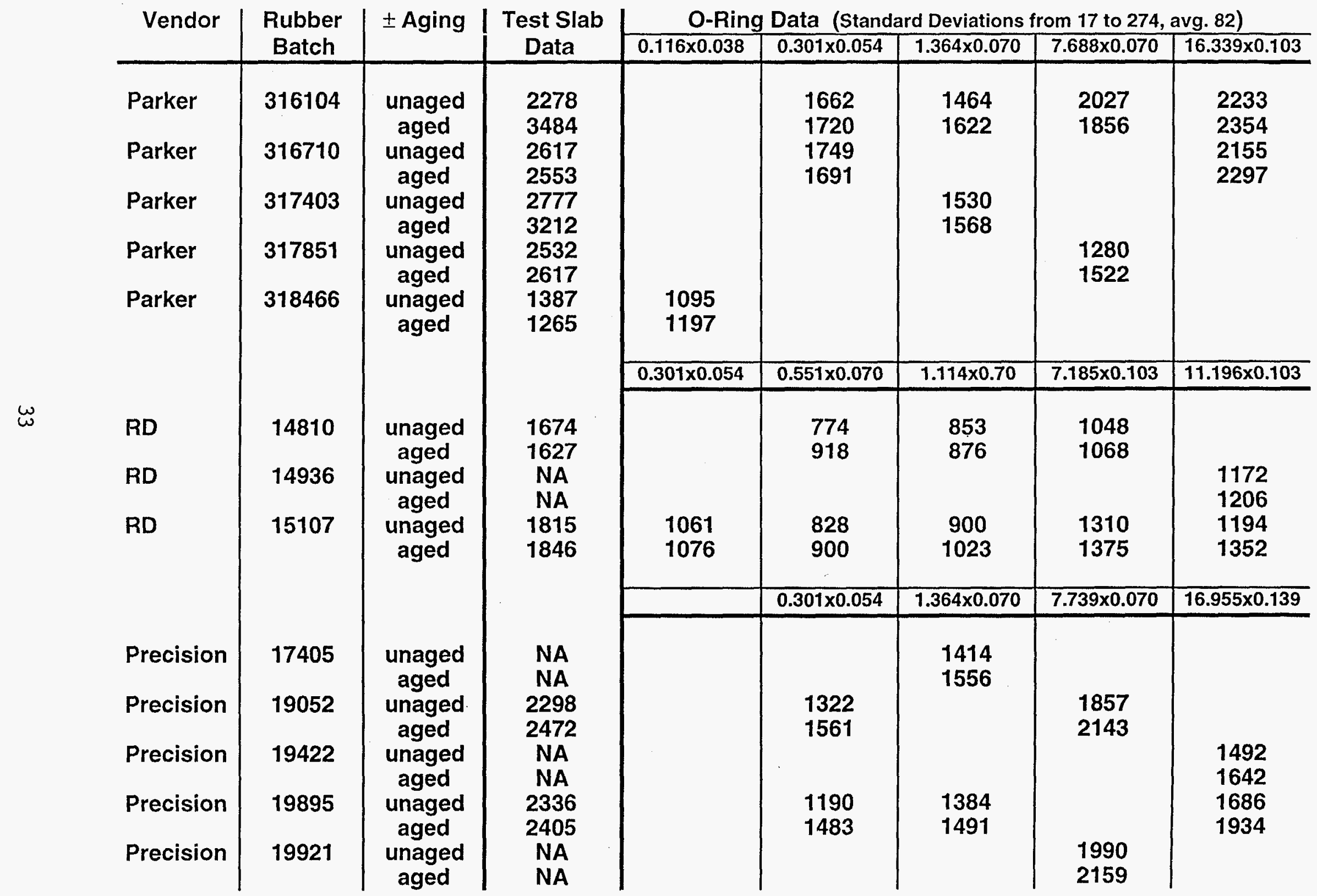




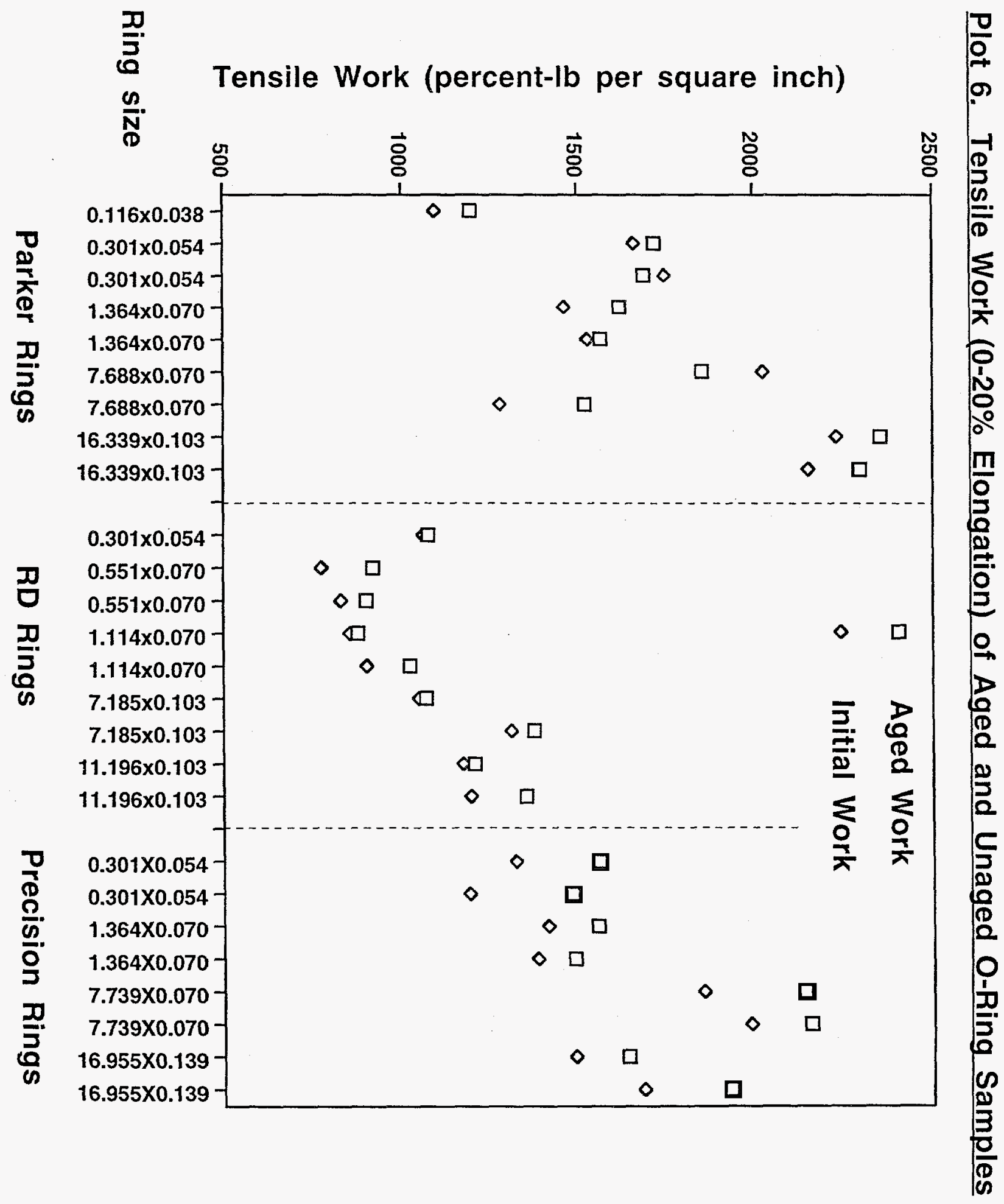




\section{O-Ring Tensile Properties vs. Test Speed}

Because of the wide range of $\mathrm{O}$-ring sizes being tested at a $20 \mathrm{in} . / \mathrm{min}$. fixture speed during the above evaluations, there was a correspondingly wide range of ring elongation rates. As shown in Table 9, a fixture speed of $20 \mathrm{in}$./min. corresponds to ring elongation rates, in percent/minute, ranging from $235 \% / \mathrm{min}$. for the largest rings up to $4230 \% / \mathrm{min}$. for the smaller rings. A typical ultimate elongation of $200 \%$ is reached for the smaller rings in only about 3 seconds, limiting the amount of data points to be measured. Concern over the possible effects of such different percent elongation rates led to a series of tensile tests in which the fixture speed was adjusted to provide ring elongation rates of either 20 or $200 \% / \mathrm{min}$. for each of the different O-ring sizes. Each ring was also tested at the fixture speed, $20 \mathrm{in.} / \mathrm{min}$., used in the tensile tests reported in the above section.

The tests in this series were carried out on rings previously obtained from Lutz, a distributor for Precision, before it was known Lutz was not the manufacturer.

As shown in the Table and in Plot 7, most properties demonstrated only a modest sensitivity to test speed. Individual plots of tensile strength (Plot H-2), tensile elongation (Plot $\mathrm{H}-3$ ) and tensile modulus (Plot I-7) have been referred to in the preceding sections and are contained in the appendices. The very low fixture rates used to achieve $20 \% / \mathrm{min}$. in some cases did significantly reduce the observed tensile properties. Within the fixture speed range of 5-20 in./min., however, most rings gave only moderate increases, if any, in tensile values.

The major benefit to be gained from reducing the tensile test speed is a longer time to ring failure and larger number of data points with more resolution. It was considered impractical to use different fixture speeds for each ring size for routine testing and, based on the relative insensitivity of the data to test speed, unnecessary. A compromise recommendation calls for two fixture speeds to be designated: $20 \mathrm{in} . / \mathrm{min}$. for the two largest W87 ring sizes and $5 \mathrm{in} . / \mathrm{min}$. for the remaining O-rings, all less than 2 in. in inner diameter. That recommendation is contained in the proposed procedure in Appendix C. Using the reduced speed should provide a failure time for the $0.301 \mathrm{in}$. ID rings of over 10 seconds and even the smallest 0.116 in. ID rings should require about 4 seconds to break.

As noted in the preceding sections, a reduction in fixture speed from 20 to $5 \mathrm{in} . / \mathrm{min}$. might be expected to reduce the observed tensile values $10-20 \%$. The proposed strength and elongation values already reflect this expectation. The proposed modulus requirement of 350 psi would have rejected none of the Lutz rings tested in this series. The lower moduli typical of RD Rubber materials might be more affected by the lower test speed and possibly lead to a higher rejection rate.

Additional tests being carried out at Kansas City will be using the $5 \mathrm{in} . / \mathrm{min}$. fixture speed for smaller rings and $20 \mathrm{in} . / \mathrm{min}$. speed for the two larger ring sizes. That data should allow any final adjustments to be made in the target tensile values if needed. 
Table 9. Tensile Strength, Elongation and Modulus vs. Test Speed

(All tests carried out on Lutz O-rings.)

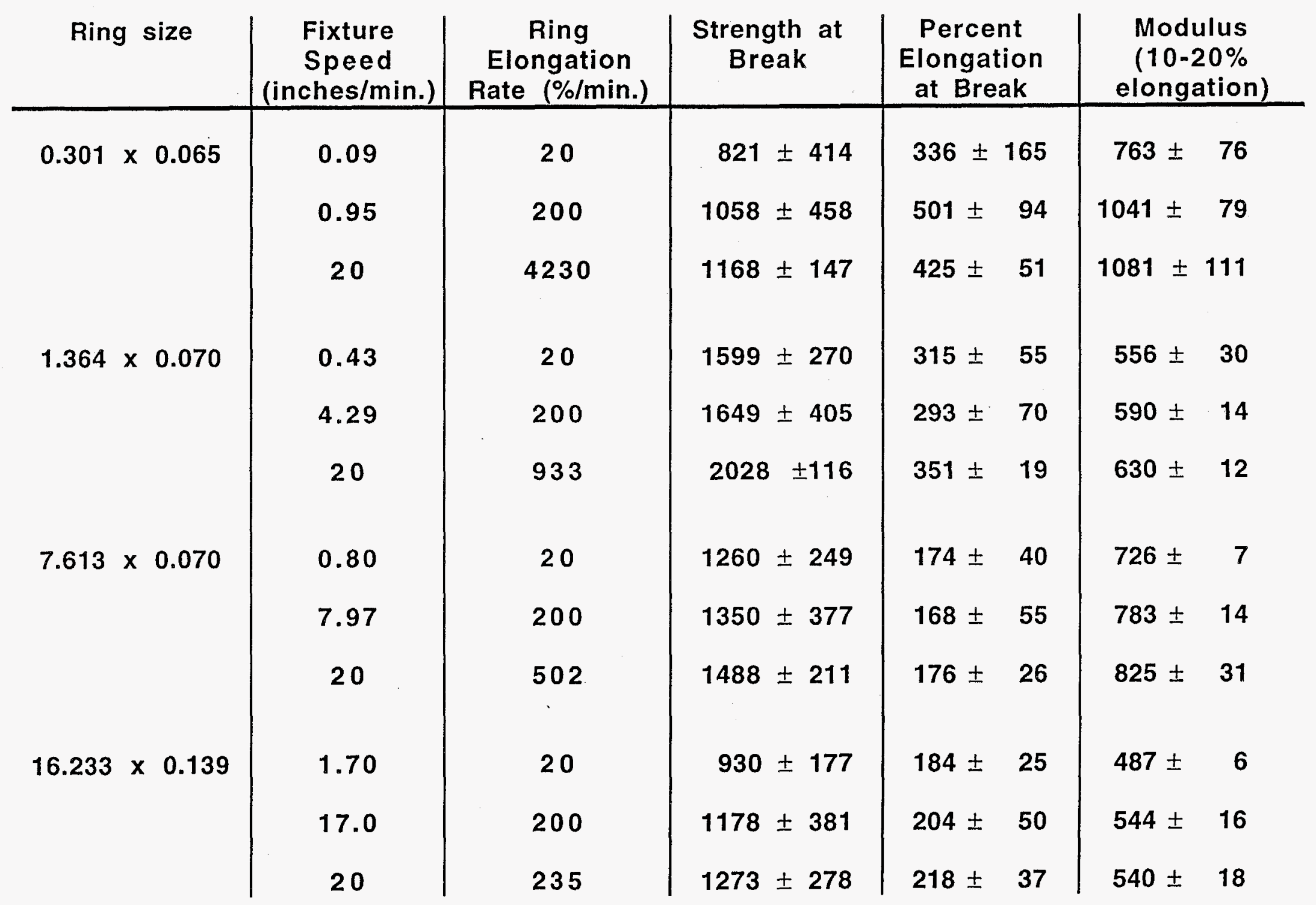


Plot 7. O-Ring Tensile Properties vs. Fixture Speed
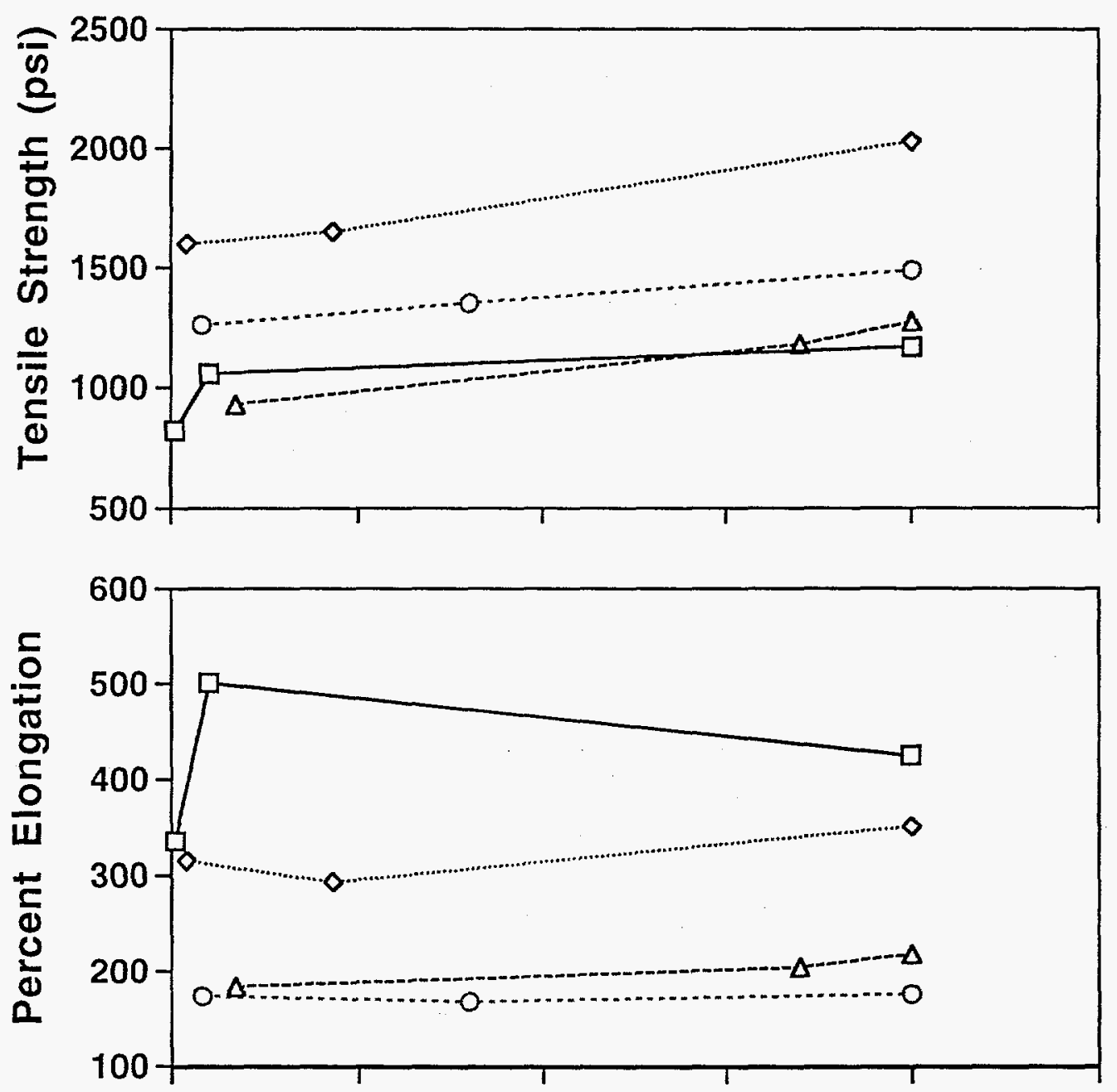

$\longrightarrow$

0.301

................ 1.364

.... 0.... 7.613

16.233

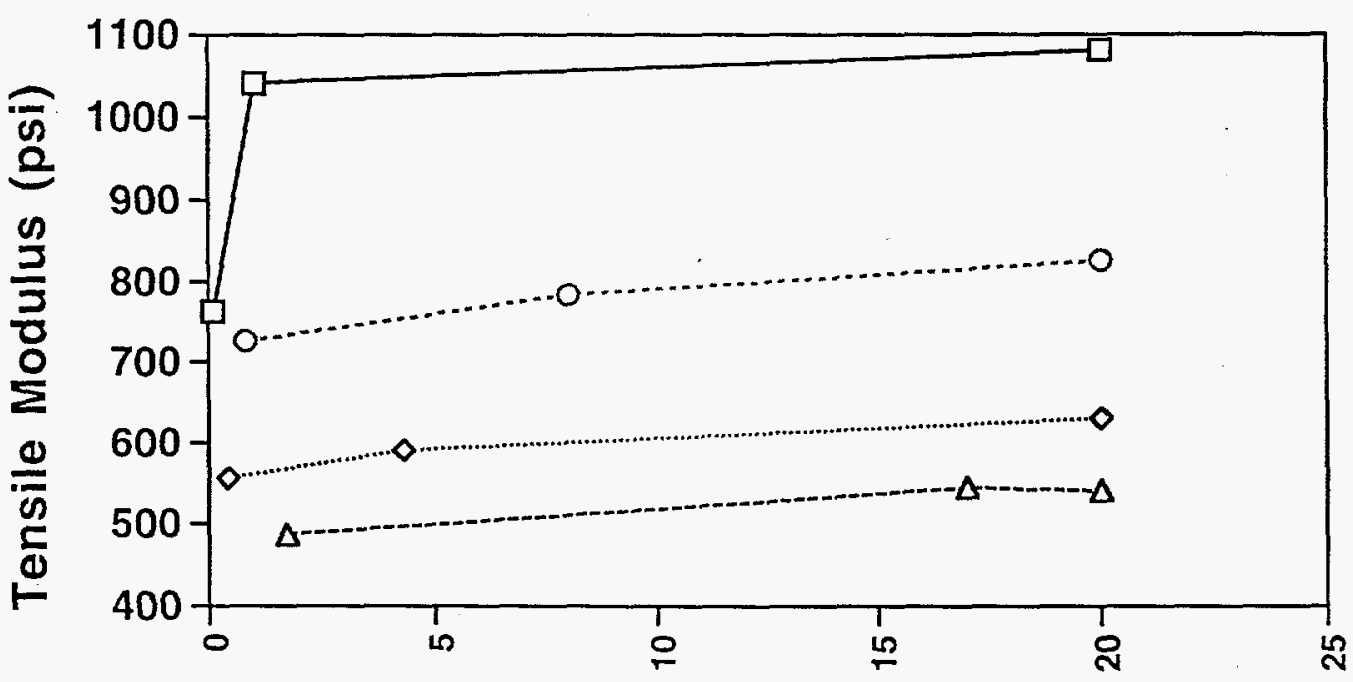

Fixture Speed (inches/min) 


\section{O-Ring Properties vs. Cure Cycle (Additional tables and plots in Appendix J \& K)}

O-ring materials failing the acceptance criteria, whether in the past using test slab samples or in the future using actual ring samples, might do so because of either formulation or processing errors. Lack of anti-oxidant, for example, would impair the material aging performance, poor mixing would affect performance uniformity, and different filler levels and under or over curing would be expected to affect many of the measured properties.

No previous Sandia studies, however, have attempted to actually correlate cure cycle with acceptance test performance. With the cooperation of RD Rubber and the Kansas City personnel, arrangements were made to deliberately undercure multiple lots of rings and slabs using one of the rubber batches already characterized as part of the study. Rheometric curing scans at Kansas City on the uncured rubber suggested that cure times of about $3 \mathrm{~min}$. and $4 \mathrm{~min}$. would produce degrees of cure of $45 \%$ and $70 \%$ instead of the nominal $95 \%$ produced by the current $10 \mathrm{~min}$. cure cycle. All cures were carried out at $150^{\circ} \mathrm{C}$. RD Rubber produced 4 lots of O-rings and one lot of test slabs each using these reduced cure times. The smallest $O$-ring size previously supplied $(0.551 \times 0.070 \mathrm{in}$.) was replaced in this series with the small O-ring size supplied by Parker and Precision ( $0.301 \times 0.054$ in.). All the rings and slabs in this series were prepared from RD Rubber butyl rubber batch 15107.

Surprisingly, none of the tests of initial material properties demonstrated a strong correlation of performance with cure time. The undercured materials gave more failures upon aging than the fully cured rings, but there was again no strong correlation of aging behavior with cure time. Plots 8 through 13 show the relative hardness, compression set, tensile strength, elongation, and tensile modulus and work for four different ring sizes and the test slabs, each with either 3,4 or 10 minutes of cure. Corresponding tables in Appendix $\mathrm{J}$ provide more details.

None of the materials with reduced cure times would have failed the initial hardness test or the currently allowed change of 10 points after aging. Most of the undercured rings would have failed the proposed maximum aging change of 4 points, however, a finding which prompted that proposed specification modification.

Only two undercured ring lots would have failed the proposed compression set maximum of $10 \%$ and none would have failed the current maximum of $15 \%$. The failing ring lots occurred randomly, however, and were not part of any general trend showing increasing compression set with decreasing cure time.

Only one ring lot, cured 4 minutes, would have failed the proposed tensile strength and elongation requirements. Two of the undercured lots would have failed the $\pm 15 \%$ maximum aging change in tensile strength and four different lots would have failed the $\pm 15 \%$ elongation change. One fully cured lot would also have failed a maximum strength and elongation change of $\pm 15 \%$. Again, these failures were largely random and not part of any clear trend. The undercured test slabs would have also failed the aging elongation change although their tensile strength performance was acceptable.

Both tensile strength and elongation, in some ring sizes, seemed to show trends with cure time, but the same trends would not be observed in other ring sizes. There was overall, no definitive behavior which would insure that undercured materials would be identified via these tensile tests.

Tensile modulus and work measurements also gave no strong correlation with cure time. In some ring sizes the modulus actually decreased with longer cure while in others the values were virtually unchanged with cure. The decreasing modulus with cure time observed in two cases may suggest the cure temperature being used is degrading the rings to some extent. Again, this same trend was not observed in all the rings and was not consistent enough to warrant additional research or vendor efforts. 
The lack of substantial changes in ring and slab properties with cure time suggested that, contrary to the rheometrics predictions, the rubber materials were nearly as fully cured after 3 or 4 minutes as they were after 10 minutes. In subsequent discussions with RD Rubber personnel, they indicated that the rubber is typically cured after only one minute in the heated press. Longer cure schedules are used to insure reproducibility.

DSC studies at Sandia on the uncured rubber and on the variously cured ring and slab samples confirmed that the cure is extremely rapid and that no significant differences in degree of cure could be noted in the materials cured 3,4 or 10 minutes. As shown in the scans in Figure 4, slight trends noted in the rings on examining samples with 3,4 and 10 minute cure times did not hold up in the slab samples. A DSC scan on an unknown sample would not be able to establish its degree of cure with any certainty. When the uncured rubber was examined (lower right of Fig. 4) a clear early endotherm was noted along with a broad exotherm. When similar samples were first cured in the DSC at $150^{\circ} \mathrm{C}$ for 2 to 15 minutes and then scanned, the observed initial endotherm had already disappeared and the subsequent exotherm was substantially reduced. The samples cured 2 or 4 minutes still gave slight exotherms, but the remaining samples were largely overlapping and featureless.

Lower temperature DSC scans were also carried out to measure anticipated increases in Tg as the cure time was increased. Again, all the samples showed similar Tg values and provided no quick and definitive measure of cure level.

Additional DSC scans (see Appendix K) of materials from the different vendors showed general similarities, particularly a broad endotherm starting at about $120^{\circ} \mathrm{C}$, between the Parker and $\mathrm{RD}$ Rubber materials. This endotherm occurs at higher temperatures than the sharp endotherm observed only in the uncured material. The Precision materials did not show this broader endothermic profile in the one rubber batch examined

Stockpile aged butyl rubber O-rings from the W76 and W87 were also examined by DSC and showed a general increase in the above broad endotherm peak with aging. In these random samplings, the effect did not appear consistent enough to provide a useful measure of $\mathrm{O}$-ring life, however. For example, three W76 O-rings from different rubber batches showed quite different DSC scans. In the W87 the limited scans available appeared more consistent in behavior, perhaps due to the use of a single O-ring vendor in this weapon. Future aged W87 O-rings should also be examined by DSC to monitor the growth of this endothermic peak and its possible correlation to O-ring performance. It should be noted that the "unaged" W87 Parker O-ring which had been stored in its shipping package and not stockpile aged did not show any endothermic peak such as that noted in more recent Parker and RD Rubber materials. This again reflects the ambiguity of assessing if observed DSC endotherms are due to aging or were present in the as-received materials.

The results of the cure study suggest two major points. First, none of the acceptance tests were able to differentiate the samples having different cure times with any certainty although the reduced maximum on hardness change with aging may be beneficial. Second, the sensitivity of properties to cure cycle is low and suggests that O-ring curing processes are both robust and tolerant of processing excursions. This may further suggest that out-of-spec materials result more from formulation and mixing deviations than from cure cycle deviations. 


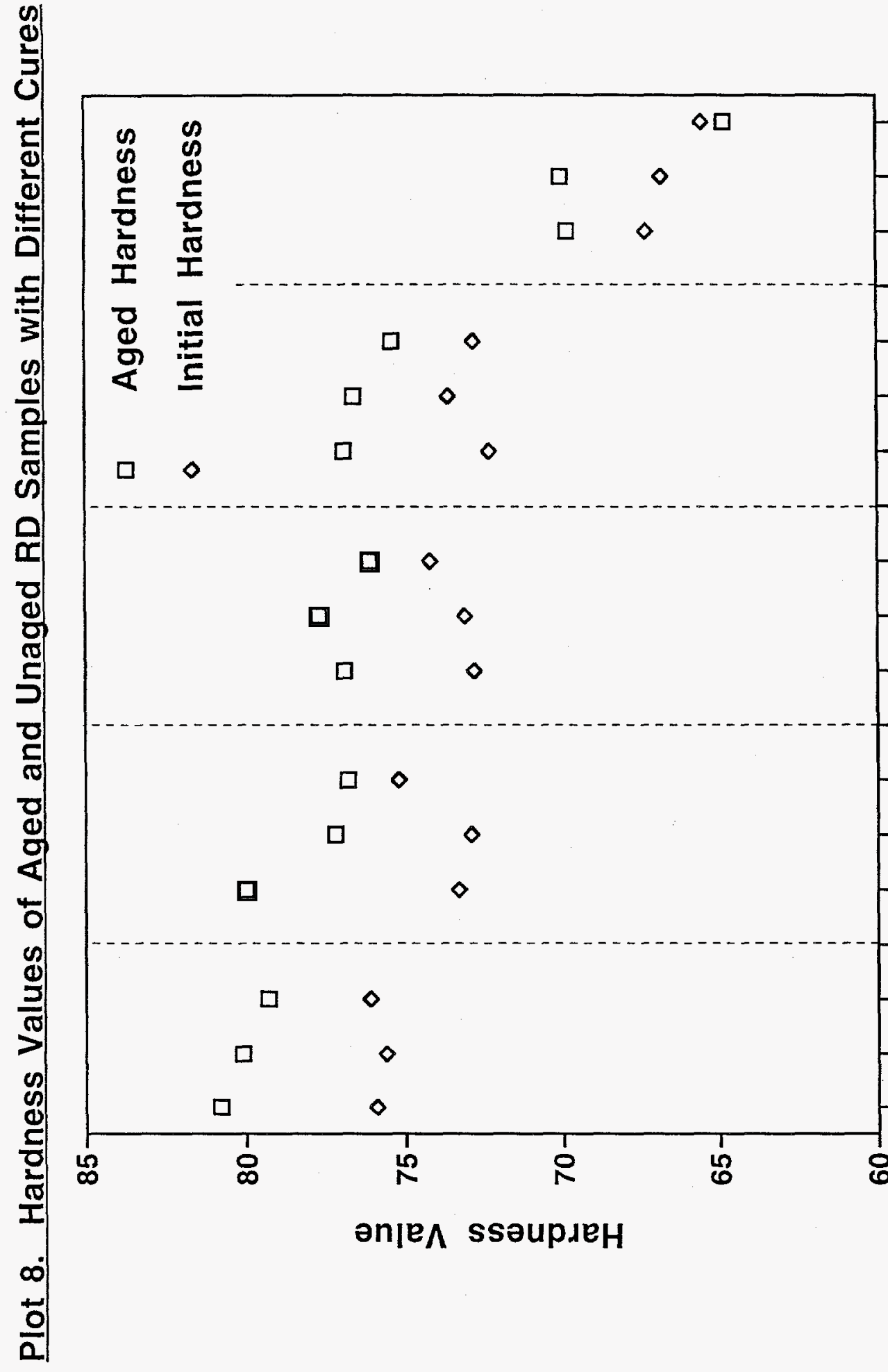

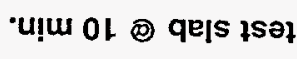

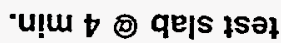

-u!̣ $\varepsilon$ (0) qe|s łsal

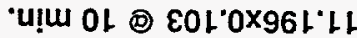

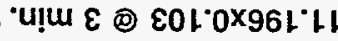

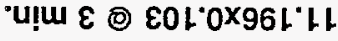

"u!̣ OL (-) EOL"OXS8L'L

-u!u b D EOLOXS8L'L

"ụu $\varepsilon$ อ) عOLOX981:L

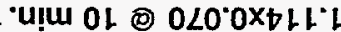

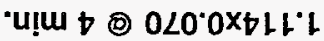

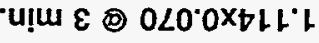

'u!u of อ $\$ 90^{\circ} 0 \times 10 \varepsilon^{\circ} 0$

'U!u $৮$ (0) $७ 90^{\circ} 0 \times 10 \varepsilon^{\circ} 0$

-u!u $\varepsilon$ () † $७ 0^{\circ} 0 \times 10 \varepsilon^{\circ} 0$

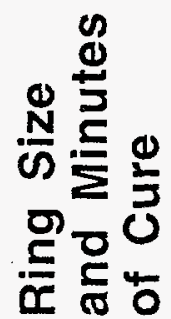




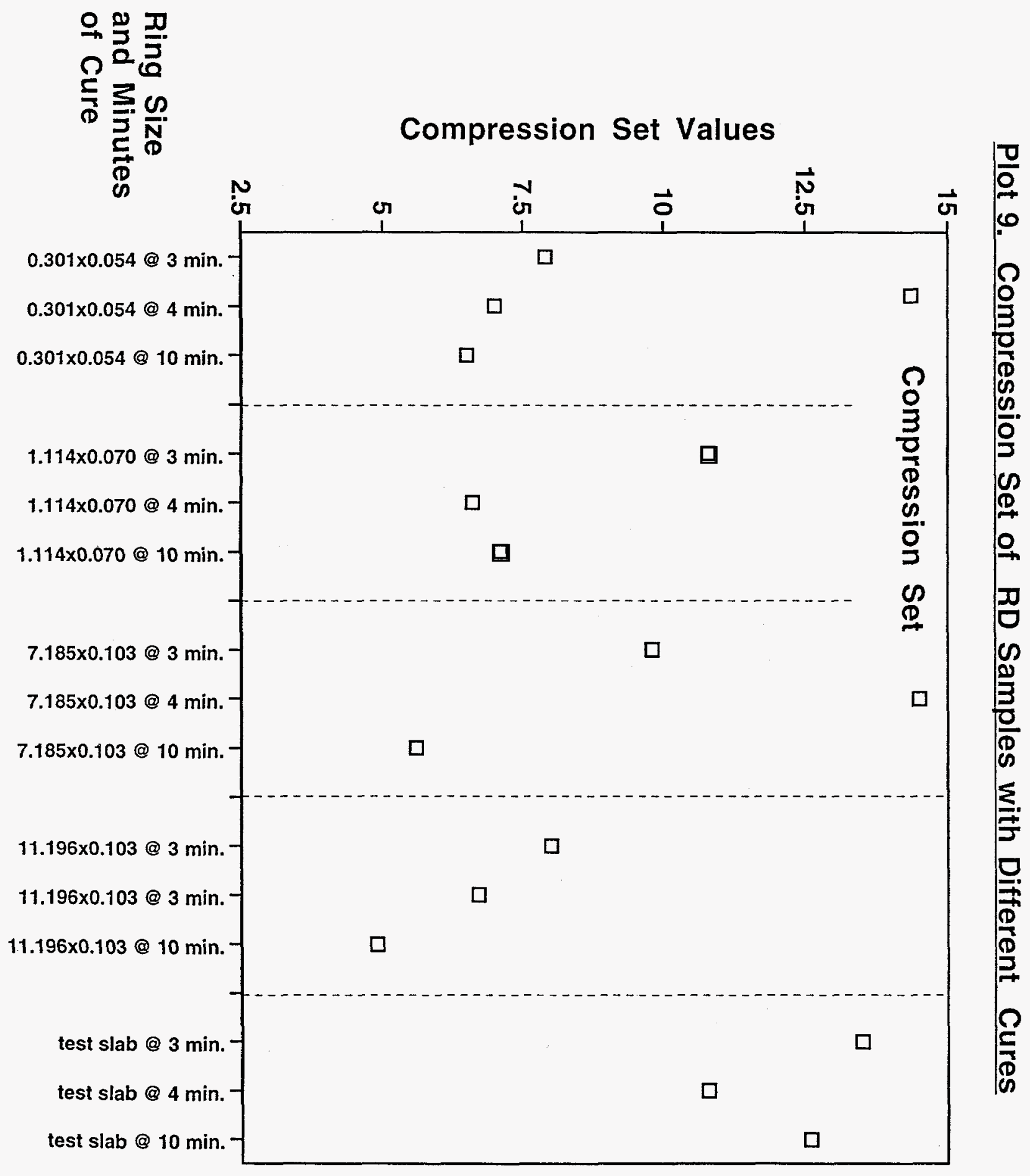




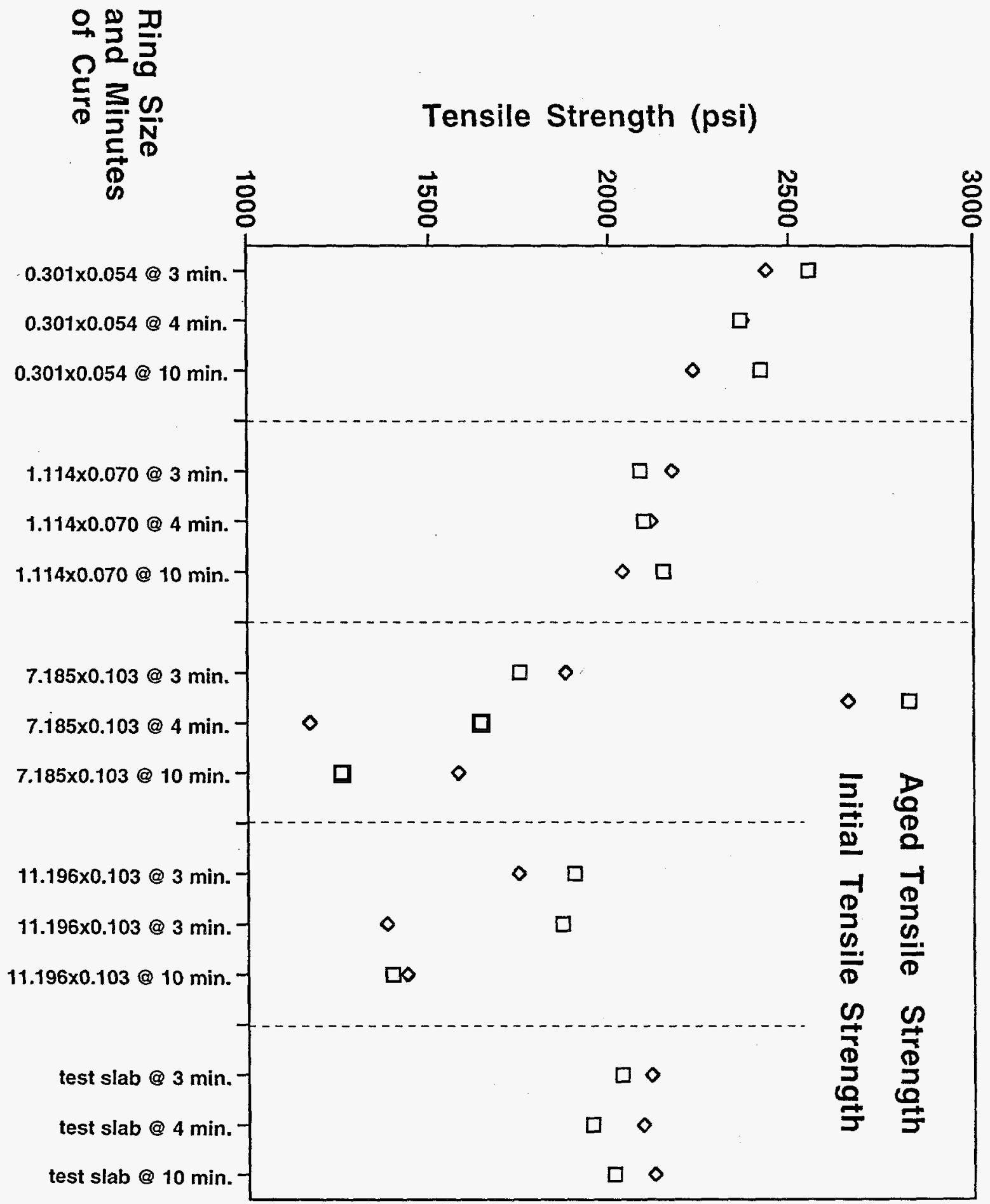




\section{Plot 11. Tensile Elongation of Aged and Unaged RD Samples with Different Cures}

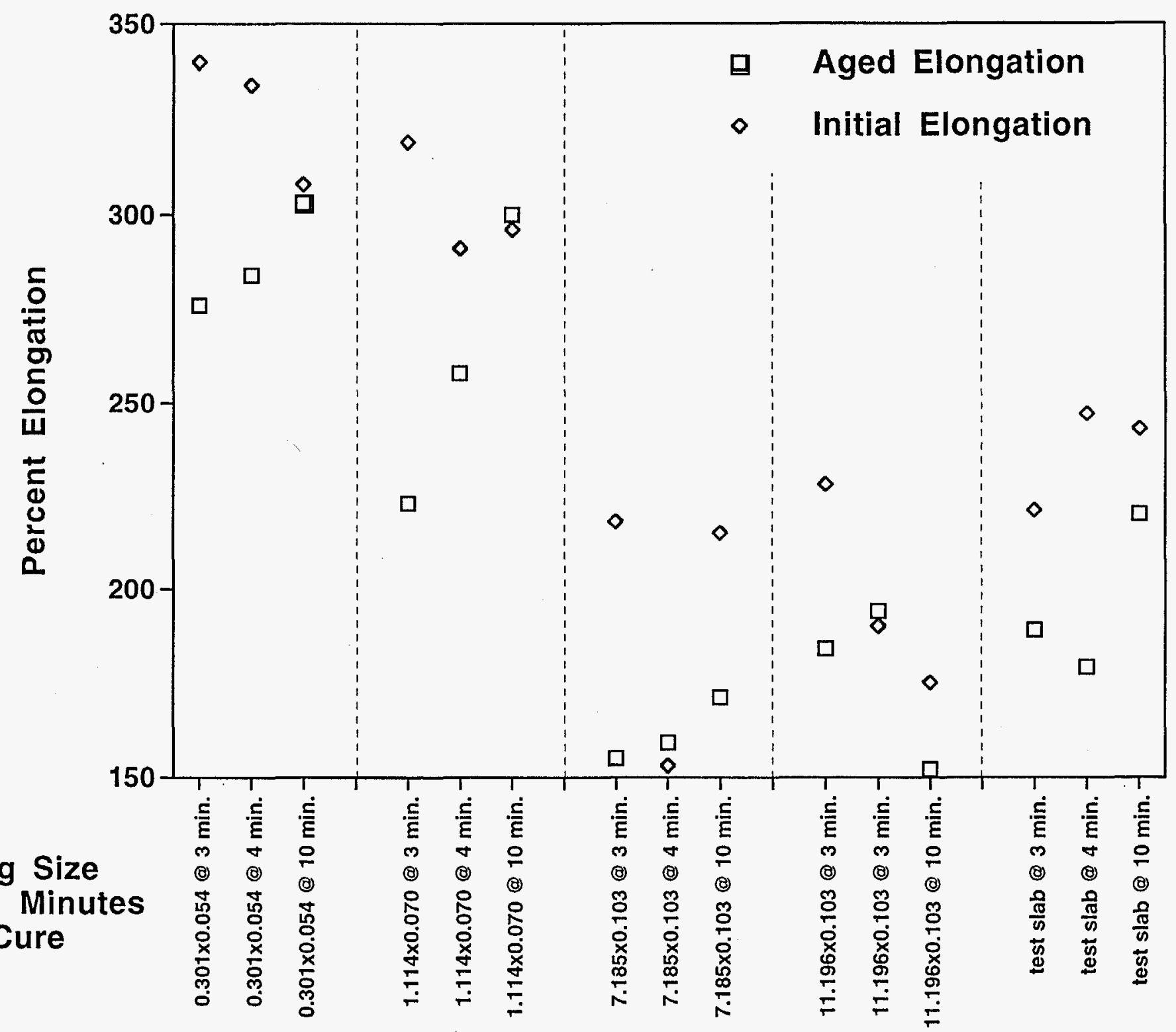




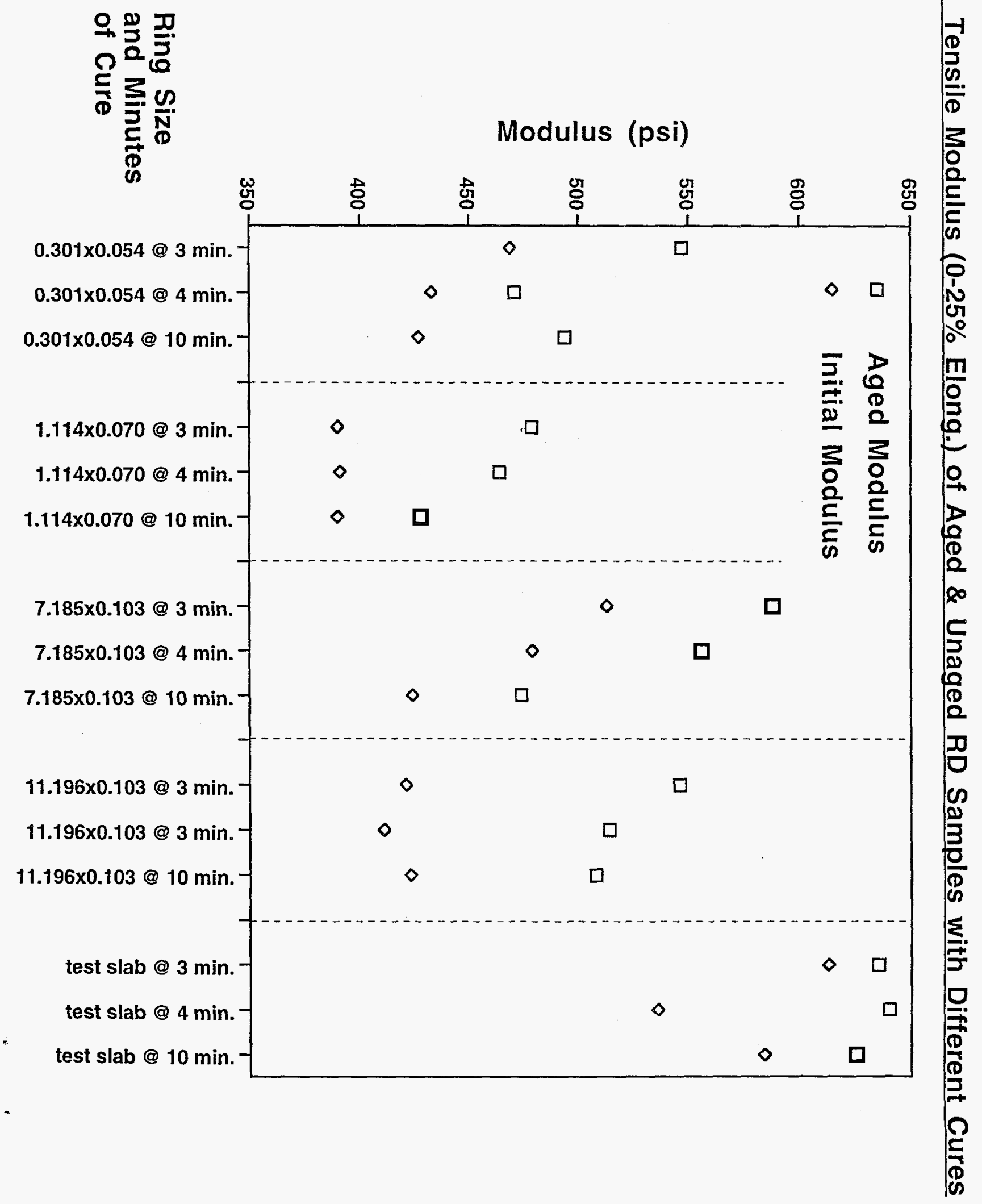




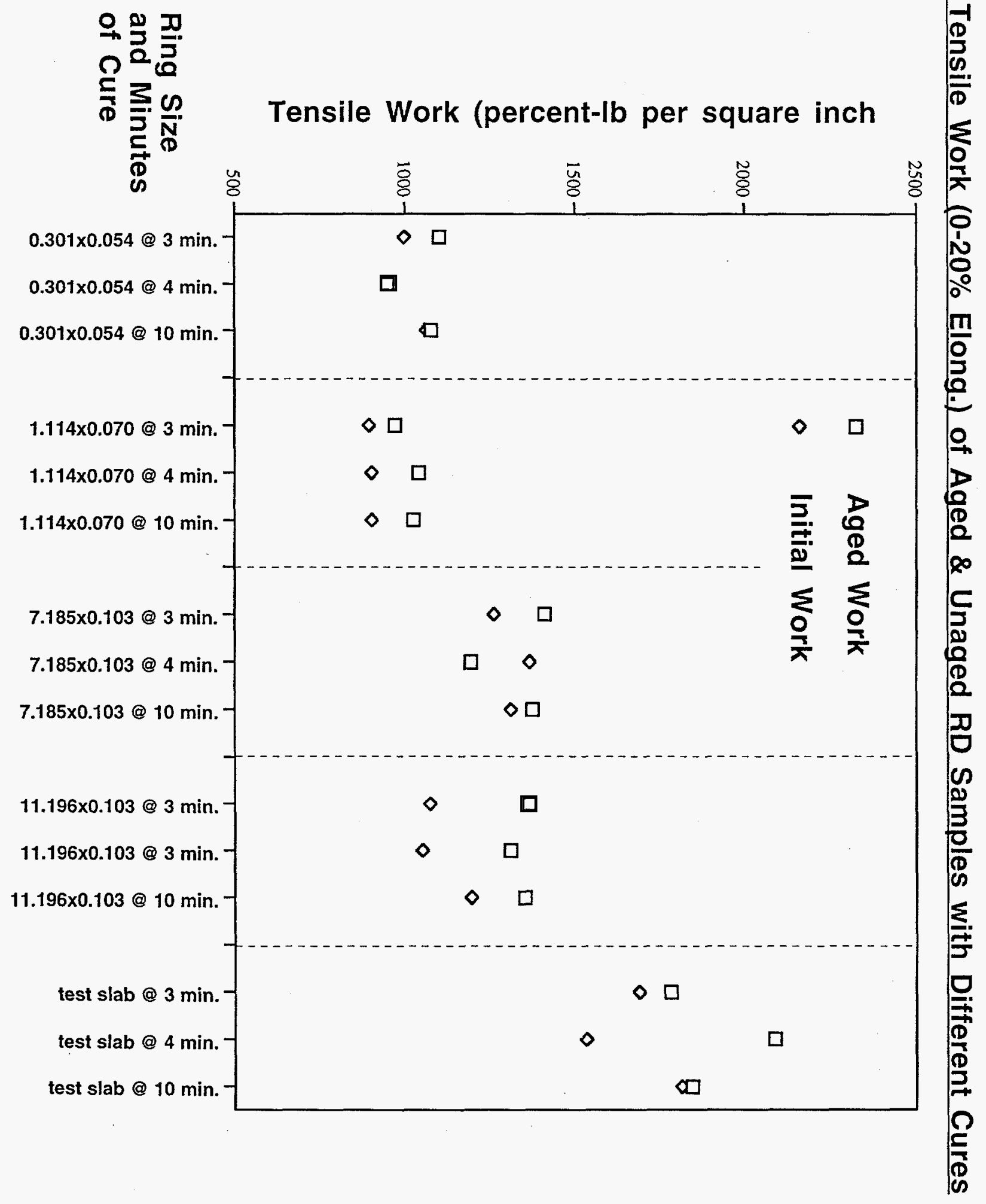




\section{Figure 4. DSC Cure Studies on RD Rubber Materials}

(endotherms are positive, exotherms are negative)

RD Butyl Rubber O-Rings, 1.114x0.070, Batch 15107 Different Cure Times

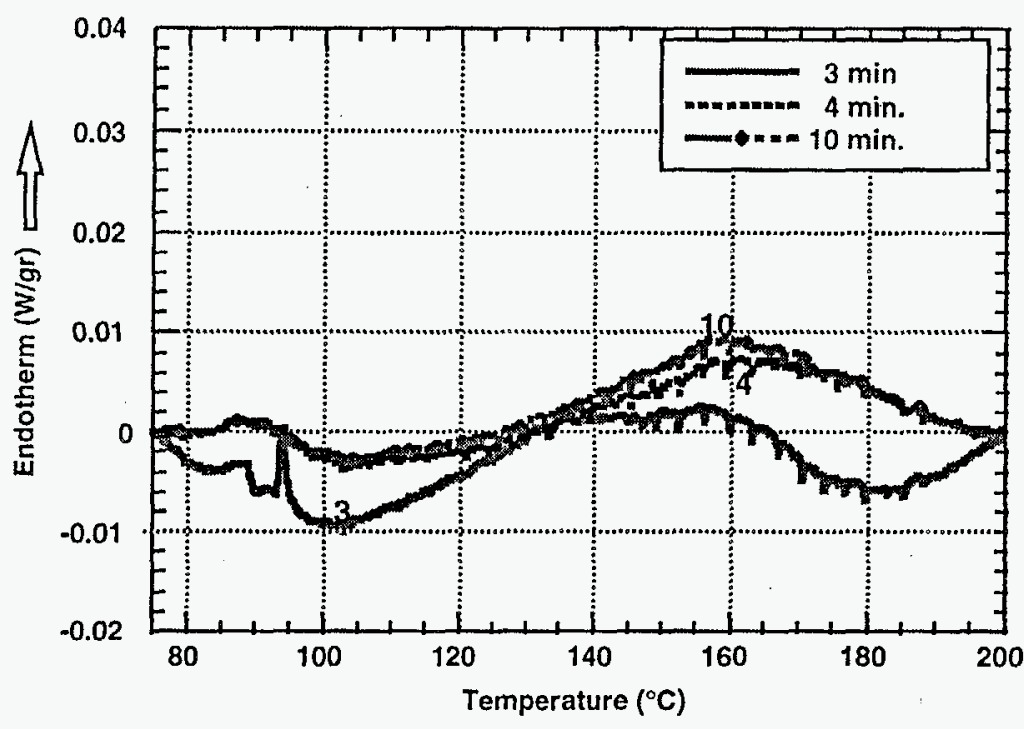

RD Butyl Rubber Test Slabs, Batch 15107 Different Cure Times

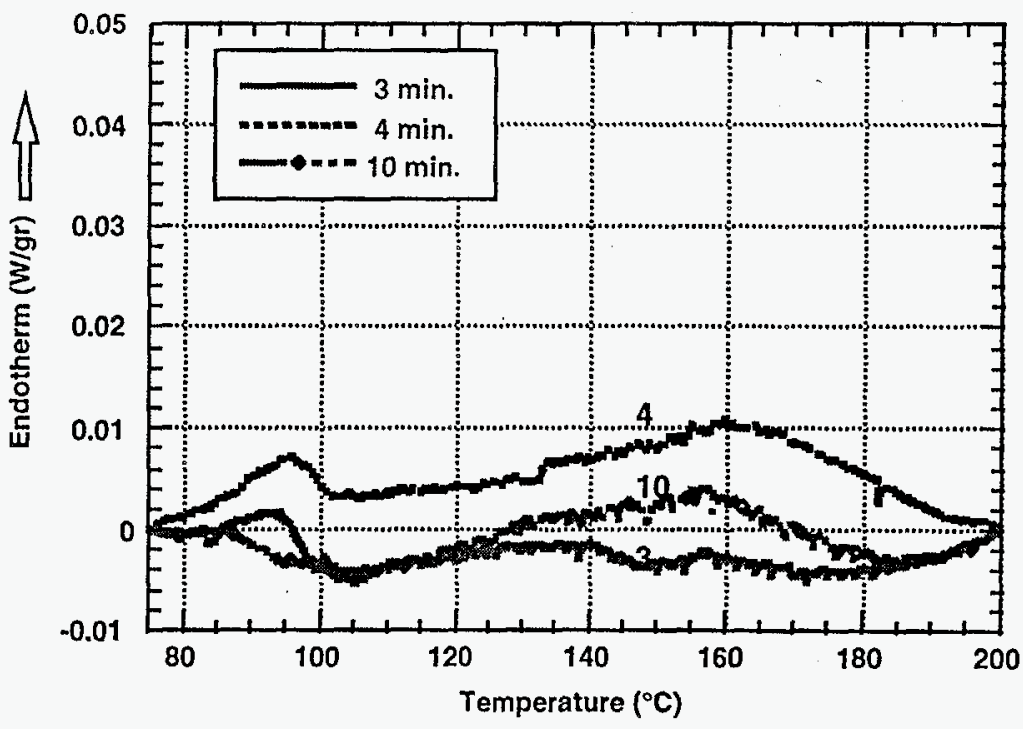

RD Butyl Rubber O-Rings, 11.196x.103, Batch 15107, Difterent Cure Times and Aged Sample

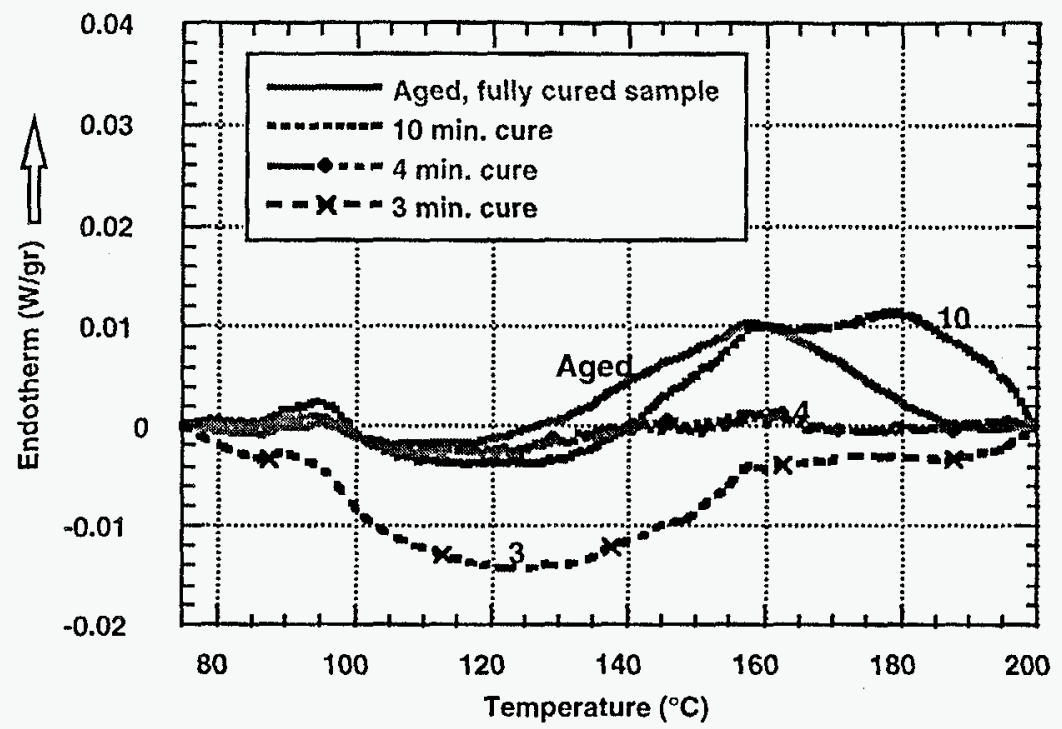

RD Butyl Rubber Batch 15107:

Cured Different Times in DSC at $150^{\circ} \mathrm{C}$

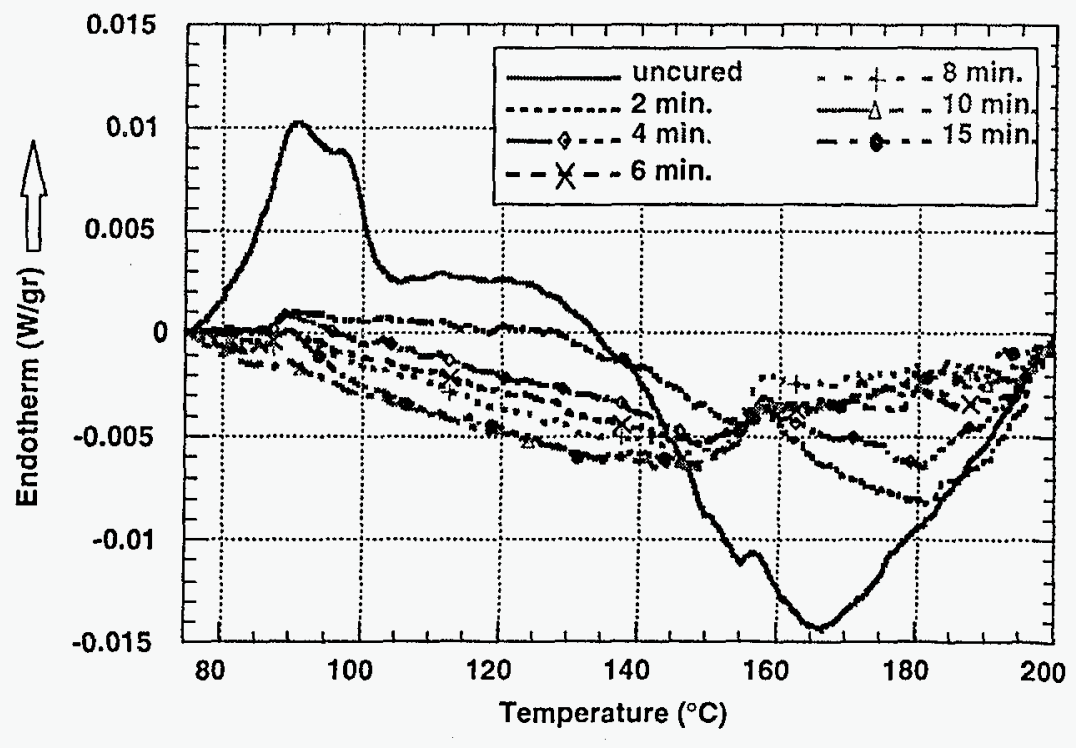




\section{Rubber Composition Tests}

An unexpected discovery near the end of this program was the finding that two lots of test slabs supplied by Parker Seals and labeled as being prepared from specific batches of butyl rubber were actually prepared from EPDM rubber. Parker has been unable to fully account for how such a substitution could have occurred and whether such errors occur with any regularity.

The two Parker test slab lots made from EPDM were those labeled as butyl batches 316710 and 317851. Other assorted Parker and RD materials which were analyzed by solid state NMR and found to be made from the expected butyl rubber included Parker tests slabs from batches 316104 and 317403, Parker O-rings from batch 316710 (16.339 in. and 0.301 in. ID), Parker O-rings from batch 317851 (7.688 in. ID), RD Rubber test slabs from batches 14810 and 15107, and RD Rubber Orings from batch 15107 (0.551 in. ID). No RD Rubber products and no O-rings from either vendor were found to be made from EPDM rubber. Typical proton NMR spectra for butyl and EPDM rubber are shown in Figure 5.

The NMR analyses were prompted by the unusually good aging characteristics, more like EPDM than butyl rubber, found by Mark Wilson for the 316710 test slabs in stress relaxation tests at Kansas City Plant. Subsequent permeation tests by Ken Gillen at Sandia, NM showed also performance similar to that expected from EPDM (much poorer than butyl) and were followed by a solid state NMR analysis confirming the EPDM composition.

None of the normal acceptance tests, including physical properties and density, nor DSC can reliably distinguish butyl and EPDM rubber. Long term aging and permeation tests are more involved and time consuming and are not candidates for qualification testing. The most definitive means, in any case, of identifying a composition as either rubber would be spectroscopic such as NMR or IR and possibly mass spectra. The cost and limited availability of solid state NMR would suggest the use of IR and this method has been used at LLNL to identify rubber samples. SpectraTech ATR (attenuated total reflectance) instruments are available for about $\$ 3 \mathrm{~K}$ or less which are capable of running IR spectra on the as-received slab or ring samples. The IR spectra of the two rubbers, like the NMR spectra, are very distinct.

Inclusion of such an IR test in future rubber material specifications would preclude the inadvertent use of O-ring seals made from the wrong base rubber. EPDM rubber provides very different permeability characteristics and lower levels of environmental protection than butyl rubber. A final decision on the type of spectral test to be used has not yet been made and will largely be determined by equipment availability. 
Figure 5. Typical Solid State NMR Spectra for Butyl and EPDM Rubber.
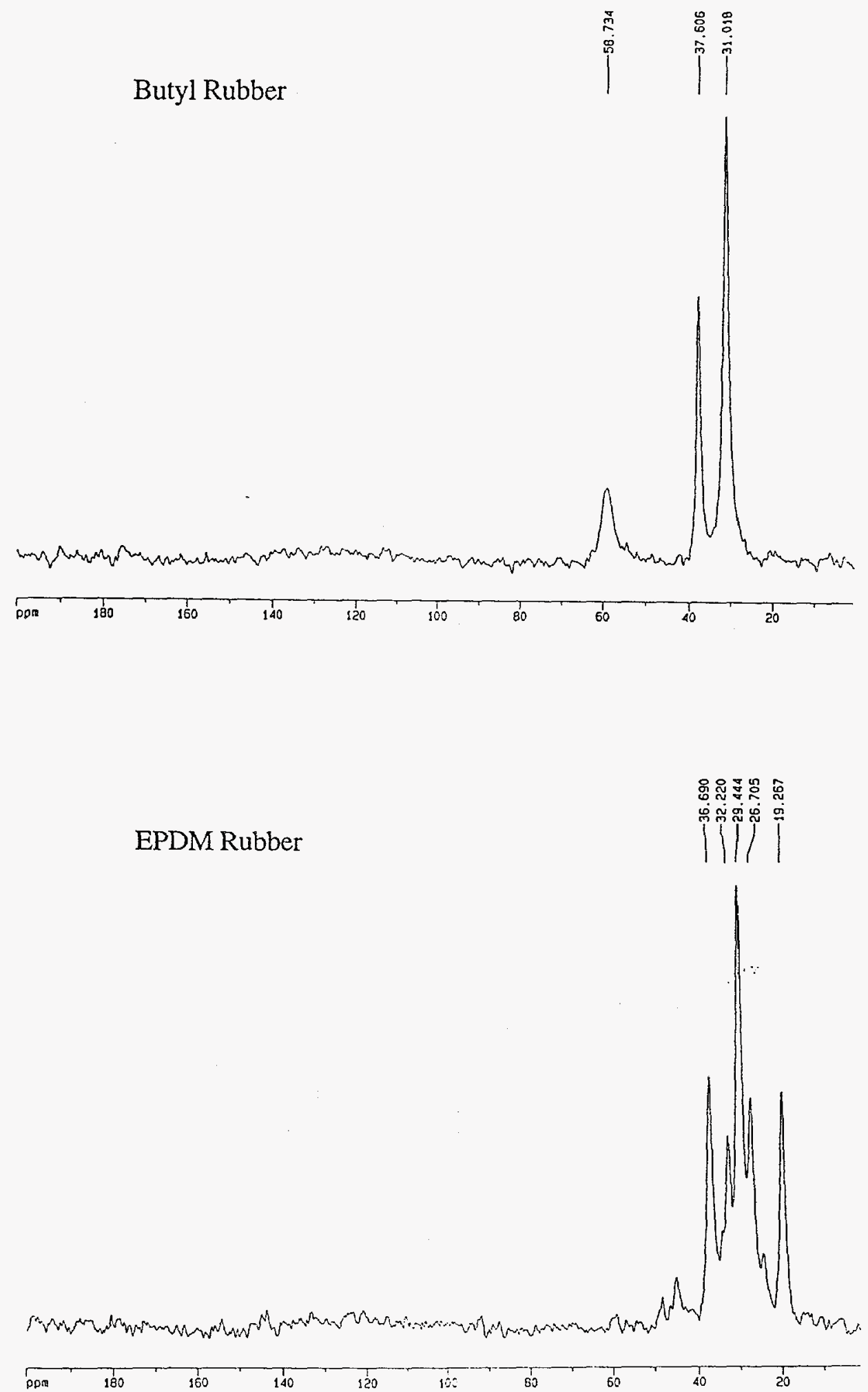


\section{Vendor Comparisons}

Of the three vendors participating in this program, only Precision provided O-rings of clearly inadequate quality. Precision is a very low cost vendor and the visual quality of their O-rings reflected their low cost. Most of the O-rings used in the test program were visually inspected at Kansas City to insure comparable quality prior to testing. Precision O-rings were typically coated with talc which had to be removed by washing and the percentage of rings passing visual inspection was low, generally less than 50\%. Test results from the Precision O-rings, as noted in the preceding sections, showed higher and sometimes out-of-spec compression set values, a key parameter. Both the poor visual quality and inconsistent compression set performance led to a decision not to include Precision as a future vendor.

Parker rings showed more variability in measured properties and also had large numbers of rings rejected for visual quality. RD Rubber rings were typically lower in hardness and tensile modulus than Parker, but they were also slightly lower, and again more uniform, in compression set, a key criteria. Both vendors appear capable of providing rings which will meet W87 requirements.

Concerns with Parker revolve around the recently discovered mislabeling and shipment of test slabs made from EPDM rubber and general, on-going difficulties noted at Kansas City with product quality and technical service. The small volume of rings required for DOE warhead production and maintenance does not warrant a highly cooperative response from this high volume vendor. RD Rubber, in contrast, is a smaller vendor and has shown a high level of cooperation as exemplified by production of the special materials needed for evaluating cure cycle effects.

\section{$\underline{\text { Summary }}$}

The accumulated test data on rings of various sizes and test slabs from three vendors indicate that hardness, compression set and tensile tests can be readily and reliably performed on O-ring samples in place of the current test slab samples. Tables 10 and 11 and Plots 14 and 15 summarize all of the hardness, compression set and tensile data discussed in the preceding sections.

Procedures and required equipment have been defined and incorporated into the new test methods detailed in Appendices A, B and C. These procedures are currently being reprocessed into the Kansas City format. Modifications have also been made where needed in the target test values and these are shown in Table 12. A comparison of Table 12 with Table 1 in the beginning of the report provides a quick review of the changes made in both procedures and target test values in switching from test slab to O-ring samples. Additional O-ring tests on materials available at Kansas City are in progress and will be evaluated before target test values, especially for the tensile tests, are finalized. An additional test proposed for future O-ring lot acceptance is spectroscopic confirmation of the rubber material used, possibly by IR. A final decision on the use of IR vs. other options has not yet been made.

Difficult remaining issues include the definition of sampling rates from O-ring lots of different ring sizes and ring counts. Appropriate statistical samples for lots with different ring counts, ranging from 100 to 1000 and beyond need to be defined in a manner which is feasible, not overly burdensome or costly, and which yet provides data with acceptable precision. If larger orders are placed to fill both current and future needs, the issue of re-certification of lots in storage will need to be addressed. The definition of the word "lot" even requires clarification as smaller rings are fabricated in molds holding multiple samples while larger rings may be molded one at a time and may require several molding days to fill an order. While a lot of O-rings would clearly need to be fabricated from a single batch of rubber, it is not clear what molding cycle constraints may also be required to insure lot uniformity. The test sampling rates suggested in Table 12 reflect only the rates required to obtain reasonable precision in the test measurements and need to be further reconciled with the sampling rates required for statistically valid sampling of lots with different ring counts. 
Table 10. Test Data Summary for Butyl Rubber Materials (Rings and Slabs) from Different Vendors

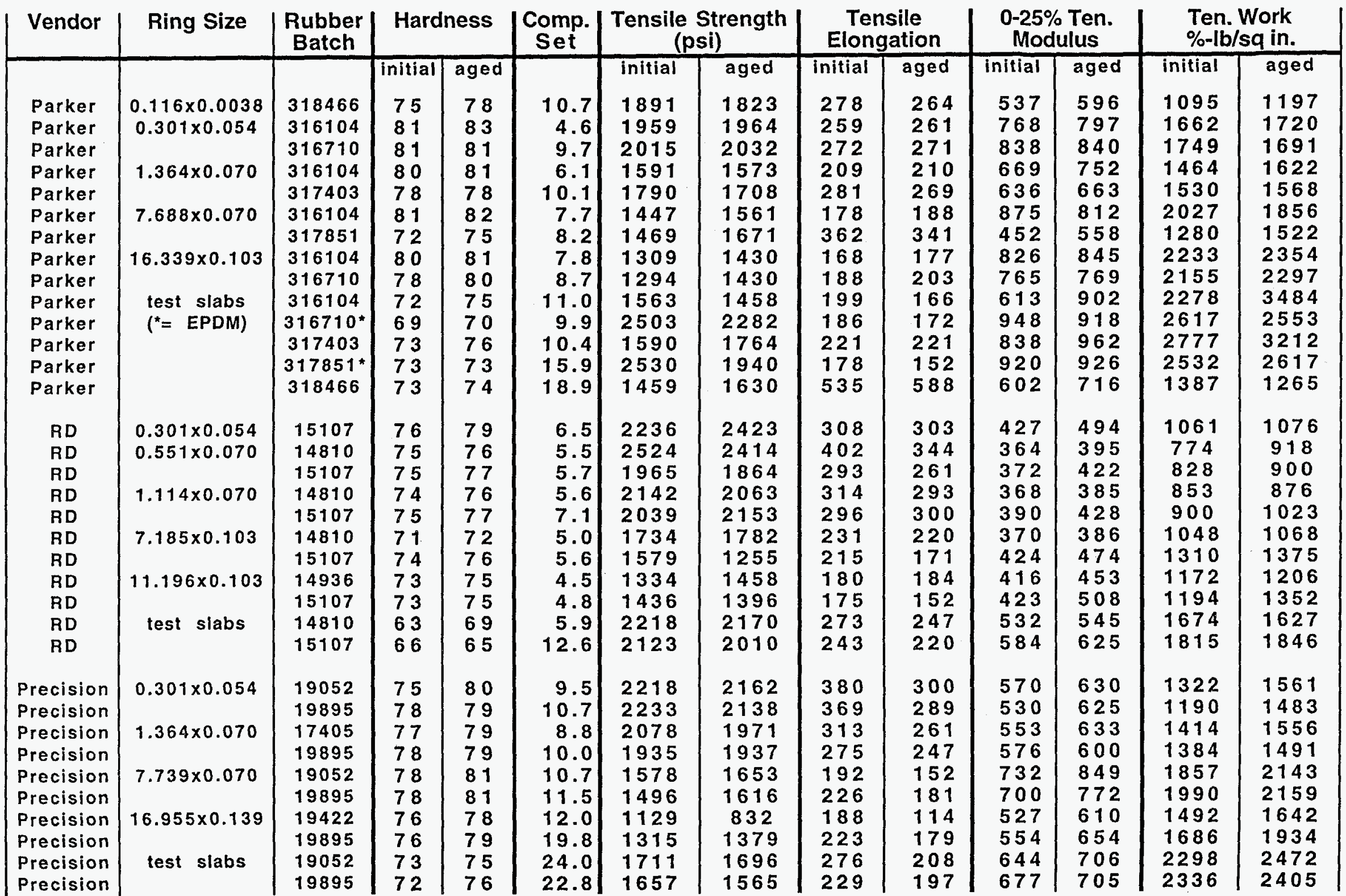

Aged samples (except compression set) exposed to 70 hours at $212^{\circ} \mathrm{F}$ plus 24 hours at room temperature. Compression set samples exposed to 22 hours aging at $25 \%$ compression and $158^{\circ} \mathrm{F}$ plus 30 min., uncompressed, at room temperature. 
Plot 14. Unaged O-Ring Test Values vs. Ring Size and Vendor

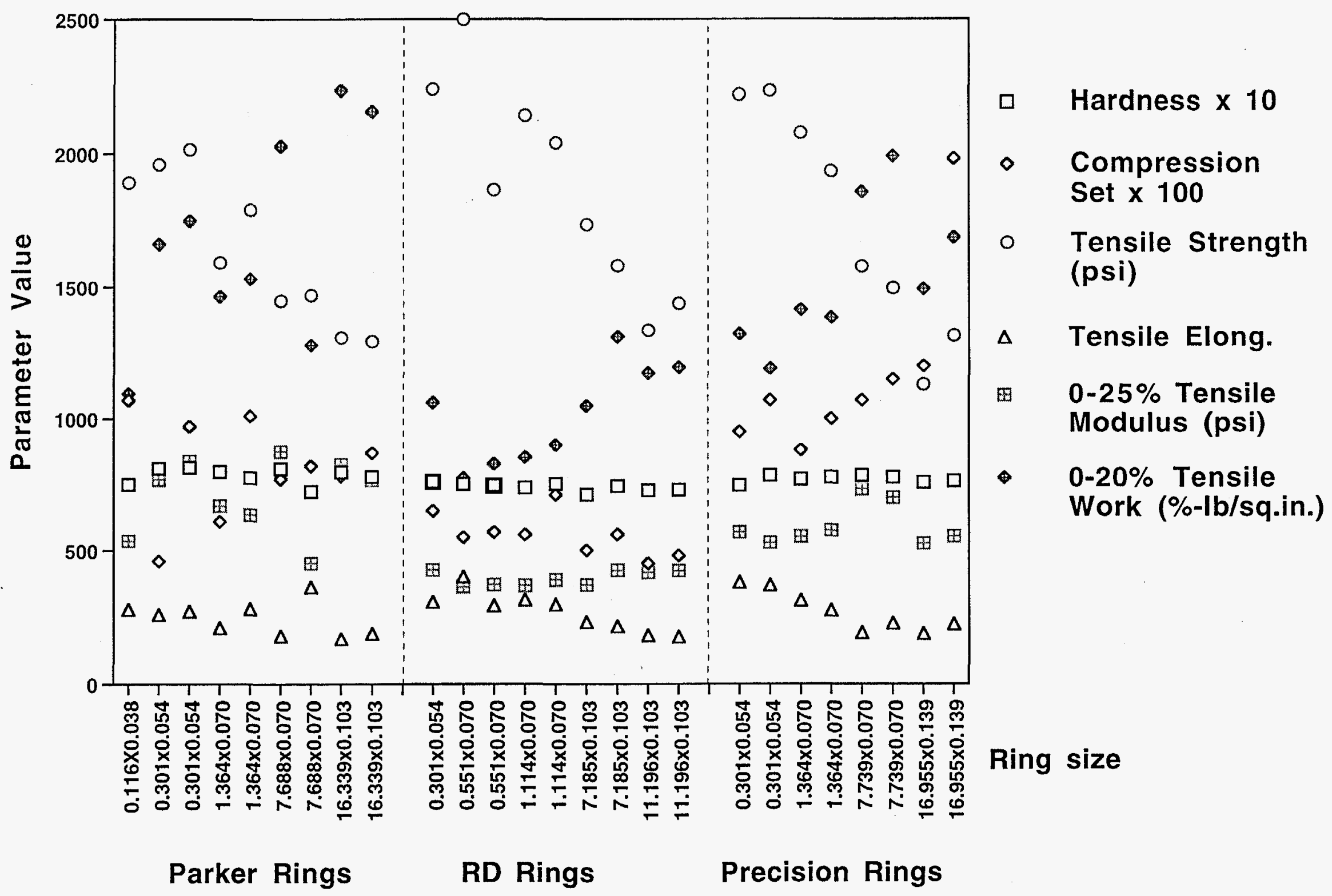


Table 11. Test Data Summary on RD Rubber Materials (Batch 15107) With Differing Cure Schedules

3 min. 12 sec. $=45 \%$ cure.

4 min. 18 sec. $=70 \%$ cure.

$10 \mathrm{~min} .=95 \%$ cure

\begin{tabular}{|c|c|c|c|c|c|c|c|c|c|c|c|c|}
\hline \multirow{4}{*}{\begin{tabular}{|l} 
Ring Size \\
$0.301 \times 0.054$
\end{tabular}} & \multirow{4}{*}{\begin{tabular}{|c} 
Cure Time \\
3 min. $12 \mathrm{sec}$.
\end{tabular}} & \multicolumn{2}{|c|}{ Hardness } & \multirow[t]{2}{*}{$\begin{array}{c}\text { Comp. } \\
\text { Set }\end{array}$} & \multicolumn{2}{|c|}{$\begin{array}{l}\text { Tensile Strength } \\
\text { (psi) }\end{array}$} & \multicolumn{2}{|c|}{$\begin{array}{l}\text { Tensile } \\
\text { Elongation }\end{array}$} & \multicolumn{2}{|c|}{$\begin{array}{l}0-25 \% \text { Ten. } \\
\text { Modulus }\end{array}$} & \multicolumn{2}{|c|}{$\begin{array}{l}\text { Ten. Work } \\
\%=l b / s q \text { in. }\end{array}$} \\
\hline & & initial & aged & & initial & aged & initial & aged & initial & aged & initial & aged \\
\hline & & 76 & 81 & 7.9 & 2429 & 2556 & 340 & 276 & 469 & 547 & 997 & 1100 \\
\hline & & 76 & 80 & 7.0 & 2374 & 2369 & 334 & 284 & 433 & 471 & 949 & 948 \\
\hline & $10 \mathrm{~min}$. & 76 & 79 & 6.5 & 2236 & 2423 & 308 & 303 & 427 & 494 & 1061 & 1076 \\
\hline $1.114 \times 0.070$ & $3 \mathrm{~min} .12 \mathrm{sec}$. & 73 & 80 & 10.8 & 2177 & 2089 & 319 & 223 & 390 & 479 & 893 & 970 \\
\hline & $4 \mathrm{~min} .18 \mathrm{sec}$. & 73 & 77 & 6.6 & 2119 & 2099 & 291 & 258 & 391 & 464 & 900 & 1040 \\
\hline & $10 \mathrm{~min}$. & 75 & 77 & 7.1 & 2039 & 2153 & 296 & 300 & 390 & 428 & 900 & 1023 \\
\hline $7.185 \times 0.103$ & $3 \mathrm{~min} .12 \mathrm{sec}$. & 73 & 77 & 9.8 & 1879 & 1751 & 218 & 155 & 513 & 588 & 1260 & 1411 \\
\hline & $4 \mathrm{~min} .18 \mathrm{sec}$. & 73 & 78 & 14.5 & 1170 & 1641 & 153 & 159 & 479 & 556 & 1366 & 1192 \\
\hline & $10 \mathrm{~min}$. & 74 & 76 & 5.6 & 1579 & 1255 & 215 & 171 & 424 & 474 & 1310 & 1375 \\
\hline $11.196 \times 0.103$ & $3 \mathrm{~min} .12 \mathrm{sec}$. & 72 & 77 & 8.0 & 1746 & 1902 & 228 & 184 & 421 & 546 & 1073 & 1365 \\
\hline & $4 \mathrm{~min} .18 \mathrm{sec}$. & 74 & 77 & 6.7 & 1380 & 1869 & 190 & 194 & 411 & 514 & 1050 & 1310 \\
\hline & $10 \mathrm{~min}$. & 73 & 75 & 4.9 & 1436 & 1396 & 175 & 152 & 423 & 508 & 1194 & 1352 \\
\hline Test Slabs & $3 \mathrm{~min} .12 \mathrm{sec}$. & 67 & 70 & 13.5 & 2116 & 2034 & 221 & 189 & 613 & 635 & 1690 & 1784 \\
\hline & $4 \mathrm{~min} .18 \mathrm{sec}$. & 67 & 70 & 10.8 & 2092 & 1950 & 247 & 179 & 536 & 640 & 1534 & 2090 \\
\hline & $10 \mathrm{~min}$. & 66 & 65 & 12.6 & 2123 & 2010 & 243 & 220 & 584 & 625 & 1815 & 1846 \\
\hline
\end{tabular}

1. 70 hours at $212^{\circ} \mathrm{F}$ plus 24 hours at room temperature.

2. 22 hours compression set aging at $25 \%$ compression and $158^{\circ} \mathrm{F}$ plus $30 \mathrm{~min}$. at room temperature. 
Parameter Value

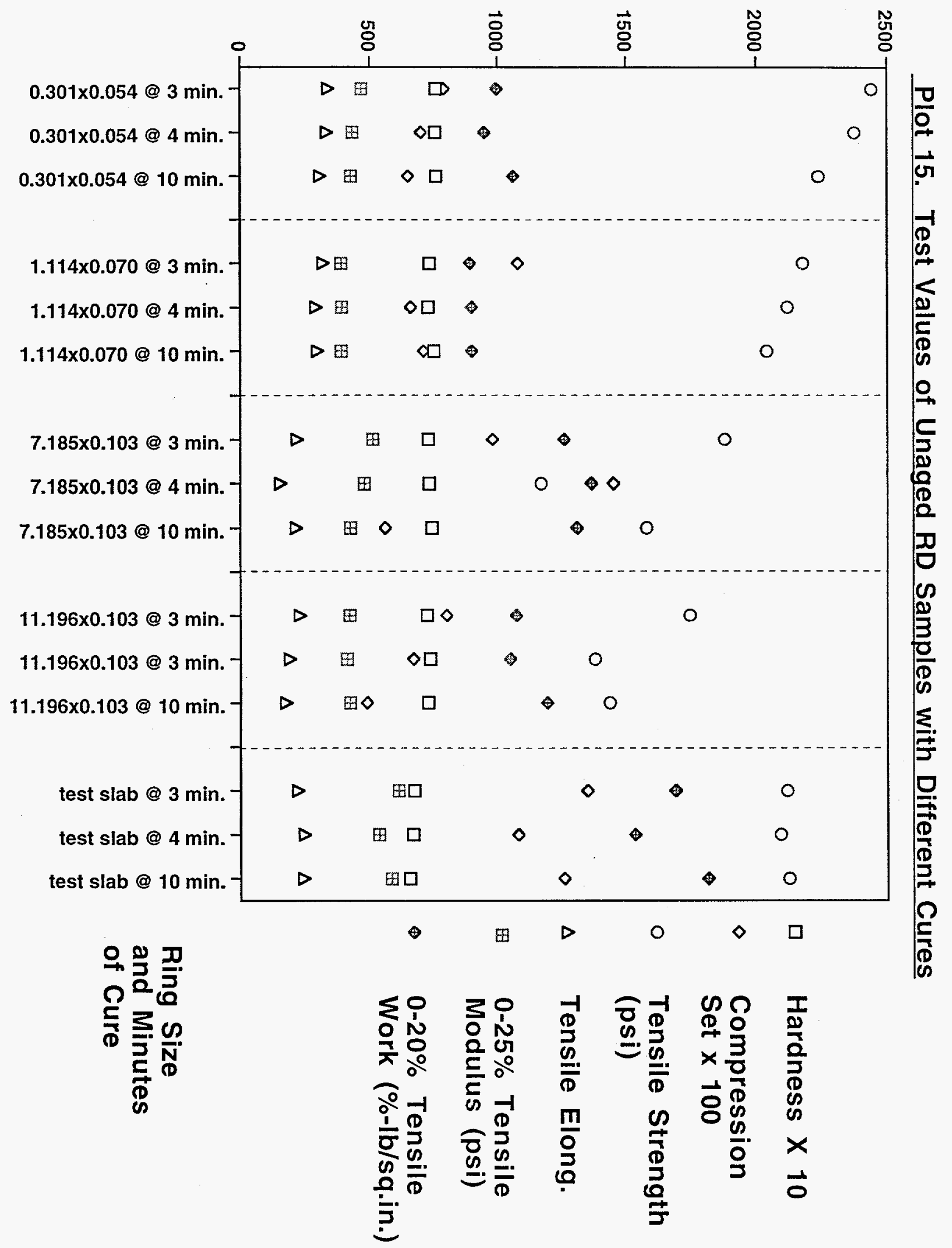




\section{Acknowledgments}

This program was initiated by Bob Anderson of the W87 group and benefited heavily from his active involvement. The successful implementation of any revisions to the current test procedures could not have happened without his involvement plus the enthusiastic cooperation of people at Kansas City. Julie Stuckey, Mark Wilson, Tom Snider and Ed Kibalo were all active collaborators as well as discerning customers. All the ring visual inspections were carried out at Kansas City and the materials required for the cure study were procured through $\mathrm{KC}$. Even more important have been the continuous and open discussions regarding the history and issues involved in revising these O-ring test procedures.

The vast majority of the testing, data assembly, vendor contacts, sample exchanges with $\mathrm{KC}$, and any other tasks were all very capably handled by co-author Kevin Wagter.

The tensile test procedures were developed and tests performed by John Totten and the innovative split-spool tensile fixtures were designed and procured by John Korellis. Molly Jacobs made the numerous initial contacts and orders with O-ring and equipment vendors and Ja Lee Yio made many of the very early hardness and ring thickness measurements. DSC characterization of the slabs and rings with different cures and of the various aged samples was carried out by Don Meeker.

Valuable suggestions were made by Craig Henderson and by Ken Gillen who also contributed his long experience in aging studies. 
Appendix A: Proposed Test Method for Rubber O-Ring Hardness

(to be reformatted and issued as test specification 9951007A) 


\section{Test Method for Rubber O-Ring Hardness}

\section{Scope}

1.1 This test method describes a procedure for measuring the hardness of rubber O-ring samples. The hardness is obtained by the difference in penetration depth of a probe of specified dimensions under two contact conditions: (1) with a small initial force and (2) with a much larger final force. The differential penetration is automatically taken at a specified time and converted to a hardness scale value.

\section{Significance and Use}

2.1 International Hardness tests are based on measurement of the penetration of a rigid probe into the rubber specimen under specified conditions. The measured penetration is converted into International Rubber Hardness Degrees ranging from zero to 100 where 100 represents a material of infinite elastic modulus.

\section{Summary of Method}

3.1 O-rings are marked for identification and positioning as test specimens.

3.2 Initial hardness measurements on test specimens are taken and recorded.

3.3 Test specimens are heat aged for 70 hours at $212^{\circ} \mathrm{F}$.

3.4 Final hardness measurements on test specimens are taken and recorded approximately 24 hours after removal from the oven.

3.5 The heat aging difference is calculated from the average initial and final hardness measurements.

\section{Apparatus}

4.1 Micro Durometer- (See Figure 4.1)

4.1.1 A Shore M Digital Micro Durometer with a resolution of \pm 0.01 points is required. Dial durometers are not suitable. The durometer should automatically record the hardness 1 second after impact.

4.1.2 The durometer must be mounted in a hydraulically controlled stand.

4.1.3 Double pin fixtures are required to hold the ring in place. Fixtures of a standard range are typically provided with the durometer. If the O-rings have a cross section not covered, a custom sized fixture should be ordered.

Figure 4.1

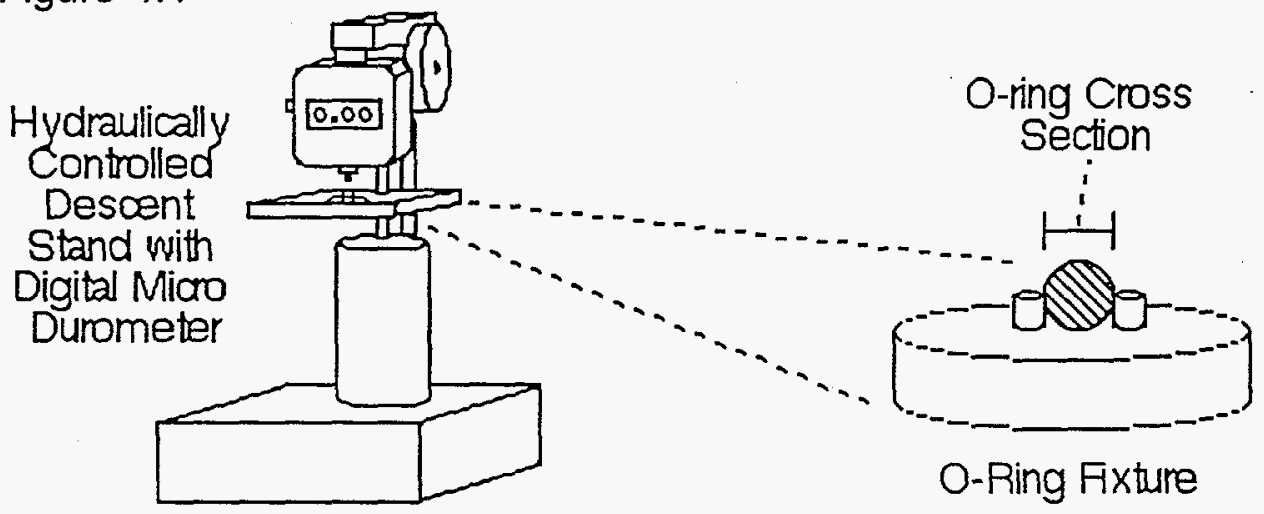

4.2 Oven- A force ventilated or gravity convection oven capable of maintaining a uniform temperatures of $212 \pm 10^{\circ} \mathrm{F}$ should be used. The oven should contain blocks or a fixtured perforated rack at least one inch, preferably several inches, 
above the oven floor to support the aging rack. An additional verifying temperature chart recorder is desirable.

4.3 Heat Aging Rack-

4.3.1 The rack should have a flat, non-heat conducting surface that does not restrict air flow around the O-rings.

4.3.2 The rack frame can be made by assembling custom wood frame segments (used to build frames for painting canvases and available at crafts or art supply stores) or any thin wood slats (available at hardware stores).

4.3.3 The surface can be made out of any natural loose weave material. It needs to be open enough to allow air flow while being tight enough to completely support the O-rings. Needle point netting (available crafts or fabric supply stores) seems to work best, but any equivalent material will do. Avoid synthetic fibers which might contaminate or adhere to the O-rings.

4.3.4 Stretch the fabric over the frame like a canvas and staple it in place.

Figure 4.3

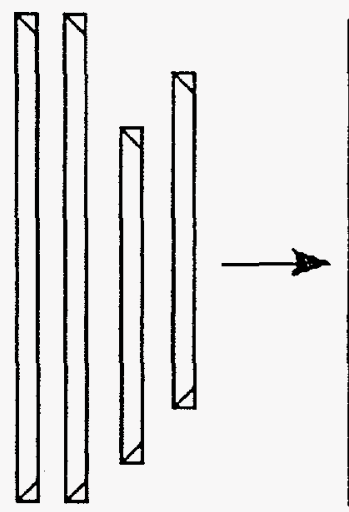

Slats
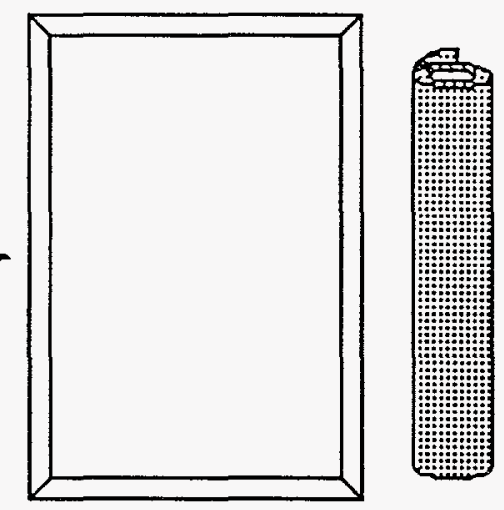

Frame and Netting

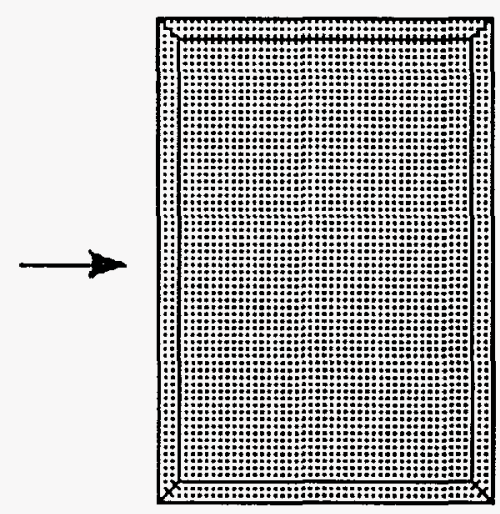

Finished Radk

\section{Number of Test Specimens}

5.1 Sacrificial O-rings must be of the same size and from the same lot as the O-ring they are to represent.

5.2 Sampling plan. (to be determined)

\section{Test Specimen Preparation}

6.1 Lay out the O-rings on a flat surface. Arrange them in a flat and relaxed state, approximately circular, with no twists or loops.

6.2 Marking test specimens (See Figure 6.2)

6.2.1 Use water based correction fluid to mark target dots on the specimens.

6.2.2a On small O-rings (inside diameter $\leq 2.0$ inches) mark two dots approximately $180^{\circ}$ apart on the top surface to denote the sampling sites.

6.2.2b On large O-rings (inside diameter $>2.0$ inches) mark four dots approximately $90^{\circ}$ apart on the top to denote the sampling sites.

6.2.3 The $A$ and UA designations indicate the location of hardness measurements on unaged (UA) and aged (A) samples.

6.2.4 Mark a dot on the outside curve of the O-ring adjacent to a sample dot to denote the "origin". 
Figure 6.2

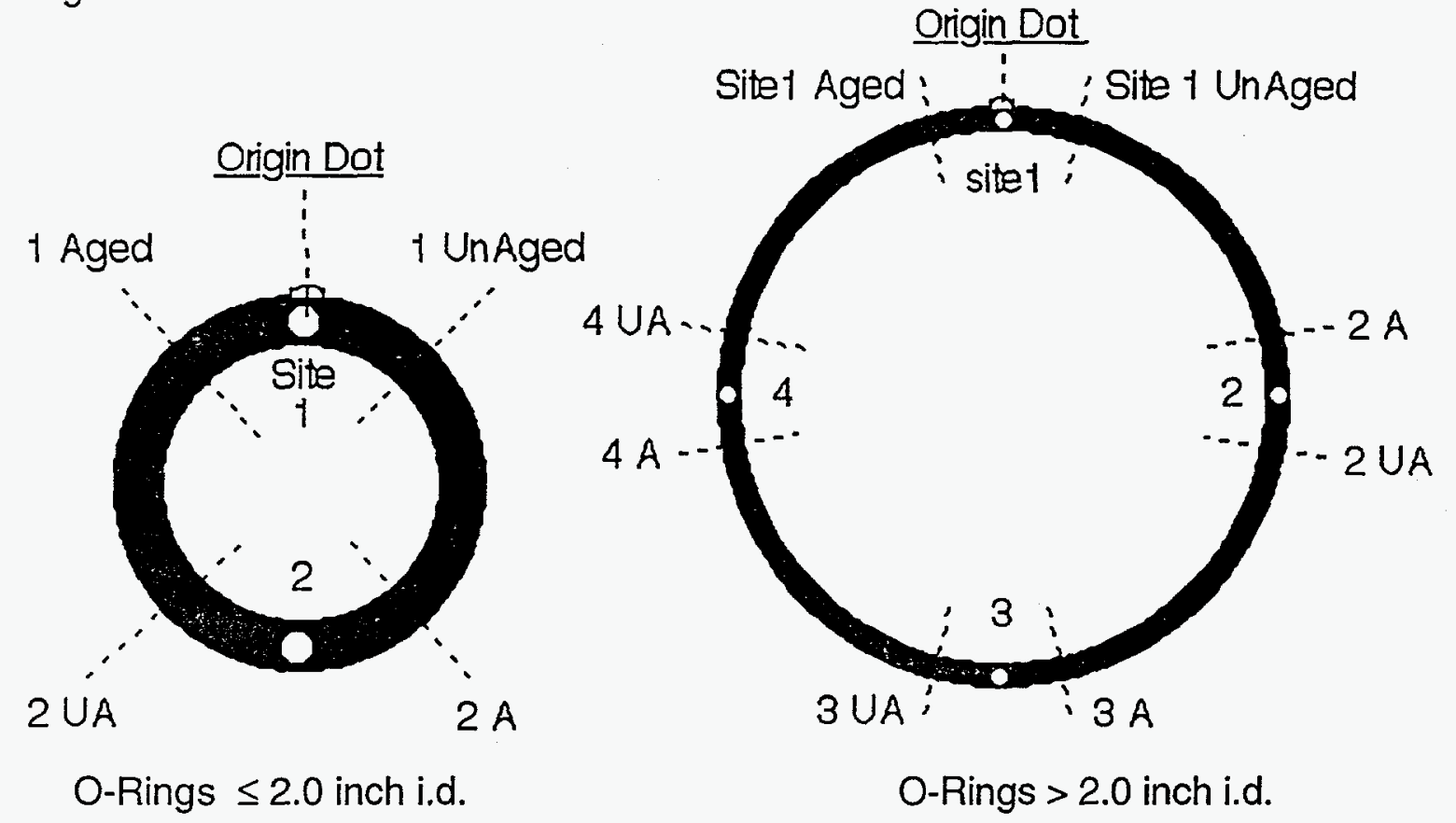

\section{Test Procedure}

7.1 Preparations

7.1.1 Preheat the oven to $212 \pm 10^{\circ} \mathrm{F}$

7.1.2 With the double pin fixture removed from the durometer platform, raise and drop the durometer assembly ten times to equilibrate the oil in the piston. This will result in a smoother motion over the range of descent, giving more consistent measurements. This should be repeated whenever the durometer has been idle for more than 30 minutes.

7.1.3 Select the appropriate sized double pin fixture for the O-rings being tested and fit it into the durometer platform.

7.1.4 Carefully lower the probe, making sure it does not touch the metal platform. Check to see if the probe is exactly centered between the O-ring pins so that the durometer probe will contact the O-ring at its apex. Realign the platform or the probe if needed until the probe is centered.

7.2 Initial hardness readings

7.2.1 Place the O-rings on the durometer platform in the same orientation as they were marked. For larger $\mathrm{O}$-rings an adjacent flat surface, raised to the height of the durometer with a jack stand, is required to keep the O-ring from being distorted by drooping.

7.2.2 Make sure the O-ring is centered between the two posts of the O-ring fixture with the origin and site 1 dots slightly (about $1 / 4$ inch) to the left of the pins.

7.2.3 There should be no distortions of the O-ring during the measurement. The ring may be held lightly to keep it centered as long as no bending or stretching forces are applied.

7.2.4 Flip the lever that starts the durometer descent. The durometer will take the measurement 1 second after contact with the O-ring. Record the value.

7.2.5 Raise the durometer back to its starting position.

7.2.6 Continue the sampling progression around the O-ring in a clockwise direction. The site dots should always be about $1 / 4$ inch to the left of the pins. 
7.2.7 Record vendor, part size, lot number and hardness reading of each site on each O-ring in a log book.

\subsection{Heat Aging}

7.3.1 Once the initial measurements are taken, place the O-rings on the heat aging rack. Arrange the O-rings so they are flat, relaxed and do not touch one another. The larger rings may have to be doubled over to fit on the rack.

7.3.2 Make a sketch of the layout to keep track of the locations and identity of the $\mathrm{O}$-rings being aged if multiple lots are being tested. If desired, the O-rings may also be identified with tags attached with string.

7.3.3 Place the heat aging rack with O-rings in the preheated oven at $212 \pm 10^{\circ} \mathrm{F}$ for $70.0 \pm 0.5$ hours.

7.3.4 Use hot gloves to remove the heat aging rack and O-rings from the oven.

7.3.5 Cool the O-rings on the rack for at least 16 and no more than 48 hours.

7.4 Take final hardness readings on the test specimens

7.4.1 Repeat the procedure used above except that all measurements should be made with the dots slightly (about $1 / 4$ inch) to the right of the pins. Measurements may not be made in exactly the same location due to puncturing of the ring surface by the hardness probe.

7.4.2 Record all measurements in a log book.

\section{Calculation}

8.1 Calculate the change in hardness expressed as difference from the original to final hardness as follows:

$$
\Delta \mathrm{H}=\mathrm{h}_{\mathrm{o}}-\mathrm{h}_{\mathrm{f}}
$$

where:

$$
\begin{array}{lll}
\Delta H & = & \text { change in hardness } \\
h_{0} & = & \text { average original hardness of specimens. } \\
h_{f} & = & \text { average final hardness of specimens. }
\end{array}
$$

\section{Report}

The report shall include the following:

9.1 Description of O-ring lot, including vendor, rubber compound and batch number, ring part number, ring size (inside diameter and cross section), lot size (number of O-rings), and date the lot was produced and received.

9.2 Number of O-rings used, date and time of the test, and ambient temperature.

9.3 Test Results

9.3.1 Original average hardness, $h_{0}$, of the O-rings.

9.3.2 Final average hardness, $h_{f}$ of the O-rings.

9.3.3 Change in hardness, expressed as the difference in points between the average initial and average final hardness of the samples. 
Appendix B: Proposed Test Method for Rubber O-Ring Compression Set (to be reformatted and issued as test specification 9951009A) 


\section{Test Method for Rubber O-Ring Compression Set}

\section{Scope}

1.1 This test method describes a procedure for measuring the compression set of rubber O-ring samples under constant deflection conditions in air.

\section{Significance and Use}

2.1 Compression set tests measure the ability of rubber compounds to retain elastic properties after prolonged compressive stresses. The testing involves the maintenance of a fixed deflection at an elevated temperature. Compression set tests are primarily applicable to service conditions involving static stresses.

\section{Summary of Method}

3.1 O-rings are cut and marked for identification and positioning as test specimens. 3.2 Initial cross section thickness measurements on test specimens are taken and recorded.

3.3 Test specimens are compressed to a constant deflection and maintained under this condition for 22 hours at $158^{\circ} \mathrm{F}$.

3.4 Final cross section thickness measurements on test specimens are taken and recorded $30 \pm 10$ minutes after removal from the compression device.

3.5 The compression set value is calculated from the average initial and final thickness measurements.

\section{Apparatus}

4.1 Laser Micrometer- A laser micrometer capable of measuring sample thickness with a resolution of \pm 0.0001 in. is required. Fixtures typically provided with such micrometers must be modified (see Figure 4.1) to provide a flat plane on which the O-ring samples can be placed. Use of such flat plane fixtures allows alignment of the compressed plane of the ring segments parallel to the laser reading beam

\section{Figure 4.1}

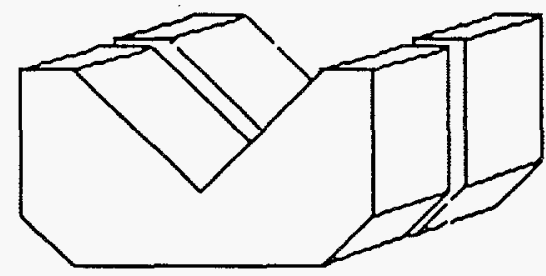

Stock LaserMic sample fixture

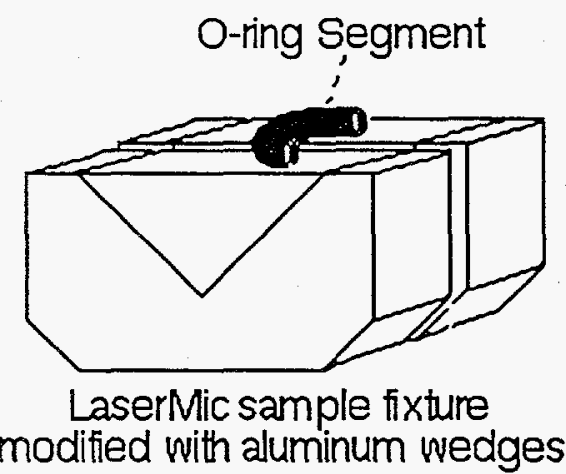

modified with aluminum wedges

\subsection{Compression Device-}

4.2.1 Samples are to be compressed in a constant deflection device consisting of two or more parallel compression plates assembled by means of a frame or threaded bolts. The device shall be portable and self-contained after assembly and designed such that the parallelism of the plates can be maintained.

4.2.2 The plates between which the test specimens are compressed shall be made of steel of sufficient thickness (typically 0.5 in.) to withstand the compressive stresses without bending. The surfaces against which the specimens are held 
shall have a highly polished chrome-plated finish and shall be cleaned thoroughly and wiped dry before each test.

4.3 Spacer Bars- A set of 4 steel spacer bars are required, per layer, to maintain the constant deflection distance of $75 \%$ of the nominal Cross Section diameter of the O-rings being tested $( \pm 0.001$ inch).

4.4 Oven- A force ventilated or gravity convection oven capable of maintaining a uniform temperature of $158 \pm 10^{\circ} \mathrm{F}$ shall be used. The oven should contain a sturdy rack at least one inch, preferably several inches, above the oven floor to hold the compression set apparatus. An additional verifying temperature chart recorder is desirable

4.5 Cooling surface- A surface with low thermal conductivity, such as wood or cardboard covered with a clean layer of paper, should be used as a cooling surface.

\section{Number of Test Specimens}

5.1 Sacrificial O-rings must be of the same size and from the same lot as the O-rings they are to represent.

5.2 Sampling plan (to be determined)

\section{Test Specimen Preparation}

6.1 Cutting test specimens (See Figure 6.1)

6.1.1 Small O-rings ( $<2.0$ inch inside diameter) are to be cut in half to give two specimens per O-ring.

6.1.2 Large O-rings ( $>2.0$ inch inside diameter) are to be cut into quarters, and a 2.0 inch specimen then cut from the end of each quarter. The rest of the Oring pieces may be discarded or used for other tests.

Figure 6.1

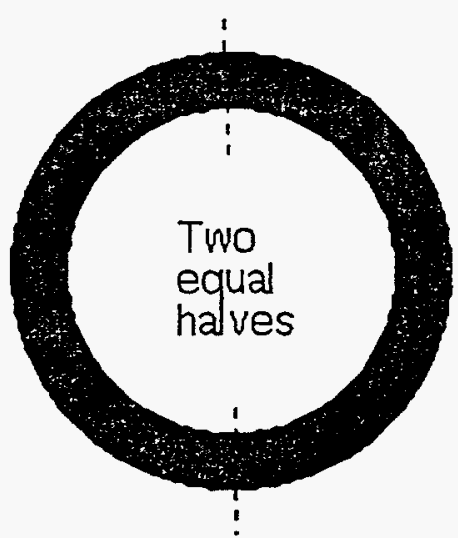

O-Rings $\leq 2.0$ in. id

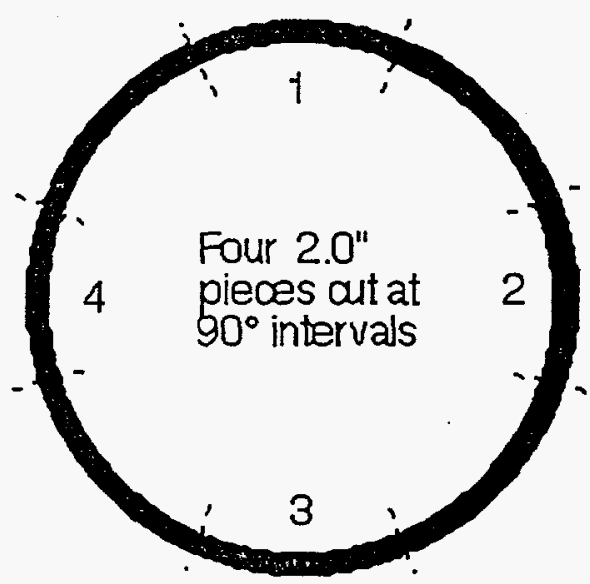

O-Rings $>2.0 \mathrm{in}$. id

6.2 Lay out the cut test specimens on a flat surface. Roll the specimens gently about until they are flat and stable.

6.3 Marking test specimens (See Figure 6.3)

6.3.1 Use water based correction fluid to mark target dots on the specimens.

6.3.2 Mark two target dots, approximately $5 \mathrm{~mm}$ apart, about midway along the outside curve of the O-ring segment to denote the measurement area.

6.3.3 Mark a position dot on the top end of the segment to denote orientation 
Figure 6.3
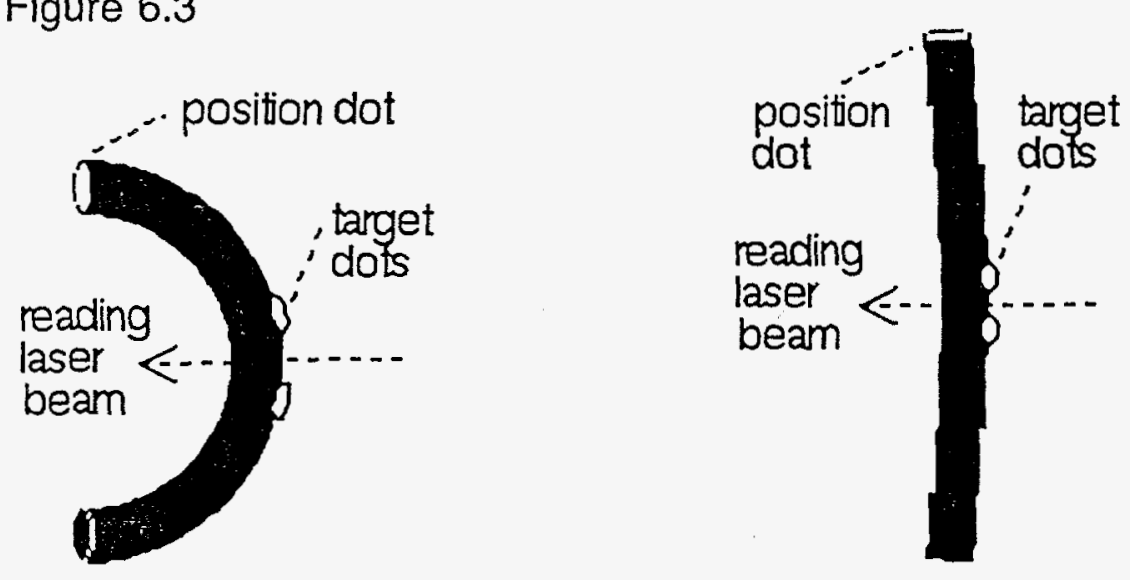

\section{Test Procedure}

\subsection{Preparations}

7.1.1 Preheat oven to $158 \pm 10^{\circ} \mathrm{F}$

7.1.2 Clean the surfaces of the compression plates that will come in contact with the O-rings with alcohol (methanol, ethanol, or isopropanol) and wipe dry with lint free cloth or paper.

7.1.3 Spray the surfaces with a thin coat of dry Teflon mold release and rewipe.

7.1.4 Turn on, calibrate if necessary, and center the laser micrometer.

7.2 Initial thickness readings

7.2.1 Place test segments on the laser micrometer platform in the same orientation as they were marked, with the reading laser centered between the two target dots (See Figures 6.3 \& 7.3).

7.2.2 Record vendor, part size, lot number, and thickness reading of each specimen in a log book.

7.3 Compressing test specimens

7.3.1 Place the compression set apparatus on a flat surface and remove the top nuts and top plates, leaving only the bottom plate and compression screws.

7.3.2 Place the test specimens on the bottom compression plate in the same flat and relaxed manner with the dots to the side as was used in taking the initial thickness reading. Specimens should not touch each other or the screws.

7.3.3 Select spacers that are $75 \%$ of the nominal cross section of the O-rings that are being tested (see Table 7.3). Wipe any oil or dirt off the spacers and place them on the plates. Make sure the spacers do not touch the specimens.

Table 7.3

O-ring Cross Section Diameter
0.038 inches
0.054 inches
0.070 inches
0.103 inches
0.139 inches

Appropriate Spacer Thickness

0.0285 inches

0.0405 inches

0.0525 inches

0.0772 inches

0.1042 inches 
Figure 7.3
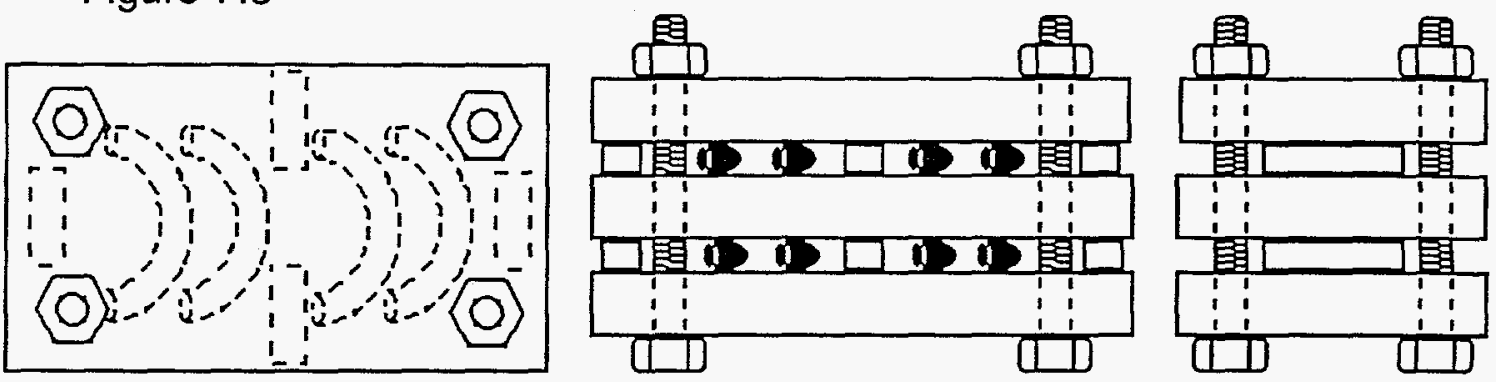

7.3.4 A second layer plate, set of specimens and appropriate spacers may be added if desired.

7.3.5 Replace top plate and nuts, being careful not to disturb the specimens and spacers.

7.3.6 Finger tighten and then use a pair of wrenches to tighten down the plates. Cross tighten the nuts using half turns to keep the pressure as even as possible. Keep tightening the nuts until all the specimens are flattened and the spacers don't slide out when the assembly is tipped sideways. If there are many O-ring pieces this may require a lot of torque.

7.4 Place the assembled compression set apparatus in the preheated oven at $158 \pm 10^{\circ} \mathrm{F}$ for $22.0 \pm 0.5$ hours.

7.5 Cooling

7.5.1 Use hot gloves to remove the compression apparatus from the oven.

7.5.2 Immediately loosen and remove the nuts in reverse manner of how they were tightened and separate the plates.

7.5.3 Gently scrape the test specimens off the plates with a flat sheet of paper or a blade being careful not to bend or stretch them.

7.5.4 Place the O-ring segments on a clean piece of paper on a flat piece of wood in the same positions as when their initial thickness measurements were taken and let them cool for 30-60 minutes.

7.6 Take final thickness readings on the test specimens

7.6.1 Follow the same procedure used for the initial readings to take the final readings. Measurements should be made as close to the same orientation and location as the initial measurements.

7.6.2 Again record all measurements in a log book.

\section{Calculations}

8.1 Calculate the actual percent compression of the O-ring speciments as follows: (This value indicates how close the actual compression was to the target $75 \%$.)

where:

$$
T \%=\left[\left(t_{0}-t_{b}\right) / t_{0}\right] \times 100
$$

$\mathrm{T} \%=$ actual percent compression of the specimens.

$\mathrm{t}_{\mathrm{o}}=$ average original thickness of the specimens.

$t_{b}=$ thickness of spacer bar used.

8.2 Calculate the compression set expressed as a percentage of the imposed compression as follows:

where:

$$
C=\left[\left(t_{0}-t_{f}\right) /\left(t_{0}-t_{b}\right)\right] \times 100
$$


C $=$ compression set.

$t_{0}=$ average original thickness of the specimens.

$t_{f}=$ average final thickness of the specimens.

$\mathrm{t}_{\mathrm{b}}=$ thickness of spacer bar used.

9. Report

The report shall include the following:

9.1 Description of O-ring lot, including vendor, rubber compound and batch number, ring part number, ring size (inside diameter and cross section), lot size (number of O-rings), and date the lot was produced and received.

9.2 Number of specimens used, date and time of the test, and ambient temperature.

9.3 Test Results

9.3.1 Original average thickness, $t_{0}$, of the test specimens.

9.3.2 Final average thickness, $t_{f}$, of the test specimens.

9.3.3 Size of spacers used, $t_{b}$.

9.3.4 Actual percentage compression of the specimen, $T_{\%}$.

9.3.5 Compression set, expressed as a percentage of the original deflection, C. 
Appendix C: Proposed Test Method for Rubber O-Ring Tensile Properties

(to be reformatted and issued as test specification 9951008A) 


\section{Test Method for Rubber O-Ring Tensile Properties}

\section{Scope}

1.1 This test method describes a procedure for measuring the ultimate strength, ultimate elongation and linear modulus at $25 \%$ elongation of rubber O-rings before and after aging in air.

\section{Significance and Use}

2.1 The tensile properties of intact rubber O-rings reflect the bulk properties, the level of defects, and surface aging effects of the materials. Specific fixtures are used in the test which differ slightly from those used in ASTM tests and which accomodate multiple loops of larger O-rings. Different test elongation speeds are used for single vs. multiple looped rings.

\section{Summary of Method}

3.1 Two identical sets of O-rings are bagged and labeled as test specimens.

3.2 Initial tensile measurements on the first set of test specimens are taken and recorded.

3.3 The second set of test specimens is heat aged for 70 hours at $212^{\circ} \mathrm{F}$.

3.4 Final tensile measurements on the second set of test specimens are taken and recorded approximately 24 hours after removal from the oven.

3.5 The heat aging difference is calculated from the average initial and final tensile measurements.

\section{Apparatus}

4.1 Testing Machine-

4.1.1 Tensile tests shall be made on a screw driven machine equipped to produce uniform grip separation speeds between 5 and 20 inches/minute for a distance of at least 30 inches. Different speeds are used for smaller and larger $O$-rings to insure adequate data collection times for the smaller rings and reasonable test times for the larger rings. No significant sensitivity of the tensile data to test speed has been noted within the ranges used.

4.1.2 The testing machine shall have both a suitable load cell and a recording device for measuring the applied force within $\pm 2 \%$. Both chart recorders and computer controlled recorders may be used if they provide suitable resolution.

4.2 Test Fixtures- All tests will be conducted on Sandia furnished fixtures or fixtures designed to Sandia specifications.

4.2.1 The base fixtures are shown in Figure 4.2 and are designed to fit a standard screw driven test machine.

4.2.2 The split spool fixtures are made with a range of groove and spool sizes to accommodate different $\mathrm{O}$-rings and are designed to fit interchangeably on the base fixtures.

4.2.3 The spools required for different O-ring sizes, and the initial spool separation distance for each O-ring size are given in Table 4.2

4.3 Oven- A force ventilated or gravity convection oven capable of maintaining a uniform temperatures of $212 \pm 10^{\circ} \mathrm{F}$ should be used. The oven should contain blocks or a fixtured perforated rack at least one inch, preferably several inches, above the oven floor to support the aging rack. An additional verifying temperature chart recorder is desirable. 
Figure 4.2

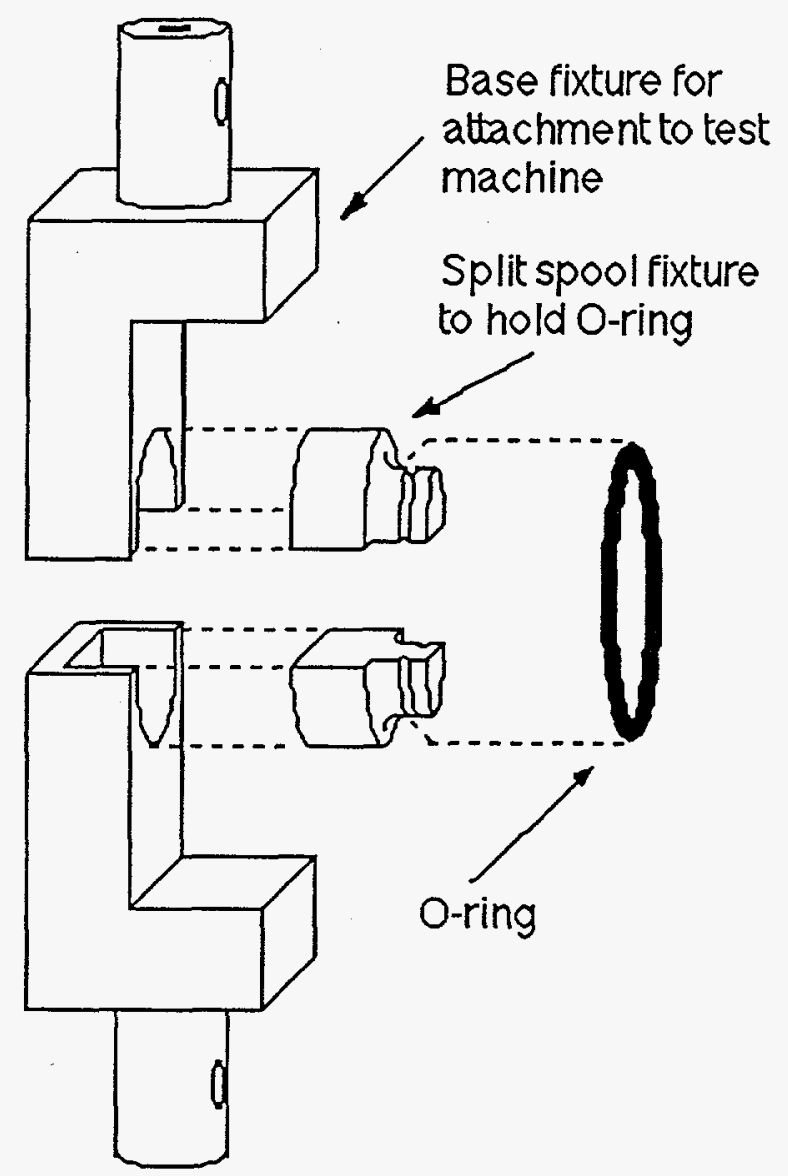

Split spool briple loop fixture with additional grooves to hold large O-rings
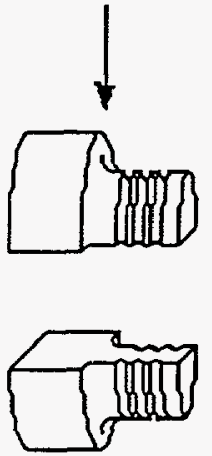

Table 4.2 O-Ring Dimensions and Corresponding Fixture and Test Parameters

O-ring inside O-ring cross spool groove number of initial fixture fixture diameter section diameter diameter loops

(D)

(\#) gap distance speed (id) (cs)

$\left(L_{i}\right)$

(in./ min.)

0.116 in.

0.038 in.

0.090 in. 0.038 in.

1

0.041 in.

5.0

0.301 in. 0.054 in. 0.196 in. 0.054 in. 0.165 in.

5.0

0.652 in. 0.070 in. 0.250 in. 0.070 in. 0.631 in.

5.0

$1.239 \mathrm{in.}$ 0.070 in. 0.250 in. 0.070 in.

1.554 in.

5.0

1.301 in.

0.070 in. 0.250 in. 0.070 in.

1.651 in.

5.0

1.364 in.

0.070 in. 0.250 in. 0.070 in.

1.750 in.

5.0

1.487 in.

0.103 in. 1.000 in. 0.103 in.

$0.765 \mathrm{in}$.

5.0

$1.739 \mathrm{in.}$

0.070 in. 0.250 in. 0.070 in.

2.339 in.

5.0

1.913 in.

0.070 in.

$0.250 \mathrm{in.} 0.070 \mathrm{in.}$

7.688 in.

0.070 in.

$1.040 \mathrm{in.} 0.070 \mathrm{in.}$

2.612 in.

5.0

16.339 in

0.103 in. 1.000 in. 0.103 in.

2.392 in.

20.0

6.984 in.

20.0

\subsection{Heat Aging Rack- (See Figure 4.4)}

4.4.1 The rack should have a flat, non-heat conducting surface that does not restrict air flow around the O-rings. 
4.4.2 The rack frame may be made by assembling custom wood frame segments (used to build frames for painting canvases and available at crafts or art supply stores) or any thin wood slats (available at hardware stores).

4.4.3 The surface can be made out of any natural loose weave material. It needs to be open enough to allow air flow while being tight enough to completely support the O-rings. Needle point netting (available at crafts or fabric supply stores) seems to work best, but any equivalent material will do. Avoid synthetic fibers which might contaminate or adhere to the O-rings. 4.4.4 Stretch the fabric over the frame like a canvas and staple it in place.

Figure 4.4

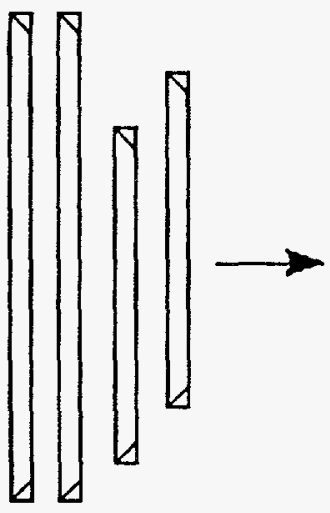

Slats
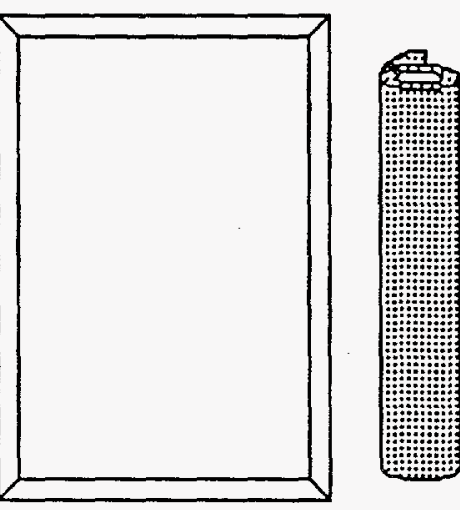

Frame and Netting

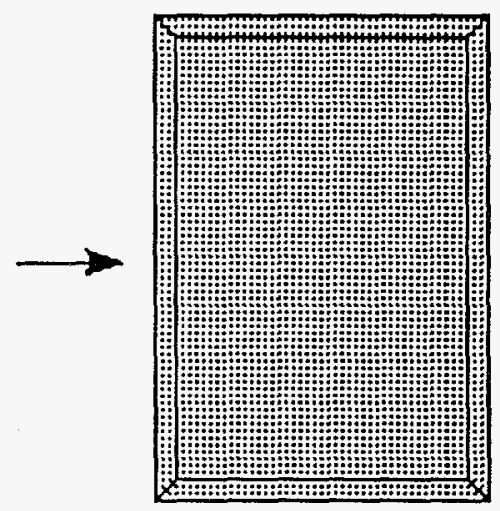

Finished Rack

\section{Number of Test Specimens}

5.1 Sacrificial O-rings must be of the same size and from the same lot as the O-ring they are to represent.

5.2 Sampling plan (to be determined)

\section{Test Specimen Preparation}

6.1 Select and label two sets of O-rings, designating one set "non-aged" and the other as "aged". It is convenient to store the O-rings in labeled plastic bags.

\section{Test Procedure}

\subsection{Preparations}

7.1.1 Preheat oven to $212 \pm 10^{\circ} \mathrm{F}$.

7.2 Heat Aging

7.2.1 Place the O-rings which are later to be used to determine "aged" tensile properties on the heat aging rack. Arrange the O-rings so they are flat, relaxed and do not touch one another. Some of the largest O-rings may have to be doubled over to fit on the rack.

7.2.2 Place the heat aging rack with O-rings in the preheated oven at $212 \pm 10^{\circ} \mathrm{F}$ for $70.0 \pm 0.5$ hours.

7.2.3 Use hot gloves to remove the heat aging rack and O-rings from the oven.

7.2.4 Cool the O-rings on the rack for at least 16 and no more than 48 hours.

7.3 Initial tensile readings on "non-aged" test specimens

7.3.1 Select the appropriate sized split spool O-ring fixture for the O-rings being tested and fit it into the base fixture (see Table 4.2). O-rings with inner diameters of 7.185 inch or larger shall be tested using the three loop 
configuration to insure adequate elongation and ring failure. The required crossings in the multi-looped configurations should be arranged such that there is single crossing of strands on each side of the spools (see Figure 7.3).

Figure 7.3

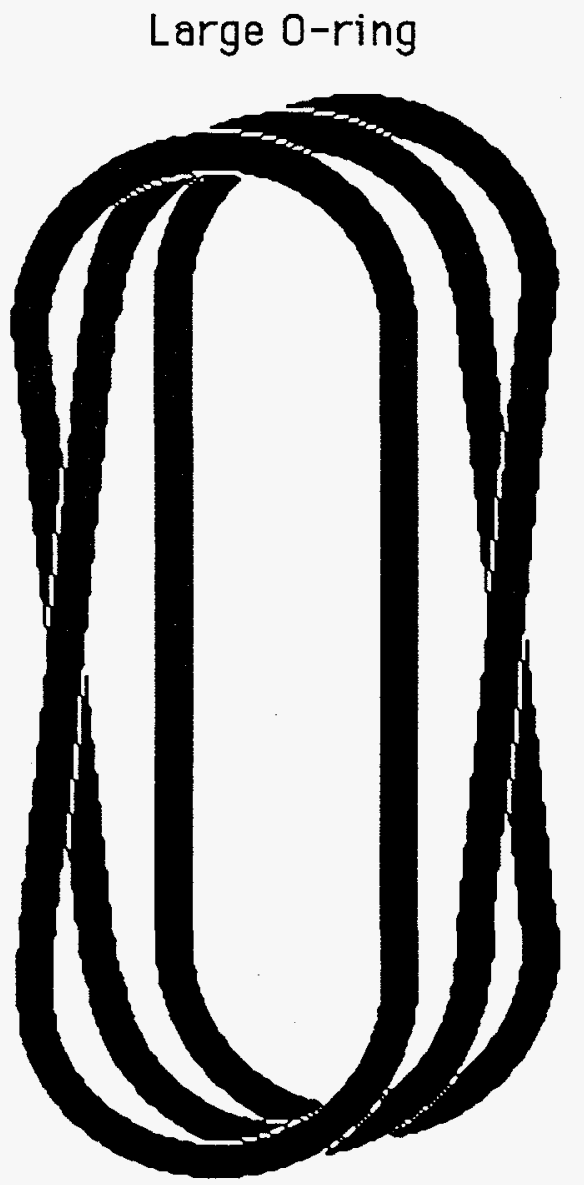

$$
\begin{gathered}
\text { Expanded face on yiew } \\
\text { of triple spool with O-ring } \\
\text { partially hidden in } \\
\text { grooves }
\end{gathered}
$$

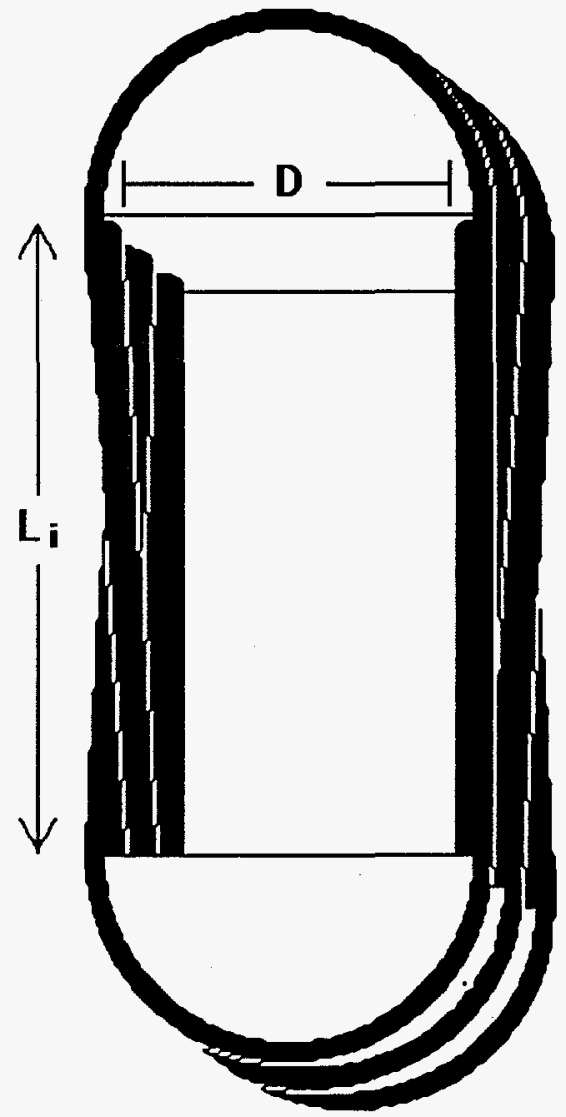

7.3.2 Bring the two halves of the split spool fixture together and reset the gap distance (L) to zero.

7.3.3 Adjust the initial gap distance $\left(L_{i}\right)$ to the value given in Table 4.2 for the Oring being tested.

7.3.4 Lubricate the O-ring with mineral oil and install the O-ring in the groove(s) of the split spool spindle.

7.3.5 Reset the strain force $\left(F_{i}\right)$ equal to zero.

7.3.6 Set the fixture separation speed at either 5 inches/minute (for singlelooped rings) or 20 inches/minute (for larger, triple-looped rings).

7.3.7 Start the stress-strain recording device and begin elongation at the selected speed. Continue elongation until sample failure.

7.3.8 Identify and save data as appropriate to the chart recorder or computer.

7.3.9 Repeat the procedure on the remaining O-rings.

7.4 Tensile measurements on the "aged" test specimens should follow the same procedure used for the initial measurements. The aged O-rings should be tested 16 to 48 hours after removal from the oven, preferably about 24 hours. 


\section{Data Analysis}

8.1 Definitions (see Figure 8.1)

Figure 8.1
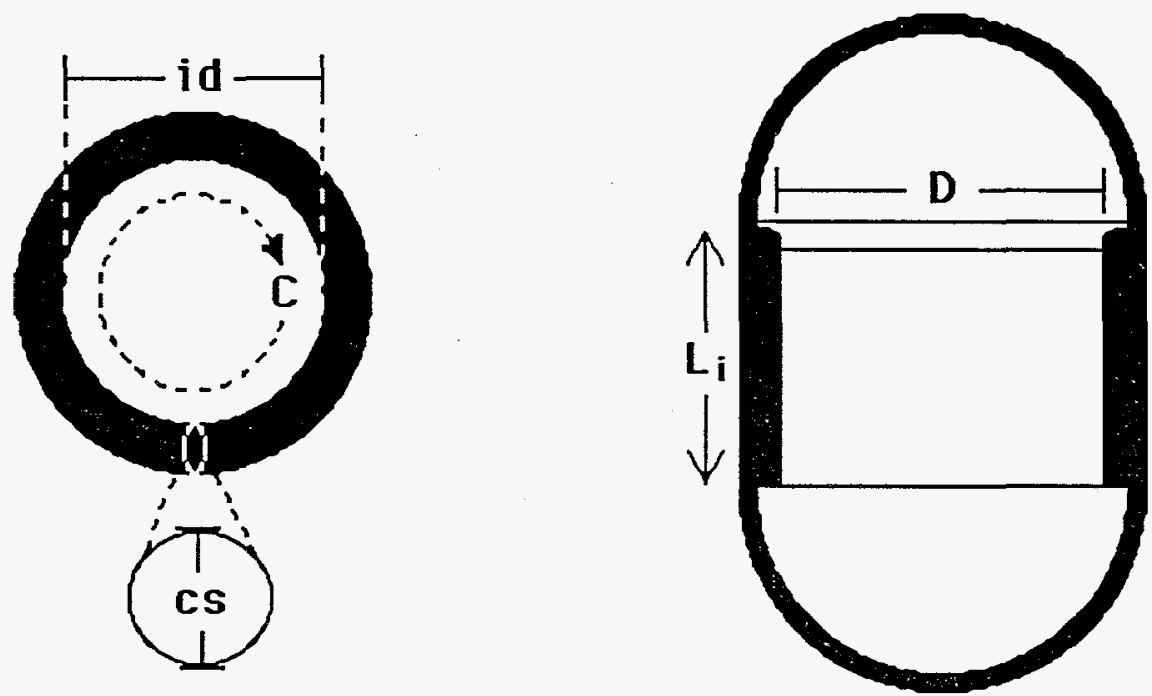

i.d. = the nominal inside diameter of the O-ring.

c.s. = the nominal cross section diameter of the O-ring.

$C=$ the inside Circumference of the O-ring. $(C=i d X \pi)$

$D=$ the Diameter of the split spool fixture.

$G=$ the circumference of the split spool fixture. ( $G=D X \pi$ )

$\mathrm{L}_{\mathrm{i}}=$ the initial fixture gap distance or Length between the split spool fixtures that corresponds to $0 \%$ elongation of the O-ring being tested. These values are given in Table 4.2

for the single looped O-rings $L_{i}=(C-G) / 2$

for the triple looped O-rings $L_{i}=(C-3 G) / 6$

$F_{i}=$ the initial Force when the split spool fixtures, with O-ring installed, are set to $L_{i} \quad$ By definition, $F_{i}=0$.

$L_{x}$ and $F_{X}$ are the fixture gap distance and corresponding force at any point " $x$ " during the test. $\mathrm{L}_{25 \%}$ and $\mathrm{F}_{25 \%}$ are used for the modulus calculations.

$L_{f}$ and $F_{f}$ are the final fixture gap distance and corresponding force at the maximum elongation before break.

\subsection{Calculations}

8.3.1 Maximum Elongation at break $(\mathrm{e} \% \max )$ is calculated as a percentage of the original O-ring circumference:

8.3.1a Elongation for single looped small O-rings

$$
e \%_{\max }=\left[\left(2 \times \Delta L_{f}\right) / C\right] \times 100 \text { where } \Delta L_{f}=L_{f}-L_{i}
$$

8.3.1b Elongation for triple looped large O-rings

$$
e \%_{\max }=\left[\left(6 \times \Delta L_{f}\right) / C\right] \times 100 \text { where } \Delta L_{f}=L_{f}-L_{i}
$$


8.3.2 Maximum Strength $\left(S_{\max }\right)$ is calculated as pounds per square inch.

8.3.2a Strength for single looped small O-rings

$$
S_{\max }=\Delta F_{f} /\left[2 X(\mathrm{cs} / 2)^{2} X \pi\right] \text { where } \Delta F_{f}=F_{f}-F_{i}
$$

8.3.2b Strength for triple looped larger O-rings

$$
S_{\max }=\Delta F_{f} /\left[6 X(\operatorname{cs} / 2)^{2} X \pi\right] \text { where } \Delta F_{f}=F_{f}-F_{i}
$$

If the recording device has been reset such that $F_{i}$ is zero, then $\Delta F_{f}=F_{f}$ in the above calculations.

8.3.3 Modulus is calculated as pounds per square inch. Use Table 8.3.3 to find the $\mathrm{L}_{25 \%}$ Distance value corresponding to the O-rings being tested. Convert the $L_{25 \%}$ value to a $F_{25 \%}$ Force value using the Force vs Distance graph for that O-ring (see the example in Figure 8.3)

8.3.3a Modulus (or stress at $25 \%$ elongation) for single looped rings

$$
M_{25}=\Delta F_{25 \%} /\left[2 X(c s / 2)^{2} X \pi\right] / 0.25 \text { where } \Delta F_{25 \%}=F_{25 \%}-F_{i}
$$

8.3.3b Modulus (or stress at $25 \%$ elongation) for triple looped rings

$$
M_{25}=\Delta F_{25 \%} /\left[6 X(\operatorname{cs} / 2)^{2} X \pi\right] / 0.25 \text { where } \Delta F_{25 \%}=F_{25 \%}-F_{i}
$$

If the recording device has been reset such that $F_{i}$ is zero, then $\Delta F_{25 \%}=$ $F_{25 \%}$ in the above calculations.

Figure 8.3 Force vs. Elongation Distance Graph

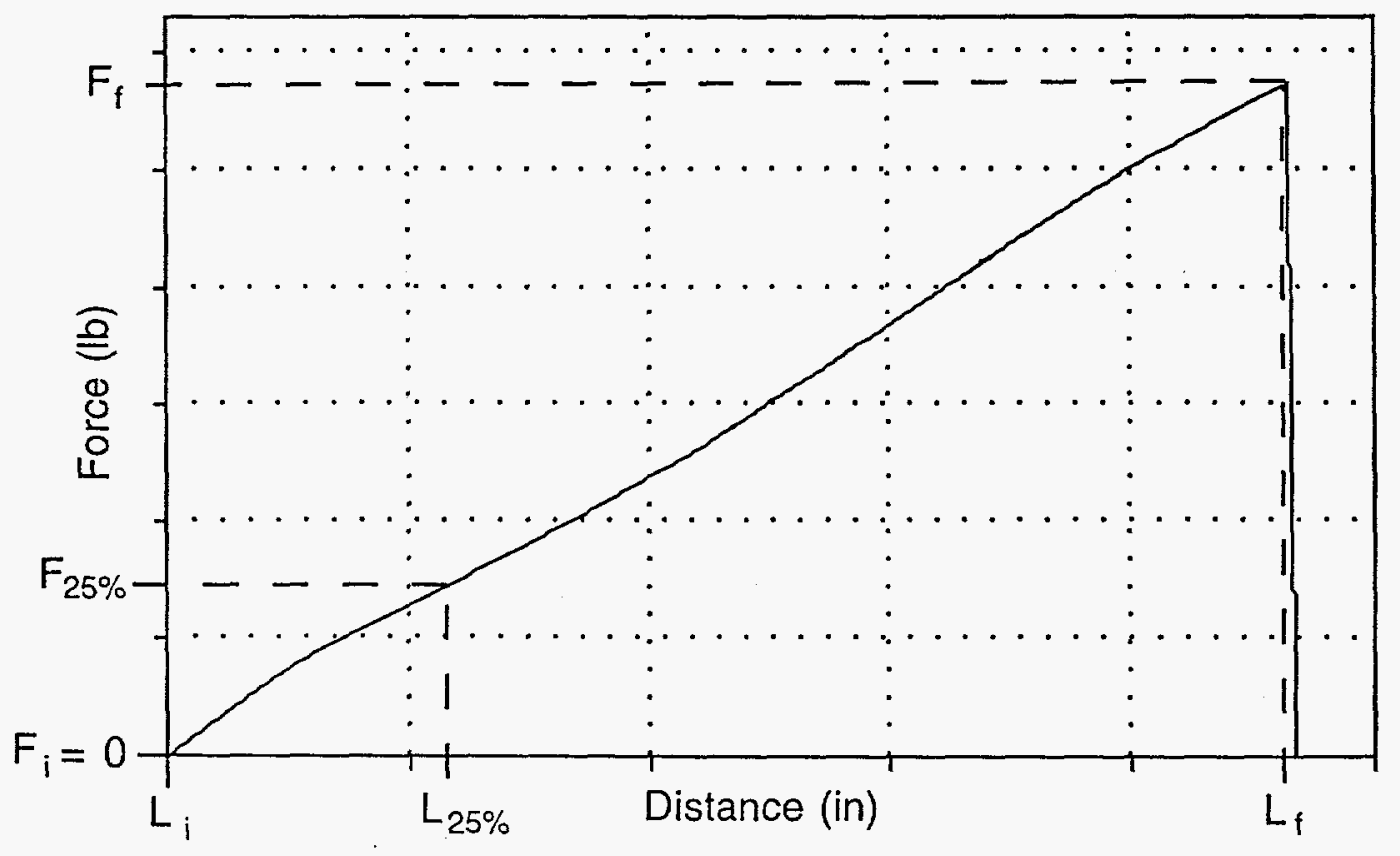


Table 8.3.3 O-Ring and Spool Dimensions and Corresponding Test Parameters

\begin{tabular}{|c|c|c|c|c|c|c|c|c|c|c|}
\hline \multicolumn{3}{|c|}{ O-Ring Dimensions } & \multicolumn{3}{|c|}{ Spool Dimensions } & \multicolumn{5}{|c|}{ Test Parameters } \\
\hline $\begin{array}{l}\text { O-ring } \\
\text { inside } \\
\text { diameter } \\
\text { (inches) }\end{array}$ & $\begin{array}{l}\text { O-ring } \\
\text { inside } \\
\text { circum. } \\
\text { (inches) }\end{array}$ & $\begin{array}{l}\text { O-ring } \\
\text { cross } \\
\text { section } \\
\text { (inches) }\end{array}$ & $\begin{array}{c}\text { spool } \\
\text { diameter } \\
\text { (inches) }\end{array}$ & $\begin{array}{l}\text { spool } \\
\text { circum. } \\
\text { (inches) }\end{array}$ & $\begin{array}{l}\text { groove } \\
\text { diameter }\end{array}$ & $\left\{\begin{array}{l}\text { no. } \\
\text { of } \\
\text { loops }\end{array}\right.$ & $\begin{array}{c}\text { initial } \\
\text { fixture } \\
\text { gap, } L_{i} \\
\text { (inches) } \\
\end{array}$ & $\begin{array}{l}\text { O-ring } \\
\text { circum. } \\
\times 125 \% \\
\text { (inches) }\end{array}$ & $\begin{array}{c}\mathrm{L}_{25 \%} \\
\text { fixture } \\
\text { gap } \\
\text { (inches) }\end{array}$ & $L_{25 \%}-L_{i}$ \\
\hline & 0.364 & 0.038 & 0.090 & 0.283 & 0.038 & 1 & 0.041 & 0.455 & 0.087 & 0.046 \\
\hline & & & 196 & & & 1 & & & & \\
\hline & & & 0.250 & & & 1 & & & & \\
\hline & 3.8 & 0.0 & 0.250 & 0.7 & & 1 & & 4.8 & 2.0 & \\
\hline 1.301 & 4.087 & 0.070 & 0.250 & 0.7 & & 1 & & & 2.1 & \\
\hline & & & & & & 1 & & & & \\
\hline & 4.672 & 0.1 & 1.000 & 3.14 & & 1 & 0.7 & & 1.347 & \\
\hline & & 0.0 & & & & 1 & & & & \\
\hline & & & $0.2 t$ & & & 1 & & & & \\
\hline & 24.1 & 0.0 & 1.040 & & & 3 & 2.392 & & & \\
\hline & & 0.103 & 1.000 & 3.142 & 0.103 & 3 & 6.984 & 64.131 & 9.117 & 2.133 \\
\hline
\end{tabular}

\section{Report}

The report shall include the following:

9.1 Description of O-ring lot, including vendor, rubber compound and batch number, ring part number, ring size (inside diameter and cross section), lot size (number of O-rings) and date the lot was produced and received.

9.2 Number of O-rings used, date and time of the test, and ambient temperature.

9.3 Test Results

9.3.1 Original average value of $e \% \max$ (maximum elongation at break), $S_{\max }$ (maximum strength at break) and $\mathrm{M}_{25}$ (linear $25 \%$ elongation modulus).

9.3.2 Final average value of $\mathrm{e}_{\max }, \mathrm{S}_{\max }$ and $\mathrm{M}_{25}$.

9.3.3 Change in $\mathrm{e}_{\max }, \mathrm{S}_{\max }$ and $\mathrm{M}_{25}$ expressed as a percentage of the original values. 
Appendix D: Current Butyl Rubber O-Ring Specification (SS453883)

Contents:

1) Table D-1. Current W87 Butyl Rubber O-Rings.

2) Copy of SS453883 
Table D-1. Current W87 Butyl Rubber O-Rings (all made from Parker B612-70 per SS453883)

\begin{tabular}{|c|c|c|c|c|}
\hline W87 Part No. & Parker No. & Quantity & Application & $\begin{array}{c}\text { Size } \\
\text { (id x cs in inches) } \\
\end{array}$ \\
\hline 453907 & $5-102$ & 13 & FSA seal screw/WES deck & $0.116 \times 0.038$ \\
\hline 453882 & $5-710$ & 4 & $\mathrm{RF}$ conn/mon plug and aft bulkhead & $0.301 \times 0.054$ \\
\hline 455915 & $5-252$ & 1 & $\begin{array}{l}\text { purge valve cap/valve body (part } \\
458376 \text {, Parker } 2-112 \text {, in Alt } 342 \\
\text { list) }\end{array}$ & $0.652 \times 0.070$ \\
\hline 453876 & $2-026$ & 1 & MSAD actuator/WES deck & $1.239 \times 0.070$ \\
\hline 453879 & 2-027 & 1 & MSAD actuator cover/actuator & $1.301 \times 0.070$ \\
\hline 453877 & $2-028$ & 1 & FSA/WES deck (det. cable hole) & $1.364 \times 0.070$ \\
\hline 453878 & $2-128$ & 2 & CF2703/WES deck \& aft bulkhead & $1.487 \times 0.103$ \\
\hline 453880 & $2-031$ & 1 & det. conn. cover/FSA & $1.739 \times 0.070$ \\
\hline 453881 & $5-796$ & 1 & monitor plug/WES deck & $1.913 \times 0.070$ \\
\hline 453875 & non-std & 1 & WES deck/RV body & $7.688 \times 0.070$ \\
\hline 453874 & non-std & 1 & aft bulkhead/RV body & $16.339 \times 0.103$ \\
\hline $\begin{array}{l}\text { adjusting pin } \\
\text { top cover } \\
\text { connector } \\
\text { cover screws }\end{array}$ & $\begin{array}{c}2-008 \\
2-029 \\
2-017 \\
\text { non-std }\end{array}$ & $\begin{array}{l}1 \\
1 \\
1 \\
2\end{array}$ & $\begin{array}{l}\text { LLNL parts supplied within actuator } \\
\text { assembly }\end{array}$ & \\
\hline
\end{tabular}

W87 Non-Butyl Rubber O-Rings

\begin{tabular}{c|c|c|l|c} 
W87 Part No. & $\begin{array}{c}\text { Parker } \\
\text { Compound }\end{array}$ & Quantity & \multicolumn{1}{|c|}{ Application } & Rubber Type \\
\hline 453468 & V894-90 & 1 & pit tube/WES deck (SS453864) & Viton \\
455887 & E692-75 & 1 & purge valve/aft bulkhead (SS453414) & EP/EPDM \\
455888 & E692-75 & 1 & purge valve seal (SS453414) & EP/EPDM \\
452889 & E981-50 & 2 & CF2711 \& CF2989 conn pad & EP/EPDM \\
$231485-02$ & E515-80 & 2 & stem seal/valve & EP/EPDM
\end{tabular}


S. BEASLEY JNH

R. ANDERSON

E. KIBALO IAK KCD-EDS

TIE SLKC DRC 2
PC5KC

5366

ME1KC

(W1RL.DOC)

PREFORMED PACKINGS, ELASTOMERIC REQUIREMENTS FOR W87 (U)

CHANGE HISTORY

CONTROL NUMBER

SS453883-000

\begin{abstract}
ISSUE
\end{abstract}
$N$

RELEASE/CHANGE NO.

951806KC C REV 2
- DATE

$1 / 96$ 
1. GENERAL

1.1. Scope.

This specification defines the material, design parameters and acceptance requirements for preformed elastomeric packings for the 187 .

1.2. Purpose.

The w87 0-rings are intended to maintain a moisture and chemical barrier for a 20 year stockpile life.

1.3. Records.

The Production Agency shall retain records of all tests and certifications indicated in the text for a period of

25 years.

1.4. - Definitions.

1.4.1. Design Agency.

Sandia National Laboratories, Livermore, California, Code Ident. 14214.

1.4.2. Production Agency.

Alliedsignal Corporation, Kansas City Division, Code Ident. 14061.

1.4.3. Manufacturer.

R. D. Rubber Technology, Corporation or Parker Hannifin Corporation.

1.4.4. Deleted.

1.4.5. Batch Definition.

A batch shall be that quantity of material compounded at one time either on a mill or in a mixer.

1.4.6. Manufacturer's Cure Date Definition.

The date the preformed packings are manufactured (quarter and yearl. 
1.4.7. Expiration Date.

The first day of the month following the shelf life. Example: Cure date 1089 - Shelf life 12 quarters from cure date. Expiration date would be $4 / 1 / 92$.

2. DOCUMENTS

The following documents form a part of this specification to the extent stated herein.

\begin{tabular}{|c|c|}
\hline MIL-STD- 413 & $\begin{array}{l}\text { Visual Inspection Guide for } \\
\text { Elastomeric o-rings }\end{array}$ \\
\hline MIL-B-131 & $\begin{array}{l}\text { Barrier Materials, Watervaporproof, } \\
\text { Heatsealable }\end{array}$ \\
\hline ANSI/ASQC 21.4 & $\begin{array}{l}\text { Sampling Procedures and Tables for } \\
\text { Inspection by Attributes }\end{array}$ \\
\hline
\end{tabular}

3. REQUIREMENTS

3.1. Design.

The preformed packing shall be an o-ring type.

3.2. Raw Material.

The preformed packing shall be made from a non-halogenated, Butyl rubber compound.

Approved Compound

Company/Manufacturer

B $612-70$

Parker Hannifin Corporation,

3.3. Dimensions and Tolerances.

a. The dimensions and tolerances are given on individual drawings.

b. Maximum allowable flash extension is 0.003 inch and maximum allowable flash thickness is 0.005 inch. 
SS453883

ISSUE N

PAGE 4 OF 7

\subsection{Physical Properties.}

The physical properties of the preformed packings shall meet the requirements listed in Table 1 when tested on ASTM test sheets.

\section{TABLE 1:}

Property

original

Tensile strength, psi

Elongation, of

Hardness, Shore A pts.

Specific Gravity
Values

Air Age, $70 \pm 0.1$ hours

(e) $212 \pm 5^{\circ} \mathrm{F}$

Tensile Strength, psi

Elongation

Hardness, Shore A, pts.

Air Age, $22 \pm 0.1$ hours

(e) $158 \pm 5^{\circ} \mathrm{F}$

Compression set
1600 minimum

200 minimum

65-75

$1.14 \pm 0.02$

Test Method

ASTM-D-412

ASTM-D-412

ASTM-D-2240

ASTM-D-297

3.4 .1

\pm 15 \% max change

ASTM-D-412

ASTM-D-412

ASTM-D-2240

$15 \%$ maximum

ASTM-D-395, Method B

\subsubsection{Air Aging.}

Air Aging for $70 \pm: 1$ hours at $212 \pm 5^{\circ} \mathrm{F}$. . The test speçimens shall be aged per ASTM-D-573 and cooled at room temperature for 24 hours \pm 2 hours prior to testing per Table 1 .

\subsection{Workmanship.}

a. Each preformed packing shall be consistent with requirements established in MIL-STD-413. There must be no defects or foreign materials in the rubber which will alter its ability to form a seal or endanger longevity by chemical interactions. Questionable flaws should be cleared with the KC product engineer for approval or rejection.

b. When an off-resigter (mismatch) condition exists that is acceptable per MIL-STD-413, any cross-section diameter measurements, other than $90^{\circ}$ from the parting line, shall be an average of two measurements taken approximately equidistant in opposite directions from the parting line. 


\subsection{Identification.}

Permanent marking is not required on the individual preformed packing. Product shall be identified by markings on unit packages specified in 5.1. Temporary marking of packings for the manufacturer's identification are allowed, but shall in no way affect the properties or function of the packings.

\subsection{Shelf Life.}

The manufacturer's cure date shall be designated by the quarter and year in which the o-ring was cured (i.e. 1096 would designate an 0 -ring cured during the first quarter 0 : 1996). The shelf life of the o-ring shall be 36 months from the end of the quarter designated as the cure date. The expiration date is the first day of the month following the shelf life li.e. for a cure date of 1096, the expiration date would be $4 / 1 / 99$ )

\section{QUALITY PROVISIONS}

\subsection{Manufacturer's Certification.}

The manufacturer shall identify the material content of the product by compound number, batch or lot number, and cure date.

\subsection{Production Agency Inspection.}

\subsubsection{Sampling.}

An AQL of 0.25, general inspection level II per ANSI/ASQC $\mathrm{Z} 1.4$ is required. If. the sample fails, 1008 inspection of the entire lot is acceptable for lot disposition. Any portion of the parts returned to the Supplier or scrapped shall not be considered part of the $100 \%$ inspection.

4.2.2. Dimensional Inspection.

The Production Agency shall verify conformance with individual drawings.

4.2.3. Physical Properties.

a. The Production Agency shall verify properties on ASTM test sheets molded from the same batch of material and molded within 30 days of the product the test sheets represent. Properties shall meet the requirements and shall be determined per 3.4 . 
b. Manufacturer's certification shall be verified on each shipment of product. The manufacturer shall certify that the product conforms to 3.4. Actual test data shall be furnished with each lot submitted for acceptance.

c. For the purposes of physical properties verificaticn, the properties for several part numbers may be combined to meet the requirements of this specification provided the requirements of 4.2 .3 .a are met.

\subsubsection{Workmanship.}

The Production Agency shall examine the preformed packing per 3.5 .

\section{PACKAGING AND HANDLING}

5.1. Packaging Material.

Heat sealable, foil lined, kraft bag per MIL-B-13I, Class 2.

5.1.1. Supplier.

The supplier shall ship preformed packings to KCD sealed in either bulk or individual packaging per 5.1. The supplier must provide KCD with unsealed individual packaging when using bulk packaging. The supplier must package the preformed packings per 5.1 no later than one quarter from the cure date.

5.1.2. KCD.

Packaging per 5.1.1 must remain sealed until time of inspection. The preformed packings in a package opened for inspection shall be reheat sealed within 45 days in individual packaging per 5.1. After inspection, the sealed packages may not be opened until use. 
SS453883

ISSUE N

Page 7 of 7

5.2.

\section{Marking.}

Each unit package shall be marked with the following information.

Design Agency Part Number

Manufacturer's Name

Manufacturer's Compound Number

Manufacturer's Batch or Lot Number.

Manufacturer's Cure Date (Quarter and Year)

Expiration Date:

DO NOT OPEN UNTIL READY FOR INSPECTION OR USE.

6.3. Storage Conditions.

Preformed packings covered by this specification shall be stored by the Production Agency at $45^{\circ} \mathrm{F}$ to $100^{\circ} \mathrm{F}$.

6. ENVIRONMENTS

All seals will encounter the following environments:

$\begin{array}{ll}\text { Temperature Extremes } & \begin{array}{l}\text { Tmax }=100^{\circ} \mathrm{F} \\ \text { Tmin }=-25^{\circ} \mathrm{F} \\ \text { Short Term }(<2 \mathrm{hrs}) \\ \operatorname{Tmax}=175^{\circ} \mathrm{F} \\ \operatorname{Tmin}=-30^{\circ} \mathrm{F}\end{array} \\ \text { Moisture } & \begin{array}{l}\text { Dew Point } 50^{\circ} \mathrm{E} \text { External to } \\ \text { Sealed Zone }\end{array} \\ \text { Ereon } 12 & 220 \text { ppm max } \\ \text { Ozone } & 0.60 \text { ppm short term } \\ & 0.23 \text { ppm long term } \\ & 0.045 \text { ppm average annual } \\ \text { Salt } & 21300 \text { ppm by mass of air } \\ & 2700 \text { long term } \\ \text { Molds and Eungi } & \text { Any within the Continental us } \\ \text { Expected Life } & 20 \text { years after assembly } \\ \text { Intrinsic Radiation } & \text { Low Level } \beta\end{array}$


Contents:

1) Table E-1. Participating O-Ring Vendors

2) Table E-2. Non-participating O-Ring Vendors

3) Table E-3. Equipment Vendors 
Table E-1. Participating Vendors

\begin{tabular}{|c|c|c|}
\hline Vendor and Phone No. & $\begin{array}{r}\text { Address } \\
\end{array}$ & Items Ordered \\
\hline $\begin{array}{l}\text { Parker Seals } \\
\text { O Ring Division } \\
606-269-2351\end{array}$ & $\begin{array}{l}2360 \text { Palumbo Dr. } \\
\text { Lexington, KY } 50505\end{array}$ & $\begin{array}{l}0.301 \times 0.054 \text { in. } \\
1.364 \times 0.070 \text { in. } \\
7.688 \times 0.070 \text { in. } \\
16.339 \times 0.103 \text { in. } \\
\text { test slabs }(6 \times 6 \times 0.072 \text { in.) }\end{array}$ \\
\hline $\begin{array}{l}\text { RD Rubber } \\
310-802-7888\end{array}$ & $\begin{array}{l}13230 \text { E. Firestone Blvd. } \\
\text { Suite P } \\
\text { Santa Fe Springs, CA } 90670\end{array}$ & $\begin{array}{l}0.551 \times 0.070 \text { in. } \\
1.114 \times 0.070 \text { in. } \\
7.185 \times 0.103 \text { in. } \\
11.196 \times 0.103 \text { in. } \\
\text { test slabs }(6 \times 6 \times 0.072 . \text { in. })\end{array}$ \\
\hline $\begin{array}{l}\text { Precision } \\
612-333-7464\end{array}$ & $\begin{array}{l}742 \text { N. Washington Ave. } \\
\text { Minneapolis, MN } 55401\end{array}$ & $\begin{array}{l}0.301 \times 0.054 \text { in. } \\
1.365 \times 0.070 \text { in. } \\
7.354 \times 0.070 \text { in. } \\
16.955 \times 0.139 \text { in. } \\
\text { test slabs }(6 \times 6 \times 0.072 \text { in. })\end{array}$ \\
\hline
\end{tabular}


Table E-2. Non-participating Vendors

\begin{tabular}{|c|c|c|}
\hline Vendor and Phone No. & $\begin{array}{r}\text { Address } \\
\end{array}$ & Reason for not participating \\
\hline $\begin{array}{l}\text { Apple Rubber Products } \\
716-684-656\end{array}$ & $\begin{array}{l}310 \text { Erie St. } \\
\text { Lancaster, NY } 14086\end{array}$ & $\begin{array}{l}\text { Butyl rubber material made by } \\
\text { offshore vendor and cannot } \\
\text { guarantee it is non-halogenated. }\end{array}$ \\
\hline $\begin{array}{l}\text { Bryant Rubber } \\
310-530-2530\end{array}$ & $\begin{array}{l}1112 \text { Lomita Blvd. } \\
\text { Harbor City, CA } 90710\end{array}$ & No butyl rubber \\
\hline $\begin{array}{l}\text { Burke Rubber } \\
209-571-6400\end{array}$ & $\begin{array}{l}2250 \text { S. 10th St. } \\
\text { San Jose, CA } 95112\end{array}$ & Custom tooling required \\
\hline $\begin{array}{l}\text { Century Rubber } \\
800-364-9541\end{array}$ & $\begin{array}{l}\text { 21609 Parthenia St. } \\
\text { Conoga Park, CA } 91304\end{array}$ & Custom tooling required \\
\hline $\begin{array}{l}\text { GAPI USA } \\
800-442-4274\end{array}$ & $\begin{array}{l}\text { P.O. Box 90064-T } \\
\text { Dayton, OH 45490-0064 }\end{array}$ & No butyl rubber \\
\hline $\begin{array}{l}\text { Hydroseal } \\
909-279-9981\end{array}$ & $\begin{array}{l}170 \text { Vander Unit A } \\
\text { Corona, CA } 91720\end{array}$ & Distributor for Precision \\
\hline $\begin{array}{l}\text { Kirkhill Rubber Co. } \\
714-529-4901\end{array}$ & $\begin{array}{l}\text { Cypress Court } \\
\text { Brea, CA } 92621\end{array}$ & Custom tooling required \\
\hline $\begin{array}{l}\text { Kotek America Inc., } \\
714-863-3126\end{array}$ & $\begin{array}{l}17752 \text { Cowan St. } \\
\text { Irvine, CA } 92714\end{array}$ & Minimum batch size 1,000 pieces \\
\hline $\begin{array}{l}\text { Lutz Sales Co. } \\
708-437-9393\end{array}$ & $\begin{array}{l}55 \text { North Lively Blvd. } \\
\text { Elk Grove Village, IL } 60007\end{array}$ & Distributor for Precision \\
\hline $\begin{array}{l}\text { Parco Inc. } \\
909-947-2200\end{array}$ & $\begin{array}{l}\text { 2150 Parco Ave } \\
\text { Ontario, CA } 91761\end{array}$ & $\begin{array}{l}\text { Halogenated butyl rubber- } \\
\text { Distributor for Kirkhill? }\end{array}$ \\
\hline $\begin{array}{l}\text { Polyseal } \\
800-274-9722\end{array}$ & $\begin{array}{l}725 \text { Channing Wy } \\
\text { Berkeley, CA } 95376\end{array}$ & No butyl rubber \\
\hline $\begin{array}{l}\text { Price Rubber } \\
209-239-7478\end{array}$ & $\begin{array}{l}17760 \text { Ideal Pkwy } \\
\text { Manteca, CA } 95336\end{array}$ & Custom tooling required \\
\hline $\begin{array}{l}\text { Ro-Lab } \\
800-726-1009\end{array}$ & $\begin{array}{l}8830 \text { W. Linne Road } \\
\text { Tracy, CA } 95376\end{array}$ & Halogenated butyl rubber \\
\hline $\begin{array}{l}\text { R.T. Enterprises } \\
800-423-9272\end{array}$ & $\begin{array}{l}7540 \text { Linder Ave. } \\
\text { Skokie, IL } 60077\end{array}$ & No butyl rubber \\
\hline $\begin{array}{l}\text { Southwest Rubber \& Supply } \\
602-252-9524\end{array}$ & $\begin{array}{l}\text { 4007-TS. 20th St. } \\
\text { Phoenix, AZ 85040-1400 }\end{array}$ & Minimum batch size 1,000 pieces \\
\hline $\begin{array}{l}\text { Wynn's Precision, Inc. } \\
602-894-2361\end{array}$ & $\begin{array}{l}708 \text { West 22nd Street } \\
\text { Tempe, AZ } 85282\end{array}$ & $\begin{array}{l}\text { Could not meet material } \\
\text { requirements. }\end{array}$ \\
\hline
\end{tabular}




\section{Table E-3. Equipment Vendors}

\begin{tabular}{|l|l|}
\hline \multicolumn{1}{|c|}{ Vendor Information } & \multicolumn{1}{c|}{ Items Ordered } \\
\hline $\begin{array}{l}\text { Instron Corp. } \\
\text { (Shore Division acquired through purchase) } \\
\text { 100 Royal St. } \\
\text { Canton, MA 02021 } \\
\text { 617-575-5856 }\end{array}$ & $\begin{array}{l}\text { Shore M Durometers (digital and dial) plus } \\
\text { hydraulic stands and O-ring double pin fixtures. } \\
\text { cost: } \$ 3921 \text { for Model 2000 digital durmometer } \\
\text { and stand plus } \$ 250 \text { for custom fixtures } \\
\text { Shore Model } 910 \text { Thickness Gauge (shown to } \\
\text { have inadequate resolution for O-ring } \\
\text { measurements). } \\
\text { cost: } \$ 1251\end{array}$ \\
\hline $\begin{array}{l}\text { Laser Mike, Inc. } \\
\text { 6060 Executive Blvd. } \\
\text { Dayton, Ohio 45424 } \\
\text { 513-233-9935 }\end{array}$ & $\begin{array}{l}\text { Laser Micrometer, Model 183B, plus V-block } \\
\text { platform and calibration pins. } \\
\text { cost: } \$ 6863\end{array}$ \\
\hline $\begin{array}{l}\text { E.H. Benz Co. } \\
73 \text { Maplehurst Ave. } \\
\text { Providence, RI 02908 } \\
\text { 800-230-8684 }\end{array}$ & $\begin{array}{l}\text { Compression set test fixtures, double layer } \\
\text { (smaller and poorer design than those from Custom } \\
\text { Scientific, but with better surface finish). } \\
\text { cost: } \$ 2990\end{array}$ \\
\hline $\begin{array}{l}\text { Custom Scientific Instruments } \\
\text { 13 Wing Drive } \\
\text { Cedar Knolls, NJ 07927 } \\
\text { 800-229-1274 }\end{array}$ & $\begin{array}{l}\text { Compression set test fixtures, double layer } \\
\text { (more robust design than those from Benz, but } \\
\text { plagued with poor surface finishes and } \\
\text { unresponsive technical service). } \\
\text { cost: } \$ 1900\end{array}$ \\
\hline $\begin{array}{l}\text { Charles F. Siebenthal } \\
\text { 3819 Osuna, N.E. } \\
\text { Albuquerque, NM } 87109 \\
505-344-3467\end{array}$ & $\begin{array}{l}\text { Gauge blocks used as spacers in compression set } \\
\text { tests. 8 each of 5 sizes (0.02850, 0.04050, } \\
0.05200,0.07725, \text { and 0.10425 inches) } \\
\text { cost: } \$ 1490\end{array}$ \\
\hline
\end{tabular}


Contents:

Table F-1. Hardness and Compression Set Data on Butyl Rubber O-Rings

Table F-2. Effect of Sampling Rate (4 vs. 8 points per ring) on Hardness and Compression Set Data

Plot F-3. Effect of Sampling Rate (4 vs. 8 points per ring) on Hardness Values

Plot F-4. S Standard Deviations of Hardness Measurements vs. Sample Rate

Table F-5. Hardness Data from Single O-Rings Compared to Stacked O-Rings

Table F-6 Operator Sensitivity of Hardness Testing

Table F-7. Round-Robin Shore M Hardness Testing

Table F-8. Shore A vs. Shore M Durometer Hardness Data

Table F-9. Hardness of Small RD Rubber O-Rings (detailed test data)

Table F-10. Hardness of Medium RD Rubber O-Rings (detailed test data)

Table F-11. Hardness of Large RD Rubber O-Rings (detailed test data)

Table F-12. Hardness of Small Parker and Precision O-Rings (detailed test data)

Table F-13. Hardness of Medium and Large Parker O-Rings (detailed test data)

Table F-14. Hardness of Medium and Large Precision O-Rings (detailed test data)

Table F-15. Hardness Data for Test Slabs (detailed test data) 
Table F-1. Hardness and Compression Set Data on Butyl Rubber O-Rings

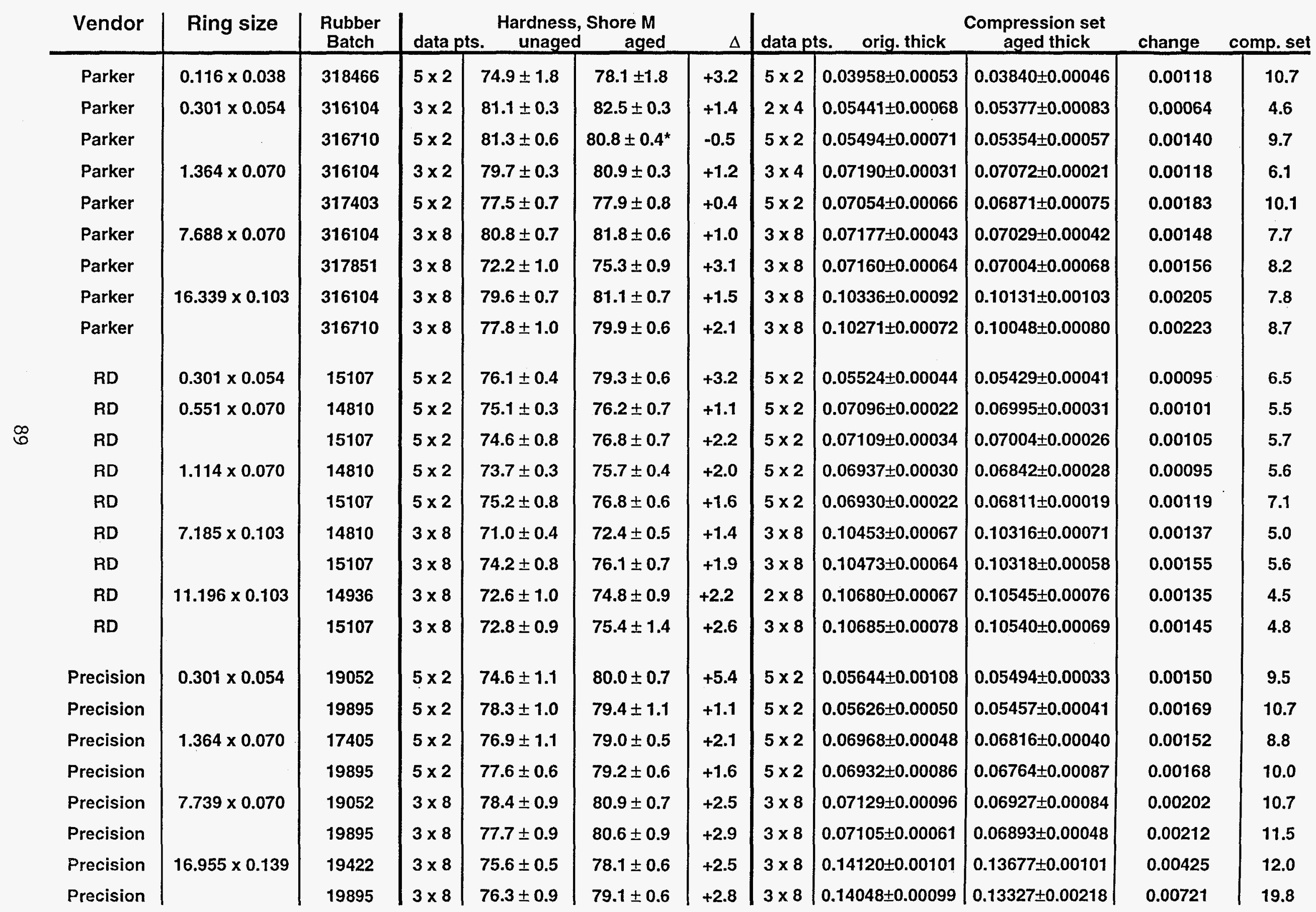


Table F-2. Effect of Sampling Rate (4 vs. 8 points per ring) on Hardness and Compression Set Data

\begin{tabular}{|c|c|c|c|c|c|c|c|c|c|c|c|c|}
\hline & Vendor & Ring size & $\begin{array}{l}\text { Rubber } \\
\text { Batch }\end{array}$ & \multicolumn{4}{|c|}{ Hardness, Shore M } & \multicolumn{3}{|r|}{$\begin{array}{c}\text { Compression Set } \\
\text { aged thick }\end{array}$} & change & comp. set \\
\hline & Parker & $7.688 \times 0.070$ & $\begin{array}{c}316104 \\
\text { ODDS } \\
\text { EVENS }\end{array}$ & $\begin{array}{l}3 \times 8 \\
3 \times 4 \\
3 \times 4\end{array}$ & $\begin{array}{l}80.8 \pm 0.7 \\
80.8 \pm 0.7 \\
80.8 \pm 0.7\end{array}$ & $\begin{array}{l}81.8 \pm 0.6 \\
81.8 \pm 0.5 \\
81.8 \pm 0.7\end{array}$ & $\begin{array}{l}+1.0 \\
+1.0 \\
+1.0\end{array}$ & $\begin{array}{l}3 \times 8 \\
3 \times 4 \\
3 \times 4\end{array}$ & $\begin{array}{l}0.07177 \pm 0.00043 \\
0.07173 \pm 0.00044 \\
0.07182 \pm 0.00042\end{array}$ & $\begin{array}{l}0.07029 \pm 0.00042 \\
0.07028 \pm 0.00046 \\
0.07030 \pm 0.00037\end{array}$ & $\begin{array}{l}0.00148 \\
0.00145 \\
0.00152\end{array}$ & $\begin{array}{l}7.7 \\
7.5 \\
7.8\end{array}$ \\
\hline & Parker & & $\begin{array}{c}317851 \\
\text { ODDS } \\
\text { EVENS }\end{array}$ & $\begin{array}{l}3 \times 8 \\
3 \times 4 \\
3 \times 4\end{array}$ & $\begin{array}{l}72.2 \pm 1.0 \\
72.4 \pm 1.0 \\
72.0 \pm 0.9\end{array}$ & $\begin{array}{l}75.3 \pm 0.9 \\
75.3 \pm 0.7 \\
75.3 \pm 1.0\end{array}$ & $\begin{array}{l}+3.1 \\
+2.9 \\
+3.3\end{array}$ & $\begin{array}{l}3 \times 8 \\
3 \times 4 \\
3 \times 4\end{array}$ & $\begin{array}{l}0.07160 \pm 0.00064 \\
0.07155 \pm 0.00073 \\
0.07165 \pm 0.00053\end{array}$ & $\begin{array}{l}0.07004 \pm 0.00068 \\
0.07016 \pm 0.00068 \\
0.06993 \pm 0.00066\end{array}$ & $\begin{array}{l}0.00156 \\
0.00139 \\
0.00172\end{array}$ & $\begin{array}{l}8.2 \\
7.3 \\
9.0\end{array}$ \\
\hline & Parker & $16.339 \times 0.103$ & $\begin{array}{l}316104 \\
\text { ODDS } \\
\text { EVENS }\end{array}$ & $\begin{array}{l}3 \times 8 \\
3 \times 4 \\
3 \times 4\end{array}$ & $\begin{array}{l}79.6 \pm 0.7 \\
79.7 \pm 0.5 \\
79.5 \pm 0.9\end{array}$ & $\begin{array}{l}81.1 \pm 0.7 \\
81.1 \pm 0.8 \\
81.1 \pm 0.6\end{array}$ & $\begin{array}{l}+1.5 \\
+1.4 \\
+1.6\end{array}$ & $\begin{array}{l}3 \times 8 \\
3 \times 4 \\
3 \times 4\end{array}$ & $\begin{array}{l}0.10336 \pm 0.00092 \\
0.10339 \pm 0.00085 \\
0.10332 \pm 0.00099\end{array}$ & $\begin{array}{l}0.10131 \pm 0.00103 \\
0.10132 \pm 0.00092 \\
0.10130 \pm 0.00112\end{array}$ & $\begin{array}{l}0.00205 \\
0.00207 \\
0.00202\end{array}$ & $\begin{array}{l}7.8 \\
7.8 \\
7.7\end{array}$ \\
\hline & Parker & & $\begin{array}{c}316710 \\
\text { ODDS } \\
\text { EVENS }\end{array}$ & $\begin{array}{l}3 \times 8 \\
3 \times 4 \\
3 \times 4\end{array}$ & $\begin{array}{l}77.8 \pm 1.0 \\
77.8 \pm 0.9 \\
77.8 \pm 1.0\end{array}$ & $\begin{array}{l}79.9 \pm 0.6 \\
79.9 \pm 0.8 \\
79.9 \pm 0.3\end{array}$ & $\begin{array}{l}+2.1 \\
+2.1 \\
+2.1\end{array}$ & $\begin{array}{l}3 \times 8 \\
3 \times 4 \\
3 \times 4\end{array}$ & $\begin{array}{l}0.10271 \pm 0.00072 \\
0.10262 \pm 0.00062 \\
0.10280 \pm 0.00079\end{array}$ & $\begin{array}{l}0.10048 \pm 0.00080 \\
0.10039 \pm 0.00059 \\
0.10057 \pm 0.00096\end{array}$ & $\begin{array}{l}0.00223 \\
0.00223 \\
0.00223\end{array}$ & $\begin{array}{l}8.7 \\
8.7 \\
8.6\end{array}$ \\
\hline & RD & $7.185 \times 0.103$ & $\begin{array}{c}14810 \\
\text { ODDS } \\
\text { EVENS }\end{array}$ & $\begin{array}{l}3 \times 8 \\
3 \times 4 \\
3 \times 4\end{array}$ & $\begin{array}{l}71.0 \pm 0.4 \\
71.0 \pm 0.5 \\
71.0 \pm 0.4\end{array}$ & $\begin{array}{l}72.4 \pm 0.5 \\
72.3 \pm 0.5 \\
72.4 \pm 0.5\end{array}$ & $\begin{array}{l}+1.4 \\
+1.3 \\
+1.4\end{array}$ & $\begin{array}{l}3 \times 8 \\
3 \times 4 \\
3 \times 4\end{array}$ & $\begin{array}{l}0.10453 \pm 0.00067 \\
0.10478 \pm 0.00075 \\
0.10428 \pm 0.00045\end{array}$ & $\begin{array}{l}0.10316 \pm 0.00071 \\
0.10329 \pm 0.00069 \\
0.10303 \pm 0.00071\end{array}$ & $\begin{array}{l}0.00137 \\
0.00149 \\
0.00125\end{array}$ & $\begin{array}{l}5.0 \\
5.4 \\
4.6\end{array}$ \\
\hline ○ & RD & & $\begin{array}{l}15107 \\
\text { ODDS } \\
\text { EVENS }\end{array}$ & $\begin{array}{l}3 \times 8 \\
3 \times 4 \\
3 \times 4\end{array}$ & $\begin{array}{l}74.2 \pm 0.8 \\
74.3 \pm 0.7 \\
74.1 \pm 0.8\end{array}$ & $\begin{array}{l}76.1 \pm 0.7 \\
75.9 \pm 0.6 \\
76.2 \pm 0.7\end{array}$ & $\begin{array}{l}+1.9 \\
+1.6 \\
+2.1\end{array}$ & $\begin{array}{l}3 \times 8 \\
3 \times 4 \\
3 \times 4\end{array}$ & $\begin{array}{l}0.10473 \pm 0.00064 \\
0.10495 \pm 0.00053 \\
0.10451 \pm 0.00067\end{array}$ & $\begin{array}{l}0.10318 \pm 0.00058 \\
0.10344 \pm 0.00050 \\
0.10292 \pm 0.00053\end{array}$ & $\begin{array}{l}0.00155 \\
0.00151 \\
0.00159\end{array}$ & $\begin{array}{l}5.6 \\
5.4 \\
5.8\end{array}$ \\
\hline & RD & $11.196 \times 0.103$ & $\begin{array}{l}14936 \\
\text { ODDS } \\
\text { EVENS }\end{array}$ & $\begin{array}{l}3 \times 8 \\
3 \times 4 \\
3 \times 4\end{array}$ & $\begin{array}{l}72.6 \pm 1.0 \\
72.6 \pm 1.1 \\
72.6 \pm 0.8\end{array}$ & $\begin{array}{l}74.8 \pm 0.9 \\
74.9 \pm 1.0 \\
74.7 \pm 0.7\end{array}$ & $\begin{array}{l}+2.2 \\
+2.3 \\
+2.1\end{array}$ & $\begin{array}{l}2 \times 8 \\
2 \times 4 \\
2 \times 4\end{array}$ & $\begin{array}{l}0.10680 \pm 0.00067 \\
0.10685 \pm 0.00075 \\
0.10674 \pm 0.00058\end{array}$ & $\begin{array}{l}0.10545 \pm 0.00076 \\
0.10550 \pm 0.00087 \\
0.10540 \pm 0.00063\end{array}$ & $\begin{array}{l}0.00135 \\
0.00135 \\
0.00134\end{array}$ & $\begin{array}{l}4.5 \\
4.6 \\
4.5\end{array}$ \\
\hline & $\mathrm{RD}$ & & $\begin{array}{l}15107 \\
\text { ODDS } \\
\text { EVENS }\end{array}$ & $\begin{array}{l}3 \times 8 \\
3 \times 4 \\
3 \times 4\end{array}$ & $\begin{array}{l}72.8 \pm 0.9 \\
72.5 \pm 0.6 \\
73.1 \pm 1.0\end{array}$ & $\begin{array}{l}75.4 \pm 1.4 \\
75.2 \pm 1.2 \\
75.6 \pm 1.5\end{array}$ & $\begin{array}{l}+2.6 \\
+2.7 \\
+2.5\end{array}$ & $\begin{array}{l}3 \times 8 \\
3 \times 4 \\
3 \times 4\end{array}$ & $\begin{array}{l}0.10685 \pm 0.00078 \\
0.10698 \pm 0.00094 \\
0.10673 \pm 0.00055\end{array}$ & $\begin{array}{l}0.10540 \pm 0.00069 \\
0.10547 \pm 0.00083 \\
0.10534 \pm 0.00049\end{array}$ & $\begin{array}{l}0.00145 \\
0.00151 \\
0.00139\end{array}$ & $\begin{array}{l}4.9 \\
5.1 \\
4.7\end{array}$ \\
\hline & Precision & $7.739 \times 0.070$ & $\begin{array}{r}19052 \\
\text { ODDS } \\
\text { EVENS }\end{array}$ & $\begin{array}{l}3 \times 8 \\
3 \times 4 \\
3 \times 4\end{array}$ & $\begin{array}{l}78.4 \pm 0.9 \\
78.4 \pm 1.0 \\
78.4 \pm 0.7\end{array}$ & $\begin{array}{l}80.9 \pm 0.7 \\
80.9 \pm 0.6 \\
80.8 \pm 0.8\end{array}$ & $\begin{array}{l}+2.5 \\
+2.5 \\
+2.4\end{array}$ & $\begin{array}{l}3 \times 8 \\
3 \times 4 \\
3 \times 4\end{array}$ & $\begin{array}{l}0.07129 \pm 0.00096 \\
0.07122 \pm 0.00082 \\
0.07135 \pm 0.00107\end{array}$ & $\begin{array}{l}0.06927 \pm 0.00084 \\
0.06912 \pm 0.00081 \\
0.06942 \pm 0.00085\end{array}$ & $\begin{array}{l}0.00202 \\
0.00210 \\
0.00193\end{array}$ & $\begin{array}{l}10.7 \\
11.2 \\
10.2\end{array}$ \\
\hline & Precision & & $\begin{array}{l}19895 \\
\text { ODDS } \\
\text { EVENS }\end{array}$ & $\begin{array}{l}3 \times 8 \\
3 \times 4 \\
3 \times 4\end{array}$ & $\begin{array}{l}77.7 \pm 0.9 \\
77.8 \pm 0.8 \\
77.6 \pm 1.0\end{array}$ & $\begin{array}{l}80.6 \pm 0.9 \\
80.4 \pm 1.1 \\
80.7 \pm 0.7\end{array}$ & $\begin{array}{l}+2.8 \\
+2.6 \\
+3.1\end{array}$ & $\begin{array}{l}3 \times 8 \\
3 \times 4 \\
3 \times 4\end{array}$ & $\begin{array}{l}0.07105 \pm 0.00061 \\
0.07123 \pm 0.00073 \\
0.07088 \pm 0.00037\end{array}$ & $\begin{array}{l}0.06893 \pm 0.00048 \\
0.06918 \pm 0.00055 \\
0.06867 \pm 0.00016\end{array}$ & $\begin{array}{l}0.00212 \\
0.00205 \\
0.00221\end{array}$ & $\begin{array}{l}11.5 \\
11.0 \\
12.0\end{array}$ \\
\hline & Precision & $16.955 \times 0.139$ & $\begin{array}{c}19422 \\
\text { ODDS } \\
\text { EVENS }\end{array}$ & $\begin{array}{l}3 \times 8 \\
3 \times 4 \\
3 \times 4\end{array}$ & $\begin{array}{l}75.6 \pm 0.5 \\
75.8 \pm 0.4 \\
75.3 \pm 0.5\end{array}$ & $\begin{array}{l}78.1 \pm 0.6 \\
78.1 \pm 0.5 \\
78.1 \pm 0.7\end{array}$ & $\begin{array}{l}+2.5 \\
+2.3 \\
+2.8\end{array}$ & $\begin{array}{l}3 \times 8 \\
3 \times 4 \\
3 \times 4\end{array}$ & $\begin{array}{l}0.14120 \pm 0.00101 \\
0.14113 \pm 0.00090 \\
0.14127 \pm 0.00111\end{array}$ & $\begin{array}{l}0.13677 \pm 0.00101 \\
0.13667 \pm 0.00077 \\
0.13687 \pm 0.00120\end{array}$ & $\begin{array}{l}0.00425 \\
0.00446 \\
0.00440\end{array}$ & $\begin{array}{l}11.9 \\
12.0 \\
11.8\end{array}$ \\
\hline & Precision & & $\begin{array}{r}19895 \\
\text { ODDS } \\
\text { EVENS }\end{array}$ & $\begin{array}{l}3 \times 8 \\
3 \times 4 \\
3 \times 4\end{array}$ & $\begin{array}{l}76.3 \pm 0.9 \\
76.3 \pm 0.9 \\
76.4 \pm 1.0\end{array}$ & $\begin{array}{l}79.1 \pm 0.6 \\
78.9 \pm 0.7 \\
79.3 \pm 0.5\end{array}$ & $\begin{array}{l}+2.8 \\
+2.6 \\
+3.0\end{array}$ & $\begin{array}{l}3 \times 8 \\
3 \times 4 \\
3 \times 4\end{array}$ & $\begin{array}{l}0.14048 \pm 0.00099 \\
0.14097 \pm 0.00095 \\
0.14000 \pm 0.00078\end{array}$ & $\begin{array}{l}0.13327 \pm 0.00218 \\
0.13336 \pm 0.00163 \\
0.13319 \pm 0.00261\end{array}$ & $\begin{array}{l}0.00721 \\
0.00761 \\
0.00681\end{array}$ & $\begin{array}{l}19.8 \\
20.6 \\
18.9\end{array}$ \\
\hline
\end{tabular}




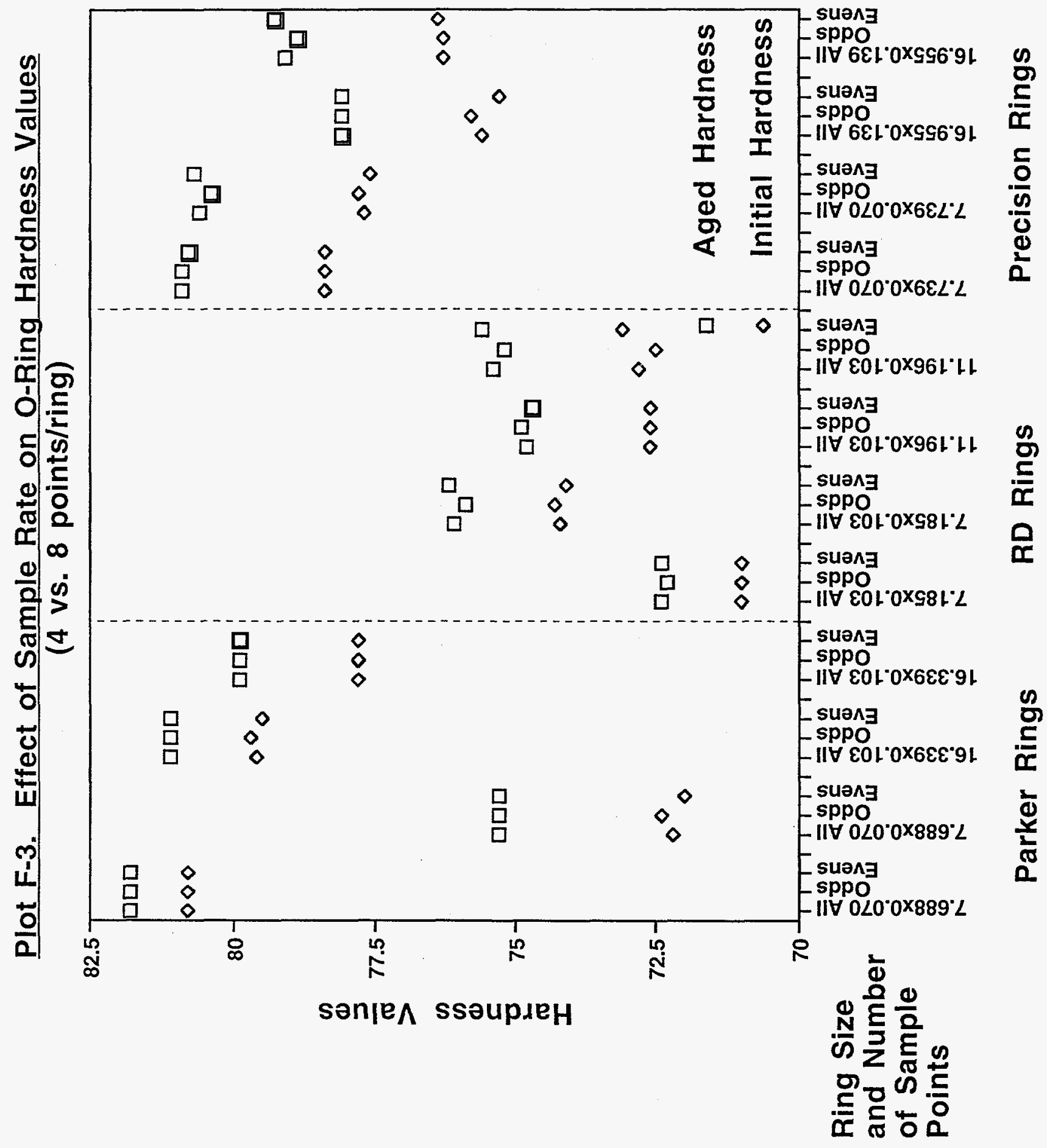




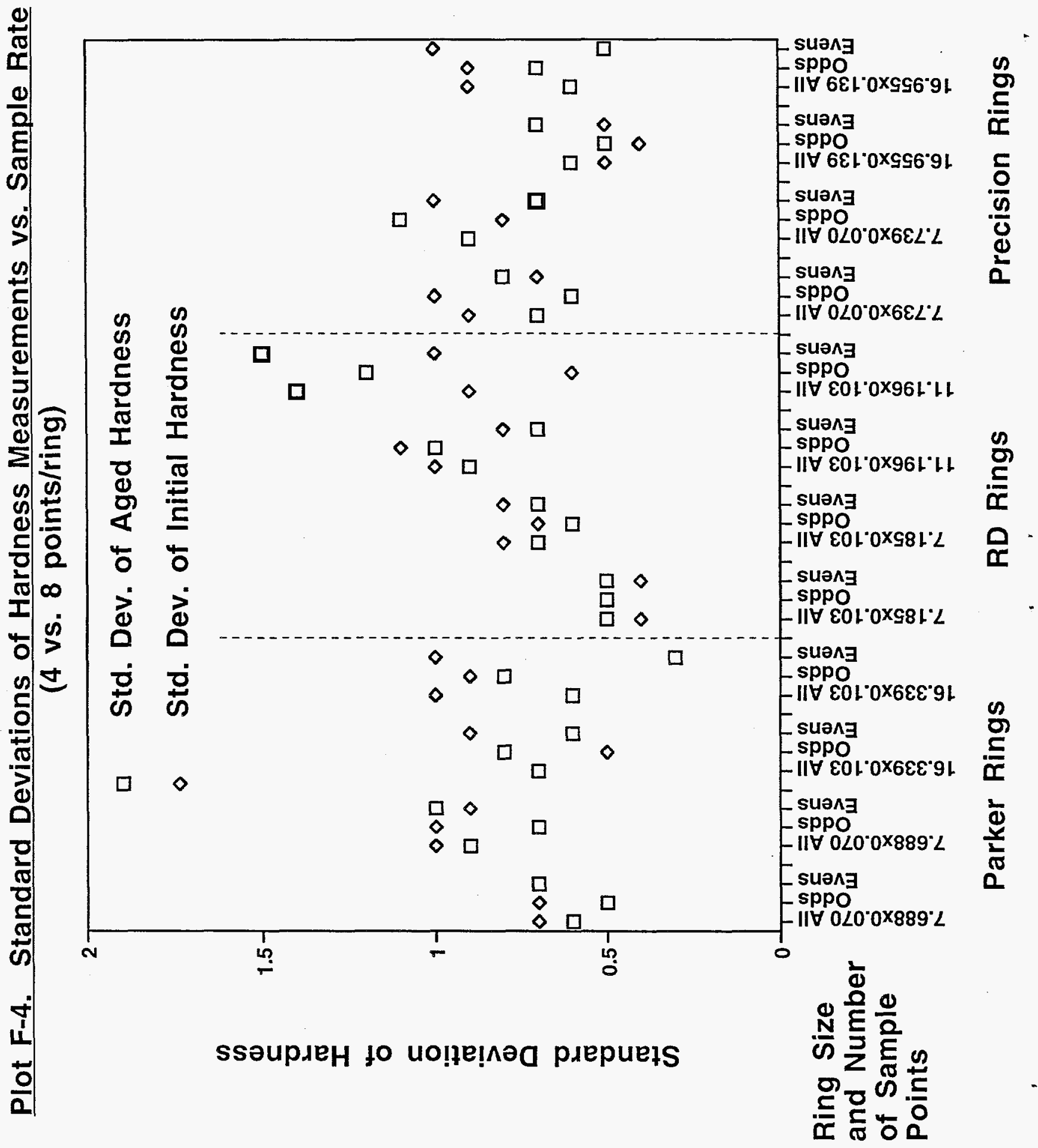


Table F-5. Hardness Data from Single O-Rings Compared to Stacked O-Rings

\begin{tabular}{|c|c|c|c|c|c|c|}
\hline \multirow[t]{2}{*}{ Ring dimensions } & \multicolumn{3}{|c|}{ Hardness Values on Single Rings } & \multicolumn{3}{|c|}{ Hardness Values on Stacked Rings } \\
\hline & $\underline{\text { Ring \#1 }}$ & $\underline{\text { Ring \#2 }}$ & Average & $\frac{\text { Ring \#1 on }}{\text { top }}$ & $\frac{\text { Ring } \# 2 \text { on }}{\text { top }}$ & Average \\
\hline $0.301 \times 0.065$ & $78.3 \pm 1.1$ & $78.9 \pm 1.1$ & 78.6 & $77.9 \pm 0.7$ & $77.6 \pm 1.7$ & 77.8 \\
\hline $1.364 \times 0.070$ & $78.0 \pm 0.5$ & $78.2 \pm 0.3$ & 78.1 & $76.2 \pm 0.2$ & $76.3 \pm 0.3$ & 76.3 \\
\hline $7.688 \times 0.070$ & $79.5 \pm 0.4$ & $78.8 \pm 0.3$ & 79.2 & $76.9 \pm 0.5$ & $77.1 \pm 0.8$ & 77.0 \\
\hline $16.339 \times 0.140$ & $74.2 \pm 0.9$ & $73.2 \pm 0.7$ & 73.7 & $71.5 \pm 1.2$ & $71.8 \pm 1.4$ & 71.7 \\
\hline
\end{tabular}

All measurements carried out on Lutz O-rings. Each value in the table is the average of five measurements. Rings with a cross section of 0.065 inches were tested in the double pin fixture with a gap of 0.070 inches. 
Table F-6. Operator Sensitivity of Hardness Testing...(BOLD = high reading, italics $=$ low reading)

using Shore M Digital Durometer with automatic 1 second readings:

\begin{tabular}{|c|c|c|c|c|c|c|c|c|}
\hline \multirow{2}{*}{ Ring dimensions } & \multirow{2}{*}{$\begin{array}{l}\text { Readings/ring } \\
\mathrm{x} \text { no. of rings }\end{array}$} & \multicolumn{3}{|c|}{ Initial Hardness } & \multicolumn{4}{|c|}{ Hardness after Aging } \\
\hline & & Operator \#1 & Operator \#2 Operator \#3 & Range & Operator \#1 & & Operator \#3 & Range \\
\hline $0.301 \mathrm{x}$ & $2 \times 5$ & $79.3 \pm 0.7$ & $79.4 \pm 0.6 \quad 78.1 \pm 0.8$ & $78.1-79.4$ & $81.1 \pm 0.3$ & $80.3 \pm 1.3$ & $81.1 \pm 0.8$ & $80.3-$ \\
\hline $1.364 \times 0.070$ & $2 \times 5$ & $75.6 \pm 0.6$ & $77.4 \pm 0.4 \quad 77.5 \pm 0.9$ & $75.6-77.5$ & $80.5 \pm 0.6$ & $79.6 \pm 0.6$ & $80.1 \pm 0.5$ & $79.6-80.5$ \\
\hline $7.688 \times 0.070$ & $2 \times 5$ & $77.3 \pm 1.0$ & $78.6 \pm 1.1 \quad \mathbf{7 9 . 0} \pm \mathbf{0 . 8}$ & $77.3-79.0$ & $81.1 \pm 0.6$ & $80.9 \pm 0.6$ & $81.2 \pm 0.6$ & $80.9-81.2$ \\
\hline $16.339 \times 0.103$ & $2 \times 5$ & $77.1 \pm 0.8$ & $77.4 \pm 0.977 .9 \pm 1.5$ & $77.1-77.9$ & $80.2 \pm 0.5$ & $79.6 \pm 0.7$ & $80.7 \pm 0.9$ & $79.6-80.7$ \\
\hline
\end{tabular}

using Shore M Dial Durometer with estimated 1 second readings:

\begin{tabular}{|c|c|c|c|c|c|c|c|}
\hline Ring dimensions & Readings/ring & & Initial $\mathrm{H}$ & ardness & & Hardness after Aging & \\
\hline $0.301 \times 0.054$ & $4 \times 1$ & $76.9 \pm 0.6$ & $75.9 \pm 1.9$ & $74.3 \pm 1.2$ & $74.3-76.9$ & & \\
\hline $7.688 \times 0.070$ & $72 \times 1$ & $76.2 \pm 1.1$ & $75.8 \pm 1.2$ & $74.7 \pm 1.0$ & $74.7-76.2$ & & \\
\hline $16.339 \times 0.103$ & $72 \times 1$ & $77.6 \pm 0.9$ & $77.4 \pm 1.0$ & $76.6 \pm 0.9$ & $76.6-77.6$ & & \\
\hline
\end{tabular}

using Shore M Dial Durometer with estimated 10 second readings:

\begin{tabular}{|c|c|c|c|c|c|c|c|}
\hline$\underline{\text { Ring dimensions }}$ & $\frac{\text { Readings/ring }}{\mathrm{X} \text { no. of rings }}$ & Operator \#1 Operator \#2 & $\frac{\text { ardness }}{\text { Operator \#3 }}$ & $\underline{\text { Range }}$ & Operator \#1 & $\begin{array}{l}\text { Hardness after Aging } \\
\text { Operator \#2 Operator } \# 3\end{array}$ & Range \\
\hline $0.301 \times 0.054$ & $4 \times 1$ & $78.3 \pm 0.6 \quad 77.0 \pm 2.0$ & $75.1 \pm 1.1$ & $75.1-78.3$ & & & \\
\hline $7.688 \times 0.070$ & $72 \times 1$ & $76.7 \pm 0.976 .5 \pm 1.1$ & $75.0 \pm 1.0$ & $75.0-76.7$ & & & \\
\hline $16.339 \times 0.103$ & $72 \times 1$ & $77.3 \pm 0.7 \quad 77.4 \pm \mathbf{1 . 0}$ & $76.4 \pm 0.9$ & $76.4-77.4$ & & & \\
\hline
\end{tabular}

All tests used Parker Batch 316104 O-rings. Readings were taken on the same durometer and on the same face of the O-ring. Readings were grouped to measure similar ring areas but offset to avoid re-puncturing of the ring. Operator code: $\# 1=\mathrm{JY}, \# 2=\mathrm{KW}, \# 3=\mathrm{LD}$. 
Table F-7. Round-Robin Hardness Testing with Shore M Digital Durometers

$$
(\text { Bold }=\text { high reading and italics }=\text { low reading })
$$

\begin{tabular}{l|c|c|c}
\multicolumn{1}{c|}{ Durometer No. } & SN 3217 & SN 3225 & SN 3224 \\
\hline Sample: & & & \\
Green std. block (63.1 hardness) & $\mathbf{6 4 . 4} \pm \mathbf{0 . 2}$ & $63.3 \pm 0.3$ & $62.5 \pm 0.7$ \\
Red std. block (71.2 hardness) & $\mathbf{7 3 . 4} \pm \mathbf{0 . 6}$ & $72.8 \pm 0.4$ & $71.2 \pm 0.5$ \\
Brown std. block (79.7 hardness) & $\mathbf{8 0 . 8} \pm \mathbf{0 . 5}$ & $80.1 \pm 0.5$ & $78.5 \pm 1.2$ \\
Parker 0.301 x 0.054 (316710) & $\mathbf{8 2 . 1} \pm \mathbf{0 . 4}$ & $81.0 \pm 0.6$ & $80.6 \pm 0.8$ \\
Parker 7.688 x 0.070 (317851) & $\mathbf{7 3 . 0} \pm \mathbf{0 . 9}$ & $72.6 \pm 0.7$ & $71.7 \pm 1.1$ \\
Parker 16.399 x 0.103 (316710) & $76.6 \pm 1.1$ & $\mathbf{7 8 . 2} \pm \mathbf{0 . 7}$ & $\mathbf{7 8 . 2} \pm \mathbf{0 . 9}$
\end{tabular}

Hardness standard blocks: 5 readings taken

O-Rings: $\quad 5$ rings $x 2$ readings $=10$ readings taken

Durometers SN 3217 and 3225 are located at Sandia, CA and tests were run by Kevin Wagter.

Durometer SN 3224 is located at Kansas City Plant and tests were run by Julie Stuckey. 
Table F-8. Shore A vs. Shore M Dial Durometer Hardness Data (1 vs. $10 \mathrm{sec}$. readings)

Sample

Test Blocks (given value)

White (31.9)
Yellow (47.0)
Blue(56.2)
Breen (64.0)
Red (74.5)
Brown (83.3)
Black (90.9)

Test Slabs (batch number)

Parker single (316104)

Parker stack (316104)

RD Rubber single (14810)

RD Rubber stack (14810)

Precision single (19052A)

Precision stack (19052A)

O-Rings, I.D. X C.S.

(Parker 316104, RD 14810)

Parker $0.301 \times 0.054$

Parker 1.364 x 0.070

Parker $7.688 \times 0.070$

Parker $16.339 \times 0.103$

RD Rubber $0.551 \times 0.070$

RD Rubber $1.114 \times 0.070$
Type A Dial Durometer

$\sim 10 \mathrm{sec}$.

$\sim 1 \mathrm{sec}$.

$29.6 \pm 0.4(5)$

$27.5 \pm 0.5(5)$

$44.1 \pm 0.2(5)$

$41.9 \pm 0.2(5)$

$50.6 \pm 0.7(5)$

$49.2 \pm 0.4(5)$

$59.4 \pm 0.5(5)$

$57.0 \pm 0.0(5)$

$70.0 \pm 0.0(5)$

$81.2 \pm 0.4(5)$

$67.8 \pm 0.4(5)$

$79.2 \pm 0.4(5)$

$88.4 \pm 0.9(5)$

$87.0 \pm 0.9(5)$

$75.2 \pm 1.4(30) \quad 71.0 \pm 1.5(30)$

$72.4 \pm 0.7(30) \quad 67.6 \pm 0.7(30)$

$68.0 \pm 1.0(30) \quad 62.6 \pm 1.0(30)$

$63.3 \pm 0.7(30) \quad 56.3 \pm 0.7(30)$

$74.1 \pm 2.1(30)$

$69.5 \pm 1.8(30)$

$69.8 \pm 2.9(30)$

$64.8 \pm 2.7(30)$

$74.0 \pm 0.3(30)$

NA

NA

NA

NA

NA

NA

NA

NA

NA

NA
$73.5 \pm 0.7(30)$

$66.4 \pm 0.4(30)$

$65.5 \pm 0.5(30)$

$74.0 \pm 0.3(30)$

$72.4 \pm 0.9(30) \quad 70.7 \pm 1.0(30)$

Type M Dial Durometer

$\simeq 10 \mathrm{sec}$.

$29.6 \pm 0.5(5) \quad 29.5 \pm 0.5(5)$

$46.2 \pm 0.3(5) \quad 46.2 \pm 0.3(5)$

$54.0 \pm 0.0(5) \quad 54.0 \pm 0.0(5)$

$62.0 \pm 0.5(5) \quad 61.5 \pm 0.5(5)$

$73.0 \pm 0.0(5) \quad 72.0 \pm 0.0(5)$

$81.6 \pm 0.5(5) \quad 81.0 \pm 0.6(5)$

$89.3 \pm 0.7(5) \quad 89.0 \pm 0.7(5)$

$72.6 \pm 0.9(30)$

$72.1 \pm 0.9(30)$

$64.8 \pm 0.4(30)$

$64.3 \pm 0.5(30)$

$71.1 \pm 0.9(30)$

$74.6 \pm 2.2(4) \quad 75.8 \pm 2.6(4)$

$75.4 \pm 0.7(9) \quad 75.8 \pm 0.7(9)$

$73.7 \pm 1.4(37) \quad 73.6 \pm 1.5(37)$

$76.8 \pm 1.4(37) \quad 75.9 \pm 1.3(37)$

$69.3 \pm 0.7(9) \quad 70.6 \pm 0.8(9)$

$68.1 \pm 0.6(9)$

$69.1 \pm 0.8(9)$

Numbers in parentheses indicate the number of individual readings taken. 
Table F-9. Hardness of Small RD Rubber O-Rings $(0.301 \times 0.054,0.551 \times 0.070$ and $1.114 \times 0.054)$

\begin{tabular}{|c|c|c|c|c|c|c|c|c|c|c|c|}
\hline \multicolumn{2}{|c|}{$0.301 \times 0.054$} & \multirow[b]{2}{*}{ Initial Hardness } & \multirow{2}{*}{$\begin{array}{c}\text { RD } 15107 \\
\text { Aged Hardness }\end{array}$} & \multicolumn{3}{|c|}{$0.301 \times 0.054$ (4 min. cure) } & \multirow{2}{*}{$\begin{array}{c}\text { RD } 15107 \\
\text { Aged Hardness }\end{array}$} & \multicolumn{3}{|c|}{0.301 x 0.054 ( $3 \mathrm{~min}$. cure $)$} & \multirow{2}{*}{$\begin{array}{c}\text { RD } 15107 \\
\text { Aged Hardness }\end{array}$} \\
\hline Bing & Site & & & Ring & Site & Initial Hardness & & Bing & Site & Initial Hardness & \\
\hline \multirow[t]{2}{*}{1} & $\overline{1}$ & 76.1 & 79.8 & 1 & 1 & 74.8 & 79.4 & 1 & 1 & 75.0 & 79.6 \\
\hline & 2 & 75.8 & 79.4 & & 2 & 75.5 & 80.3 & & 2 & 75.4 & 80.4 \\
\hline \multirow[t]{2}{*}{2} & 1 & 75.9 & 79.7 & 2 & 1 & 74.6 & 79.1 & 2 & 1 & 76.6 & 81.2 \\
\hline & 2 & 76.6 & 79.5 & & 2 & 73.7 & 81.0 & & 2 & 75.6 & 81.6 \\
\hline \multirow[t]{2}{*}{3} & 1 & 76.4 & 79.0 & 3 & 1 & 75.7 & 80.4 & 3 & 1 & 75.6 & 80.0 \\
\hline & 2 & 75.9 & 78.9 & & 2 & 76.4 & 79.4 & & 2 & 76.3 & 81.4 \\
\hline \multirow[t]{2}{*}{4} & 1 & 76.2 & 79.3 & 4 & 1 & 76.1 & 80.8 & 4 & 1 & 74.7 & 79.7 \\
\hline & 2 & 76.6 & 79.1 & & 2 & 75.5 & 80.5 & & 2 & 74.5 & 80.8 \\
\hline \multirow[t]{2}{*}{5} & 1 & 75.0 & 78.1 & 5 & 1 & 76.4 & 80.4 & 5 & 1 & 77.8 & 82.3 \\
\hline & 2 & 76.0 & 80.5 & & 2 & $\underline{77.2}$ & $\underline{80.1}$ & & 2 & 77.7 & 81.3 \\
\hline \multicolumn{2}{|c|}{$\begin{array}{l}\text { Avg } \pm \text { S.D.: } \\
\text { Hardness Change }\end{array}$} & $76.1 \pm 0.5$ & $\begin{array}{c}79.3 \pm 0.6 \\
3.2\end{array}$ & \multicolumn{3}{|c|}{$\begin{array}{l}\text { Avg } \pm \text { S.D.: } \\
\text { Hardness Change }\end{array}$} & $\begin{array}{c}80.1 \pm 0.6 \\
4.5\end{array}$ & \multicolumn{3}{|c|}{$\begin{array}{l}\text { Avg } \pm \text { S.D.: } \\
\text { Hardness Change }\end{array}$} & $\begin{array}{c}80.8 \pm 0.9 \\
4.9\end{array}$ \\
\hline \multicolumn{3}{|c|}{$1.114 \times 0.070$} & RD 15107 & \multicolumn{3}{|c|}{$1.114 \times 0.070$ (4 min. cure) } & RD 15107 & \multicolumn{3}{|c|}{$1.114 \times 0.070$ ( $3 \mathrm{~min}$. cure $)$} & RD 15107 \\
\hline Ring & Site & Initial Hardness & Aged Hardness & Ring & Site & Initial Hardness & Aged Hardness & Bing & Site & Initial Hardness & Aged Hardness \\
\hline \multirow[t]{2}{*}{1} & 1 & 75.6 & 77.5 & 1 & 1 & 73.0 & 78.2 & 1 & 1 & 73.4 & 80.1 \\
\hline & 2 & 76.0 & 76.6 & & 2 & 73.9 & 77.1 & & 2 & 70.8 & 80.1 \\
\hline \multirow[t]{2}{*}{2} & 1 & 75.1 & 75.6 & 2 & 1 & 73.8 & 76.7 & 2 & 1 & 74.6 & 79.9 \\
\hline & 2 & 73.9 & 77.2 & & 2 & 71.9 & 76.4 & & 2 & 71.9 & 79.6 \\
\hline \multirow[t]{2}{*}{3} & 1 & 76.0 & 77.0 & 3 & 1 & 72.8 & 77.0 & 3 & 1 & 72.3 & 80.2 \\
\hline & 2 & 74.6 & 76.9 & & 2 & 73.3 & 77.9 & & 2 & 74.2 & 80.1 \\
\hline \multirow[t]{2}{*}{4} & 1 & 76.3 & 76.8 & 4 & 1 & 71.5 & 77.5 & 4 & 1 & 74.7 & 80.1 \\
\hline & 2 & 75.1 & 76.7 & & 2 & 73.5 & 77.0 & & 2 & 73.9 & 80.4 \\
\hline \multirow[t]{2}{*}{5} & 1 & 75.9 & 76.2 & 5 & 1 & 73.2 & 77.2 & 5 & 1 & 73.5 & 79.4 \\
\hline & 2 & $\underline{73.8}$ & 77.8 & & 2 & 72.3 & $\underline{77.0}$ & & 2 & 73.7 & 80.0 \\
\hline \multicolumn{2}{|c|}{$\begin{array}{l}\text { Avg } \pm \text { S.D.: } \\
\text { Hardness Change }\end{array}$} & $75.2 \pm 0.9$ & $\begin{array}{c}76.8 \pm 0.6 \\
1.6\end{array}$ & $\begin{array}{l}\text { Avg } \pm \\
\text { Hardne }\end{array}$ & D.: & $72.9 \pm 0.8$ & $\begin{array}{c}77.2 \pm 0.5 \\
4.3\end{array}$ & $\begin{array}{l}\text { Avg } \pm \\
\text { Hardn }\end{array}$ & $\begin{array}{l}\text { D.: } \\
\text { s Cha }\end{array}$ & $73.3 \pm 1.3$ & $\begin{array}{c}80.0 \pm 0.3 \\
6.7\end{array}$ \\
\hline 0.5512 & 0.070 & & RD 14810 & 0.551 & 0.070 & & RD 15107 & 1.114 & 0.070 & & RD 14810 \\
\hline Ring & Site & Initial Hardness & Aged Hardness & Ring & Site & Initial Hardness & Aged Hardness & Bing & Site & Initial Hardness & Aged Hardness \\
\hline 1 & 1 & 75.2 & 74.7 & 1 & 1 & 76.0 & 77.8 & 1 & 1 & 73.7 & 75.9 \\
\hline & 2 & 75.4 & 76.4 & & 2 & 75.9 & 77.8 & & 2 & 73.4 & 75.6 \\
\hline 2 & 1 & 75.1 & 76.7 & 2 & 1 & 74.1 & 76.3 & 2 & 1 & 74.1 & 75.5 \\
\hline & 2 & 75.1 & 77.1 & & 2 & 73.8 & 76.4 & & 2 & 73.8 & 74.9 \\
\hline 3 & 1 & 74.6 & 75.6 & 3 & 1 & 74.8 & 76.2 & 3 & 1 & 74.2 & 76.3 \\
\hline & 2 & 75.6 & 76.4 & & 2 & 74.3 & 75.7 & & 2 & 73.2 & 75.5 \\
\hline 4 & 1 & 75.7 & 76.1 & 4 & 1 & 73.9 & 77.7 & 4 & 1 & 73.9 & 76.1 \\
\hline & 2 & 74.9 & 76.6 & & 2 & 74.1 & 77.2 & & 2 & 73.9 & 76.1 \\
\hline 5 & 1 & 74.9 & 75.6 & 5 & 1 & 75.3 & 76.8 & 5 & 1 & 73.8 & 75.7 \\
\hline & 2 & 74.8 & 77.2 & & 2 & 74.1 & 76.5 & & 2 & 73.1 & 75.2 \\
\hline $\begin{array}{l}\text { Avg } \pm S \\
\text { Hardne }\end{array}$ & $\begin{array}{l}\text { D.: } \\
\text { s Change }\end{array}$ & $75.1 \pm 0.4$ & $\begin{array}{c}76.2 \pm 0.8 \\
1.1\end{array}$ & $\begin{array}{l}\text { Avg } \pm \\
\text { Hardne }\end{array}$ & $\begin{array}{l}\text { D.: } \\
\text { is Cha }\end{array}$ & $74.6 \pm 0.8$ & $\begin{array}{c}76.8 \pm 0.7 \\
2.2\end{array}$ & $\begin{array}{l}\text { Avg } \pm \\
\text { Hardne }\end{array}$ & $\begin{array}{l}\text { D.: } \\
\text { Cha }\end{array}$ & $73.7 \pm 0.4$ & $\begin{array}{c}75.7 \pm 0.4 \\
2.0\end{array}$ \\
\hline
\end{tabular}




\section{Table F-10. Hardness of Medium RD Rubber O-Rings (7.185 $\times 0.103$ )}

\section{$7.185 \times 0.103$ RD 15107}

Ring Site Initial Hard. Aged Hard.

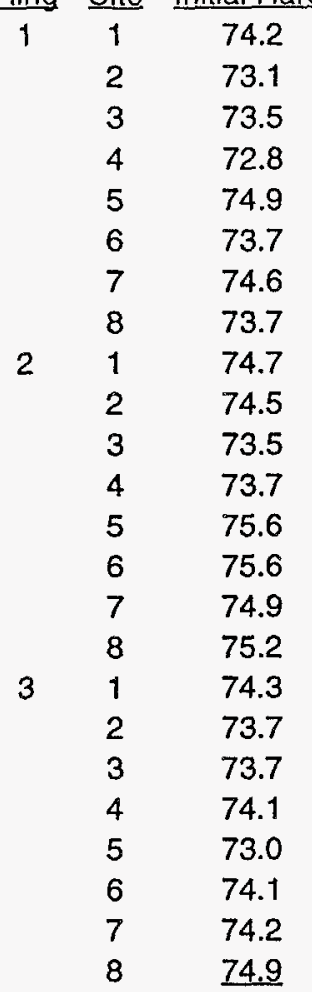

Avg \pm S.D.: $\quad \frac{74.2 \pm 0.8}{74.2 \pm}$ Hardness Change

Odd No. Values Only

Avg \pm S.D.: $\quad 74.3 \pm 0.7$ Hardness Change

Even No. Values Only Avg \pm S.D.: $\quad 74.1 \pm 0.8$ Hardness Change

75.1
76.3
75.3
76.0
75.7
76.2
76.6
76.7
77.0
75.8
75.3
77.0
75.1
74.8
76.2
75.3
76.8
77.3
75.9
76.6
75.6
76.2
76.2
76.7
$76.1 \pm 0.7$
1.9

1.9

\section{$75.9 \pm 0.7$}

1.6

$76.2 \pm 0.7$
2.1

$7.185 \times 0.103$ RD 15107

\section{4 minute cure}

Ring Site Initial Hard. Aged Hard.
11

1
2

73.4

73.0

72.7

73.0

72.2

73.1

73.0

$\begin{array}{rll} & 8 & 73.1 \\ 2 \quad 1 & 72.5 \\ & 2 & 73.9\end{array}$

73.9

73.2

72.8

72.8

73.3

73.2

73.5

73.7

73.2

74.3

73.9

72.9

73.0

72.6

73.0

Avg \pm S.D.: $\quad 73.1 \pm 0.5$

Hardness Change

Odd No. Values Only

Avg \pm S.D.: $\quad 73.0 \pm 0.6$

Hardness Change

Even No. Values Only

Avg \pm S.D.: $\quad 73.2 \pm 0.4$

Hardness Change

$$
\begin{aligned}
& 77.5 \\
& 77.6
\end{aligned}
$$

78.1

77.9

77.9

78.5

78.0

77.6

77.5

77.7

77.2

77.0

78.1

77.5

77.4

77.6

77.5

77.2

77.7

77.6

78.1

77.5

77.5

77.4

$77.7 \pm 0.3$

4.5

$77.7 \pm 0.3$

4.7

$77.6 \pm 0.4$

4.4
$7.185 \times 0.103$ RD 15107

3 minute cure

Ring Site Initial Hard. Aged Hard. Ring Site Initial Hard. Aged Hard.
1 Initial Ha

$$
73.1
$$

$$
72.2
$$

$$
73.3
$$

74.3

72.0

70.5

$$
73.3
$$$$
73.0
$$$$
74.5
$$$$
71.2
$$$$
74.3
$$$$
74.3
$$

74.6

$$
74.1
$$

74.5

$$
70.8
$$$$
72.5
$$$$
69.3
$$$$
72.8
$$$$
70.4
$$$$
73.1
$$$$
70.9
$$$$
8 \quad 73.8
$$

Avg \pm S.D.: $\quad 72.8 \pm 1.5$

Hardness Change

Odd No. Values Only

Avg \pm S.D.: $\quad 72.1 \pm 1.8$

Hardness Change

$76.9 \pm 0.7$

Even No. Values Only

Avg \pm S.D.: $\quad 73.5 \pm 0.9$

Hardness Change
Aged Hard

$$
77.8
$$

77.4

77.1

77.5

77.6

76.7

75.4

78.7

77.1

76.7

76.8

77.1

78.9

76.8

76.7

76.5

76.0

76.6

75.4

76.4

77.0

75.7

$\underline{77.8}$

$76.9 \pm 0.9$

4.2

4.9

$77.0 \pm 1.0$

3.5
$7.185 \times 0.103 R D 14810$

$1 \frac{1}{72.3} \quad \frac{73.3}{71.4}$

$\begin{array}{lll}1 & 72.3 & 73.3 \\ 3 & 71.4 & 72.5\end{array}$

$70.9 \quad 72.2$

$71.3 \quad 72.4$

$70.6 \quad 73.2$

$71.4 \quad 73.7$

$71.4 \quad 71.4$

$\begin{array}{rrr}7 & 71.3 & 72.9\end{array}$

$\begin{array}{llll}2 & 1 & 71.0 & 72.1\end{array}$

$71.7 \quad 72.4$

$71.4 \quad 72.6$

$70.6 \quad 72.3$

$70.2 \quad 72.2$

$70.5 \quad 72.7$

$70.9 \quad 72.1$

$70.5 \quad 72.2$

$\begin{array}{llll}3 & 1 & 70.9 & 72.4\end{array}$

$71.1 \quad 72.3$

$71.0 \quad 71.9$

$70.9 \quad 72.0$

$70.8 \quad 72.1$

$\begin{array}{ll}70.8 & 71.7\end{array}$

$70.8 \quad 72.0$

$\underline{70.7} \quad \underline{72.2}$

Avg \pm S.D.: $\quad 71.0 \pm 0.5 \quad 72.4 \pm 0.5$

Hardness Change

1.4

Odd No. Values Only

Avg \pm S.D.: $\quad 71.0 \pm 0.5 \quad 72.3 \pm 0.5$

Hardness Change

1.3

Even No. Values Only

Avg \pm S.D.: $\quad 71.0 \pm 0.4 \quad 72.4 \pm 0.5$

Hardness Change 
Table F-11. Hardness of Large RD Rubber O-Rings (11.196x0.103)

\section{$11.196 \times 0.103$ RD 15107}

Ring Site Initial Hard. AgedHard.

\section{$11.196 \times 0.103$ RD 15107}

4 minute cure

Bing Site Initial Hard. Aged
$11.196 \times 0.103$ RD 15107

3 minute cure

Ring Site Initial Hard. A

73.3
73.8
73.1
73.4

77.4

77.8

77.2

76.6

77.0

72.5

$72.8 \pm 0.9$

Avg \pm S.D.: $72.8 \pm 0$
Hardness Change

Odd No. Values Only

Avg \pm S.D.: $\quad 72.5 \pm 0.6$

Hardness Change

Even No. Values Only

Avg \pm S.D.: $\quad 73.1 \pm 1.1$

Hardness Change
76.6

75.

$75.4 \pm 1.4$

2.6

\section{$75.2 \pm 1.2$}

2.7

$75.6 \pm 1.6$

2.5
72.5

73.5

73.7

73.6

73.8

74.2

73.7

73.8

73.8

73.0

74.4

73.5

73.0

73.5

73.9

73.8

75.1

73.8

73.4

76.6

76.3

78.0

74.6

76.0

76.0

76.5

76.9

75.8

76.2

77.5

76.0

76.8

76.6

76.7

76.7

76.0

76.5

$\underline{77.3}$

Avg \pm S.D.: $\quad 73.6 \pm 0.6$

Hardness Change

3.0

Odd No. Values Only

Avg \pm S.D.: $\quad 73.5 \pm 0.5$

Hardness Change

$76.5 \pm 0.7$

2.9

Even No. Values Only

Avg \pm S.D.: $\quad 73.6 \pm 0.7$

Hardness Change
$76.8 \pm 0.7$

3.2
1

2

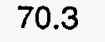

72.8

69.4

70.0

69.7

70.6

69.4

70.2

$\begin{array}{lll}2 & 1 & 71.7\end{array}$

73.5

72.7

72.6

73.8

74.2

72.0

$\begin{array}{lll} & 8 & 74.1 \\ 3 & 1 & 74.3\end{array}$

74.1

73.1

74.1

73.6

73.2

73.0

$8 \quad \underline{74.0}$

Avg \pm S.D.: $\quad \frac{74.0}{72.4 \pm 1.7}$

Hardness Change

Odd No. Values Only

Avg \pm S.D.: $\quad 71.9 \pm 1.8$

Hardness Change

5.0

Even No. Values Only

Avg \pm S.D.: $\quad 72.8 \pm 1.6$

Hardness Change
$76.8 \pm 0.8$

4.0

\section{$11.196 \times 0.103$ RD 14936}

Ring Site Initial Hard. Aged Hard.

$\begin{array}{llll}1 & 1 & 72.5 & 74.6\end{array}$

$2 \quad 73.2 \quad 75.4$

$\begin{array}{lll}3 & 72.2 & 74.8\end{array}$

$4 \quad 71.6 \quad 74.5$

$5 \quad 71.0 \quad 74.5$

$\begin{array}{lll}6 & 71.2 & 74.6\end{array}$

$\begin{array}{lll}7 & 70.4 & 72.7\end{array}$

$\begin{array}{llll}2 & 8 & 71.9 & 73.9 \\ 2 & 1 & 72.9 & 74.7\end{array}$

$\begin{array}{lll}2 & 72.8 & 75.2\end{array}$

$\begin{array}{lll}3 & 74.2 & 75.9\end{array}$

$\begin{array}{lll}4 & 73.6 & 76.1\end{array}$

$\begin{array}{lll}5 & 72.3 & 75.5\end{array}$

$\begin{array}{lll}6 & 73.6 & 75.3\end{array}$

$\begin{array}{lll}7 & 73.3 & 76.0\end{array}$

$\begin{array}{lll}8 & 71.8 & 73.9\end{array}$

75.5

$\begin{array}{lll}2 & 73.4 & 75.7\end{array}$

$\begin{array}{lll}3 & 73.0 & 76.3\end{array}$

$\begin{array}{lll}4 & 73.0 & 73.9\end{array}$

$\begin{array}{lll}5 & 72.2 & 73.3\end{array}$

$\begin{array}{lll}6 & 72.0 & 74.0\end{array}$

$\begin{array}{lll}7 & 73.4 & 75.4\end{array}$

$\begin{array}{ccc}8 & \underline{73.5} & \underline{74.3} \\ \text { Avg } \pm \text { S.D.: } & 72.6 \pm 1.0 & 74.8 \pm 0.9\end{array}$

Hardness Change

2.2

Odd No. Values Only

Avg \pm S.D.: $\quad 72.6 \pm 1.1 \quad 74.9 \pm 1.1$

Hardness Change

2.3

Even No. Values Only

Avg \pm S.D.: $\quad 72.6 \pm 0.9 \quad 74.7 \pm 0.8$

Hardness Change

2.1 
Table F-12. Hardness of Small Parker and Precision O-Rings $(0.116 \times 0.038,0.301 \times 0.054$ and $1.364 \times 0.070)$

\begin{tabular}{|c|c|c|}
\hline \multicolumn{3}{|c|}{$0.116 \times 0.038$} \\
\hline Ring & Site & Initial Hardness \\
\hline \multirow[t]{2}{*}{1} & 1 & 77.9 \\
\hline & 2 & 77.1 \\
\hline \multirow[t]{2}{*}{2} & 1 & 76.2 \\
\hline & 2 & 76.0 \\
\hline \multirow[t]{2}{*}{3} & 1 & 74.2 \\
\hline & 2 & 74.4 \\
\hline \multirow[t]{2}{*}{4} & 1 & 72.4 \\
\hline & 2 & 75.0 \\
\hline \multirow[t]{2}{*}{5} & 1 & 72.6 \\
\hline & 2 & 73.2 \\
\hline \multicolumn{2}{|c|}{ Avg \pm S.D.: } & $74.9 \pm 1.8$ \\
\hline \multicolumn{3}{|c|}{ Hardness Change } \\
\hline \multicolumn{3}{|c|}{$1.364 \times 0.070$} \\
\hline Ring & Site & Initial Hardness \\
\hline \multirow[t]{2}{*}{1} & 1 & 79.8 \\
\hline & 2 & 79.5 \\
\hline \multirow[t]{2}{*}{2} & 1 & 79.9 \\
\hline & 2 & 79.2 \\
\hline \multirow[t]{2}{*}{3} & 1 & 79.6 \\
\hline & 2 & 80.2 \\
\hline
\end{tabular}

Parker 316104

Aged Hardness

\begin{tabular}{l}
80.8 \\
80.6 \\
81.0 \\
81.4 \\
80.6 \\
80.7 \\
\hline
\end{tabular}

Avg \pm S.D.: $\quad 79.7 \pm 0.3$

Hardness Change

\section{$0.301 \times 0.054$}

Bing Site Initial Hardness

\begin{tabular}{|c|c|c|}
\hline \multirow[t]{2}{*}{1} & 1 & 77.6 \\
\hline & 2 & 78.9 \\
\hline \multirow[t]{2}{*}{2} & 1 & 78.6 \\
\hline & 2 & 78.4 \\
\hline \multirow[t]{2}{*}{3} & 1 & 76.3 \\
\hline & 2 & 78.7 \\
\hline \multirow[t]{2}{*}{4} & 1 & 79.8 \\
\hline & 2 & 78.6 \\
\hline \multirow[t]{2}{*}{5} & 1 & 78.9 \\
\hline & $\begin{array}{l}2 \\
\text { s.D.: }\end{array}$ & $\frac{77.1}{78.3 \pm 1.0}$ \\
\hline
\end{tabular}

$$
\begin{gathered}
80.9 \pm 0.3 \\
1.2
\end{gathered}
$$

Precision 19895

Aged Hardness

79.0
78.0
79.7
80.1
77.6
80.0
80.3
81.5
79.3
78.4
$79.4 \pm 1.2$
1.1

1.1

\begin{tabular}{c} 
Parker 318466 \\
Aged Hardness \\
\hline 79.5 \\
80.5 \\
78.6 \\
79.9 \\
75.7 \\
76.8 \\
77.1 \\
79.5 \\
75.0 \\
78.4 \\
$78.1 \pm 1.8$ \\
3.2
\end{tabular}

\begin{tabular}{|c|c|c|}
\hline \multicolumn{3}{|c|}{$0.301 \times 0.054$} \\
\hline Ring & Site & Initial Hardness \\
\hline 1 & 1 & 81.5 \\
\hline & 2 & 80.9 \\
\hline 2 & 1 & 80.9 \\
\hline & 2 & 81.0 \\
\hline 3 & 1 & 80.8 \\
\hline & 2 & 81.4 \\
\hline
\end{tabular}

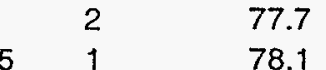

Avg \pm S.D.: $\quad 81.1 \pm 0.3$
Hardness Change

$1.364 \times 0.070$

Ring Site Initial Hardness

$1 \quad 1$

76.2

$2 \quad \begin{aligned} & 2 \\ & 2 \quad 1\end{aligned}$

$\begin{array}{ll}3 & 2 \\ 3 & 1\end{array}$

$\begin{array}{ll} & 2 \\ 4 & 1\end{array}$

$\begin{array}{ll} & 2 \\ 5 & 1\end{array}$

77.1

$$
78.2
$$$$
\begin{aligned}
& 77.5 \\
& 78.9
\end{aligned}
$$$$
76.6
$$

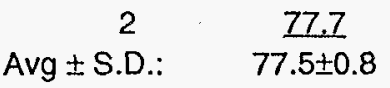

Hardness Change

\begin{tabular}{c} 
Parker 316104 \\
Aged Hardness \\
\hline 82.9 \\
82.4 \\
82.0 \\
82.6 \\
82.5 \\
82.3 \\
\\
$82.5 \pm 0.3$ \\
1.4
\end{tabular}

\section{Parker 317403}

Aged Hardness

77.8
76.4
77.9
77.3
78.1
78.6
78.7
79.0
77.1
78.3
$77.9 \pm 0.8$
0.4

$1.364 \times 0.070$

Ring Site Initial Hardness

Precision 17405 Aged Hardness

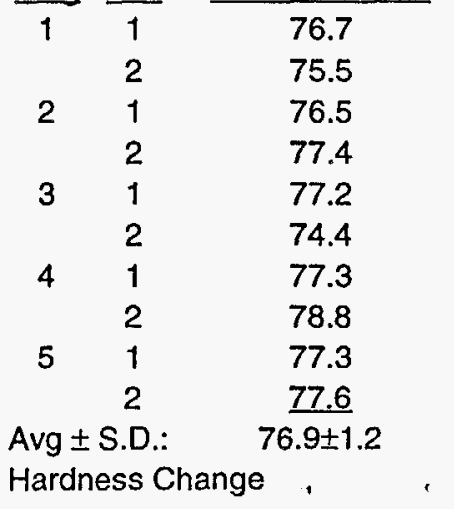

78.9
79.3
78.3
79.0
78.4
78.7
79.9
79.8
78.8
79.3
$79.0 \pm 0.5$
2.1

$0.301 \times 0.054$

\begin{tabular}{|c|c|c|}
\hline \multirow[t]{2}{*}{1} & 1 & 82.1 \\
\hline & 2 & 80.3 \\
\hline \multirow[t]{2}{*}{2} & 1 & 80.5 \\
\hline & 2 & 81.2 \\
\hline \multirow[t]{2}{*}{3} & 1 & 80.6 \\
\hline & 2 & 81.5 \\
\hline \multirow[t]{2}{*}{4} & 1 & 81.3 \\
\hline & 2 & 81.5 \\
\hline \multirow[t]{2}{*}{5} & 1 & 81.8 \\
\hline & 2 & $\underline{82.0}$ \\
\hline & S.D.: & $81.3 \pm 0.6$ \\
\hline
\end{tabular}

Ring Site Initial Hardness

\section{$0.301 \times 0.054$}

\begin{tabular}{|c|c|c|c|}
\hline \multirow[t]{2}{*}{1} & 1 & 75.7 & 80.6 \\
\hline & 2 & 73.0 & 79.7 \\
\hline \multirow[t]{2}{*}{2} & 1 & 73.4 & 79.7 \\
\hline & 2 & 73.1 & 80.1 \\
\hline \multirow[t]{2}{*}{3} & 1 & 74.6 & 79.8 \\
\hline & 2 & 73.8 & 79.9 \\
\hline \multirow[t]{2}{*}{4} & 1 & 75.6 & 78.6 \\
\hline & 2 & 75.6 & 80.1 \\
\hline \multirow[t]{2}{*}{5} & 1 & 75.4 & 80.0 \\
\hline & 2 & 76.1 & 81.3 \\
\hline & S.D.: & $74.6 \pm 1.2$ & $80.0 \pm 0.7$ \\
\hline \multicolumn{3}{|c|}{ Hardness Change } & 5.4 \\
\hline
\end{tabular}

Ring Site Initial Hardness

\section{$1.364 \times 0.070$}

Ring Site Initial Hardness

Parker 316710

Aged Hardness

80.6

80.9

79.8

81.3

80.7

81.2

80.7

80.9

81.1

$\underline{80.8}$

$80.8 \pm 0.4$

$-0.5$

\section{Precision 19052}

\begin{tabular}{|c|c|c|}
\hline \multirow[t]{2}{*}{1} & 1 & 78.3 \\
\hline & 2 & 76.9 \\
\hline \multirow[t]{2}{*}{2} & 1 & 77.1 \\
\hline & 2 & 76.8 \\
\hline \multirow[t]{2}{*}{3} & 1 & 77.3 \\
\hline & 2 & 78.8 \\
\hline \multirow[t]{2}{*}{4} & 1 & 77.6 \\
\hline & 2 & 78.2 \\
\hline \multirow[t]{2}{*}{5} & 1 & 78.0 \\
\hline & 2 & $\underline{77.1}$ \\
\hline & S.D.: & $77.6 \pm 0.7$ \\
\hline
\end{tabular}

Aged Hardness

Precision 19895

Aged Hardness

80.2

78.2

79.0

79.2

79.3

79.5

79.7

$79 . .7$

78.3

79.4

$79.2 \pm 0.6$ 
Table F-13. Hardness of Medium and Large Parker O-Rings ( $7.688 \times 0.070$ and $16.339 \times 0.103$ )

\begin{tabular}{|c|c|c|c|c|c|c|c|c|c|c|c|c|c|c|c|}
\hline \multirow{2}{*}{\multicolumn{2}{|c|}{$\begin{array}{l}7.688 \times 0.070 \\
\text { Ring Site }\end{array}$}} & \multicolumn{2}{|c|}{ Parker 316104} & \multicolumn{4}{|c|}{$7.688 \times 0.070$ Parker 317851} & \multicolumn{4}{|c|}{$16.339 \times 0.103$ Parker 316104} & \multicolumn{4}{|c|}{$16.339 \times 0.103$ Parker 316710} \\
\hline & & Initial Hard. & Aged Hard. & Ring & Site & Initial Hard. & Aged Hard. & Ring & Site & Initial Hard. & Aged Hard. & Ring & Site & Initial Hard. & Aged Hard. \\
\hline \multirow[t]{8}{*}{1} & 1 & 81.6 & 82.5 & 1 & 1 & 73.2 & 74.8 & 1 & 1 & 80.5 & 82.0 & 1 & 1 & 78.8 & 81.4 \\
\hline & 2 & 80.8 & 82.4 & & 2 & 71.7 & 74.2 & & 2 & 80.0 & 82.0 & & 2 & 76.4 & 79.9 \\
\hline & 3 & 80.7 & 82.0 & & 3 & 70.8 & 75.1 & & 3 & 80.0 & 81.6 & & 3 & 76.7 & 78.0 \\
\hline & 4 & 81.7 & 82.0 & & 4 & 71.3 & 75.7 & & 4 & 79.4 & 80.5 & & 4 & 78.4 & 79.9 \\
\hline & 5 & 81.7 & 82.0 & & 5 & 72.8 & 75.1 & & 5 & 79.8 & 80.5 & & 5 & 77.6 & 79.9 \\
\hline & 6 & 80.8 & 83.1 & & 6 & 73.6 & 76.8 & & 6 & 79.8 & 81.1 & & 6 & 77.9 & 79.9 \\
\hline & 7 & 81.6 & 82.6 & & 7 & 74.3 & 76.9 & & 7 & 80.0 & 81.2 & & 7 & 78.4 & 79.9 \\
\hline & 8 & 81.8 & 82.4 & & 8 & 72.9 & 77.2 & & 8 & 79.4 & 80.5 & & 8 & 78.5 & 80.2 \\
\hline \multirow[t]{8}{*}{2} & 1 & 81.1 & 82.0 & 2 & 1 & 72.4 & 75.6 & 2 & 1 & 79.9 & 81.5 & 2 & 1 & 78.8 & 79.7 \\
\hline & 2 & 80.4 & 81.6 & & 2 & 72.9 & 75.6 & & 2 & 79.5 & 81.5 & & 2 & 77.6 & 79.6 \\
\hline & 3 & 81.2 & 82.2 & & 3 & 73.5 & 75.4 & & 3 & 79.0 & 81.6 & & 3 & 78.2 & 79.9 \\
\hline & 4 & 81.9 & 81.3 & & 4 & 71.2 & 76.2 & & 4 & 79.5 & 81.6 & & 4 & 78.2 & 79.1 \\
\hline & 5 & 81.0 & 82.2 & & 5 & 72.4 & 76.2 & & 5 & 79.1 & 81.0 & & 5 & 77.6 & 79.7 \\
\hline & 6 & 81.2 & 82.5 & & 6 & 72.2 & 75.7 & & 6 & 78.2 & 80.7 & & 6 & 79.0 & 79.8 \\
\hline & 7 & 79.5 & 81.6 & & 7 & 73.1 & 74.9 & & 7 & 80.2 & 81.0 & & 7 & 78.3 & 80.4 \\
\hline & 8 & 80.0 & 80.9 & & 8 & 72.6 & 74.9 & & 8 & 80.9 & 81.4 & & 8 & 78.1 & 80.0 \\
\hline \multirow[t]{8}{*}{3} & 1 & 80.7 & 81.3 & 3 & 1 & 70.5 & 75.3 & 3 & 1 & 79.9 & 81.2 & 3 & 1 & 78.5 & 80.9 \\
\hline & 2 & 79.4 & 80.5 & & 2 & 70.8 & 74.5 & & 2 & 78.0 & 80.1 & & 2 & 78.8 & 80.5 \\
\hline & 3 & 80.6 & 81.1 & & 3 & 72.2 & 74.2 & & 3 & 79.4 & 79.1 & & 3 & 76.0 & 80.4 \\
\hline & 4 & 80.6 & 81.9 & & 4 & 72.2 & 74.2 & & 4 & 80.1 & 81.1 & & 4 & 75.2 & 79.7 \\
\hline & 5 & 80.6 & 81.1 & & 5 & 72.1 & 75.3 & & 5 & 79.5 & 82.0 & & 5 & 78.0 & 79.1 \\
\hline & 6 & 80.3 & 81.6 & & 6 & 72.2 & 74.3 & & 6 & 80.6 & 82.1 & & 6 & 77.8 & 80.3 \\
\hline & 7 & 79.3 & 81.5 & & 7 & 71.5 & 74.4 & & 7 & 78.9 & 80.4 & & 7 & 76.2 & 80.0 \\
\hline & 8 & $\underline{80.8}$ & $\underline{81.3}$ & & 8 & $\underline{70.6}$ & $\underline{74.8}$ & & 8 & $\underline{78.1}$ & 80.7 & & 8 & 77.4 & 80.1 \\
\hline \multirow{2}{*}{\multicolumn{3}{|c|}{$\begin{array}{l}\text { Avg } \pm \text { S.D.: } \quad 80.8 \pm 0.7 \\
\text { Hardness Change }\end{array}$}} & $81.8 \pm 0.6$ & $\operatorname{Avg} \pm$ & S.D.: & $72.2 \pm 1.0$ & $75.3 \pm 0.9$ & $\operatorname{Avg} \pm$ & S.D.: & $79.6 \pm 0.7$ & $81.1 \pm 0.7$ & Avg \pm & S.D.: & $77.8 \pm 1.0$ & $79.9 \pm 0.6$ \\
\hline & & & 1.0 & Hardn & ess C & lange & 3.1 & Hardn & ess C & lange & 1.5 & Hardn & ess $\mathrm{C}$ & hange & 2.2 \\
\hline \multicolumn{4}{|c|}{ Odd No. Values Only } & \multicolumn{4}{|c|}{ Odd No. Values Only } & \multicolumn{4}{|c|}{ Odd No. Values Only } & \multicolumn{4}{|c|}{ Odd No. Values Only } \\
\hline \multicolumn{3}{|c|}{$\begin{array}{l}\text { Avg } \pm \text { S.D.: } \quad 80.8 \pm 0.8 \\
\text { Hardness Change }\end{array}$} & $\begin{array}{c}81.8 \pm 0.5 \\
1.0\end{array}$ & \multicolumn{3}{|c|}{$\begin{array}{l}\text { Avg } \pm \text { S.D.: } \quad 72.4 \pm 1.1 \\
\text { Hardness Change }\end{array}$} & $\begin{array}{c}75.3 \pm 0.7 \\
2.9\end{array}$ & \multicolumn{3}{|c|}{$\begin{array}{l}\text { Avg } \pm \text { S.D.: } 79.7 \pm 0.5 \\
\text { Hardness Change }\end{array}$} & $\begin{array}{c}81.1 \pm 0.8 \\
1.4\end{array}$ & \multicolumn{3}{|c|}{$\begin{array}{l}\text { Avg } \pm \text { S.D.: } 77.8 \pm 1.0 \\
\text { Hardness Change }\end{array}$} & $\begin{array}{c}79.9 \pm 0.9 \\
2.2\end{array}$ \\
\hline \multicolumn{4}{|c|}{ Even No. Values Only } & \multicolumn{4}{|c|}{ Even No. Values Only } & \multicolumn{4}{|c|}{ Even No. Values Only } & \multicolumn{4}{|c|}{ Even No. Values Only } \\
\hline \multicolumn{3}{|c|}{$\begin{array}{l}\text { Avg } \pm \text { S.D.: } \quad 80.8 \pm 0.8 \\
\text { Hardness Change }\end{array}$} & $\begin{array}{c}81.8 \pm 0.7 \\
1.0\end{array}$ & \multicolumn{3}{|c|}{$\begin{array}{l}\text { Avg } \pm \text { S.D.: } \quad 72.0 \pm 0.9 \\
\text { Hardness Change }\end{array}$} & $\begin{array}{c}75.3 \pm 1.0 \\
3.3\end{array}$ & \multicolumn{3}{|c|}{$\begin{array}{l}\text { Avg } \pm \text { S.D.: } \quad 79.5 \pm 0.9 \\
\text { Hardness Change }\end{array}$} & $\begin{array}{c}81.1 \pm 0.6 \\
1.7\end{array}$ & \multicolumn{3}{|c|}{$\begin{array}{l}\text { Avg } \pm \text { S.D.: } 77.8 \pm 1.1 \\
\text { Hardness Change }\end{array}$} & $\begin{array}{c}79.9 \pm 0.4 \\
2.1\end{array}$ \\
\hline
\end{tabular}


Table F-14. Hardness of Medium and Large Precision O-Rings (7.739 $\times 0.070$ and $16.955 \times 0.139)$

$7.739 \times 0.070$ Precision 19052

Ring Site Initial Hard. Aged Hard.

1

1
2
3

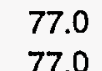

77.0

80.1

77.5

78.2

78.7

79.3

76.8

77.9

217.8

78.3

80.0

79.5

78.4

77.3

77.9

78.6

3

\begin{tabular}{ll}
1 & 79.9 \\
2 & 78.9 \\
3 & 79.3 \\
4 & 79.1 \\
5 & 78.9 \\
6 & 78.1 \\
7 & 78.9 \\
8 & $\underline{78.8}$ \\
\hline
\end{tabular}

Avg \pm S.D.: $\quad 78.4 \pm 0.9$

Hardness Change

Odd No. Values Only

Avg \pm S.D.: $\quad 78.4 \pm 1.1$

Hardness Change

Even No. Values Only

Avg \pm S.D.: $\quad 78.4 \pm 0.8$

Hardness Change

81.3

79.3

80.4

81.2

80.1

80.4

81.1

81.9

81.8

81.6

81.1

81.0

80.6

81.2

81.4

80.9

81.7

82.0

80.3

79.3

81.3

$\underline{80.6}$

$80.9 \pm 0.7$ 2.4
$7.739 \times 0.070$ Precision 19895

Ring Site Initial Hard. Aged Hard.

11

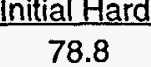

$\frac{\text { aed Hard }}{77.4}$

Avg $\pm S$.

Hardness Change

78.1

77.1

79.9

80.5

77.2

77.5

76.1

76.6

78.5

76.5

76.2

78.0

79.2

77.9

76.9

78.2

77.9

78.3

78.4

77.3

76.7

79.3

78.6

78.3

77.5

Odd No. Values Only

Avg \pm S.D.: $\quad 77.8 \pm 0.8$

Hardness Change

Even No. Values Only

Avg \pm S.D.: $77.6 \pm 1.0$

Hardness Change

813

80.5

81.4

81.4

79.5

81.4

79.9

81.4

81.2

80.9

81.0

81.9

80.5

79.7

80.5

80.0

80.3

80.2

81.5

$\underline{79.8}$

$80.6 \pm 1.0$

2.8

$80.4 \pm 1.1$

2.6

$80.7 \pm 0.8$

3.1
$16.955 \times 0.139$ Precision 19422

Ring Site Initial Hard. Aged Hard.

$\begin{array}{rrrr}1 & 1 & 75.5 & 77.8 \\ & 2 & 75.2 & 78.1\end{array}$

77.9

78.4

77.9

78.0

78.2

77.1

78.4

78.5

78.9

79.1

77.9

78.9

78.0

78.1

79.6

77.6

76.9

78.2

78.1

77.6

77.4

$75.6 \pm 0.5$

$8.1 \pm 0.6$

2.5

Odd No. Values Only

Avg \pm S.D.: $\quad 75.8 \pm 0.4 \quad 78.1 \pm 0.6$

Hardness Change

2.3

Even No. Values Only

Avg \pm S.D.: $\quad 75.3 \pm 0.5 \quad 78.1 \pm 0.7$

Hardness Change

2.8
$16.955 \times 0.139$ Precision 19895

Ring Site Initial Hard. Aged Hard.

$\begin{array}{llll}1 & 1 & 75.7 & 79.0\end{array}$
$76.1 \quad 79.6$

$76.1 \quad 79.2$

$77.3 \quad 79.1$

$75.9 \quad 78.0$

$76.4 \quad 78.8$

$75.0 \quad 78.0$

$\begin{array}{llll} & 8 & 75.3 & 79.3 \\ 2 & 1 & 75.2 & 78.4\end{array}$

$\begin{array}{llll}2 & 76.0 & 79.0\end{array}$

$76.9 \quad 79.5$

$74.2 \quad 78.6$

$75.9 \quad 79.4$

$76.7 \quad 80.2$

$76.3 \quad 78.8$

$76.6 \quad 79.6$

$\begin{array}{llll}3 & 1 & 76.8 & 78.4\end{array}$

$\begin{array}{lll}2 & 75.2 & 78.5\end{array}$

$\begin{array}{lll}3 & 77.6 & 78.0\end{array}$

$\begin{array}{lll}4 & 77.3 & 79.7\end{array}$

$\begin{array}{lll}5 & 78.0 & 80.0\end{array}$

$\begin{array}{lll}6 & 77.7 & 79.6\end{array}$

$\begin{array}{lll}7 & 76.3 & 79.8\end{array}$

$\begin{array}{ccc}8 & 77.6 & \frac{79.8}{\text { Avg }} \pm \text { S.D.: }\end{array} \quad \frac{76.3 \pm 1.0}{79.1 \pm 0.7}$

Hardness Change

2.8

Odd No. Values Only

Avg \pm S.D.: $\quad 76.3 \pm 0.9 \quad 78.9 \pm 0.7$

Hardness Change

Even No. Values Only

Avg \pm S.D.: $\quad 76.4 \pm 1.1$

Hardness Change

$79.3 \pm 0.5$

3.1 


\section{Table F-15. Hardness Data for Test Slabs}

\begin{tabular}{|c|c|c|}
\hline \multicolumn{3}{|c|}{ Parker 316104} \\
\hline Site & Initial & Aged \\
\hline 1 & 71 & 74 \\
\hline 2 & 72 & 74 \\
\hline 3 & 73 & 75 \\
\hline 4 & 73 & 75 \\
\hline Avq: & $72.3 \pm 1$ & $.5 \pm 0.6$ \\
\hline
\end{tabular}

Hardness Change: 2.2

\section{RD 14810}

Site Initial Aged

$\begin{array}{lll}1 & 63 & 67 \\ 2 & 63 & 68\end{array}$

$\begin{array}{lll}3 & 63 & 69\end{array}$

$4 \quad 64 \quad 70$

Avg: $\quad 63.3 \pm 0.568 .5 \pm 1.3$

Hardness Change: $\quad 5.2$

\section{Precision 19052A}

Site Initial Aged

$\begin{array}{lll}1 & 73 & 76 \\ 2 & 73 & 75\end{array}$

$3 \quad 73 \quad 74$

$4 \quad 72 \quad 74$

Avg: $\quad 72.8 \pm 0.574 .8 \pm 1.0$

Hardness Change: 2.0

\section{Parker 316710}

$\begin{array}{ccc}\frac{\text { Site }}{1} & \frac{\text { Initial }}{68} & \frac{\text { Aged }}{70} \\ 2 & 69 & 70 \\ 3 & 69 & 71 \\ 4 & \underline{70} & \underline{70} \\ \text { Avg: } & 69.0 \pm 0.8 & 70.3 \pm 0.5\end{array}$

Hardness Change: $\quad 1.3$

\section{RD 15107}

$\begin{array}{ccc}\frac{\text { Site }}{1} & \frac{\text { Initial }}{65} & \frac{\text { Aged }}{64} \\ 2 & 65 & 65 \\ 3 & 66 & 65 \\ 4 & \underline{66} & \underline{65} \\ \text { Avg: } & 65.5 \pm 0.6 & 64.8 \pm 0.5 \\ \text { lardness Change: } & -0.7\end{array}$

\section{Precision 19895A}

$$
\text { Site Initial Aged }
$$

$\begin{array}{lll}1 & 71 & 76 \\ 2 & 71 & 75\end{array}$

$\begin{array}{lll}3 & 72 & 75\end{array}$

$4 \quad \underline{72} \quad \underline{76}$

Avg: $\quad 71.5 \pm 0.6 \quad 75.5 \pm 0.6$

Hardness Change: $\quad 4.0$

\section{Parker 317403}

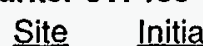

$\begin{array}{llll}1 & 72 & 76 \\ 2 & 73 & 75 \\ 3 & 72 & 76 \\ 4 & \underline{74} & \underline{76}\end{array}$

Avg: $\quad 72.8 \pm 1.075 .8 \pm 0.5$

Hardness Change:

3.0

RD 15107 (4 min. cure)

$\begin{array}{ccc}\frac{\text { Site }}{1} & \frac{\text { Initial }}{67} & \frac{\text { Aged }}{69} \\ 2 & 66 & 69 \\ 3 & 66 & 70 \\ 4 & \underline{68} & \underline{72} \\ \text { Avg: } & 66.8 \pm 1.0 & 70.0 \pm 1.4\end{array}$

Hardness Change: $\quad 3.2$

\section{Parker 317851}

\begin{tabular}{|c|c|c|}
\hline Site & Initial & Aged \\
\hline 1 & 73 & 74 \\
\hline 2 & 72 & 73 \\
\hline 3 & 73 & 73 \\
\hline 4 & 74 & 73 \\
\hline
\end{tabular}

Avg: $\quad 73.0 \pm 0.873 .3 \pm 0.5$

Hardness Change: $\quad 0.3$

RD 15107 (3 min. cure)

$\begin{array}{ccc}\frac{\text { Site }}{1} & \frac{\text { Initial }}{68} & \frac{\text { Aged }}{69} \\ 2 & 66 & 69 \\ 3 & 67 & 70 \\ 4 & \underline{68} & \underline{71} \\ \text { Avg: } & 67.3 \pm 1.0 & 69.8 \pm 1.0\end{array}$

Hardness Change: $\quad 2.5$

\section{Parker 318466}

Site Initial

$173 \quad 74$

$2 \quad 73 \quad 75$

$\begin{array}{lll}3 & 72 & 74\end{array}$

Avg: $\quad 72.8+0.474 .0+0.7$

Hardness Change: $\quad 1.2$ 
Contents:

Tables G-1 and G-2. See Tables F-1 and F-2.

Plot G-3. Effect of Sampling Rate (4 vs. 8 points per ring) on Compression Set Data Plot G-4. Standard Deviations of Thickness Measurements vs. Sample Rate

Table G-5. Thickness Measurements and Standard Deviations Summary

Table G-6. O-Ring Thickness vs. Time After Compression Aging

Table G-7. Compression Set of Small RD Rubber O-Rings (detailed test data)

Table G-8. Compression Set of Medium RD Rubber O-Rings (detailed test data)

Table G-9. Compression Set of Large RD Rubber O-Rings (detailed test data)

Table G-10. Compression Set of Small Parker and Precision O-Rings (detailed test data)

Table G-11. Compression Set of Medium and Large Parker O-Rings (detailed test data)

Table G-12. Compression Set of Medium and Large Precision O-Rings (detailed test data)

Table G-13. Compression Set of Test Slabs (detailed test data) 


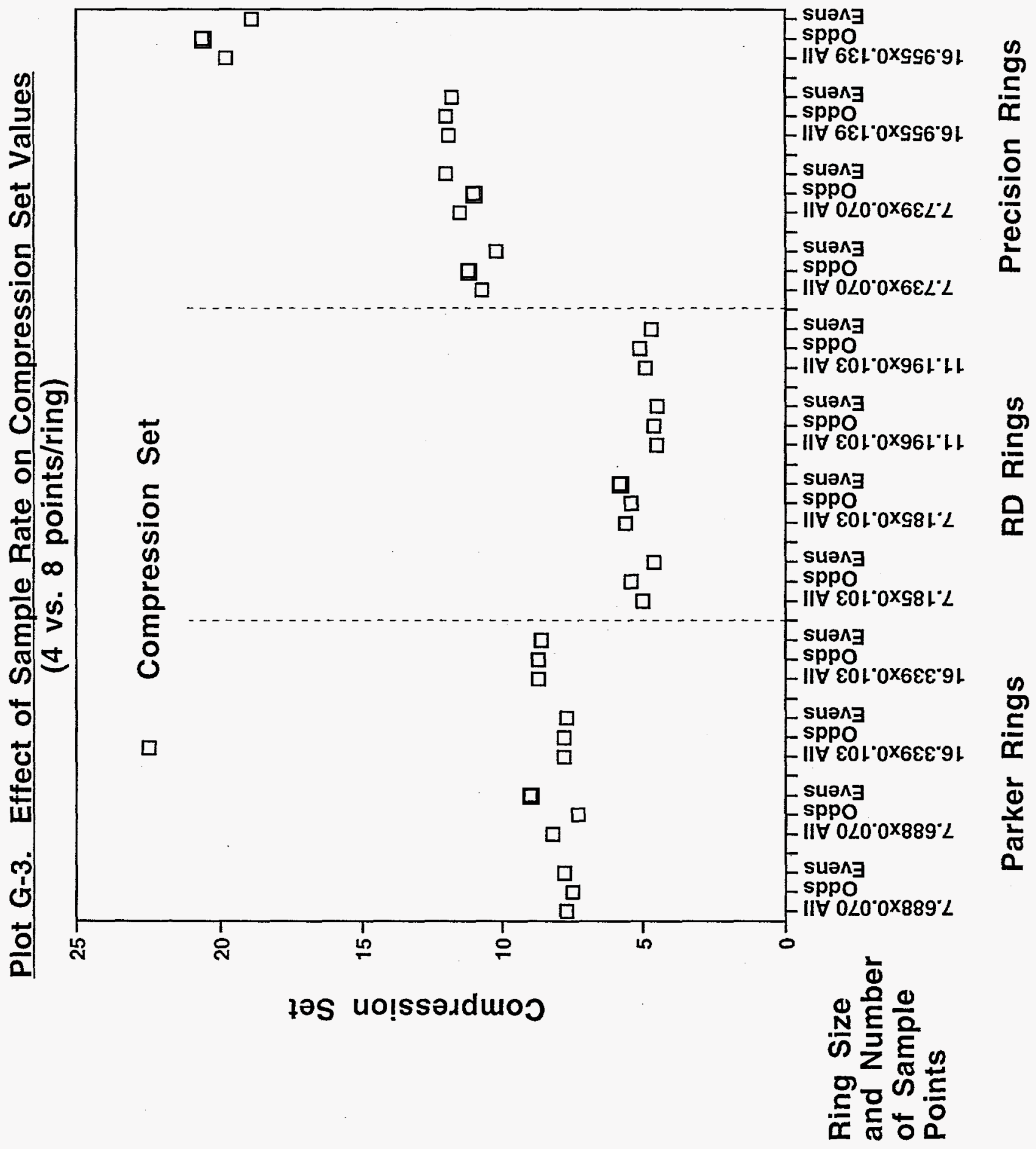




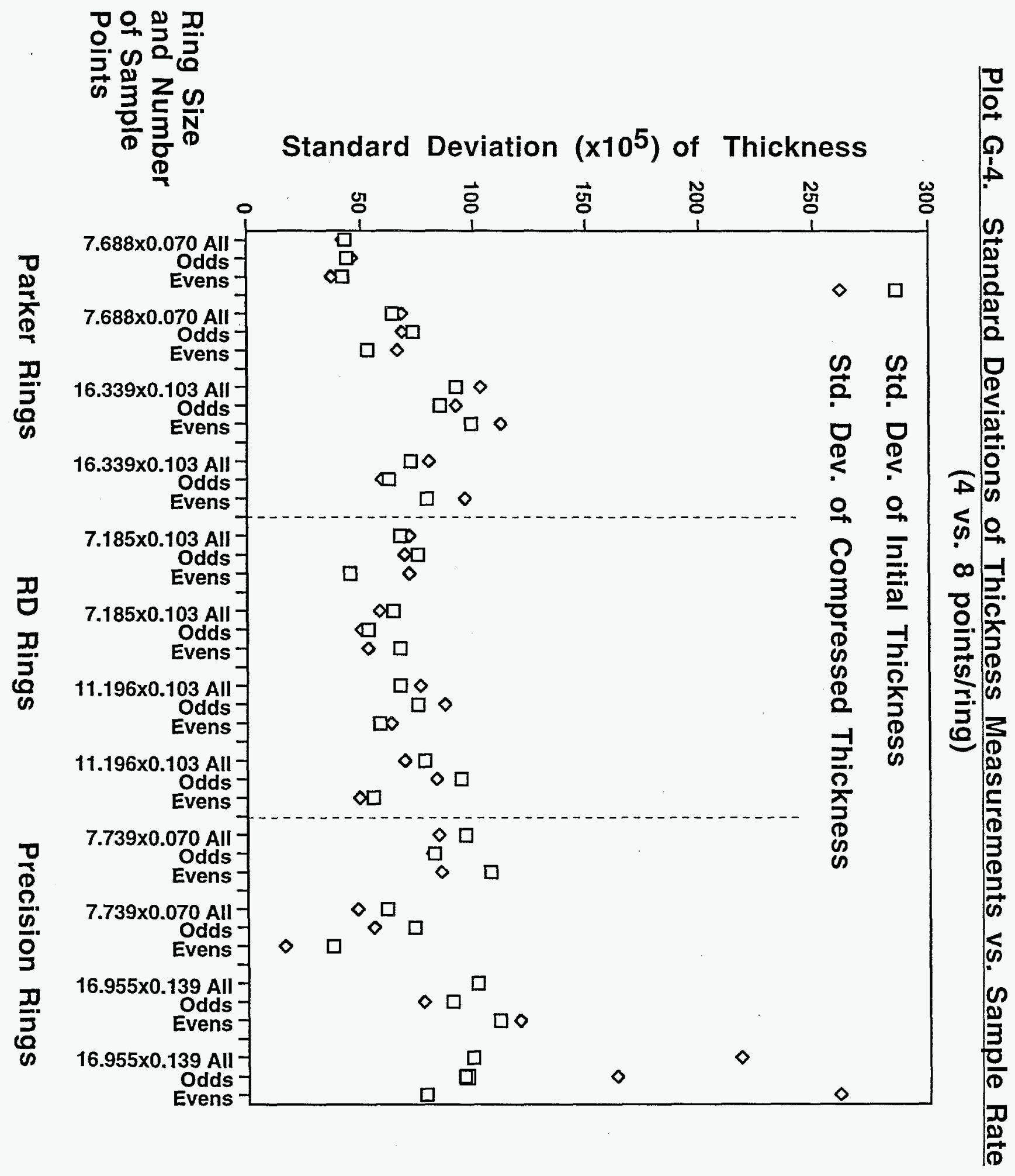


Table G-5. Compression Set Thickness Measurements and Standard Deviations

\begin{tabular}{|c|c|c|c|c|c|}
\hline $\begin{array}{l}\text { Nominal } \\
\text { ring } \\
\text { thickness }\end{array}$ & $\begin{array}{c}\text { Range of thickness } \\
\text { measurements } \\
\text { (before and after } \\
\text { compression set) } \\
\end{array}$ & $\begin{array}{l}\text { Range of Standard } \\
\text { Deviations }\end{array}$ & $\begin{array}{l}\text { Average } \\
\text { Standard } \\
\text { Deviation }\end{array}$ & $\begin{array}{c}\text { Range of thickness } \\
\text { changes observed } \\
\text { during compression } \\
\text { set }\end{array}$ & $\begin{array}{c}\text { Average } \\
\text { observed } \\
\text { thickness } \\
\text { change } \\
\end{array}$ \\
\hline 0.038 & $0.03840-0.03958$ & $0.00046-0.00053$ & 0.00050 & 0.00118 & 0.00118 \\
\hline 0.054 & $0.05354-0.05644$ & $0.00033-0.00108$ & 0.00060 & $0.00064-0.00169$ & 0.00124 \\
\hline 0.070 & $0.06764-0.07190$ & $0.00019-0.00096$ & 0.00049 & $0.00095-0.00212$ & 0.00147 \\
\hline 0.103 & $0.10685-0.10048$ & $0.00058-0.00103$ & 0.00075 & $0.00135-0.00223$ & 0.00167 \\
\hline$A L L *$ & & $0.00019-0.00108$ & 0.00058 & & \\
\hline
\end{tabular}

* Precision rings with a thickness of 0.139 excluded. 
Table G-6. O-Ring Thickness vs. Time After Compression Aging

\begin{tabular}{cc}
$\begin{array}{c}\text { Time @ Ambient } \\
\text { (hr:min:sec) }\end{array}$ & $\begin{array}{c}\text { Cross Section } \\
\text { (Inches) }\end{array}$ \\
\hline $0: 00: 40$ & 0.03922 \\
$0: 01: 00$ & 0.03921 \\
$0: 01: 30$ & 0.03921 \\
$0: 02: 00$ & 0.03921 \\
$0: 02: 30$ & 0.03922 \\
$0: 03: 00$ & 0.03921 \\
$0: 04: 00$ & 0.03922 \\
$0: 05: 00$ & 0.03923 \\
$0: 07: 00$ & 0.03924 \\
$0: 10: 00$ & 0.03924 \\
$0: 15: 00$ & 0.03924 \\
$0: 20: 00$ & 0.03925 \\
$0: 30: 00$ & 0.03925 \\
$0: 40: 00$ & 0.03925 \\
$1: 00: 00$ & 0.03925 \\
$1: 30: 00$ & 0.03925 \\
$2: 00: 00$ & 0.03925 \\
& \\
0 & \\
Time @ Ambient & Cross Section \\
(hr:min:sec) & (Inches) \\
\hline $0: 00: 51$ & 0.06858 \\
$0: 00: 58$ & 0.06852 \\
$0: 01: 02$ & 0.06845 \\
$0: 01: 40$ & 0.06838 \\
$0: 02: 20$ & 0.06833 \\
$0: 03: 00$ & 0.06833 \\
$0: 04: 00$ & 0.06830 \\
$0: 05: 00$ & 0.06829 \\
$0: 07: 00$ & 0.06829 \\
$0: 10: 00$ & 0.06829 \\
$0: 15: 00$ & 0.06830 \\
$0: 20: 00$ & 0.06831 \\
$0: 30: 00$ & 0.06832 \\
$0: 40: 00$ & 0.06833 \\
$1: 00: 00$ & 0.06835 \\
$1: 30: 00$ & 0.06837 \\
$2: 00: 00$ & 0.06837 \\
& \\
&
\end{tabular}

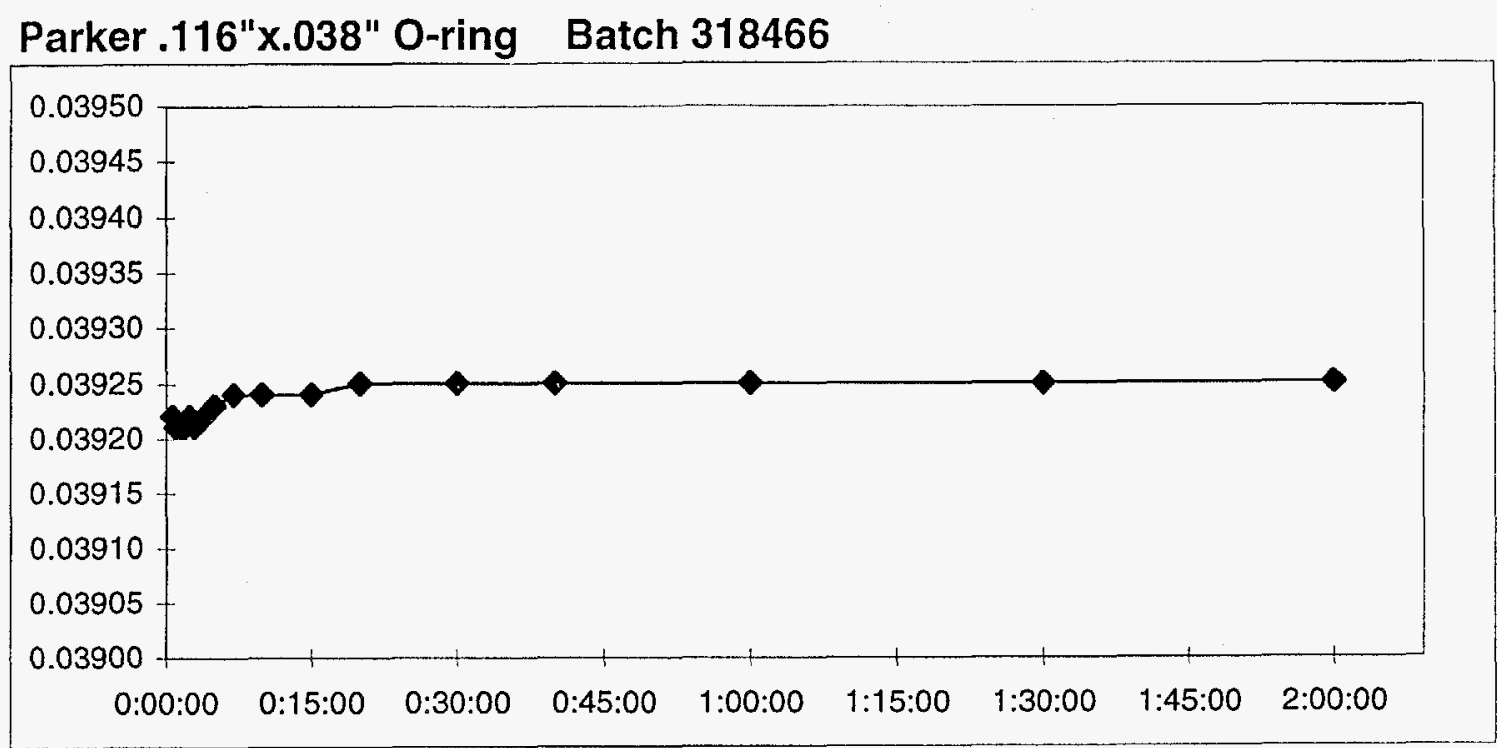

Parker 1.364"x.070" O-ring Batch 317403

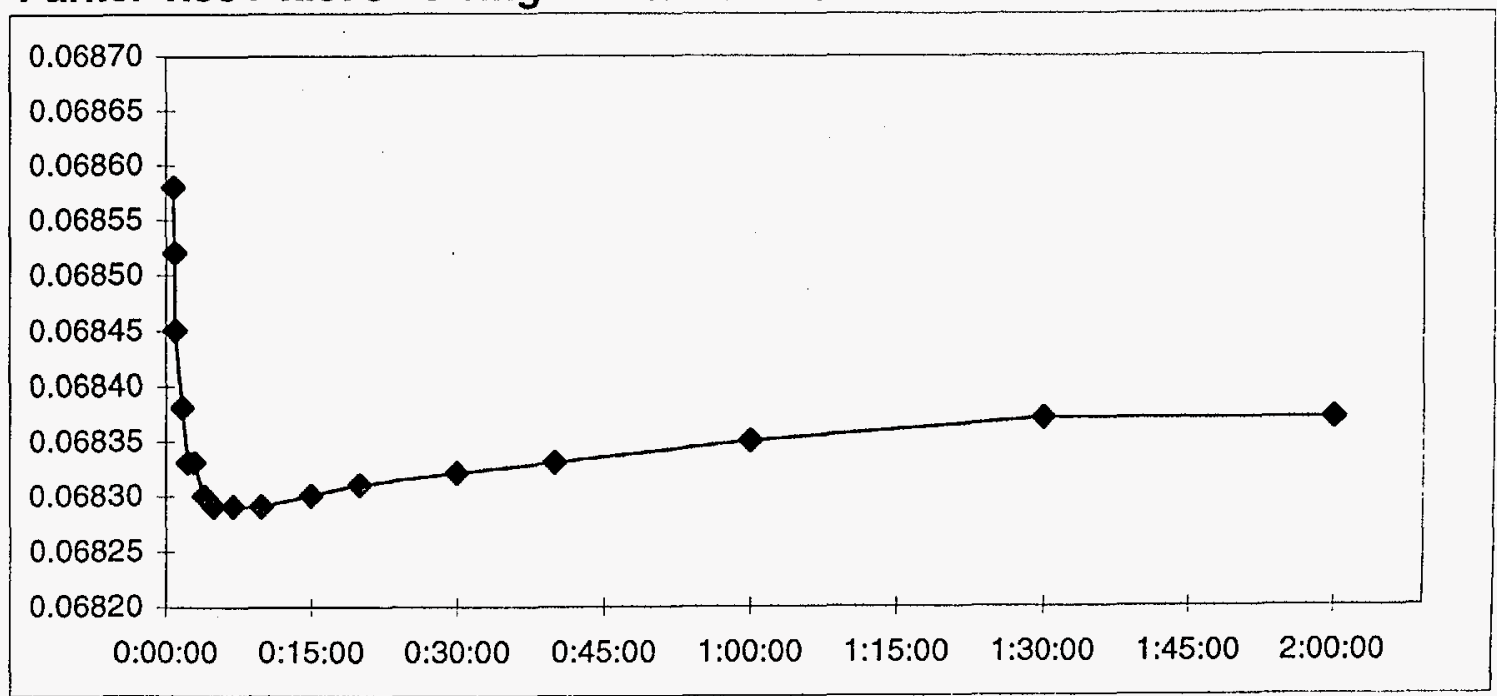


Table G-7. Compression Set of Small RD 0-Rings $(0.301 \times 0.054,0.551 \times 0.070$ and $1.114 \times 0.070)$

\begin{tabular}{|c|c|c|c|}
\hline \multicolumn{2}{|c|}{$0.301 \times 0.054$} & \multicolumn{2}{|r|}{ RD 15107} \\
\hline Bing & Site & Initial Thickness & Aged Thickness \\
\hline \multirow[t]{2}{*}{1} & $\overline{1}$ & .05542 & .05446 \\
\hline & 2 & .05590 & .05486 \\
\hline \multirow[t]{2}{*}{2} & 1 & .05490 & .05380 \\
\hline & 2 & .05474 & .05380 \\
\hline \multirow[t]{2}{*}{3} & 1 & .05574 & .05476 \\
\hline & 2 & .05578 & .05476 \\
\hline \multirow[t]{2}{*}{4} & 1 & .05532 & .05440 \\
\hline & 2 & .05514 & .05428 \\
\hline \multirow[t]{2}{*}{5} & 1 & .05476 & .05394 \\
\hline & 2 & .05466 & .05380 \\
\hline
\end{tabular}

Avg \pm S.D.: $\quad 0.05524 \pm 0.000470 .05429 \pm 0.00043$ Compression Set:

6.5
$0.301 \times 0.054$ ( $4 \mathrm{~min}$. cure)

Site Initial Thickness Aged Thickness

RD 15107

$1.114 \times 0.070$

Ring Site Initial Thickness Aged Thickness

\begin{tabular}{ll}
\hline 1 & 1 \\
& 2 \\
& 2 \\
3 & 1 \\
& 2 \\
& 1 \\
4 & 2 \\
4 & 1 \\
& 2 \\
5 & 1 \\
& 2
\end{tabular}

.06950

.06936

.06882

.06910

.06948

.06950

.06922

.06944

.06948

Avg \pm S.D.: $\quad 0.06930 \pm 0.000230 .06811 \pm 0.00020$

Compression Set:

7.1

RD 14810

$0.551 \times 0.070$

Ring Site Initial Thickness Aged Thickness

$\begin{array}{ll}1 & 1 \\ 2 & 2 \\ & 1 \\ 3 & 2 \\ & 1 \\ & 2 \\ 4 & 1 \\ & 2 \\ 5 & 1 \\ & 2\end{array}$

.07086

.07064

.07124

.07062

.07084

.07110

.07112

.07128

.07106

.07088

Avg \pm S.D.: $\quad 0.07096 \pm 0.000230 .06995 \pm 0.00032$ Compression Set:

$\begin{array}{ll}1 & 1 \\ & 2 \\ 2 & 1 \\ & 2 \\ 3 & 1 \\ & 2 \\ 4 & 1 \\ & 2 \\ 5 & 1 \\ & 2\end{array}$

Avg \pm S.D

Compression Set:

\begin{tabular}{l}
.05534 \\
.05530 \\
.05474 \\
.05428 \\
.05468 \\
.05466 \\
.05536 \\
.05484 \\
.05478 \\
.05499 \\
\hline
\end{tabular}

$05490 \pm 0.000350 .05389 \pm 0.00033$

\section{$1.114 \times 0.070$ (4 min. cure)}

Ring Site Initial Thickness Aged Thickness

$\begin{array}{ll}1 & 1 \\ & 2 \\ & 2 \\ 3 & 1 \\ & 2 \\ & 1 \\ 4 & 2 \\ & 1 \\ & 2 \\ 5 & 2 \\ & 1 \\ & 2\end{array}$

$$
\begin{aligned}
& .06922 \\
& .06930 \\
& .06990 \\
& .06938 \\
& .06944 \\
& .06914 \\
& .06948 \\
& .06976 \\
& .06978 \\
& .06972 \\
& \hline
\end{aligned}
$$

.05422

.05428

.05370

.05364

.05372

.05428

.05388

.05384

$\operatorname{Avg} \pm$ S.D.:

$0.06951 \pm 0.000260 .06839 \pm 0.00029$

Compression Set:

6.6

$0.551 \times 0.070$

RD 15107

Ring Site Initial Thickness Aged Thickness

$\begin{array}{ll}1 & 1 \\ 2 & 2 \\ & 1 \\ 3 & 2 \\ & 1 \\ 4 & 2 \\ & 1 \\ & 2 \\ 5 & 1 \\ & 2\end{array}$

$$
\begin{aligned}
& .07074 \\
& .07132 \\
& .07138 \\
& .07130 \\
& .07104 \\
& .07158 \\
& .07138 \\
& .07072 \\
& .07050
\end{aligned}
$$

\begin{tabular}{|c|c|c|c|}
\hline \multirow[t]{2}{*}{1} & 1 & .06984 & .06806 \\
\hline & 2 & .06912 & .06850 \\
\hline \multirow[t]{2}{*}{2} & 1 & .06964 & .06852 \\
\hline & 2 & .06948 & .06868 \\
\hline \multirow[t]{2}{*}{3} & 1 & .06898 & .06800 \\
\hline & 2 & .06892 & .06818 \\
\hline \multirow[t]{2}{*}{4} & 1 & .06928 & .06840 \\
\hline & 2 & .06972 & .06828 \\
\hline \multirow[t]{2}{*}{5} & 1 & .06944 & .06860 \\
\hline & 2 & .06924 & .06896 \\
\hline
\end{tabular}

$$
\begin{aligned}
& .06990 \\
& .07020 \\
& .07024 \\
& .07014 \\
& .07014 \\
& .07028 \\
& .07028 \\
& .06964
\end{aligned}
$$

Avg \pm S.D.:

.07004

Compression Set:
$0.301 \times 0.054$ (3 min. cure)

\begin{tabular}{cccc} 
Bing & $\frac{\text { Site }}{1}$ & Initial Thickness & Aged Thickness \\
\hline & 1 & .05474 & .05362 \\
2 & 2 & .05590 & .05348 \\
& 1 & .05564 & .05468 \\
3 & 2 & .05572 & .05472 \\
& 1 & .05498 & .05370 \\
4 & 2 & .05466 & .05350 \\
& 1 & .05616 & .05520 \\
5 & 2 & .05650 & .05546 \\
& 1 & .05558 & .05464 \\
& 2 & .05532 & .05434
\end{tabular}

Avg \pm S.D.: $\quad 0.05552 \pm 0.000600 .05433 \pm 0.00072$ Compression Set:

7.9

$1.114 \times 0.070$ ( $3 \mathrm{~min}$. cure)

Bing Site Initial Thickness Aged Thickness

$\begin{array}{lllll}1 & 1 & & .06954 & \\ 2 & 2 & .06974 & & .06790 \\ 2 & 1 & .06952 & & .06780 \\ 3 & 2 & .06966 & .06792 \\ 3 & 1 & .07056 & .06794 \\ & 2 & .06926 & .06756 \\ 4 & 1 & .06936 & .06784 \\ & 2 & .06966 & .06784 \\ 5 & 1 & .06972 & .06766 \\ & 2 & .06966 & .06772\end{array}$

Avg \pm S.D.: $\quad 0.06967 \pm 0.000350 .06782 \pm 0.00014$

Compression Set:

10.8

$1.114 \times 0.070$

RD 14810

Ring Site Initial Thickness Aged Thickness

Avg \pm S.D.: $\quad 0.06937 \pm 0.000310 .06842 \pm 0.00030$ Compression Set: 


\section{Table G-8. Compression Set of Medium RD Rubber O-Rings (7.185x0.103)}

\section{$7.185 \times 0.103$ RD 15107}

Ring Site Initial Thick. Aged Thick.

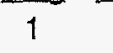

1
2
3

$$
.10342
$$$$
.10372
$$

$\begin{array}{ll}.10448 & .10298 \\ 10486 & 10316\end{array}$

$.10410 \quad .10268$

$.10382 \quad .10236$

$.10418 \quad .10290$

$.10434 \quad .10320$

2

$.10476 \quad .10330$

$.10456 \quad .10288$

$.10482 \quad .10308$

$.10368 \quad .10230$

$.10462 \quad .10320$

官

$$
.10430 \quad .10262
$$$$
.10542 \quad .10376
$$$$
.10382 \quad .10222
$$

$.10536 \quad .10386$

$.10466 \quad .10330$

$.10548 \quad .10380$

$.10542 \quad .10392$

$.10548 \quad .10386$

$.10514 \quad .10350$

$.10578 \quad .10449$

$.10580 \quad .10328$

Avg \pm S.D.: $\quad 0.10473 \quad 0.10318$ $\pm 0.00065 \quad \pm 0.00059$

Compression Set:

$$
5.6
$$

Odd No. Values Only

Avg \pm S.D.: $\quad 0.10495$ $\pm 0.00055$

Compression Set:

0.10344

$\pm 0.00052$

$$
5.4
$$

Even No. Values Only

Avg \pm S.D.: $\quad 0.10451$

$$
\begin{array}{cc}
0.10451 & 0.10292 \\
\pm 0.00070 & \pm 0.00055
\end{array}
$$

Compression Set:

\section{$7.185 \times 0.103$ RD 15107}

4 minute cure

Ring Site Initial Thick. Aged Thick.

$$
.10514
$$

1
2$$
.10504
$$

.10482

.10502

.10516

.10476

.10544

.10472

.10476

.10606

.10418

.10500

.10448

.10576

.10438

.10510

.10644

.10590

.10618

.10578

.10686

.10552

.10596

.10674

Avg \pm S.D.: $\quad 0.10538$ $\pm 0.00074$

Compression Set:

$$
\begin{array}{r}
.10050 \\
10058
\end{array}
$$

10058

.10018

.10076

.10112

.10042

.10102

.10060

.10206

.10032

.10119

.10049

.10138

.10048

10082

.10264

.10232

.10236

10208

.10314

.10184

10206

.10272

0.10133

$\pm 0.00089$

14.7

Odd No. Values Only

Avg \pm S.D.: $\quad 0.10532$ $\pm 0.00087$

0.10124

$\pm 0.00103$

15.2

Even No. Values Only

Avg \pm S.D.: $\quad 0.10545 \quad 0.10143$ $\pm 0.00061$

Compression Set:

14.3
$7.185 \times 0.103$ RD 15107

3 minute cure

Ring Site Initial Thick. Aged Thick.

$1 \frac{\text { Site }}{1}$

.10422

.10400

.10146

.10422

.10450

.10410

.10424

.10458

.10380

2

.10422

.10350

.10434

.10446

.10418

.10484

.10526

.10440

.10454

.10422

.10398

.10426

.10474

.10488

.10436

.10378

Avg \pm S.D.: $\quad 0.10432$ $\pm 0.00038$

Compression Set:

10158

.10158

.10212

.10138

.10150

.10172

.10114

.10150

.10098

.10160

.10168

.10136

.10204

.10206

.10164

.10196

.10154

.10140

.10184

.10204

.10216

.10170

.10144

0.10164

$\pm 0.00031$

dd No. Values Only $\pm 0.00035$

0.10165

$$
10.1
$$

Even No. Values Only

Avg \pm S.D.: $\quad 0.10424$ $\pm 0.00042$

$+0.00036$

Compression Set:
Avg \pm S.D.: $\quad 0.1044$

$7.185 \times 0.103$ RD 14810

Ring Site Initial Thick. Aged Thick.

11

\subsection{2}

0.10448

0.10456

$0.10410 \quad 0.10262$

$0.10460 \quad 0.10300$

$0.10500 \quad 0.10440$

$0.10458 \quad 0.10318$

$0.10436 \quad 0.10370$

$\begin{array}{llll}2 & 1 & 0.10474 & 0.10334\end{array}$

$0.10358 \quad 0.10224$

$0.10550 \quad 0.10418$

$0.10446 \quad 0.10306$

$0.10422 \quad 0.10274$

$0.10380 \quad 0.10252$

$0.10432 \quad 0.10298$

$0.10450 \quad 0.10416$

3

0.10434

0.10194

0.10434

0.10290

$0.10420 \quad 0.10316$

$0.10452 \quad 0.10290$

$0.10440 \quad 0.10294$

$0.10476 \quad 0.10326$

$8 \quad \underline{0.10496} \quad \underline{0.10272}$

Avg \pm S.D.: $\quad 0.10453 \quad 0.10316$

$\pm 0.00068 \quad \pm 0.00073$

Compression Set:

5.0

Odd No. Values Only

Avg \pm S.D.: $\quad 0.10478$ $\pm 0.00078$

0.10329

Compression Set:

Even No. Values Only

Avg \pm S.D.: $\quad 0.10428$ $\pm 0.00047$

Compression Set: 
Table G-9. Compression Set of Large RD Rubber O-Rings (11.196 $\times 0.103$ )

\section{$11.196 \times 0.103$ RD 15107}

Ring Site Initial Thick. Aged Thick.

3

$$
\begin{aligned}
& .10590 \\
& .10588 \\
& .10794 \\
& .10690 \\
& .10672 \\
& .10662 \\
& .10788 \\
& .10684 \\
& .10746 \\
& .10704 \\
& .10616 \\
& .10652 \\
& .10842 \\
& .10684 \\
& .10642 \\
& .10640 \\
& .10810 \\
& .10664 \\
& .10688 \\
& .10754 \\
& .10652 \\
& .10579 \\
& .10530 \\
& .10774 \\
& \hline 0.10685 \\
& \pm 0.00079
\end{aligned}
$$

\begin{tabular}{|c|c|c|c|}
\hline \multirow[t]{8}{*}{1} & 1 & .10394 & .10192 \\
\hline & 2 & .10442 & .10188 \\
\hline & 3 & .10328 & .10144 \\
\hline & 4 & .10462 & .10226 \\
\hline & 5 & .10430 & .10212 \\
\hline & 6 & .10442 & .10230 \\
\hline & 7 & .10354 & .10162 \\
\hline & 8 & .10376 & .10210 \\
\hline \multirow[t]{8}{*}{2} & 1 & .10454 & .10246 \\
\hline & 2 & .10308 & .10142 \\
\hline & 3 & .10388 & .10250 \\
\hline & 4 & .10382 & .10232 \\
\hline & 5 & .10358 & .10250 \\
\hline & 6 & .10332 & .10224 \\
\hline & 7 & .10418 & .10216 \\
\hline & 8 & .10358 & .10178 \\
\hline \multirow[t]{8}{*}{3} & 1 & .10374 & .10182 \\
\hline & 2 & .10356 & .10172 \\
\hline & 3 &. .10466 & .10226 \\
\hline & 4 & .10366 & .10200 \\
\hline & 5 & .10368 & .10184 \\
\hline & 6 & .10392 & .10268 \\
\hline & 7 & .10444 & .10226 \\
\hline & 8 & .10350 & .10192 \\
\hline \multirow{2}{*}{\multicolumn{2}{|c|}{ Avg \pm S.D.: }} & 0.10386 & 0.10206 \\
\hline & & \pm 0.00043 & \pm 0.00034 \\
\hline \multicolumn{3}{|c|}{ Compression Set: } & 6.8 \\
\hline
\end{tabular}

Avg \pm S.D.: $\quad \frac{.10774}{0.10685}$

Compression Set:

Odd No. Values Only

Avg \pm S.D.: $\quad 0.10698$

$$
\pm 0.00098
$$

\begin{tabular}{|c|c|c|c|}
\hline \multirow[t]{8}{*}{1} & 1 & .10552 & .10276 \\
\hline & 2 & .10500 & .10236 \\
\hline & 3 & .10542 & .10270 \\
\hline & 4 & .10466 & .10204 \\
\hline & 5 & .10522 & .10242 \\
\hline & 6 & .10522 & .10328 \\
\hline & 7 & .10464 & .10188 \\
\hline & 8 & .10422 & .10270 \\
\hline \multirow[t]{8}{*}{2} & 1 & .10480 & .10280 \\
\hline & 2 & .10430 & .10230 \\
\hline & 3 & .10484 & .10276 \\
\hline & 4 & .10512 & .10292 \\
\hline & 5 & .10332 & .10198 \\
\hline & 6 & .10426 & .10220 \\
\hline & 7 & .10464 & .10240 \\
\hline & 8 & .10460 & .10224 \\
\hline \multirow[t]{8}{*}{3} & 1 & .10434 & .10222 \\
\hline & 2 & .10400 & .10210 \\
\hline & 3 & .10478 & .10262 \\
\hline & 4 & .10514 & .10262 \\
\hline & 5 & .10504 & .10260 \\
\hline & 6 & .10464 & .10249 \\
\hline & 7 & .10480 & .10274 \\
\hline & 8 & .10382 & .10196 \\
\hline \multirow{2}{*}{\multicolumn{2}{|c|}{ Avg \pm S.D.: }} & 0.10468 & 0.10246 \\
\hline & & \pm 0.00052 & \pm 0.00035 \\
\hline \multicolumn{4}{|c|}{ Compression Set: } \\
\hline
\end{tabular}

Compression Set:

$$
\begin{aligned}
& .10454 \\
& .10466 \\
& .10624 \\
& .10580 \\
& .10546 \\
& .10554 \\
& .10670 \\
& .10538 \\
& .10594 \\
& .10568 \\
& .10496 \\
& .10550 \\
& .10686 \\
& .10584 \\
& .10510 \\
& .10502 \\
& .10604 \\
& .10440 \\
& .10460 \\
& .10598 \\
& .10496 \\
& .10476 \\
& .10426 \\
& .10546 \\
& \hline 0.10540 \\
& \pm 0.00070 \\
& \hline 4.9
\end{aligned}
$$$$
4.9
$$

0.10547 $\pm 0.00087$

5.1

Even No. Values Only

Avg \pm S.D.: $\quad 0.10673$

Compression Set:

\section{$11.196 \times 0.103$ RD 15107}

4 minute cure

Ring Site Initial Thick. Aged Thick.

Odd No. Values Only

Avg \pm S.D.: $\quad 0.10392 \quad 0.10208$ $\pm 0.00040 \quad \pm 0.00035$

Compression Set:

6.9

Even No. Values Only

Avg \pm S.D.: $\quad 0.10381 \quad 0.10205$

Compression Set:
$11.196 \times 0.103$ RD 15107

3 minute cure

Ring Site Initial Thick. Aged Thick.

Odd No. Values Only

Avg + S.D: $\quad 0.10478$ $\pm 0.00057$

Compression Set:

0.10249

$\pm 0.00032$

8.3

Even No. Values Only

Avg \pm S.D.: 0.10458 $\pm 0.00047$

Compression Set:
79

\section{$11.196 \times 0.103$ RD 14936}

Ring Site Initial Thick. Aged Thick.

$\begin{array}{llll}1 & 1 & .10618 & .10496\end{array}$

$2 \quad .10738 \quad .10574$

$3 \quad .10692 \quad .10512$

$4 \quad .10634 \quad .10482$

$5 \quad .10706 \quad .10578$

$\begin{array}{lll}6 & .10696 \quad .10572\end{array}$

$\begin{array}{lll}7 & .10678 & .10542\end{array}$

$8 \quad .10600 \quad .10456$

$2 \quad 1 \quad .10572 \quad .10446$

$.10604 \quad .10496$

$.10674 \quad .10504$

$10638 \quad .10492$

$.10850 \quad .10754$

$.10744 \quad .10606$

$.10688 \quad .10568$

$.10740 \quad .10644$

$\begin{array}{ccc}\text { Avg } \pm \text { S.D.: } & 0.10680 & 0.10545 \\ & \pm 0.00070 & \pm 0.00079 \\ \text { Compression } & \text { Set: } & 4.6\end{array}$

Odd No. Values Only

Avg \pm S.D.: $\quad 0.10685 \quad 0.10550$ $\pm 0.00080 \pm 0.00093$

Compression Set:

4.6

Even No. Values Only

Avg \pm S.D.: $\quad 0.10674 \quad 0.10540$

Compression Set: $\pm 0.00062 \pm 0.00068$ 


\begin{tabular}{|c|c|c|}
\hline \multicolumn{3}{|c|}{$0.116 \times 0.038$} \\
\hline Ring & Site & Initial Thickness \\
\hline \multirow[t]{2}{*}{1} & 1 & 0.03917 \\
\hline & 2 & 0.03933 \\
\hline \multirow[t]{2}{*}{2} & 1 & 0.03878 \\
\hline & 2 & 0.03949 \\
\hline \multirow[t]{2}{*}{3} & 1 & 0.04026 \\
\hline & 2 & 0.04024 \\
\hline \multirow[t]{2}{*}{4} & 1 & 0.03933 \\
\hline & 2 & 0.03903 \\
\hline \multirow[t]{2}{*}{5} & 1 & 0.03978 \\
\hline & 2 & 0.04036 \\
\hline
\end{tabular}

Avg \pm S.D.: $0.03958 \pm 0.00053$ Compression Set:

\section{$1.364 \times 0.070$}

Ring Site Initial Thickness

\begin{tabular}{llll}
\hline 1 & 1 & .06996 \\
& 2 & & .07004 \\
2 & 1 & .07142 \\
3 & 2 & .06966 \\
3 & 1 & .07062 \\
& 2 & .07128 \\
4 & 1 & .07160 \\
& 2 & .07074 \\
5 & 1 & .07018 \\
& 2 & .06990 \\
\hline
\end{tabular}

Avg \pm S.D.: $0.07054 \pm 0.00070$

Compression Set:

\section{$0.301 \times 0.054$}

Bing Site Initial Thickness

$\begin{array}{lll}1 & 1 & .05638 \\ & 2 & .05570 \\ 2 & 1 & .05582 \\ & 2 & .05572 \\ 3 & 1 & .05678 \\ & 2 & .05582 \\ 4 & 1 & .05672 \\ & 2 & .05712 \\ 5 & 1 & .05660 \\ & 2 & .05590 \\ & 2 & \end{array}$

Avg \pm S.D.: $0.05626 \pm 0.00052 \quad 0.05457 \pm 0.00044$ Compression Set:

\begin{tabular}{c} 
Parker 318466 \\
Aged Thickness \\
\hline 0.03883 \\
0.03836 \\
0.03805 \\
0.03796 \\
0.03905 \\
0.03925 \\
0.03826 \\
0.03785 \\
0.03800 \\
0.03835
\end{tabular}

$0.03840 \pm 0.00046$

10.7

\section{Parker 317403}

Aged Thickness

.06880

.06976

.06832

.06904

.06970

.06702

.06910

.06868

.06826

10.1

Precision 19895

Aged Thickness

.05526

.05426

.05420

.05404

.05500

.05426

.05502

.05454

.05488

05420

10.7
$0.301 \times 0.054$

Bing Site Initial Thickness

1

.05460

.05510

.05472

$\begin{array}{lll} & 4 & .05530 \\ 2 & 1 & .05368\end{array}$

2

.05312

.05462

.05412

Avg \pm S.D.: $0.05441 \pm 0.00073$ Compression Set:

$1.364 \times 0.070$

Ring Site Initial Thickness

\begin{tabular}{|c|c|c|}
\hline \multirow[t]{4}{*}{1} & 1 & .07164 \\
\hline & 2 & .07146 \\
\hline & 3 & .07188 \\
\hline & 4 & .07206 \\
\hline \multirow[t]{4}{*}{2} & 1 & .07162 \\
\hline & 2 & .07188 \\
\hline & 3 & .07184 \\
\hline & 4 & .07254 \\
\hline \multirow[t]{4}{*}{3} & 1 & .07232 \\
\hline & 2 & .07178 \\
\hline & 3 & .07214 \\
\hline & 4 & .07180 \\
\hline
\end{tabular}

Avg \pm S.D.: $0.07191 \pm 0.00031 \quad 0.07075 \pm 0.00022$

Compression Set:

\section{$1.364 \times 0.070$}

Ring Site Initial Thickness

$\begin{array}{ll}1 & 1 \\ & 2 \\ 2 & 1 \\ & 2 \\ 3 & 1 \\ & 2 \\ 4 & 1 \\ & 2 \\ 5 & 1 \\ & 2\end{array}$

.07028

.06960

.06946

.06968

.06972

.06939

.07078

.06908

.06946

.06930

Avg \pm S.D.: $0.06968 \pm 0.00050 \quad 0.06816 \pm 0.00042$ Compression Set:

\begin{tabular}{c} 
Parker 316104 \\
Aged Thickness \\
\hline .05438 \\
.05466 \\
.05410 \\
.05466 \\
.05278 \\
.05224 \\
.05392 \\
.05338 \\
\hline
\end{tabular}

$0.05377 \pm 0.00089$

4.6

Parker 316104

Aged Thickness

.07062
.07060
.07086
.07114
.07060
.07070
.07074
.07042
.07098
.07052
.07102
.07078
$.075 \pm 0.00022$
6.1

Precision 17405

Aged Thickness

\begin{tabular}{l}
.06860 \\
.06828 \\
.06780 \\
.06822 \\
.06822 \\
.06800 \\
.06774 \\
.06906 \\
.06768 \\
.06802 \\
\hline
\end{tabular}

8.8
$0.301 \times 0.054$

Bing Site Initial Thickness

$\begin{array}{ll}1 & 1 \\ & 2 \\ 2 & 1 \\ & 2 \\ 3 & 1 \\ & 2 \\ 4 & 1 \\ & 2 \\ & 2 \\ & 1 \\ & 2 \\ & 2\end{array}$

0.05440

0.05616

0.05504

0.05496

0.05536

0.05494

0.05528

0.05338

0.05444

$\underline{0.05542}$

Avg \pm S.D.: $0.05494 \pm 0.00075$

Compression Set:

Parker 316710

Aged Thickness

0.05298

0.05388

0.05380

0.05378

0.05378

0.05368

0.05376

0.05214

0.05326

$\underline{0.05430}$

\section{$0.301 \times 0.054$}

Aing Site Initial Thickness

$\begin{array}{lll}1 & 1 & .05636 \\ & 2 & .05324 \\ 2 & 1 & .05666 \\ & 2 & .05690 \\ 3 & 1 & .05680 \\ & 2 & .05698 \\ 4 & 1 & .05682 \\ & 2 & .05678 \\ 5 & 1 & .05692 \\ & 2 & .05698\end{array}$

Avg \pm S.D.: $0.05644 \pm 0.00114$

Compression Set:

9.7

$1.364 \times 0.070$

Ring Site Initial Thickness

$\begin{array}{lll}1 & 1 & .06828 \\ & 2 & .06924 \\ 2 & 1 & .06868 \\ & 2 & .07086 \\ 3 & 1 & .06872 \\ & 2 & .06928 \\ 4 & 2 & .06864 \\ & 1 & .06874 \\ & 2 & .07068 \\ 5 & 1 & .07004 \\ & 2 & \end{array}$

Precision 19052

Aged Thickness

.05426

.05456

.05480

.05494

.05552

.05516

.05490

.05502

.05510

.05510

$$
9.5
$$

Precision 19895

Aged Thickness

$$
\begin{aligned}
& .06676 \\
& .06730 \\
& .06708 \\
& .06928 \\
& .06686 \\
& .06760 \\
& .06699 \\
& .06722 \\
& .06904 \\
& .06830 \\
& \hline
\end{aligned}
$$

Avg \pm S.D.: $0.06932 \pm 0.00091 \quad 0.06764 \pm 0.00091$ Compression Set: 


\section{Table G-11. Compression Set of Medium and Large Parker O-Rings (7.688 $\times 0.070$ and $16.339 \times 0.103)$}

$7.688 \times 0.070$ Parker 316104

Ring Site Initial Thick. Aged Thick.
$7.688 \times 0.070$ Parker 317851

Ring Site Initial Thick. Aged Thick.

Ave

Compression Set:

Odd No. Values Only

Avg \pm S.D.: $\quad 0.07173$

Compression Set: $\pm 0.00046 \quad \pm 0.00048$

7.5

Even No. Values Only

Avg \pm S.D.: $\quad 0.07182$

Compression Set:

$\begin{array}{cc}0.07182 & 0.0703 \\ \pm 0.00043 & \pm 0.00038\end{array}$

7.8$$
\text { Site } 1
$$

$$
\begin{aligned}
& .07124 \\
& .07146
\end{aligned}
$$

.07150

.07176

.07074

.07162

.07062

.07130

$\begin{array}{lll} & 8 & .07130 \\ & 1 & .07306\end{array}$

.07158

.07146

.07146

.07174

.07170

.07074

.07188

$\begin{array}{lll}3 & 8 & .07188 \\ & 1 & .07220\end{array}$

.07108

.07230

.07304

.07084

.07084

.07216

.07202

Avg \pm S.D.: $\quad 0.07160$ $\pm 0.00065$

Compression Set:

Odd No. Values Only

Avg \pm S.D.: $\quad 0.07155$ $\pm 0.00077$

Compression Set:

\begin{tabular}{l}
.07038 \\
.06930 \\
.06999 \\
.06966 \\
.07020 \\
.07058 \\
.07036 \\
.07020 \\
.07172 \\
.06944 \\
.06982 \\
.07006 \\
.06904 \\
.07020 \\
.07022 \\
.06956 \\
.07052 \\
.06984 \\
.07024 \\
.07166 \\
.06894 \\
.06924 \\
.07044 \\
.06938 \\
\hline 0.07004 \\
\pm 0.00070 \\
8.2
\end{tabular}

8.2

0.07016

$\pm 0.00072$

7.3

Even No. Values Only

Avg \pm S.D.: $\quad 0.07165$

Compression Set:

0.06993

$\pm 0.00069$

9.0
$16.339 \times 0.103$ Parker 316104

Ring Site Initial Thick. Aged Thick.

$$
1
$$

1

2

$$
\begin{array}{ll}
.10294 & .09994 \\
.10310 & .10059 \\
.10464 & .10228
\end{array}
$$

.10360

.10342

.10176

.10218

.10380

$2 \quad 1 \quad .10386$

.10356

.10348

.10238

.10362

.10296

.10338

.10334

.10426

.10278

.10140

.10436

.10404

.10250

.10346

.10572

Avg \pm S.D.: $\quad \frac{10572}{0.10336}$ $\pm 0.00094$

Compression Set:

Odd No. Values Only

Avg \pm S.D.: $\quad 0.10339$ $\pm 0.00089$

Compression Set:

\begin{abstract}
10180
.09978

.10094

.10146

.10186

.10138

.10152

.10000

.10140

.10106

.10124

.10188

.10182

.10034

.09932

.10364

.10284

.10126

.10092

.10322

0.10131

$\pm 0.00105$

7.8
\end{abstract}

0.10132

$\pm 0.00097$

7.8

Even No. Values Only

Avg \pm S.D.: $\quad 0.10332$ $\pm 0.00103$

Compression Set: $\pm 0.00117$

7.7
$16.339 \times 0.103$ Parker 316710

Ring Site Initial Thick. Aged Thick.

$10 \frac{10308}{1} \quad 0.10080$

$2 \quad 0.10392 \quad 0.10220$

$\begin{array}{lll}3 & 0.10260 & 0.10082\end{array}$

$\begin{array}{lll}4 & 0.10198 & 0.10024\end{array}$

$\begin{array}{lll}5 & 0.10188 & 0.10028\end{array}$

$\begin{array}{lll}6 & 0.10260 & 0.10034\end{array}$

$\begin{array}{lll}7 & 0.10244 & 0.10000\end{array}$

$\begin{array}{lll}8 & 0.10152 & 0.09940\end{array}$

$\begin{array}{llll}2 & 1 & 0.10262 & 0.10026\end{array}$

$2 \quad 0.10374 \quad 0.10106$

$\begin{array}{lll}3 & 0.10288 & 0.10032\end{array}$

$\begin{array}{lll}4 & 0.10314 & 0.10028\end{array}$

$\begin{array}{lll}5 & 0.10240 & 0.10008\end{array}$

$\begin{array}{lll}6 & 0.10408 & 0.10272\end{array}$

$\begin{array}{lll}7 & 0.10298 & 0.10066\end{array}$

$\begin{array}{rll}7 & 0.10220 & 0.10000\end{array}$

$\begin{array}{llll}3 & 1 & 0.10330 & 0.10066\end{array}$

$\begin{array}{lll}2 & 0.10204 & 0.09936\end{array}$

$\begin{array}{lll}3 & 0.10350 & 0.10152\end{array}$

$\begin{array}{lll}4 & 0.10278 & 0.10054\end{array}$

$\begin{array}{lll}5 & 0.10110 & 0.09896\end{array}$

$\begin{array}{lll}6 & 0.10236 & 0.10028\end{array}$

$\begin{array}{lll}6 & 0.10236 & 0.10028 \\ 7 & 0.10266 & 0.10032\end{array}$

$8 \quad \underline{0.10322} \quad \underline{0.10046}$

Avg \pm S.D.: $\quad 0.10271 \quad 0.10048$

Compression Set:

$\pm 0.00082$

8.7

Odd No. Values Only

Avg \pm S.D.: $\quad 0.10262 \quad 0.10039$ $\pm 0.00065 \pm 0.00061$

Compression Set:

8.7

Even No. Values Only

$\begin{array}{llll}0.10130 & \text { Avg } \pm \text { S.D.: } & 0.10280 & 0.10057\end{array}$

Compression Set: 
Table G-12. Compression Set of Medium and Large Precision O-Rings $(7.739 \times 0.070$ and $16.955 \times 0.139)$

$7.739 \times 0.070$ Precision 19052

Ring Site Initial Thick. Aged Thick.

\begin{tabular}{|c|c|c|c|}
\hline \multirow[t]{8}{*}{1} & 1 & .07118 & .06882 \\
\hline & 2 & .07262 & .07002 \\
\hline & 3 & .07204 & .06886 \\
\hline & 4 & .07076 & .06866 \\
\hline & 5 & .07082 & .06866 \\
\hline & 6 & .07138 & .06978 \\
\hline & 7 & .07306 & .07134 \\
\hline & 8 & .07020 & .06862 \\
\hline \multirow[t]{8}{*}{2} & 1 & .07002 & .06876 \\
\hline & 2 & .07120 & .06980 \\
\hline & 3 & .07204 & .07008 \\
\hline & 4 & .07028 & .06870 \\
\hline & 5 & .07190 & .06958 \\
\hline & 6 & .07166 & .06886 \\
\hline & 7 & .07058 & .06848 \\
\hline & 8 & .07420 & .07180 \\
\hline \multirow[t]{8}{*}{3} & 1 & .07100 & .06908 \\
\hline & 2 & .07068 & .06944 \\
\hline & 3 & .07054 & .06846 \\
\hline & 4 & .07132 & .06912 \\
\hline & 5 & .07068 & .06878 \\
\hline & 6 & .07056 & .06916 \\
\hline & 7 & .07082 & .06856 \\
\hline & 8 & .07130 & .06910 \\
\hline \multirow{2}{*}{\multicolumn{2}{|c|}{ Avg \pm S.D.: }} & 0.07129 & 0.06927 \\
\hline & & \pm 0.00098 & \pm 0.00086 \\
\hline
\end{tabular}

Compression Set:

10.7

Odd No. Values Only

Avg \pm S.D.: $\quad 0.07122$ $\pm 0.00086$

Compression Set:

0.06912 $\pm 0.00084$

11.2

Even No. Values Only

Avg \pm S.D.: $\quad 0.07135$ $\pm 0.00112$

Compression Set:

$+0.00088$

10.2
$7.739 \times 0.070$ Precision 19895

Ring Site Initial Thick. Aged Thick.

$1107192 \quad 06898$

\section{.07064}

.07082

.06874

.06940

.07058

.07170

.07182

.07128

$\begin{array}{lll} & 8 & .07068 \\ 2 & 1 & .07206\end{array}$

.07206
.07100

.07056

.07078

.07096

.07066

.07036

.07116

$\begin{array}{lll}3 & 1 & .07212\end{array}$

.07130

.07020

.07064

.07234

.07072

.07048

.07052

Avg \pm S.D.: $\quad 0.07105$ $\pm 0.00062$

Compression Set:

$$
.06860
$$

.06982

.06902

.06944

.06854

.06938

.06859

.06886

.06846

.06888

.06870

.06886

.06864

.06924

.06870

.06806

.06854

.07036

.06894

.06886

.06860

0.06893

$\pm 0.00049$

11.5

Odd No. Values Only

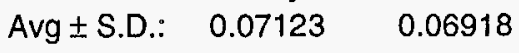

Compression Set: $\pm 0.00077 \quad \pm 0.00058$

Even No. Values Only

Avg \pm S.D.: $\quad 0.07088$ $\pm 0.00038$

10.5

Compression Set
0.06867

$\pm 0.00016$

12.0
$16.955 \times 0.139$ Precision 19422

Bing Site Initial Thick. Aged Thick

$\begin{array}{cccc}\text { Bing } & \text { Site } & \text { Initial Thick. } & \text { Aged Thick. } \\ 1 & 0.14172 & 0.13664 \\ 2 & 0.13966 & 0.13594\end{array}$

$0.14124 \quad 0.13616$

$0.14072 \quad 0.13590$

$0.14058 \quad 0.13582$

$0.14084 \quad 0.13604$

$0.14084 \quad 0.13694$

$0.14046 \quad 0.13634$

2

$0.14216 \quad 0.13726$

$0.14268 \quad 0.13764$

$0.14278 \quad 0.13794$

$0.14318 \quad 0.13870$

$0.14116 \quad 0.13692$

$0.14230 \quad 0.13876$

$0.14186 \quad 0.13772$

$0.14246 \quad 0.13888$

3

$0.14118 \quad 0.13626$

$0.14034 \quad 0.13624$

$0.14050 \quad 0.13728$

$0.14006 \quad 0.13560$

$0.14028 \quad 0.13558$

$0.14076 \quad 0.13598$

$0.13924 \quad 0.13556$

Avg \pm S.D.

0.14120 $\pm 0.00103$

Compression Set:

Odd No. Values Only

Avg \pm S.D.: $\quad 0.14113$ $\pm 0.00094$

Compression Set:

Even No. Values Only

Avg \pm S.D.: $\quad 0.14127$ $\pm 0.00116$

Compression Set: $\underline{0.13646}$

0.13677

$\pm 0.00104$

12.0

0.13667

$\pm 0.00081$

12.0

$16.955 \times 0.139$ Precision 19895

Bing Site Initial Thick. Aged Thick

$\begin{array}{llll}1 & 1 & 0.14224 & 0.13176\end{array}$

$\begin{array}{lll}2 & 0.14012 & 0.13332\end{array}$

$\begin{array}{lll}3 & 0.14086 & 0.13429\end{array}$

$\begin{array}{lll}4 & 0.13872 & 0.12884\end{array}$

$5 \quad 0.14172$

$\begin{array}{lll}6 & 0.14048 & 0.12978\end{array}$

$\begin{array}{lll}7 & 0.14054 & 0.13112\end{array}$

0.12988

$\begin{array}{llll}2 & 1 & 0.14236 & 0.13672\end{array}$

$\begin{array}{lll}2 & 0.13948 & 0.13830\end{array}$

$3 \quad 0.14126 \quad 0.13490$

$\begin{array}{lll}4 & 0.13988 & 0.13368\end{array}$

$\begin{array}{lll}5 & 0.14120 & 0.13510\end{array}$

$\begin{array}{lll}6 & 0.14126 & 0.13466\end{array}$

$\begin{array}{lll}7 & 0.14010 & 0.13240\end{array}$

$\begin{array}{lll}8 & 0.13958 & 0.13254\end{array}$

$\begin{array}{llll}3 & 1 & 0.14010 & 0.13189\end{array}$

$\begin{array}{lll}2 & 0.13866 & 0.13268\end{array}$

$\begin{array}{lll}3 & 0.13886 & 0.13312\end{array}$

$\begin{array}{lll}4 & 0.13976 & 0.13400\end{array}$

$\begin{array}{lll}5 & 0.14078 & 0.13340\end{array}$

$\begin{array}{lll}6 & 0.14040 & 0.13612\end{array}$

$\begin{array}{lll}7 & 0.14156 & 0.13402\end{array}$

$8 \quad \underline{0.14086} \quad \underline{0.13448}$

Avg \pm S.D.: $\quad 0.14048 \quad 0.13327$ $\pm 0.00101 \quad \pm 0.00222$

Compression Set:

19.8

Odd No. Values Only

Avg \pm S.D.: $\quad 0.14097 \quad 0.13336$

Compression Set: $\pm 0.00099 \quad \pm 0.00170$

Even No. Values Only

Avg \pm S.D.: $\quad 0.14000 \quad 0.13319$

0.13687

$\pm 0.00125$

11.8 $\pm 0.00081$

$\pm 0.00272$

Compression Set:

18.9 
Table G-13. Compression Set Data for Test Slabs.

\section{Parker 316104}

$\begin{array}{ccc}\frac{\text { Site }}{1} & \frac{\text { Initial }}{.3190} & \frac{\text { Aged }}{.3093} \\ 2 & .3199 & .3102 \\ 3 & .3199 & .3115 \\ 4 & \frac{.3196}{.3103} & \underline{.3103} \\ \text { Avg: } & .3196 & .311 .0\end{array}$

\section{RD 14810}

$\begin{array}{ccc}\frac{\text { Site }}{1} & \frac{\text { Initial }}{.3936} & \frac{\text { Aged }}{.3872} \\ 2 & .3930 & .3870 \\ 3 & .3934 & .3870 \\ 4 & .3933 & \underline{.3871} \\ \text { Avg: } & .3933 & .3871\end{array}$

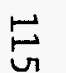

\section{Parker 316710}

$\begin{array}{ccc}\frac{\text { Site }}{1} & \frac{\text { Initial }}{.3164} & \frac{\text { Aged }}{.3085} \\ 2 & .3170 & .3087 \\ 3 & .3173 & .3089 \\ 4 & \underline{.3165} & \underline{.3088} \\ \text { Avg: } & .3168 & .3087 \\ \text { Compression Set: } & 9.9\end{array}$

\section{RD 15107}

\begin{tabular}{ccc} 
Site & Initial & Aged \\
\hline 1 & .3305 & .3180 \\
2 & .3301 & .3204 \\
3 & .3298 & .3185 \\
4 & $\underline{.3326}$ & $\underline{.3183}$ \\
Avg: & .3308 & .3188 \\
Compression Set: & 12.6
\end{tabular}

\section{Precision 19052A}

$\begin{array}{ccc}\text { Site } & \text { Initial } & \text { Aged } \\ 1 & .3190 & .2980 \\ 2 & .3196 & .3004 \\ 3 & .3194 & .2996 \\ 4 & \frac{.3196}{.3194} & \underline{.2992} \\ \text { Avg: } & .2993 \\ \text { Compression Set: } & 24.0\end{array}$

\section{Precision 19895A}

Site Initial Aged

$\begin{array}{lll}1 & .4064 & .3792\end{array}$

$\begin{array}{lll}1 & .4071 & .3785\end{array}$

$\begin{array}{lll}3 & .4050 & .3793\end{array}$

$4 \quad .4052 \quad \underline{3790}$

Avg: $\quad .4059 \quad .3790$

Compression Set: $\quad 22.8$

\section{Parker 317403}

\begin{tabular}{|c|c|c|}
\hline Site & Initial & Aged \\
\hline 1 & .3178 & .3090 \\
\hline 2 & .3174 & .3095 \\
\hline 3 & .3181 & .3094 \\
\hline 4 & 3180 & .3092 \\
\hline Avg: & .3178 & 3093 \\
\hline
\end{tabular}

\section{RD 15107 (70\% cure)}

Site Initial Aged

$\begin{array}{lll}1 & .3354 & .3272\end{array}$

$\begin{array}{lll}2 & .3363 & .3275\end{array}$

$\begin{array}{lll}3 & .3357 & .3280\end{array}$

$4 \quad \underline{3358} \quad \underline{3273}$

Avg: $\quad .3358 \quad .3275$

Compression Set: 10.8

\section{Parker 317851}

$\begin{array}{ccc}\frac{\text { Site }}{1} & \frac{\text { Initial }}{.3110} & \text { Aged } \\ 2 & .3110 & .2976 \\ 3 & .3103 & .2990 \\ 4 & .3093 & .2984 \\ \text { Avg: } & .3104 & .2985 \\ \text { Compression Set: } & 15.9\end{array}$

\section{RD 15107 (45\% cure)}

Site Initial Aged

$\begin{array}{lll}1 & .3539 & .3401\end{array}$

$\begin{array}{lll}2 & .3548 & .3409\end{array}$

$\begin{array}{lll}3 & .3527 & .3417\end{array}$

$4 \quad \underline{3504 \quad \underline{3415}}$

Avg: $\quad .3530 \quad .3411$

Compression Set: 13.5

\section{Parker 318466}

$\begin{array}{ccc}\text { Site } & \frac{\text { Initial }}{1} & \underline{\text { Aged }} \\ 2 & .3100 & .2988 \\ 3 & .3092 & .2945 \\ 4 & .3099 & .2936 \\ \text { Avg: } & \underline{.3100} & \underline{.2962} \\ \text { Compression Set: } & .2958 \\ \text { Com } & 18.9\end{array}$


Appendix H: Tensile Strength and Elongation Test Data

Contents:

Table H-1. Tensile Data vs. Fixture Parameters and Test Speed

Table H-2. Tensile Strength and Elongation Data on Butyl Rubber O-Rings

Table H-3. Tensile Strength of RD Rubber O-Rings, Cure Study (detailed test data)

Table H-4. Tensile Elongation of RD Rubber O-Rings, Cure Study (detailed test data)

Table H-5. Tensile Strength and Elongation of Other RD Rubber O-Rings (detailed test data)

Table H-6. Tensile Strength of Parker O-Rings (detailed test data)

Table H-7. Tensile Elongation of Parker O-Rings (detailed test data)

Table H-8. Tensile Strength of Precision O-Rings (detailed test data)

Table H-9. Tensile Elongation of Precision O-Rings (detailed test data)

Table H-10. Tensile Strength of Test Slabs (detailed test data)

Table H-11. Tensile Elongation of Test Slabs (detailed test data) 
Table H-1. Tensile Data vs. Fixture Parameters and Test Speed (ten tests/value for all but loop study which used six tests/value)

\begin{tabular}{|c|c|c|c|c|c|c|c|c|}
\hline Fixture Type & $\begin{array}{c}\text { Test } \\
\text { Speed }\end{array}$ & Lubed? & $\begin{array}{l}\text { No of } \\
\text { Loops }\end{array}$ & $\begin{array}{l}\text { Maximum } \\
\text { load }\end{array}$ & $\begin{array}{c}\text { Tensile } \\
\text { Elongation }\end{array}$ & \multicolumn{3}{|c|}{ Tensile Modulus (psi) } \\
\hline \multirow{3}{*}{$\begin{array}{l}\text { Non-rotating, grooved } \\
\text { split-spools* }\end{array}$} & (in./min.) & & & (pounds) & (percent) & $100 \%$ elong & $200 \%$ elong. & $300 \%$ elong. \\
\hline & 10 & yes & 1 & $75 \pm 6$ & $530 \pm 44$ & & & \\
\hline & 10 & no & 1 & $70 \pm 4$ & $486 \pm 36$ & & & \\
\hline \multirow{5}{*}{ Non-rotating rod* } & 20 & yes & 1 & $75 \pm 3$ & $525 \pm 25$ & & & \\
\hline & 20 & no & 1 & $74 \pm 3$ & $516 \pm 31$ & & & \\
\hline & 10 & yes & 1 & $76 \pm 6$ & $523 \pm 56$ & & & \\
\hline & 10 & no & 1 & $79 \pm 2$ & $545 \pm 20$ & & & \\
\hline & 20 & yes & 1 & $72 \pm 6$ & $504 \pm 50$ & & & \\
\hline \multirow{3}{*}{ Rotating rod* } & 20 & no & 1 & $73 \pm 7$ & $503 \pm 50$ & & & \\
\hline & 10 & yes & 1 & $74 \pm 3$ & $516 \pm 29$ & & & \\
\hline & 10 & no & 1 & $74 \pm 2$ & $519 \pm 20$ & & & \\
\hline \multirow{5}{*}{ Rotating rod* } & 20 & yes & 1 & $72 \pm 3$ & $501 \pm 4$ & & & \\
\hline & 20 & no & 1 & $77 \pm 1$ & $531 \pm 19$ & & & \\
\hline & 20 & yes & 1 & no break & no break & $810 \pm 20$ & $1850 \pm 590$ & NA \\
\hline & 20 & yes & 2 & $151 \pm 15$ & $392 \pm 49$ & $870 \pm 30$ & $2230 \pm 30$ & $3860 \pm 70$ \\
\hline & 20 & yes & 3 & $234 \pm 14$ & $424 \pm 49$ & $810 \pm 60$ & $2090 \pm 130$ & $3680 \pm 170$ \\
\hline
\end{tabular}

* All measurements carried out on

**All measurements carried out on Parker Buna-S O-rings, 7.484 x 0.139 inches. 
Table H-2. Tensile Strength and Elongation Data on Butyl Rubber O-Rings

\begin{tabular}{|c|c|c|c|c|c|c|c|c|c|c|}
\hline & Ring size & $\begin{array}{c}\text { Rubber } \\
\text { Batch }\end{array}$ & Rings & Loops & \multicolumn{3}{|c|}{$\begin{array}{l}\max \text { stress(psi) } \\
\text { aqed aged }\end{array}$} & \multicolumn{3}{|c|}{ percent elongation } \\
\hline Parker & $0.116 \times 0.038$ & 318466 & $8 / 8$ & 1 & $1891 \pm 309$ & $1823 \pm 164$ & -4 & $278 \pm 41$ & $264 \pm 25$ & -5 \\
\hline Parker & $0.301 \times 0.054$ & 316104 & $5 / 5$ & 1 & $1959 \pm 101$ & $1964 \pm 177$ & 0 & $259 \pm 12$ & $261 \pm 11$ & 1 \\
\hline Parker & & 316710 & $8 / 8$ & 1 & $2015 \pm 91$ & $2032 \pm 74$ & 1 & $272 \pm 14$ & $271 \pm 10$ & 0 \\
\hline Parker & $1.364 \times 0.070$ & 316104 & $5 / 5$ & 1 & $1591 \pm 123$ & $1573 \pm 38$ & -1 & $209 \pm 12$ & $210 \pm 4$ & 0 \\
\hline Parker & & 317403 & $8 / 8$ & 1 & $1790 \pm 207$ & $1708 \pm 284$ & -5 & $281 \pm 26$ & $269 \pm 45$ & -4 \\
\hline Parker & $7.688 \times 0.070$ & 316104 & $5 / 5$ & 3 & $1447 \pm 78$ & $1561 \pm 94$ & 8 & $178 \pm 9$ & $188 \pm 10$ & 6 \\
\hline Parker & & 317851 & $8 / 8$ & 3 & $1469 \pm 391$ & $1671 \pm 271$ & 14 & $362 \pm 85$ & $341 \pm 52$ & -6 \\
\hline Parker & $16.339 \times 0.103$ & 316104 & $8 / 8$ & 3 & $1309 \pm 53$ & $1430 \pm 61$ & 9 & $168 \pm 5$ & $177 \pm 6$ & 5 \\
\hline Parker & & 316710 & $8 / 8$ & 3 & $1294 \pm 257$ & $1430 \pm 148$ & 11 & $188 \pm 31$ & $203 \pm 16$ & 8 \\
\hline RD & $0.301 \times 0.054$ & 15107 & $8 / 8$ & 1 & $2236 \pm 406$ & $2423 \pm 122$ & 8 & $308 \pm 46$ & $303 \pm 13$ & -2 \\
\hline RD & $0.551 \times 0.070$ & 14810 & $8 / 8$ & 1 & $2524 \pm 71$ & $2414 \pm 304$ & -4 & $402 \pm 22$ & $344 \pm 44$ & -14 \\
\hline RD & & 15107 & $8 / 8$ & 1 & $1965 \pm 455$ & $1864 \pm 232$ & -5 & $293 \pm 56$ & $261 \pm 28$ & -11 \\
\hline $\mathrm{RD}$ & $1.114 \times 0.070$ & 14810 & $8 / 8$ & 1 & $2142 \pm 209$ & $2063 \pm 294$ & -4 & $314 \pm 32$ & $293 \pm 43$ & -7 \\
\hline $\mathrm{RD}$ & & 15107 & $8 / 8$ & 1 & $2039 \pm 236$ & $2153 \pm 107$ & 6 & $296 \pm 49$ & $300 \pm 23$ & 1 \\
\hline $\mathrm{RD}$ & $7.185 \times 0.103$ & 14810 & $8 / 8$ & 3 & $1734 \pm 454$ & $1782 \pm 431$ & 3 & $231 \pm 53$ & $220 \pm 39$ & -5 \\
\hline $\mathrm{RD}$ & & 15107 & $8 / 8$ & 3 & $1579 \pm 302$ & $1255 \pm 384$ & -21 & $215 \pm 30$ & $171 \pm 39$ & -20 \\
\hline $\mathrm{RD}$ & $11.196 \times 0.103$ & 14936 & $8 / 8$ & 3 & $1334 \pm 409$ & $1458 \pm 379$ & 9 & $180 \pm 38$ & $184 \pm 33$ & -2 \\
\hline $\mathrm{RD}$ & & 15107 & $8 / 8$ & 3 & $1436 \pm 355$ & $1396 \pm 451$ & -3 & $175 \pm 29$ & $152 \pm 30$ & -13 \\
\hline Precision & $0.301 \times 0.054$ & 19052 & $7 \pi$ & 1 & $2218 \pm 378$ & $2162 \pm 229$ & -3 & $380 \pm 63$ & $300 \pm 31$ & -21 \\
\hline Precision & & 19895 & $8 / 8$ & 1 & $2233 \pm 167$ & $2138 \pm 313$ & -4 & $369 \pm 29$ & $289 \pm 37$ & -22 \\
\hline Precision & $1.364 \times 0.070$ & 17405 & $6 / 8$ & 1 & $2078 \pm 86$ & $1971 \pm 181$ & -5 & $313 \pm 15$ & $261 \pm 26$ & -17 \\
\hline Precision & & 19895 & $8 / 8$ & 1 & $1935 \pm 112$ & $1937 \pm 210$ & 0 & $275 \pm 18$ & $247 \pm 39$ & -10 \\
\hline Precision & $7.739 \times 0.070$ & 19052 & $8 / 8$ & 3 & $1578 \pm 342$ & $1653 \pm 225$ & 5 & $192 \pm 64$ & $152 \pm 24$ & -21 \\
\hline Precision & & 19921 & $6 / 6$ & 3 & $1496 \pm 504$ & $1616 \pm 199$ & 8 & $226 \pm 23$ & $181 \pm 17$ & -20 \\
\hline Precision & $16.955 \times 0.139$ & 19422 & $8 / 8$ & 3 & $1129 \pm 250$ & $832 \pm 517$ & -26 & $188 \pm 35$ & $114 \pm 63$ & -39 \\
\hline Precision & & 19895 & $8 / 8$ & 3 & $1315 \pm 190$ & $1379 \pm 126$ & 5 & $223 \pm 23$ & $179 \pm 12$ & -20 \\
\hline
\end{tabular}


Table H-3. Tensile Strength Data for RD Rubber O-Rings, Batch 15107 Cure Study

\begin{tabular}{|c|c|c|c|c|c|c|c|c|c|c|c|}
\hline \multicolumn{3}{|c|}{$0.301 \times 0.054$} & \multirow{2}{*}{$\begin{array}{l}\text { RD } 15107 \\
\text { Aged }\end{array}$} & \multicolumn{2}{|c|}{$\begin{array}{l}0.301 \times 0.054 \\
(4 \mathrm{~min} . \text { cure })\end{array}$} & \multicolumn{2}{|r|}{ RD 15107} & \multicolumn{2}{|c|}{$\begin{array}{l}0.301 \times 0.054 \\
(3 \mathrm{~min} . \text { cure })\end{array}$} & \multicolumn{2}{|r|}{ RD 15107} \\
\hline Bing & Initial & Ring & & Ring & Initial & Ring & Aged & Ring & Initial & Ring & Aged \\
\hline 1 & $\overline{1412}$ & 9 & 2381 & 1 & 2270 & 9 & 2457 & 1 & 2510 & 9 & 2524 \\
\hline 2 & 1816 & 10 & 2395 & 2 & 2443 & 10 & 2333 & 2 & N/A & 10 & 2605 \\
\hline 3 & 2418 & 11 & 2482 & 3 & 2397 & 11 & 2342 & 3 & 2553 & 11 & 2290 \\
\hline 4 & 2553 & 12 & 2594 & 4 & 2394 & 12 & 2056 & 4 & 2446 & 12 & 2752 \\
\hline 5 & 2353 & 13 & 2199 & 5 & 2435 & 13 & 2459 & 5 & 2521 & 13 & 2643 \\
\hline 6 & 2429 & 14 & 2553 & 6 & 2425 & 14 & 2416 & 6 & 2366 & 14 & 2539 \\
\hline 7 & 2368 & 15 & 2396 & 7 & 2384 & 15 & 2317 & 7 & 2443 & 15 & 2614 \\
\hline 8 & $\underline{2543}$ & 16 & 2384 & 8 & $\underline{2244}$ & 16 & 2575 & 8 & $\underline{2163}$ & 16 & $\underline{2481}$ \\
\hline Avg: & $2237 \pm 406$ & & $2423 \pm 122$ & Avg: & $2374 \pm 75$ & & $2369 \pm 153$ & Avg: & $2429 \pm 133$ & & $2556 \pm 136$ \\
\hline \multicolumn{3}{|c|}{ Strength Change: } & $8 \%$ & \multicolumn{2}{|c|}{ Strength Change: } & & $0 \%$ & \multicolumn{2}{|c|}{ Strength Change: } & & $5 \%$ \\
\hline \multicolumn{2}{|c|}{$1.114 \times 0.070$} & & RD 15107 & \multicolumn{2}{|c|}{$\begin{array}{l}1.114 \times 0.070 \\
(4 \mathrm{~min} . \text { cure })\end{array}$} & & RD 15107 & \multicolumn{2}{|c|}{$\begin{array}{l}1.114 \times 0.070 \\
(3 \mathrm{~min} . \text { cure })\end{array}$} & & RD 15107 \\
\hline Bing & Initial & Ring & Aged & Ring & Initial & Ring & Aged & Ring & Initial & Ring & Aged \\
\hline 1 & 2247 & 9 & 2071 & 1 & 2307 & 9 & 2134 & 1 & 2380 & 9 & 1891 \\
\hline 2 & 1795 & 10 & 2213 & 2 & 1904 & 10 & 2530 & 2 & 2206 & 10 & 2272 \\
\hline 3 & 2044 & 11 & 1939 & 3 & 2151 & 11 & 2405 & 3 & 2281 & 11 & 2173 \\
\hline 4 & 2182 & 12 & 2179 & 4 & 2234 & 12 & 2277 & 4 & 2269 & 12 & 2154 \\
\hline 5 & 2223 & 13 & 2206 & 5 & 1907 & 13 & 2301 & 5 & 2364 & 13 & 2007 \\
\hline 6 & 2191 & 14 & 2121 & 6 & 2248 & 14 & 217 & 6 & 2321 & 14 & 2337 \\
\hline 7 & 2050 & 15 & 2280 & 7 & 2426 & 15 & 2408 & 7 & 1983 & 15 & 1880 \\
\hline 8 & 1582 & 16 & $\underline{2217}$ & 8 & 1773 & 16 & $\underline{2518}$ & 8 & 1608 & 16 & 1998 \\
\hline Avg: & $2039+236$ & & $2153 \pm 107$ & Avg: & $2119 \pm 230$ & & $2099 \pm 771$ & Avg: & $2177 \pm 261$ & & $2089 \pm 171$ \\
\hline \multicolumn{3}{|c|}{ Strength Change: } & $6 \%$ & \multicolumn{2}{|c|}{ Strength Change: } & & $-1 \%$ & \multicolumn{2}{|c|}{ Strength Change: } & & $-4 \%$ \\
\hline \multicolumn{2}{|c|}{$7.185 \times 0.103$} & & RD 15107 & \multicolumn{2}{|c|}{$\begin{array}{l}7.185 \times 0.103 \\
\text { (4 min. cure) }\end{array}$} & & RD 15107 & \multicolumn{2}{|c|}{$\begin{array}{l}7.185 \times 0.103 \\
\text { ( } 3 \mathrm{~min} . \text { cure) }\end{array}$} & & RD 15107 \\
\hline Ring & Initial & Ring & Aged & Ring & Initial & Ring & Aged & Ring & Initial & Ring & Aged \\
\hline 1 & 1660 & 9 & $\overline{1124}$ & 1 & 1034 & 9 & $\overline{1564}$ & 1 & 1502 & 9 & 1806 \\
\hline 2 & 1125 & 10 & 1327 & 2 & 1658 & 10 & 1749 & 2 & 1850 & 10 & 1467 \\
\hline 3 & 1243 & 11 & 1362 & 3 & 999 & 11 & 1854 & 3 & 2174 & 11 & 1778 \\
\hline 4 & 1704 & 12 & 536 & 4 & 1025 & 12 & 1709 & 4 & 2026 & 12 & 1888 \\
\hline 5 & 1607 & 13 & 1246 & 5 & 1016 & 13 & 1731 & 5 & 1886 & 13 & 1557 \\
\hline 6 & 1515 & 14 & 1878 & 6 & 887 & 14 & 1073 & 6 & 1690 & 14 & 1907 \\
\hline 7 & 2114 & 15 & 1071 & 7 & 1746 & 15 & 1607 & 7 & 1694 & 15 & 1781 \\
\hline 8 & 1662 & 16 & 1498 & 8 & $\underline{995}$ & 16 & $\underline{1845}$ & 8 & $\underline{2211}$ & 16 & 1826 \\
\hline Avg: & $1579 \pm 302$ & & $1255 \pm 384$ & Avg: & $1170 \pm 332$ & & $1642 \pm 251$ & Avg: & $1879 \pm 248$ & & $1751 \pm 157$ \\
\hline \multicolumn{3}{|c|}{ Strength Change: } & $-20 \%$ & Streng & th Change: & & $40 \%$ & Strens & th Change: & & $-7 \%$ \\
\hline 11.19 & $x 0.103$ & & RD 15107 & $\begin{array}{l}11.19 \\
(4 \mathrm{mir}\end{array}$ & $\begin{array}{l}x 0.103 \\
\text { cure) }\end{array}$ & & RD 15107 & $\begin{array}{l}11.19 \\
(3 \mathrm{mil}\end{array}$ & $\begin{array}{l}\times 0.103 \\
\text { cure) }\end{array}$ & & RD 15107 \\
\hline Ring & Initial & Ring & Aged & Ring & Initial & Ring & Aged & Bing & Initial & Ring & Aged \\
\hline 1 & 1565 & 9 & 1640 & 1 & 1153 & 9 & 1708 & 1 & 1776 & 9 & 1956 \\
\hline 2 & 1499 & 10 & 1546 & 2 & 1525 & 10 & 1841 & 2 & 1473 & 10 & 2143 \\
\hline 3 & 1920 & 11 & 1083 & 3 & 1356 & 11 & 1827 & 3 & 2066 & 11 & 1622 \\
\hline 4 & 1313 & 12 & 1557 & 4 & 1717 & 12 & 1936 & 4 & 1528 & 12 & 1436 \\
\hline 5 & 1096 & 13 & 967 & 5 & 1763 & 13 & 1454 & 5 & 1870 & 13 & 2105 \\
\hline 6 & 833 & 14 & 995 & 6 & 921 & 14 & 2216 & 6 & 1680 & 14 & 1849 \\
\hline 7 & 1798 & 15 & 1101 & 7 & 1472 & 15 & 1975 & 7 & 1919 & 15 & 2050 \\
\hline 8 & 1460 & 16 & $\underline{2282}$ & 8 & 1131 & 16 & 1993 & 8 & $165 \underline{3}$ & 16 & $\underline{2056}$ \\
\hline Avg: & $1 4 \longdiv { 3 6 \pm 3 5 5 }$ & & $1396 \pm 451$ & Avg: & $1380 \pm 296$ & & $1869 \pm 224$ & Avg: & $1746 \pm 201$ & & $1902 \pm 252$ \\
\hline Streng & th Change: & & $-3 \%$ & Strens & th Change: & & $35 \%$ & Stren & th Change: & & $9 \%$ \\
\hline
\end{tabular}


Table H-4. Tensile Elongation Data for RD Rubber O-Rings, Batch 15107 Cure Study

\begin{tabular}{|c|c|c|c|c|c|c|c|c|c|c|c|c|}
\hline \multicolumn{3}{|c|}{$0.301 \times 0.054$} & \multirow{2}{*}{$\begin{array}{l}\text { RD } 15107 \\
\text { Aged }\end{array}$} & \multicolumn{3}{|c|}{$\begin{array}{l}0.301 \times 0.054 \\
(4 \mathrm{~min} . \text { cure })\end{array}$} & \multirow{2}{*}{$\begin{array}{l}\text { RD } 15107 \\
\text { Aged }\end{array}$} & \multicolumn{2}{|c|}{$\begin{array}{l}0.301 \times 0.054 \\
(3 \mathrm{~min} . \text { cure })\end{array}$} & \multicolumn{3}{|c|}{ RD 15107} \\
\hline Ring & Initial & Ring & & Ring & Initial & Ring & & Ring & Initial & Bing & Aged & \\
\hline 1 & 218 & 9 & 307 & 1 & 320 & 9 & 289 & 1 & 354 & 9 & 280 & \\
\hline 2 & 255 & 10 & 307 & 2 & 348 & 10 & 279 & 2 & N/A & 10 & 283 & $\because$ \\
\hline 3 & 323 & 11 & 305 & 3 & 333 & 11 & 288 & 3 & 344 & 11 & 266 & \\
\hline 4 & 344 & 12 & 319 & 4 & 336 & 12 & 251 & 4 & 338 & 12 & 296 & \\
\hline 5 & 326 & 13 & 280 & 5 & 337 & 13 & 295 & 5 & 347 & 13 & 281 & \\
\hline 6 & 329 & 14 & 316 & 6 & 348 & 14 & 287 & 6 & 321 & 14 & 271 & \\
\hline 7 & 321 & 15 & 301 & 7 & 343 & 15 & 279 & 7 & 362 & 15 & 272 & \\
\hline 8 & $\underline{346}$ & 16 & 289 & 8 & $\underline{303}$ & 16 & 302 & 8 & 303 & 16 & $\underline{258}$ & \\
\hline Avg: & $308 \pm 46$ & & $303 \pm 13$ & Avg: & $334 \pm 15$ & & $284 \pm 15$ & Avg: & $338 \pm 20$ & & $276 \pm 12$ & \\
\hline \multicolumn{3}{|c|}{ Elongation Change: } & $-2 \%$ & \multicolumn{3}{|c|}{ Elongation Change: } & $-15 \%$ & \multicolumn{3}{|c|}{ Elongation Change: } & $-18 \%$ & \\
\hline \multicolumn{3}{|c|}{$1.114 \times 0.070$} & RD 15107 & \multicolumn{3}{|c|}{$\begin{array}{l}1.114 \times 0.070 \\
(4 \mathrm{~min} . \text { cure) }\end{array}$} & RD 15107 & \multicolumn{3}{|c|}{$\begin{array}{l}1.114 \times 0.070 \\
(3 \mathrm{~min} . \text { cure })\end{array}$} & RD 15107 & \\
\hline Ring & Initial & Ring & Aged & Bing & Initial & Bing & Aged & Ring & Initial & Bing & Aged & \\
\hline 1 & 336 & 9 & 293 & 1 & 300 & 9 & 220 & 1 & 351 & 9 & 191 & \\
\hline 2 & 273 & 10 & 318 & 2 & 248 & 10 & 285 & 2 & 322 & 10 & 223 & \\
\hline 3 & 268 & 11 & 271 & 3 & 309 & 11 & 269 & 3 & 332 & 11 & 255 & \\
\hline 4 & 326 & 12 & 309 & 4 & 328 & 12 & 259 & 4 & 328 & 12 & 273 & \\
\hline 5 & 354 & 13 & 304 & 5 & 277 & 13 & 233 & 5 & 353 & 13 & 244 & \\
\hline 6 & 333 & 14 & 263 & 6 & 314 & 14 & 257 & 6 & 347 & 14 & 229 & \\
\hline 7 & 263 & 15 & 326 & 7 & 316 & 15 & 246 & 7 & 294 & 15 & 178 & \\
\hline 8 & $\underline{213}$ & 16 & 320 & 8 & 232 & 16 & $\underline{292}$ & 8 & $\underline{224}$ & 16 & 191 & \\
\hline Avg: & $296 \pm 49$ & & $301 \pm 23$ & Avg: & $291 \pm 35$ & & $258 \pm 25$ & Avg: & $319 \pm 43$ & & $223 \pm 34$ & " \\
\hline \multicolumn{3}{|c|}{ Elongation Change: } & $2 \%$ & \multicolumn{3}{|c|}{ Elongation Change: } & $-11 \%$ & \multicolumn{3}{|c|}{ Elongation Change: } & $-30 \%$ & \\
\hline \multicolumn{3}{|c|}{$7.185 \times 0.103$} & RD 15107 & \multicolumn{3}{|c|}{$\begin{array}{l}7.185 \times 0.103 \\
(4 \mathrm{~min} . \text { cure })\end{array}$} & RD 15107 & \multicolumn{3}{|c|}{$\begin{array}{l}7.185 \times 0.103 \\
(3 \mathrm{~min} . \text { cure) }\end{array}$} & RD 15107 & \\
\hline Ring & Initial & Ring & Aged & Ring & Initial & Ring & Aged & Ring & Initial & Ring & Aged & \\
\hline 1 & 220 & 9 & 162 & 1 & 140 & 9 & 148 & 1 & $\overline{183}$ & 9 & 156 & \\
\hline 2 & 172 & 10 & 179 & 2 & 192 & 10 & 159 & 2 & 210 & 10 & 140 & \\
\hline 3 & 186 & 11 & 182 & 3 & 140 & 11 & 170 & 3 & 238 & 11 & 159 & \\
\hline 4 & 228 & 12 & 97 & 4 & 140 & 12 & 164 & 4 & 235 & 12 & 162 & \\
\hline 5 & 215 & 13 & 170 & 5 & 139 & 13 & 166 & 5 & 217 & 13 & 142 & \\
\hline 6 & 205 & 14 & 234 & 6 & 131 & 14 & 133 & 6 & 211 & 14 & 169 & \\
\hline 7 & 271 & 15 & 148 & 7 & 198 & 15 & 157 & 7 & 201 & 15 & 154 & \\
\hline 8 & $\underline{224}$ & 16 & 192 & 8 & 141 & 16 & 172 & 8 & $\underline{251}$ & 16 & $\underline{157}$ & \\
\hline Avg: & $215 \pm 30$ & & $171 \pm 39$ & Avg: & $153+26$ & & $159 \pm 13$ & Avg: & $218+22$ & & $155 \pm 10$ & \\
\hline \multicolumn{3}{|c|}{ Elongation Change: } & $-21 \%$ & Elong & ion Chang & & $4 \%$ & Elong & ion Chan & & $-29 \%$ & \\
\hline 11.196 & 0.103 & & RD 15107 & $\begin{array}{l}11.19 \\
(4 \mathrm{mir}\end{array}$ & $\begin{array}{l}\text { co.103 } \\
\text { cure) }\end{array}$ & & RD 15107 & $\begin{array}{l}11.19 \\
(3 \mathrm{mi}\end{array}$ & $\begin{array}{l}0.103 \\
\text { cure) }\end{array}$ & & RD 15107 & \\
\hline Ring & $\underline{\text { Initial }}$ & Ring & Aged & Ring & Initial & $\underline{\text { Ring }}$ & Aged & Ring & Initial & Ring & Aged & \\
\hline 1 & 179 & 9 & 165 & 1 & 169 & 9 & 184 & 1 & 228 & 9 & 190 & \\
\hline 2 & 178 & 10 & 159 & 2 & 204 & 10 & 195 & 2 & 199 & 10 & 218 & \\
\hline 3 & 211 & 11 & 131 & 3 & 184 & 11 & 186 & 3 & 266 & 11 & 159 & - \\
\hline 4 & 166 & 12 & 163 & 4 & 226 & 12 & 201 & 4 & 201 & 12 & 138 & \\
\hline 5 & 148 & 13 & 121 & 5 & 226 & 13 & 158 & 5 & 244 & 13 & 199 & \\
\hline 6 & 126 & 14 & 125 & 6 & 149 & 14 & 229 & 6 & 224 & 14 & 175 & . \\
\hline 7 & 209 & 15 & 136 & 7 & 201 & 15 & 205 & 7 & 246 & 15 & 195 & \\
\hline 8 & 180 & 16 & 212 & 8 & $\underline{161}$ & 16 & $\underline{195}$ & 8 & $\underline{216}$ & 16 & 194 & \\
\hline Avg: & $175 \pm 29$ & & $152 \pm 30$ & Avg: & $190 \pm 29$ & & $194 \pm 20$ & Avg: & $228 \pm 23$ & & $184 \pm 25$ & \\
\hline Elonga & ion Chan & & $-13 \%$ & Elong & tion Chang & & $2 \%$ & Elong & tion Chan & & $-20 \%$ & \\
\hline
\end{tabular}


Table H-5. Tensile Strength and Elongation Data for RD Rubber O-Rings, Various Batches and Sizes

\begin{tabular}{|c|c|c|c|c|c|c|c|c|c|c|c|}
\hline \multicolumn{2}{|c|}{$0.551 \times 0.070$} & \multicolumn{2}{|r|}{ RD 14810} & \multicolumn{2}{|c|}{$0.551 \times 0.070$} & \multicolumn{2}{|r|}{ RD 15107} & \multicolumn{2}{|c|}{$1.114 \times 0.070$} & \multicolumn{2}{|c|}{ RD 14810} \\
\hline Ring & Initial & Ring & Aged & Ring & Initial & Bing & Aged & Ring & Initial & Ring & Aged \\
\hline 1 & 2420 & 9 & 2353 & 1 & 2324 & 9 & 1541 & 1 & 2130 & 9 & 1664 \\
\hline 2 & 2482 & 10 & 2424 & 2 & 948 & 10 & 1651 & 2 & 2128 & 10 & 2414 \\
\hline 3 & 2571 & 11 & 2598 & 3 & 1928 & 11 & 2082 & 3 & 2359 & 11 & 1682 \\
\hline 4 & 2495 & 12 & 2429 & 4 & 2251 & 12 & 2039 & 4 & 2210 & 12 & 2260 \\
\hline 5 & 2465 & 13 & 2607 & 5 & 1840 & 13 & 1634 & 5 & 2267 & 13 & 2325 \\
\hline 6 & 2533 & 14 & 2603 & 6 & 2162 & 14 & 2154 & 6 & 2242 & 14 & 1934 \\
\hline 7 & 2608 & 15 & 2593 & 7 & 1920 & 15 & 1970 & 7 & 2134 & 15 & 2267 \\
\hline 8 & $\underline{2619}$ & 16 & 1704 & 8 & $\underline{2345}$ & 16 & 1843 & 8 & 1664 & 16 & 1954 \\
\hline Avg: & $2524 \pm 71$ & & $2414 \pm 304$ & Avg: & $1965 \pm 455$ & & $1864 \pm 232$ & Avg: & $2142+209$ & & $2063 \pm 294$ \\
\hline \multicolumn{3}{|c|}{ Tensile Strength Change: } & $-4 \%$ & \multicolumn{3}{|c|}{ Tensile Strength Change: } & $-5 \%$ & \multicolumn{3}{|c|}{ Tensile Strength Change: } & $-4 \%$ \\
\hline \multicolumn{2}{|c|}{$7.185 \times 0.103$} & \multicolumn{2}{|r|}{ RD 14810} & \multicolumn{4}{|c|}{$11.196 \times 0.103$} & & & & \\
\hline Ring & $\underline{\text { Initial }}$ & Ring & Aged & Ring & Initial & Ring & Aged & & & & \\
\hline 1 & 2393 & 9 & 2324 & 1 & 1408 & 9 & 1282 & & & & \\
\hline 2 & 1278 & 10 & 1656 & 2 & 1093 & 10 & 1332 & & & & \\
\hline 3 & 1.416 & 11 & 1910 & 3 & 1532 & 11 & 1221 & & & & \\
\hline 4 & 1793 & 12 & 2054 & 4 & 1548 & 12 & 1196 & & & & \\
\hline 5 & 2386 & 13 & 1962 & 5 & 586 & 13 & 1590 & & & & \\
\hline 6 & 1765 & 14 & 1615 & 6 & 1895 & 14 & 1299 & & & & \\
\hline 7 & 1224 & 15 & 868 & 7 & 1038 & 15 & 2345 & & & & \\
\hline 8 & 1620 & 16 & 1865 & 8 & 1573 & 16 & 1397 & & & & \\
\hline Avg: & $1734 \pm 454$ & & $1782 \pm 431$ & Avg: & $1334 \pm 408$ & & $1458 \pm 379$ & & & & \\
\hline \multicolumn{3}{|c|}{ Tensile Strength Change: } & $3 \%$ & Tensi & Strength $C$ & lange: & $9 \%$ & & & & \\
\hline
\end{tabular}

\begin{tabular}{|c|c|c|c|c|c|c|c|c|c|c|c|}
\hline \multicolumn{2}{|c|}{$0.551 \times 0.070$} & \multicolumn{2}{|c|}{ RD 14810} & \multicolumn{2}{|c|}{$0.551 \times 0.070$} & \multicolumn{2}{|c|}{ RD 15107} & \multicolumn{2}{|c|}{$1.114 \times 0.070$} & \multicolumn{2}{|c|}{ RD 14810} \\
\hline Ring & Initial & Ring & Aged & Ring & Initial & Ring & Aged & Ring & Initial & Ring & Aged \\
\hline 1 & 370 & 9 & 330 & 1 & 349 & 9 & 218 & 1 & 314 & 9 & 242 \\
\hline 2 & 386 & 10 & 338 & 2 & 176 & 10 & 243 & 2 & 306 & 10 & 361 \\
\hline 3 & 416 & 11 & 375 & 3 & 295 & 11 & 275 & 3 & 351 & 11 & 238 \\
\hline 4 & 388 & 12 & 343 & 4 & 342 & 12 & 273 & 4 & 327 & 12 & 311 \\
\hline 5 & 391 & 13 & 385 & 5 & 257 & 13 & 239 & 5 & 328 & 13 & 324 \\
\hline 6 & 409 & 14 & 366 & 6 & 298 & 14 & 308 & 6 & 329 & 14 & 263 \\
\hline 7 & 437 & 15 & 370 & 7 & 294 & 15 & 269 & 7 & 314 & 15 & 314 \\
\hline 8 & $\underline{416}$ & 16 & $\underline{245}$ & 8 & $\underline{334}$ & 16 & $\underline{266}$ & 8 & $\underline{242}$ & 16 & $\underline{287}$ \\
\hline Avg: & $402 \pm 22$ & & $344 \pm 44$ & Avg: & $293 \pm 56$ & & $261 \pm 28$ & Avg: & $314 \pm 32$ & & $293 \pm 43$ \\
\hline \multicolumn{3}{|c|}{ Ten. Elongation Change: } & $-14 \%$ & \multicolumn{3}{|c|}{ Ten. Elongation Change: } & $-11 \%$ & \multicolumn{3}{|c|}{ Ten. Elongation Change: } & $-7 \%$ \\
\hline \multicolumn{2}{|c|}{$7.185 \times 0.103$} & \multicolumn{2}{|c|}{ RD 14810} & \multicolumn{2}{|c|}{$11.196 \times 0.103$} & \multicolumn{2}{|c|}{ RD 14936} & & & & \\
\hline Ring & Initial & Bing & Aged & Ring & Initial & Ring & Aged & & & & \\
\hline 1 & 311 & $\overline{9}$ & 266 & 1 & 198 & $\overline{9}$ & 178 & & & & \\
\hline 2 & 180 & 10 & 208 & 2 & 168 & 10 & 175 & & & & \\
\hline 3 & 197 & 11 & 233 & 3 & 202 & 11 & 158 & & & & \\
\hline 4 & 230 & 12 & 246 & 4 & 191 & 12 & 167 & & & & \\
\hline 5 & 308 & 13 & 237 & 5 & 118 & 13 & 195 & & & & \\
\hline 6 & 231 & 14 & 206 & 6 & 246 & 14 & 166 & & & & \\
\hline 7 & 175 & 15 & 138 & 7 & 160 & 15 & 261 & & & & \\
\hline 8 & $\underline{216}$ & 16 & $\underline{229}$ & 8 & 159 & 16 & $\underline{169}$ & & & & \\
\hline Avg: & $231 \pm 53$ & & $220 \pm 39$ & Avg: & $180 \pm 38$ & & $\overline{184 \pm 33}$ & & & & \\
\hline \multicolumn{3}{|c|}{ Ten. Elongation Change: } & $-5 \%$ & \multicolumn{3}{|c|}{ Ten. Elongation Change: } & $2 \%$ & & & & \\
\hline
\end{tabular}


Table H-6. Tensile Strength Data for Parker O-Rings

\section{$0.116 \times 0.038$ Parker 318466}

\begin{tabular}{cccc} 
Ring & Initial & Ring & Aged \\
\cline { 2 - 3 } & 2220 & 9 & 1615 \\
2 & 2066 & 10 & 1753 \\
3 & 1748 & 11 & 1815 \\
4 & 1326 & 12 & 1932 \\
5 & 2034 & 13 & 1664 \\
6 & 1656 & 14 & 1734 \\
7 & 2229 & 15 & 2086 \\
8 & 1851 & 16 & 1984 \\
Avg: & $1891 \pm 309$ & & $1823 \pm 164$ \\
Strength Change: & & $-4 \%$
\end{tabular}

\section{$0.301 \times 0.054 \quad$ Parker 316104}

Ring $\frac{\text { Initial }}{1974} \quad \frac{\text { Ring }}{6} \quad \frac{\text { Aged }}{1946}$

$\begin{array}{lllll}1 & 1974 & 6 & 1946 \\ 2 & 1895 & 7 & 2049\end{array}$

$\begin{array}{llll}2 & 1895 & 7 & 2049 \\ 3 & 2085 & 8 & 1663\end{array}$

$\begin{array}{llll}4 & 2012 & 9 & 2068\end{array}$

$\stackrel{N}{N}$

$\begin{array}{llll}5 & 1827 & 10 & 2094\end{array}$

Avg: $1959 \pm 101$

Strength Change:

$1964 \pm 177$

$0 \%$

\begin{tabular}{|c|c|c|c|}
\hline \multicolumn{2}{|c|}{$7.688 \times 0.070$} & \multicolumn{2}{|c|}{ Parker 316104} \\
\hline Ring & Initial & Ring & Aged \\
\hline 1 & 1553 & 6 & 1667 \\
\hline 2 & 1335 & 7 & 1415 \\
\hline 3 & 1434 & 8 & 1542 \\
\hline 4 & 1463 & 9 & 1576 \\
\hline 5 & 1452 & 10 & 1605 \\
\hline
\end{tabular}

Avg: $\quad 1447 \pm 78$

Strength Change:

\begin{tabular}{cccc}
$0.301 \times 0.054$ & \multicolumn{2}{c}{ Parker 316710} \\
Ring & $\frac{\text { Initial }}{2}$ & Ring & Aged \\
\cline { 2 - 4 } & 2094 & 9 & 1898 \\
2 & 1921 & 10 & 2107 \\
3 & 1953 & 11 & 2064 \\
4 & 2189 & 12 & 2109 \\
5 & 2023 & 13 & 2029 \\
6 & 1996 & 14 & 2089 \\
7 & 1926 & 15 & 1984 \\
8 & 2020 & 16 & 1980 \\
Avg: & $2015 \pm 91$ & & $2033 \pm 74$ \\
Strength Change: & & $1 \%$
\end{tabular}

\section{$7.688 \times 0.070$}

Ring Initial

1 .

$2 \quad 1097$

$3 \quad 1877$

$4 \quad 1235$

$5 \quad 1939$

$6 \quad 1521$

$7 \quad 1899$

$8 \quad \underline{1190}$

Avg: $1469 \pm 391$

Strength Change:
Parker 317851

Bing Aged

$10 \quad 1706$

$11 \quad 1800$

$12 \quad 1874$

$13 \quad 1786$

$14 \quad 1922$

$15 \quad 1659$

$16 \quad \frac{1066}{1672+271}$

$14 \%$

\begin{tabular}{|c|c|c|c|}
\hline \multicolumn{2}{|c|}{$1.364 \times 0.070$} & \multicolumn{2}{|c|}{ Parker 316104} \\
\hline Bing & Initial & Ring & Aged \\
\hline 1 & 1616 & 6 & 1532 \\
\hline 2 & 1641 & 7 & 1618 \\
\hline 3 & 1629 & 8 & 1549 \\
\hline 4 & 1693 & 9 & 1559 \\
\hline 5 & 1377 & 10 & 1610 \\
\hline Avg: & $591 \pm 12$ & & $1574 \pm 38$ \\
\hline Streng & Chang & & $-1 \%$ \\
\hline
\end{tabular}

$16.339 \times 0.103$

Bing Initial

11296

$2 \quad 1358$

$3 \quad 1283$

$4 \quad 1273$

$5 \quad 1416$

$\begin{array}{ll}6 & 1258 \\ 7 & 1320\end{array}$

$7 \quad 1320$

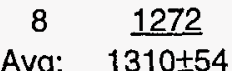

Strength Change:
Parker 316104

Bing Aged

1372

$10 \quad 1478$

$11 \quad 1390$

$12 \quad 1506$

131460

$14 \quad 1330$

$15 \quad 1433$

$16 \quad 1471$

$1430 \pm 61$

$9 \%$
$1.364 \times 0.070$

\begin{tabular}{cc} 
Ring & Initial \\
\hline 1 & 1876 \\
2 & 1499 \\
3 & 1446 \\
4 & 1779 \\
5 & 1923 \\
6 & 1865 \\
7 & 2011 \\
8 & 1924 \\
Avg: & $1790 \pm 207$ \\
Strength Change:
\end{tabular}

$16.339 \times 0.103$

$\frac{\text { Ring }}{1} \quad \frac{\text { Initial }}{1423}$

$\begin{array}{ll}1 & 1338 \\ 3 & 1583\end{array}$

$3 \quad 1583$

$\begin{array}{cc}4 & 810 \\ 5 & 1560\end{array}$

$5 \quad 1560$

$\begin{array}{ll}6 & 1237\end{array}$

$7 \quad 1068$

$\begin{array}{cc}8 & 1336 \\ \text { Avg: } & 1294 \pm 257\end{array}$

Strength Change:
Parker 317403

\begin{tabular}{cc} 
Bing & Aged \\
\hline 9 & 1430 \\
10 & 1932 \\
11 & 1636 \\
12 & 2070 \\
13 & 1947 \\
14 & 1882 \\
15 & 1425 \\
16 & 1341 \\
& $1708 \pm 284$ \\
& $-5 \%$
\end{tabular}

\section{Parker 316710}

Ring Aged

$10 \quad 1546$

$11 \quad 1482$

$12 \quad 1437$

$13 \quad 1460$

$14 \quad 1148$

$15 \quad 1516$

$16 \quad 1270$

$1430 \pm 148$

$10 \%$ 


\section{Table H-7. Tensile Elongation Data for Parker O-Rings}

\section{$0.116 \times 0.038$ Parker 318466}

$\begin{array}{cccc}\text { Ring } & \text { Initial } & \text { Ring } & \text { Aged } \\ 1 & 326 & 9 & 234 \\ 2 & 298 & 10 & 259 \\ 3 & 255 & 11 & 269 \\ 4 & 205 & 12 & 284 \\ 5 & 300 & 13 & 233 \\ 6 & 242 & 14 & 255 \\ 7 & 320 & 15 & 306 \\ 8 & 278 & 16 & \underline{274} \\ \text { Avg: } & 278 \pm 41 & & 264 \pm 25 \\ \text { Elongation Change: } & -5 \%\end{array}$

$0.301 \times 0.054 \quad$ Parker 316104

Ring Initial Ring Aged

$1 \quad 260 \quad 6 \quad 250$

$\begin{array}{llll}2 & 244 & 7 & 257\end{array}$

$\begin{array}{llll}3 & 277 & 8 & 274\end{array}$

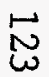

$\begin{array}{cccc}4 & 261 & 9 & 252 \\ 5 & \underline{253} & 10 & \underline{271}\end{array}$

Avg: $\quad 259 \pm 12$

$261 \pm 11$

Elongation Change:

$1 \%$

\section{$0.301 \times 0.054$}

Parker 316710

$1.364 \times 0.070$

Parker 316104

$1.364 \times 0.070$

Parker 317403

\begin{tabular}{cccc} 
Ring & $\frac{\text { Initial }}{28}$ & Ring & Aged \\
\hline 1 & 288 & 9 & 264 \\
2 & 249 & 10 & 286 \\
3 & 269 & 11 & 257 \\
4 & 285 & 12 & 281 \\
5 & 261 & 13 & 274 \\
6 & 283 & 14 & 278 \\
7 & 262 & 15 & 265 \\
8 & 276 & 16 & 260 \\
Avg: & $272 \pm 14$ & & $271 \pm 11$ \\
Elongation Change: & $0 \%$
\end{tabular}

$\begin{array}{cccc}\text { Ring } & \text { Initial } & \text { Bing } & \text { Aged } \\ 1 & 212 & 6 & 204 \\ 2 & 214 & 7 & 214 \\ 3 & 213 & 8 & 207 \\ 4 & 218 & 9 & 212 \\ 5 & \underline{188} & 10 & \underline{214}\end{array}$

\begin{tabular}{|c|c|c|c|}
\hline \multicolumn{2}{|c|}{$7.688 \times 0.070$} & \multicolumn{2}{|c|}{ Parker 31610} \\
\hline Ring & Initial & Ring & Aged \\
\hline 1 & 192 & 6 & 198 \\
\hline 2 & 168 & 7 & 173 \\
\hline 3 & 174 & 8 & 186 \\
\hline 4 & 180 & 9 & 188 \\
\hline 5 & 175 & 10 & 195 \\
\hline
\end{tabular}

Avg: $\quad 178 \pm 9$ $188 \pm 10$ Elongation Change:

\section{Avg: $209 \pm 12$}

Elongation Change:

\section{$210 \pm 4$}

7.688 $0.070 \quad$ Parker 317851

\subsection{9x0.103 Parker 316104}

Bing Initial Bing Aged

$\frac{\text { Ring }}{1} \frac{\text { Initial }}{250} \quad \frac{\text { Ring }}{9} \frac{\text { Aged }}{312}$

1250

1

\begin{tabular}{|c|c|c|c|}
\hline 1 & 165 & 9 & 171 \\
\hline 2 & 172 & 10 & 182 \\
\hline 3 & 166 & 11 & 173 \\
\hline 4 & 165 & 12 & 183 \\
\hline 5 & 179 & 13 & 179 \\
\hline 6 & 164 & 14 & 167 \\
\hline 7 & 170 & 15 & 176 \\
\hline 8 & 166 & 16 & 182 \\
\hline Avg: & $168 \pm 5$ & & $177 \pm 6$ \\
\hline
\end{tabular}

\begin{tabular}{|c|c|c|c|}
\hline Ring & Initial & Bing & Aged \\
\hline 1 & 302 & 9 & 224 \\
\hline 2 & 226 & 10 & 300 \\
\hline 3 & 261 & 11 & 274 \\
\hline 4 & 280 & 12 & 335 \\
\hline 5 & 281 & 13 & 298 \\
\hline 6 & 301 & 14 & 287 \\
\hline 7 & 295 & 15 & 215 \\
\hline 8 & $\underline{301}$ & 16 & 217 \\
\hline Avg: & $281 \pm 26$ & & $269 \pm 45$ \\
\hline \multicolumn{3}{|c|}{ Elongation Change: } & $-4 \%$ \\
\hline
\end{tabular}

Elongation Change:

\section{$16.339 \times 0.103$}

$\frac{\text { Ring }}{1} \frac{\text { Initial }}{202}$

2188

Ring Aged

$\begin{array}{lll}188 & 10-217\end{array}$

$\begin{array}{llll}3 & 222 & 11 & 207\end{array}$

$\begin{array}{llll}4 & 129 & 12 & 205\end{array}$

$\begin{array}{llll}5 & 222 & 13 & 206\end{array}$

$\begin{array}{llll}6 & 181 & 14 & 173\end{array}$

$8 \quad 193 \quad 16 \quad 183$

Avg: $\quad 188 \pm 31$

Elongation Change: 
Table H-8. Tensile Strength Data for Precision O-Rings

\begin{tabular}{|c|c|c|c|c|c|c|c|c|c|c|c|c|c|c|c|}
\hline \multicolumn{2}{|c|}{$0.301 \times 0.054$} & \multicolumn{2}{|c|}{ Precision 19052} & \multicolumn{2}{|c|}{$0.301 \times 0.054$} & \multicolumn{2}{|c|}{ Precision 19895} & \multicolumn{2}{|c|}{$1.364 \times 0.070$} & \multicolumn{2}{|c|}{ Precision 17405} & \multicolumn{2}{|c|}{$1.364 \times 0.070$} & \multicolumn{2}{|c|}{ Precision 19895} \\
\hline Ring & Initial & Bing & Aged & Ring & Initial & Ring & Aged & Ring & Initial & Ring & Aged & Ring & Initial & Ring & Aged \\
\hline 1 & 2382 & 9 & N/A & 1 & 2264 & 9 & 2286 & 1 & 2112 & 9 & 2103 & 1 & 2050 & 9 & 2012 \\
\hline 2 & 2385 & 10 & 2286 & 2 & 2218 & 10 & 2269 & 2 & 2090 & 10 & 1984 & 2 & 1890 & 10 & 1974 \\
\hline 3 & 2477 & 11 & 2319 & 3 & 1935 & 11 & 1382 & 3 & N/A & 11 & 2134 & 3 & 1912 & 11 & 1792 \\
\hline 4 & N/A & 12 & 2092 & 4 & 2386 & 12 & 2180 & 4 & 2073 & 12 & 2118 & 4 & 1994 & 12 & 1952 \\
\hline 5 & 2432 & 13 & 2108 & 5 & 2024 & 13 & 2202 & 5 & $N / A$ & 13 & 2138 & 5 & 2027 & 13 & 2019 \\
\hline 6 & 2357 & 14 & 2329 & 6 & 2372 & 14 & 2171 & 6 & 2104 & 14 & 1807 & 6 & 1884 & 14 & 2095 \\
\hline 7 & 1410 & 15 & 2307 & 7 & 2330 & 15 & 2241 & 7 & 2173 & 15 & 1714 & 7 & 1710 & 15 & 2158 \\
\hline 8 & 2083 & 16 & 1695 & 8 & 2333 & 16 & 2375 & 8 & 1917 & 16 & 1766 & 8 & 2014 & 16 & 1490 \\
\hline Avg: & $2218 \pm 378$ & & $2162 \pm 229$ & Avg: & $2233 \pm 167$ & & $2138 \pm 313$ & Avg: & $2078 \pm 86$ & & $1971 \pm 181$ & Avg: & $1935 \pm 112$ & & $1937 \pm 210$ \\
\hline \multicolumn{3}{|c|}{ Strength Change: } & $-3 \%$ & \multicolumn{3}{|c|}{ Strength Change: } & $-4 \%$ & \multicolumn{3}{|c|}{ Strength Change: } & $-5 \%$ & \multicolumn{2}{|c|}{ Strength Change: } & & $0 \%$ \\
\hline \multicolumn{2}{|c|}{$7.739 \times 0.070$} & \multicolumn{2}{|c|}{ Precision 19052} & \multicolumn{2}{|c|}{$7.739 \times 0.070$} & \multicolumn{2}{|c|}{ Precision 19921} & \multicolumn{2}{|c|}{$16.955 \times 0.139$} & \multicolumn{2}{|c|}{ Precision 19422} & \multicolumn{2}{|c|}{$16.955 \times 0.139$} & \multicolumn{2}{|c|}{ Precision 19895} \\
\hline Ring & Initial & Ring & Aged & Ring & Initial & Ring & Aged & Bing & Initial & Ring & Aged & Ring & Initial & Ring & Aged \\
\hline 1 & 1590 & 9 & 1231 & 1 & 1891 & 7 & 1468 & 1 & 958 & 9 & 796 & 1 & 1411 & 9 & 1289 \\
\hline 2 & 1322 & 10 & 1595 & 2 & 1483 & 8 & 1774 & 2 & 910 & 10 & 482 & 2 & 1065 & 10 & 1542 \\
\hline 3 & 1327 & 11 & 1513 & 3 & 1650 & 9 & 1359 & 3 & 1133 & 11 & 1627 & 3 & 1260 & 11 & 1251 \\
\hline 4 & 2192 & 12 & 1622 & 4 & 507 & 10 & 1495 & 4 & 1098 & 12 & 155 & 4 & 1088 & 12 & 1206 \\
\hline 5 & 1417 & 13 & 1800 & 5 & 1653 & 11 & 1836 & 5 & 1119 & 13 & 1399 & 5 & 1585 & 13 & 1527 \\
\hline 6 & 1377 & 14 & 1984 & 6 & 1789 & 12 & 1761 & 6 & 825 & 14 & 1085 & 6 & 1242 & 14 & 1346 \\
\hline 7 & 2027 & 15 & 1681 & & & & & 7 & 1471 & 15 & 804 & 7 & 1333 & 15 & 1421 \\
\hline 8 & 1370 & 16 & 1796 & & & & & 8 & 1514 & 16 & 308 & 8 & 1533 & 16 & 1448 \\
\hline Avg: & $1578 \pm 342$ & & $1653+225$ & Avg: & $1496 \pm 504$ & & $1616 \pm 198$ & Avg: & $1129 \pm 250$ & & $832 \pm 518$ & Avg: & $1315 \pm 190$ & & $1379 \pm 126$ \\
\hline Streng & th Change: & & $5 \%$ & Streng & th Change: & & $8 \%$ & Streng & th Change: & & $-26 \%$ & Streng & Change: & & $5 \%$ \\
\hline
\end{tabular}


Table H-9. Tensile Elongation Data for Precision O-Rings

\begin{tabular}{|c|c|c|c|c|c|c|c|c|c|c|c|c|c|c|c|}
\hline \multicolumn{2}{|c|}{$0.301 \times 0.054$} & \multicolumn{2}{|c|}{ Precision 19052} & \multicolumn{2}{|c|}{$0.301 \times 0.054$} & \multicolumn{2}{|c|}{ Precision 19895} & \multicolumn{2}{|c|}{$1.364 \times 0.070$} & \multicolumn{2}{|c|}{ Precision 17405} & \multicolumn{2}{|c|}{$1.364 \times 0.070$} & \multicolumn{2}{|c|}{ Precision 19895} \\
\hline Ring & Initial & Bing & Aged & Ring & Initial & Ring & Aged & Ring & Initial & Ring & Aged & Ring & Initial & Ring & Aged \\
\hline 1 & 393 & 9 & N/A & 1 & 374 & 9 & 305 & 1 & 321 & 9 & 287 & 1 & 284 & 9 & 293 \\
\hline 2 & 428 & 10 & 309 & 2 & 359 & 10 & 308 & 2 & 316 & 10 & 262 & 2 & 275 & 10 & 252 \\
\hline 3 & 415 & 11 & 318 & 3 & 316 & 11 & 198 & 3 & $N / A$ & 11 & 278 & 3 & 282 & 11 & 230 \\
\hline 4 & N/A & 12 & 297 & 4 & 394 & 12 & 303 & 4 & 301 & 12 & 283 & 4 & 297 & 12 & 250 \\
\hline 5 & 413 & 13 & 286 & 5 & 339 & 13 & 291 & 5 & $N / A$ & 13 & 281 & 5 & 296 & 13 & 253 \\
\hline 6 & 404 & 14 & 329 & 6 & 390 & 14 & 298 & 6 & 323 & 14 & 234 & 6 & 265 & 14 & 274 \\
\hline 7 & 246 & 15 & 322 & 7 & 393 & 15 & 293 & 7 & 331 & 15 & 226 & 7 & 249 & 15 & 261 \\
\hline 8 & $\underline{359}$ & 16 & 239 & 8 & 387 & 16 & $\underline{315}$ & 8 & $\underline{290}$ & 16 & 233 & 8 & 253 & 16 & 161 \\
\hline Avg: & $380 \pm 63$ & & $300 \pm 31$ & Avg: & $369 \pm 29$ & & $289 \pm 38$ & Avg: & $314 \pm 15$ & & $261 \pm 26$ & Avg: & $275 \pm 18$ & & $247 \pm 39$ \\
\hline \multicolumn{3}{|c|}{ Elongation Change: } & $-21 \%$ & \multicolumn{3}{|c|}{ Elongation Change: } & $-22 \%$ & \multicolumn{3}{|c|}{ Elongation Change: } & $-17 \%$ & \multicolumn{2}{|c|}{ Elongation Change: } & & $-10 \%$ \\
\hline \multicolumn{2}{|c|}{$7.739 \times 0.070$} & \multicolumn{2}{|c|}{ Precision 19052} & \multicolumn{2}{|c|}{$7.739 \times 0.070$} & \multicolumn{2}{|c|}{ Precision 19921} & \multicolumn{2}{|c|}{$16.955 \times 0.139$} & \multicolumn{2}{|c|}{ Precision 19422} & \multicolumn{2}{|c|}{$16.955 \times 0.139$} & \multicolumn{2}{|c|}{ Precision 19895} \\
\hline Ring & Initial & Ring & Aged & Bing & Initial & Bing & Aged & Ring & Initial & Ring & Aged & Ring & Initial & Ring & Aged \\
\hline 1 & $\overline{188}$ & 9 & 125 & 1 & 267 & 7 & 173 & 1 & 159 & 9 & 111 & 1 & 227 & 9 & 174 \\
\hline 2 & 154 & 10 & 138 & 2 & 207 & 8 & 203 & 2 & 161 & 10 & 78 & 2 & 228 & 10 & 195 \\
\hline 3 & 142 & 11 & 135 & 3 & 231 & 9 & 159 & 3 & 199 & 11 & 206 & 3 & 236 & 11 & 160 \\
\hline 4 & 318 & 12 & 140 & 4 & 207 & 10 & 171 & 4 & 180 & 12 & 23 & 4 & 179 & 12 & 169 \\
\hline 5 & 160 & 13 & 160 & 5 & 210 & 11 & 199 & 5 & 193 & 13 & 185 & 5 & 249 & 13 & 191 \\
\hline 6 & 155 & 14 & 201 & 6 & 231 & 12 & 180 & 6 & 142 & 14 & 146 & 6 & 206 & 14 & 170 \\
\hline 7 & 263 & 15 & 151 & & & & & 7 & 236 & 15 & 111 & 7 & 212 & 15 & 185 \\
\hline 8 & 158 & 16 & 164 & & & & & 8 & $\underline{236}$ & 16 & $\underline{53}$ & 8 & $\underline{245}$ & 16 & 186 \\
\hline Avg: & $1 \overline{92 \pm 64}$ & & $\sqrt{152 \pm 24}$ & Avg: & $226 \pm 23$ & & $181 \pm 17$ & Avg: & $188 \pm 35$ & & $114 \pm 63$ & Avg: & $223 \pm 23$ & & $179 \pm 12$ \\
\hline Elong & tion Chan & & $-21 \%$ & Elong & tion Chan & ge: & $-20 \%$ & Elong & tion Cha & ge: & $-39 \%$ & Elonge & on Change: & & $-20 \%$ \\
\hline
\end{tabular}


Table H-10. Tensile Strength Data for Test Slabs

\begin{tabular}{|c|c|c|}
\hline \multicolumn{3}{|c|}{ Parker 316104} \\
\hline Site & Initial & Aged \\
\hline 1 & 1689 & 1550 \\
\hline 2 & 1390 & 1580 \\
\hline 3 & 1563 & 1396 \\
\hline 4 & 1608 & 1304 \\
\hline
\end{tabular}

Avg: $1563+126 \quad 1458+130$ Strength Change: $\quad-7 \%$

\section{RD 14810}

Site Initial

$2 \quad 2162$

$3 \quad 2157$

$4 \quad 2300$

Avg: $2218 \pm 70 \quad 2170 \pm 122$

Strength Change: $\quad-2 \%$

\section{Precision 19052A}

$\begin{array}{ccc}\frac{\text { Site }}{1} & \frac{\text { Initial }}{1744} & \frac{\text { Aged }}{1737} \\ 2 & 1556 & 1723 \\ 3 & 1587 & 1603 \\ 4 & \frac{1957}{1711 \pm 183} & \frac{1721}{1696 \pm 62}\end{array}$

Strength Change:

\section{Parker 316710}

Site Initial

$1 \quad 2469$

22618

$3 \quad 2379$

$4 \quad 2546$

Avg: $2503+103$ 2282+203 Strength Change: $\quad-9 \%$

\section{RD 15107}

Site Initial

$1 \quad 2055$

$3 \quad 2173$

$4 \quad 2101$

Avg: $2123 \pm 55 \quad 2010 \pm 137$

Strength Change: $\quad-5 \%$

\section{Precision 19895A}

Site Initial

1. 1673

21659

$3 \quad 1578$

$4 \quad 1717$

Avg: $\quad 1657 \pm 58 \quad 1565 \pm 150$

Strength Change: $\quad-6 \%$

\section{Parker 317403}

Site Initial

$1 \quad 1761$

21605

31569

$4 \quad 1424$

Avg: $1590 \pm 138$

Strength Change:

\begin{tabular}{l} 
Aged \\
1766 \\
1768 \\
1668 \\
1856 \\
\hline
\end{tabular}

$1765 \pm 77$

\section{RD 15107 (4 min. cure)}

Site Initial Aged

$1 \quad 2123 \quad 1895$

$2 \quad 2133 \quad$ N/A

$3 \quad 2057 \quad 2114$

$4 \quad 2052 \quad \underline{1842}$

Avg: $\quad 2091 \pm 43 \quad 1950 \pm 144$

Strength Change: $\quad-7 \%$

\section{Parker 317851}

Site Initial

12669

$2 \quad 2599$

32370

$4 \quad \underline{2481}$

Avg: $2530 \pm 132$

Strength Change:

Aged
2180
2216
1427
1938

$940 \pm 364$

RD 15107 (3 min. cure)

Site Initial Aged

$1 \quad 2343 \quad 1924$

$2 \quad 2057 \quad 2118$

$3 \quad 2017 \quad 2100$

$4 \quad 2046 \quad 1994$

Avg: $2116 \pm 152 \quad 2034 \pm 91$

Strength Change: $\quad-4 \%$

\section{Parker 318466 \\ Site Initial Aged \\ $1122-1651$ \\ $3 \quad 1531 \quad 1655$ \\ $4 \quad 1528 \quad$ NA}

Avg: $1459 \pm 233 \quad 1630 \pm 40$

Strength Change: $\quad 12 \%$ 
Table H-11. Tensile Elongation Data for Test Slabs

\begin{tabular}{|c|c|c|}
\hline \multicolumn{3}{|c|}{ Parker 316104} \\
\hline Site & Initial & Aged \\
\hline 1 & 216 & 164 \\
\hline 2 & 188 & 186 \\
\hline 3 & 187 & 153 \\
\hline 4 & 206 & 161 \\
\hline Avg: & $199 \pm 14$ & $166 \pm 14$ \\
\hline
\end{tabular}

Elongation Change $-17 \%$

\section{RD 14810}

Site Initial Aged

$1261 \quad 246$

$2 \quad 279 \quad 241$

$3 \quad 269 \quad 231$

$\begin{array}{ccc}4 & \frac{283}{3} & \frac{271}{247 \pm 17}\end{array}$

Elongation Change $-9 \%$

\begin{tabular}{|c|c|c|}
\hline \multicolumn{3}{|c|}{ Parker 316710} \\
\hline Site & Initial & Aged \\
\hline 1 & 186 & 166 \\
\hline 2 & 193 & 185 \\
\hline 3 & 174 & 168 \\
\hline 4 & 191 & 169 \\
\hline Avg: & $186 \pm 9$ & $172 \pm 9$ \\
\hline Elongat & Change & $-8 \%$ \\
\hline
\end{tabular}

\section{RD 15107}

\begin{tabular}{|c|c|c|}
\hline Site & Initial & Aged \\
\hline 1 & 236 & 232 \\
\hline 2 & 230 & 226 \\
\hline 3 & 238 & 218 \\
\hline 4 & 266 & 205 \\
\hline Avg: & $243 \pm 16$ & $220 \pm 12$ \\
\hline
\end{tabular}

Elongation Change $-9 \%$

Precision 19895A

$\begin{array}{ccc}\text { Site } & \text { Initial } & \text { Aged } \\ 1 & 248 & 189 \\ 2 & 217 & 210 \\ 3 & 229 & 172 \\ 4 & 222 & \underline{219} \\ \text { Avg: } & 229 \pm 14 & 198 \pm 21 \\ \text { Elongation Change } & -14 \%\end{array}$

Elongation Change $-14 \%$

\section{Parker 317403}

Site Initial

$\begin{array}{ll}1 & 227 \\ 2 & 241\end{array}$

3223

$4 \quad 193$

Avg: $\quad 221+20 \quad 221 \pm 16$

Elongation Change $0 \%$

RD 15107 (4 min. cure)

$\begin{array}{ccc}\frac{\text { Site }}{1} & \frac{\text { Initial }}{243} & \frac{\text { Aged }}{187} \\ 2 & 250 & \text { N/A } \\ 3 & 238 & 187 \\ 4 & 259 & 164 \\ \text { Avg: } & 248 \pm 9 & 179 \pm 13 \\ \text { longation Change } & -28 \%\end{array}$

Parker 317851

\begin{tabular}{|c|c|c|}
\hline Site & Initial & Aged \\
\hline 1 & 181 & 163 \\
\hline 2 & 188 & 169 \\
\hline 3 & 164 & 131 \\
\hline 4 & 181 & 144 \\
\hline Avg: & $179 \pm 10$ & \\
\hline
\end{tabular}

Elongation Change $-15 \%$

RD 15107 (3 min. cure)

Site Initial Aged

$\begin{array}{lll}1 & 234 & 167\end{array}$

$2 \quad 216 \quad 202$

$\begin{array}{lll}3 & 218 & 187\end{array}$

$4 \quad 217 \quad 198$

Avg: $221 \pm 9 \quad 189 \pm 16$

\section{Parker 318466}

\begin{tabular}{|c|c|c|}
\hline Site & Initial & \\
\hline 1 & 569 & \\
\hline 2 & 412 & \\
\hline 3 & 522 & \\
\hline 4 & 636 & \\
\hline Avg: & $535 \pm 95$ & \\
\hline
\end{tabular}

Precision 19052A

Site Initial $\frac{\text { Aged }}{263}$

$\begin{array}{lll}1 & 263 & 208 \\ 3 & 245 & 218\end{array}$

$3 \quad 327 \quad 190$

$4 \quad 270 \quad 216$

Avg: $276 \pm 35 \quad 208 \pm 13$

Elongation Change $-25 \%$ 
Appendix I: Tensile Modulus and Work Test Data

Contents:

Table I-1. Tangential Tensile Modulus Data on Butyl Rubber O-Rings (all elongation ranges)

Table I-2. Tangential Tensile Modulus Data Plus Averages (all elongation ranges)

Plot I-3. Modulus vs. Percent Elongation Range of Unaged Samples

Plot I-4. Modulus vs. Percent Elongation Range of Aged Samples

Plot I-5. Average Modulus of Unaged and Aged Samples

Table I-6. Tensile Work Integration (0-20\% elongation) on Butyl Rubber O-Rings

Table I-7. Linear Tensile Modulus (0-25\% elongation) on Butyl Rubber O-Rings

Table I-8. Tensile Modulus (0-25\%) of RD Rubber O-Rings, Cure Study (detailed test data)

Table I-9. Tensile Modulus (0-25\%) of Other RD Rubber O-Rings (detailed test data)

Table I-10. Tensile Modulus (0-25\%) of Parker O-Rings (detailed test data)

Table I-11. Tensile Modulus (0-25\%) of Precision O-Rings (detailed test data)

Table I-12. Tensile Modulus (0-25\%) of Test Slabs (detailed test data) 
Table 1-1. Non-Linear, Tangential Tensile Modulus Data (all elongation ranges) on Butyl Rubber O-Rings

\begin{tabular}{|c|c|c|c|c|c|c|c|c|c|c|c|c|c|c|c|c|c|c|}
\hline Vendor & Ring size & $\begin{array}{l}\text { Rubber } \\
\text { Batch }\end{array}$ & \begin{tabular}{c|} 
Ring \\
No.
\end{tabular} & \multicolumn{3}{|c|}{$\begin{array}{c}\text { Modulus } \\
5-10 \%\end{array}$} & \multicolumn{3}{|c|}{$\begin{array}{c}\text { Modulus } \\
10-15 \%\end{array}$} & \multicolumn{3}{|c|}{$\begin{array}{c}\text { Modulus } \\
5-15 \%\end{array}$} & \multicolumn{3}{|c|}{$\begin{array}{c}\text { Modulus } \\
10-20 \%\end{array}$} & \multicolumn{3}{|c|}{$\begin{array}{c}\text { Modulus } \\
0-25 \%\end{array}$} \\
\hline & & & & unaged & aged & $\Delta \%$ & unaged & aged & $\Delta \%$ & unaged & aged & $\Delta \%$ & unaged & aged & $\Delta \%$ & unaged & aged & $\Delta \%$ \\
\hline Parker & $0.116 \times 0.038$ & 318466 & $8 / 8$ & $592 \pm 36$ & $575 \pm 55$ & -3 & $548 \pm 79$ & $652 \pm 60$ & 19 & $568 \pm 57$ & $622 \pm 53$ & 10 & $521 \pm 75$ & $621 \pm 31$ & 19 & $537 \pm 46$ & $596 \pm 32$ & 11 \\
\hline Parker & $0.301 \times 0.054$ & 316104 & $5 / 4$ & $839 \pm 67$ & $887 \pm 156$ & 6 & $795 \pm 83$ & $785 \pm 83$ & -1 & $801 \pm 56$ & $825 \pm 118$ & 3 & $743 \pm 47$ & $752 \pm 125$ & 1 & $768 \pm 35$ & $797 \pm 101$ & 4 \\
\hline Parker & & 316710 & $7 / 5$ & $912 \pm 125$ & $981 \pm 154$ & 8 & $846 \pm 65$ & $846 \pm 219$ & 0 & $851 \pm 77$ & $882 \pm 174$ & 4 & $798 \pm 40$ & $814 \pm 102$ & 2 & $838 \pm 48$ & $840 \pm 99$ & 0 \\
\hline Parker & $1.364 \times 0.070$ & 316104 & $4 / 3$ & $693 \pm 27$ & $906 \pm 30$ & 31 & $566 \pm 69$ & $655 \pm 36$ & 16 & $652 \pm 41$ & $782 \pm 17$ & 20 & $565 \pm 57$ & $714 \pm 14$ & 26 & $669 \pm 36$ & $752 \pm 18$ & 12 \\
\hline Parker & & 317403 & $7 / 8$ & $760 \pm 59$ & $744 \pm 84$ & -2 & $669 \pm 61$ & $672 \pm 68$ & 0 & $713 \pm 31$ & $694 \pm 62$ & -3 & $580 \pm 28$ & $635 \pm 43$ & 9 & $636 \pm 13$ & $663 \pm 32$ & 4 \\
\hline Parker & $7.688 \times 0.070$ & 316104 & $5 / 5$ & $951 \pm 182$ & $815 \pm 236$ & -14 & $848 \pm 75$ & $749 \pm 89$ & -12 & $907 \pm 125$ & $774 \pm 149$ & -15 & $829 \pm 85$ & $756 \pm 92$ & -9 & $875 \pm 49$ & $812 \pm 77$ & -7 \\
\hline Parker & & 317851 & $8 / 7$ & $473 \pm 33$ & $605 \pm 33$ & 28 & $372 \pm 41$ & $533 \pm 34$ & 43 & $423 \pm 28$ & $569 \pm 32$ & 35 & $377 \pm 48$ & $481 \pm 27$ & 28 & $452 \pm 34$ & $558 \pm 21$ & 23 \\
\hline Parker & $16.339 \times 0.103$ & 316104 & $8 / 8$ & $1006 \pm 13$ & $1044 \pm 146$ & 4 & $767 \pm 16$ & $759 \pm 32$ & -1 & $884 \pm 11$ & $891 \pm 79$ & 1 & $696 \pm 11$ & $691 \pm 21$ & -1 & $826 \pm 5$ & $845 \pm 33$ & 2 \\
\hline Parker & & 316710 & $8 / 8$ & $936 \pm 19$ & $962 \pm 45$ & 3 & $699 \pm 16$ & $674 \pm 15$ & -4 & $814 \pm 14$ & $808 \pm 23$ & -1 & $636 \pm 17$ & $613 \pm 15$ & -4 & $765 \pm 15$ & $769 \pm 19$ & 1 \\
\hline RD & $0.301 \times 0.054$ & 15107 & $8 / 8$ & $544 \pm 67$ & $517 \pm 53$ & -5 & $315 \pm 46$ & $479 \pm 60$ & 52 & $414 \pm 15$ & $490 \pm 44$ & 18 & $381 \pm 31$ & $504 \pm 27$ & 32 & $427 \pm 17$ & $494 \pm 24$ & 16 \\
\hline RD & $0.551 \times 0.070$ & 14810 & $7 / 8$ & $421 \pm 171$ & $440 \pm 100$ & 5 & $371 \pm 19$ & $404 \pm 53$ & 9 & $406 \pm 43$ & $397 \pm 37$ & -2 & $348 \pm 9$ & $394 \pm 21$ & 13 & $364 \pm 8$ & $395 \pm 12$ & 9 \\
\hline RD & & 15107 & $8 / 6$ & $457 \pm 88$ & $507 \pm 64$ & 11 & $400 \pm 66$ & $403-63$ & 1 & $386 \pm 26$ & $452 \pm 28$ & 17 & $353 \pm 29$ & $398 \pm 25$ & 13 & $372 \pm 14$ & $422 \pm 25$ & 13 \\
\hline RD & $1.114 \times 0.070$ & 14810 & $7 / 8$ & $368 \pm 44$ & $428 \pm 42$ & 16 & $329 \pm 60$ & $380 \pm 37$ & 16 & $389 \pm 12$ & $410 \pm 25$ & 5 & $303 \pm 40$ & $347 \pm 26$ & 15 & $368 \pm 12$ & $385 \pm 21$ & 5 \\
\hline RD & & 15107 & $7 / 8$ & $412 \pm 71$ & $484 \pm 35$ & 17 & $379 \pm 54$ & $398 \pm 54$ & 5 & $419 \pm 27$ & $457 \pm 14$ & 9 & $341 \pm 38$ & $376 \pm 26$ & 10 & $390 \pm 26$ & $428 \pm 19$ & 10 \\
\hline RD & $7.185 \times 0.103$ & 14810 & $7 / 8$ & $401 \pm 22$ & $420 \pm 16$ & 5 & $321 \pm 14$ & $344 \pm 13$ & 7 & $354 \pm 7$ & $384 \pm 9$ & 8 & $333 \pm 12$ & $345 \pm 13$ & 4 & $370 \pm 14$ & $386 \pm 19$ & 4 \\
\hline $\mathrm{RD}$ & & 15107 & $8 / 8$ & $471 \pm 23$ & $519 \pm 17$ & 10 & $400 \pm 15$ & $443 \pm 16$ & 11 & $424 \pm 11$ & $467 \pm 11$ & 10 & $366 \pm 12$ & $420 \pm 21$ & 15 & $424 \pm 18$ & $474 \pm 17$ & 12 \\
\hline RD & $11.196 \times 0.103$ & 14936 & $7 / 7$ & $452 \pm 23$ & $493 \pm 16$ & 9 & $396 \pm 27$ & $447 \pm 31$ & 13 & $412 \pm 12$ & $459 \pm 22$ & 11 & $381 \pm 22$ & $423 \pm 39$ & 11 & $416 \pm 15$ & $453 \pm 28$ & 9 \\
\hline$R D$ & & 15107 & $7 / 8$ & $452 \pm 30$ & $529 \pm 25$ & 17 & $373 \pm 16$ & $476 \pm 32$ & 28 & $409 \pm 8$ & $396 \pm 20$ & -3 & $385 \pm 25$ & $477 \pm 25$ & 24 & $423 \pm 21$ & $508 \pm 18$ & 20 \\
\hline Precision & $0.301 \times 0.054$ & 19052 & $7 / 7$ & $646 \pm 90$ & $623 \pm 39$ & -4 & $500 \pm 157$ & $543 \pm 135$ & 9 & $570 \pm 42$ & $630 \pm 19$ & 11 & $483 \pm 45$ & $514 \pm 45$ & 6 & $570 \pm 29$ & $630 \pm 18$ & 11 \\
\hline Precision & & 19895 & $8 / 8$ & $613 \pm 93$ & $682 \pm 50$ & 11 & $513 \pm 49$ & $583 \pm 62$ & 14 & $543 \pm 43$ & $611 \pm 59$ & 13 & $490 \pm 17$ & $537 \pm 62$ & 10 & $530 \pm 17$ & $625 \pm 27$ & 18 \\
\hline Precision & $1.364 \times 0.070$ & 17405 & $6 / 8$ & $660 \pm 39$ & $698 \pm 28$ & 6 & $526 \pm 9$ & $575 \pm 27$ & 9 & $579 \pm 24$ & $636 \pm 19$ & 10 & $475 \pm 18$ & $561 \pm 34$ & 18 & $553 \pm 20$ & $633 \pm 23$ & 14 \\
\hline Precision & & 19895 & $8 / 7$ & $664 \pm 58$ & $662 \pm 47$ & 0 & $522 \pm 29$ & $526 \pm 39$ & 1 & $592 \pm 20$ & $590 \pm 33$ & 0 & $485 \pm 20$ & $511 \pm 46$ & 5 & $576 \pm 19$ & $600 \pm 37$ & 4 \\
\hline Precision & $7.739 \times 0.070$ & 19052 & $8 / 8$ & $794 \pm 36$ & $841 \pm 35$ & 6 & $676 \pm 71$ & $776 \pm 31$ & 15 & $717 \pm 48$ & $812 \pm 26$ & 13 & $678 \pm 63$ & $768 \pm 45$ & 13 & $732 \pm 53$ & $849 \pm 36$ & 16 \\
\hline Precision & & 19921 & $6 / 6$ & $839 \pm 41$ & $890 \pm 32$ & 6 & $671 \pm 32$ & $722 \pm 21$ & 8 & $730 \pm 32$ & $797 \pm 19$ & 9 & $589 \pm 21$ & $648 \pm 10$ & 10 & $700 \pm 23$ & $772 \pm 14$ & 10 \\
\hline Precision & $16.955 \times 0.139$ & 19422 & $8 / 8$ & $635 \pm 29$ & $702 \pm 32$ & 11 & $482 \pm 25$ & $547 \pm 19$ & 13 & $551 \pm 22$ & $617 \pm 23$ & 12 & $444 \pm 23$ & $519 \pm 15$ & 17 & $527 \pm 17$ & $610 \pm 17$ & 16 \\
\hline Precision & & 19895 & $8 / 8$ & $651 \pm 34$ & $746 \pm 34$ & 15 & $476 \pm 14$ & $561 \pm 29$ & 18 & $559 \pm 18$ & $652 \pm 26$ & 17 & $430 \pm 13$ & $539 \pm 27$ & 25 & $554 \pm 13$ & $654 \pm 28$ & 18 \\
\hline
\end{tabular}


Table 1-2. Non-Linear. Tangential Tensile Modulus Data (all elongation ranges and averages) on Butyl Rubber O-Rings

\begin{tabular}{|c|c|c|c|c|c|c|c|c|c|c|c|c|c|c|}
\hline \multirow[t]{2}{*}{ Vendor } & \multirow[t]{2}{*}{ Ring size } & \multirow[t]{2}{*}{$\begin{array}{c}\text { Rubber } \\
\text { Batch }\end{array}$} & \multicolumn{2}{|c|}{$\begin{array}{c}\text { Modulus } \\
5-10 \% \\
\end{array}$} & \multicolumn{2}{|c|}{$\begin{array}{c}\text { Modulus } \\
10-15 \%\end{array}$} & \multicolumn{2}{|c|}{$\begin{array}{c}\text { Modulus } \\
5-15 \% \\
\end{array}$} & \multicolumn{2}{|c|}{$\begin{array}{l}\text { Modulus } \\
10-20 \%\end{array}$} & \multicolumn{2}{|c|}{$\begin{array}{c}\text { Modulus } \\
0-25 \%\end{array}$} & \multicolumn{2}{|c|}{$\begin{array}{l}\text { Average } \\
\text { Modulus }\end{array}$} \\
\hline & & & unaged & aged & unaged & aged & unaged & aged & unaged & aged & unaged & aged & unaged & aged \\
\hline Parker & $0.116 \times 0.038$ & 318466 & 592 & 575 & 548 & 652 & 568 & 622 & 521 & 621 & 537 & 596 & 553 & 613 \\
\hline Parker & $0.301 \times 0.054$ & 316104 & 839 & 887 & 795 & 785 & 801 & 825 & 743 & 752 & 768 & 797 & 789 & 809 \\
\hline Parker & & 316710 & 912 & 981 & 846 & 846 & 851 & 882 & 798 & 814 & 838 & 840 & 849 & 873 \\
\hline Parker & $1.364 \times 0.070$ & 316104 & 693 & 906 & 566 & 655 & 652 & 782 & 565 & 714 & 669 & 752 & 629 & 762 \\
\hline Parker & & 317403 & 760 & 744 & 669 & 672 & 713 & 694 & 580 & 635 & 636 & 663 & 672 & 682 \\
\hline Parker & $7.688 \times 0.070$ & 316104 & 951 & 815 & 848 & 749 & 907 & 774 & 829 & 756 & 875 & 812 & 882 & 781 \\
\hline Parker & & 317851 & 473 & 605 & 372 & 533 & 423 & 569 & 377 & 481 & 452 & 558 & 419 & 549 \\
\hline Parker & $16.339 \times 0.103$ & 316104 & 1006 & 1044 & 767 & 759 & 884 & 891 & 696 & 691 & 826 & 845 & 836 & 846 \\
\hline \multirow[t]{2}{*}{ Parker } & & 316710 & 936 & 962 & 699 & 674 & 814 & 808 & 636 & 613 & 765 & 769 & 770 & 765 \\
\hline & & avg. & $\underline{796}$ & $\underline{835}$ & $\underline{679}$ & 703 & $\underline{735}$ & $\underline{761}$ & $\underline{638}$ & $\underline{675}$ & 708 & 737 & $\underline{711}$ & $\underline{742}$ \\
\hline $\mathrm{RD}$ & $0.301 \times 0.054$ & 15107 & 544 & 517 & 315 & 479 & 414 & 490 & 381 & 504 & 427 & 494 & 416 & 497 \\
\hline $\mathrm{RD}$ & $0.551 \times 0.070$ & 14810 & 421 & 440 & 371 & 404 & 406 & 397 & 348 & 394 & 364 & 395 & 382 & 406 \\
\hline RD & & 15107 & 457 & 507 & 400 & 403 & 386 & 452 & 353 & 398 & 372 & 422 & 394 & 436 \\
\hline$R D$ & $1.114 \times 0.070$ & 14810 & 368 & 428 & 329 & 380 & 389 & 410 & 303 & 347 & 368 & 385 & 351 & 390 \\
\hline $\mathrm{RD}$ & & 15107 & 412 & 484 & 379 & 398 & 419 & 457 & 341 & 376 & 390 & 428 & 388 & 429 \\
\hline $\mathrm{RD}$ & $7.185 \times 0.103$ & 14810 & 401 & 420 & 321 & 344 & 354 & 384 & 333 & 345 & 370 & 386 & 356 & 376 \\
\hline RD & & 15107 & 471 & 519 & 400 & 443 & 424 & 467 & 366 & 420 & 424 & 474 & 417 & 465 \\
\hline RD & $11.196 \times 0.103$ & 14936 & 452 & 493 & 396 & 447 & 412 & 459 & 381 & 423 & 416 & 453 & 411 & 455 \\
\hline \multirow[t]{2}{*}{ RD } & & 15107 & 452 & 529 & 373 & 476 & 409 & 396 & 385 & 477 & 423 & 508 & 408 & 477 \\
\hline & & avg. & 442 & $\underline{482}$ & $\underline{365}$ & $\underline{419}$ & $\underline{401}$ & $\underline{435}$ & $\underline{355}$ & $\underline{409}$ & $\underline{395}$ & $\underline{438}$ & 391 & $\underline{437}$ \\
\hline Precision & $0.301 \times 0.054$ & 19052 & 646 & 623 & 500 & 543 & 570 & 630 & 483 & 514 & 570 & 630 & 554 & 588 \\
\hline Precision & & 19895 & 613 & 682 & 513 & 583 & 543 & 611 & 490 & 537 & 530 & 625 & 538 & 608 \\
\hline Precision & $1.364 \times 0.070$ & 17405 & 660 & 698 & 526 & 575 & 579 & 636 & 475 & 561 & 553 & 633 & 559 & 621 \\
\hline Precision & & 19895 & 664 & 662 & 522 & 526 & 592 & 590 & 485 & 511 & 576 & 600 & 568 & 578 \\
\hline Precision & $7.739 \times 0.070$ & 19052 & 794 & 841 & 676 & 776 & 717 & 812 & 678 & 768 & 732 & 849 & 719 & 809 \\
\hline Precision & & 19921 & 839 & 890 & 671 & 722 & 730 & 797 & 589 & 648 & 700 & 772 & 706 & 766 \\
\hline Precision & $16.955 \times 0.139$ & 19422 & 635 & 702 & 482 & 547 & 551 & 617 & 444 & 519 & 527 & 610 & 528 & 599 \\
\hline \multirow[t]{2}{*}{ Precision } & & 19895 & 651 & 746 & 476 & 561 & 559 & 652 & 430 & 539 & 554 & 654 & 534 & 630 \\
\hline & & avg. & $\underline{688}$ & $\underline{731}$ & $\underline{546}$ & $\underline{604}$ & $\underline{605}$ & $\underline{668}$ & $\underline{509}$ & $\underline{575}$ & $\underline{593}$ & 672 & $\underline{588}$ & $\underline{650}$ \\
\hline
\end{tabular}




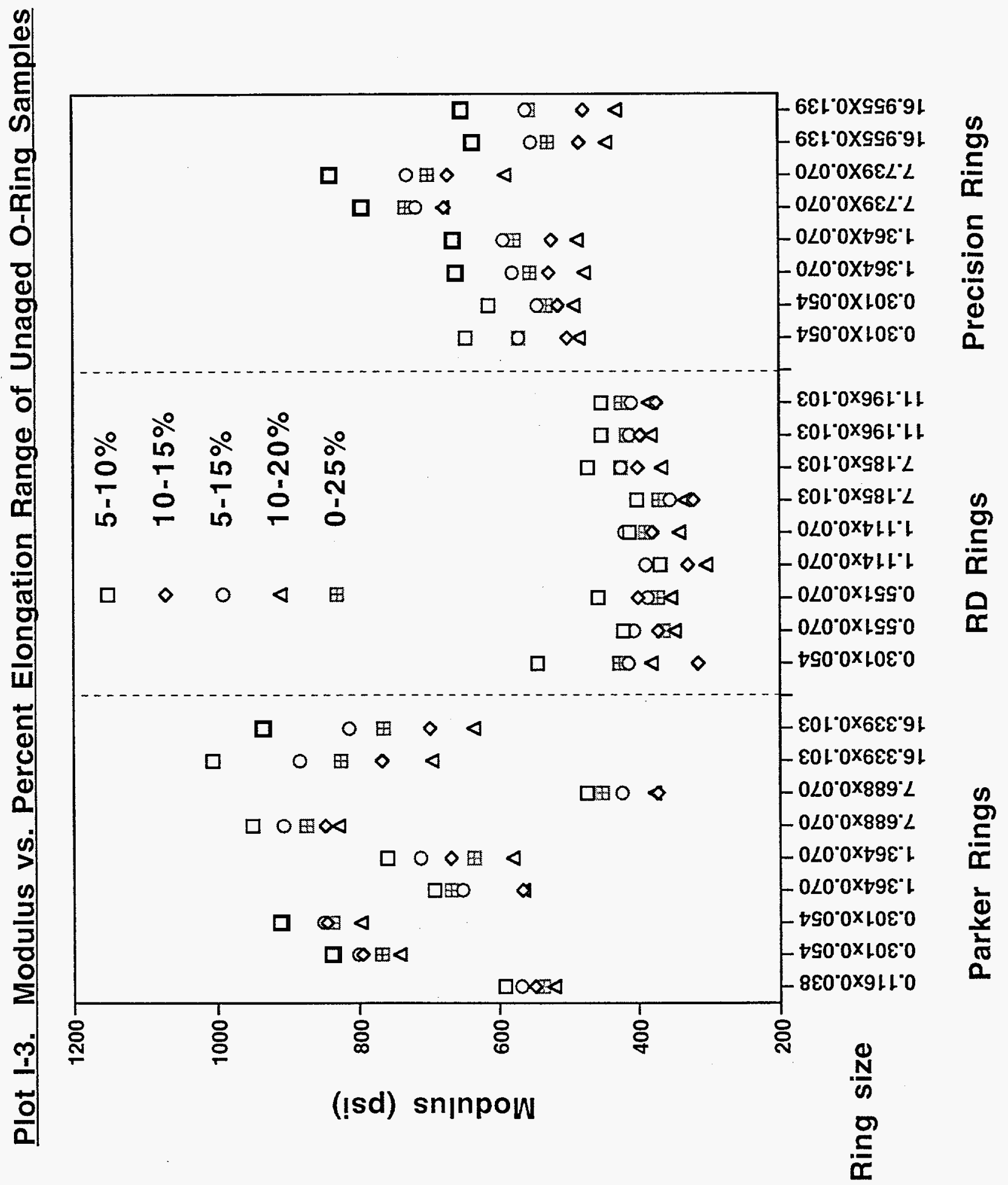




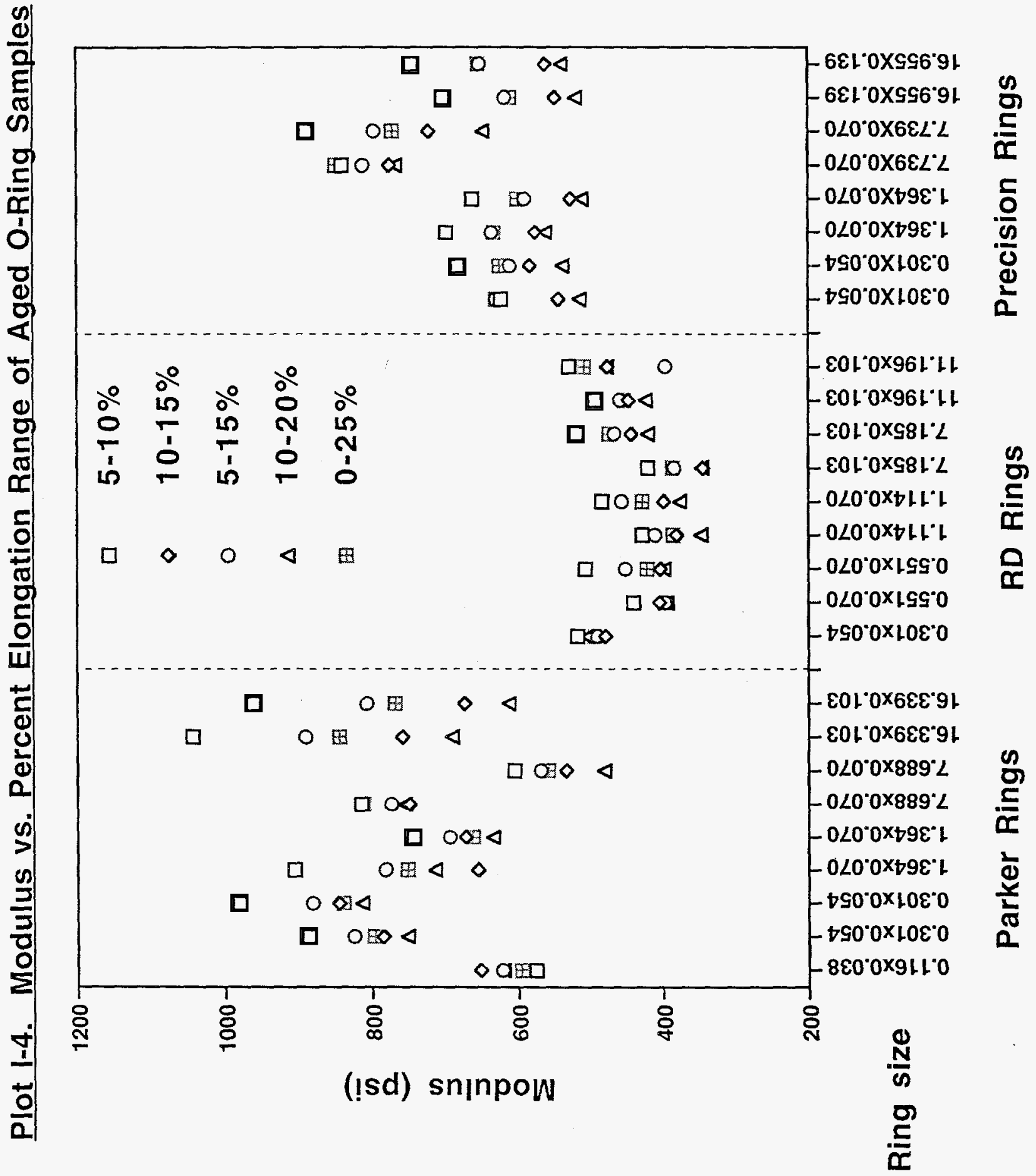




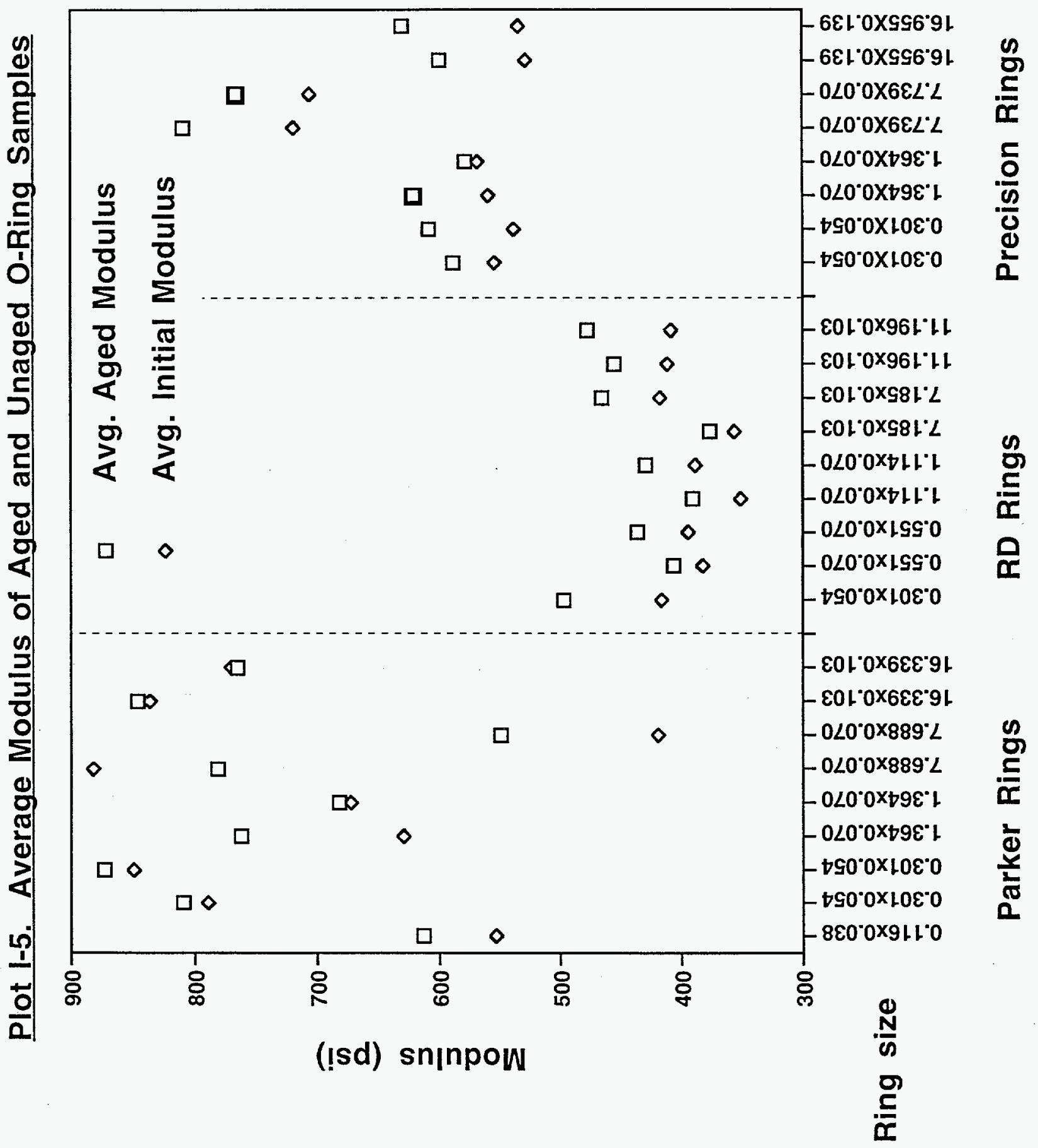


Table 1-6. Tensile Work Integration (0-20\% elongation) Data on Butyl Rubber O-Rings

\begin{tabular}{|c|c|c|c|c|c|c|c|c|c|c|}
\hline Vendor & Ring size & $\begin{array}{c}\begin{array}{c}\text { Rubber } \\
\text { Batch }\end{array} \\
\end{array}$ & Rings & Loops & $\begin{array}{r}\text { IN } \\
\text { unaged }\end{array}$ & $\begin{array}{r}\text { B/SQ.IN. } \\
\text { aged }\end{array}$ & $\Delta \%$ & $\begin{array}{r}\text { PER } \\
\text { unaged }\end{array}$ & $\begin{array}{c}\text { T-LB/SQ.IN } \\
\text { aged } \\
\end{array}$ & $\Delta \%$ \\
\hline Parker & $0.116 \times 0.038$ & 318466 & $8 / 8$ & 1 & $2.00 \pm 0.14$ & $2.18 \pm 0.18$ & 9 & $1095 \pm 79$ & $1197 \pm 97$ & 9 \\
\hline Parker & $0.301 \times 0.054$ & 316104 & $5 / 4$ & 1 & $7.86 \pm 0.63$ & $8.13 \pm 1.10$ & 3 & $1662+133$ & $1720 \pm 229$ & 3 \\
\hline Parker & & 316710 & $7 / 5$ & 1 & $8.27 \pm 0.63$ & $7.86 \pm 1.10$ & -5 & $1749 \pm 134$ & $1691 \pm 182$ & -3 \\
\hline Parker & $1.364 \times 0.070$ & 316104 & $4 / 3$ & 1 & $31.4 \pm 1.5$ & $34.8 \pm 0.7$ & 11 & $1464 \pm 70$ & $1622 \pm 33$ & 11 \\
\hline Parker & & 317403 & $7 / 8$ & 1 & $32.8 \pm 1.7$ & $33.6 \pm 2.5$ & 2 & $1530 \pm 81$ & $1568 \pm 118$ & 2 \\
\hline Parker & $7.688 \times 0.070$ & 316104 & $5 / 5$ & 3 & $383 \pm 29$ & $351 \pm 44$ & -8 & $2027 \pm 188$ & $1856 \pm 274$ & -8 \\
\hline Parker & & 317851 & $8 / 7$ & 3 & $221 \pm 11$ & $267 \pm 9$ & 21 & $1280 \pm 55$ & $1522 \pm 63$ & 19 \\
\hline Parker & $16.339 \times 0.103$ & 316104 & $8 / 8$ & 3 & $837 \pm 8$ & $873 \pm 66$ & 4 & $2233 \pm 30$ & $2354 \pm 230$ & 5 \\
\hline Parker & & 316710 & $8 / 8$ & 3 & $799 \pm 12$ & $834 \pm 38$ & 4 & $2155 \pm 33$ & $2297 \pm 138$ & 7 \\
\hline$R D$ & $0.301 \times 0.054$ & 15107 & $8 / 8$ & 1 & $5.02 \pm 0.60$ & $5.09 \pm 0.47$ & 1 & $1061 \pm 128$ & $1076 \pm 99$ & 1 \\
\hline RD & $0.551 \times 0.070$ & 14810 & $7 / 8$ & 1 & $6.70 \pm 0.52$ & $7.95 \pm 0.33$ & 19 & $774 \pm 60$ & $918 \pm 38$ & 19 \\
\hline $\mathrm{RD}$ & & 15107 & $8 / 6$ & 1 & $7.17 \pm 0.44$ & $7.79 \pm 0.15$ & 9 & $828 \pm 51$ & $900 \pm 17$ & 9 \\
\hline RD & $1.114 \times 0.070$ & 14810 & $7 / 8$ & 1 & $14.9 \pm 0.5$ & $15.3 \pm 1.0$ & 3 & $853 \pm 29$ & $876 \pm 57$ & 3 \\
\hline RD & & 15107 & $7 / 8$ & 1 & $15.8 \pm 0.9$ & $17.9 \pm 0.6$ & 13 & $900 \pm 53$ & $1023 \pm 37$ & 14 \\
\hline $\mathrm{RD}$ & $7.185 \times 0.103$ & 14810 & $7 / 8$ & 3 & $173 \pm 6$ & $177 \pm 10$ & 2 & $1048 \pm 40$ & $1068 \pm 74$ & 2 \\
\hline RD & & 15107 & $8 / 8$ & 3 & $210 \pm 11$ & $226 \pm 11$ & 8 & $1310 \pm 80$ & $1375 \pm 85$ & 5 \\
\hline RD & $11.196 \times 0.103$ & 14936 & $7 / 7$ & 3 & $302 \pm 14$ & $317 \pm 18$ & 5 & $1172 \pm 62$ & $1206 \pm 62$ & 3 \\
\hline RD & & 15107 & $7 / 8$ & 3 & $308 \pm 17$ & $355 \pm 16$ & 15 & $1194 \pm 76$ & $1352 \pm 60$ & 13 \\
\hline Precision & $0.301 \times 0.054$ & 19052 & $7 \pi$ & 1 & $6.25 \pm 0.35$ & $7.38 \pm 0.29$ & 18 & $1322 \pm 75$ & $1561 \pm 61$ & 18 \\
\hline Precision & & 19895 & $8 / 8$ & 1 & $5.63 \pm 0.21$ & $7.01 \pm 0.31$ & 25 & $1190 \pm 44$ & $1483 \pm 66$ & 25 \\
\hline Precision & $1.364 \times 0.070$ & 17405 & $6 / 8$ & 1 & $30.3 \pm 1.3$ & $33.3 \pm 1.1$ & 10 & $1414 \pm 59$ & $1556 \pm 51$ & 10 \\
\hline Precision & & 19895 & $8 / 7$ & 1 & $29.7 \pm 1.6$ & $32.0 \pm 1.7$ & 8 & $1384 \pm 77$ & $1491 \pm 77$ & 8 \\
\hline Precision & $7.739 \times 0.070$ & 19052 & $8 / 8$ & 3 & $338 \pm 15$ & $391 \pm 12$ & 16 & $1857 \pm 74$ & $2143 \pm 75$ & 15 \\
\hline Precision & & 19921 & $6 / 6$ & 3 & $347 \pm 12$ & $378 \pm 13$ & 9 & $1990 \pm 68$ & $2159 \pm 85$ & 8 \\
\hline Precision & $16.955 \times 0.139$ & 19422 & $8 / 8$ & 3 & $577 \pm 9$ & $643 \pm 11$ & 11 & $1492 \pm 40$ & $1642 \pm 24$ & 10 \\
\hline Precision & & 19895 & $8 / 8$ & 3 & $628 \pm 9$ & $729 \pm 26$ & 16 & $1686 \pm 22$ & $1934 \pm 71$ & .15 \\
\hline
\end{tabular}


Table 1-7. Linear Tensile Modulus (0-25\% elongation) Data on Butyl Rubber O-Rings

\begin{tabular}{|c|c|c|c|c|c|c|c|}
\hline Vendor & Ring size & $\begin{array}{c}\text { Rubber } \\
\text { Batch }\end{array}$ & Rings & Loops & unaged & $\begin{array}{l}\text { PSI } \\
\text { aged } \\
\end{array}$ & $\Delta \%$ \\
\hline Parker & $0.116 \times 0.038$ & 318466 & $8 / 8$ & 1 & $527 \pm 39$ & $581 \pm 31$ & 10.2 \\
\hline Parker & $0.301 \times 0.054$ & 316104 & $5 / 4$ & 1 & $754 \pm 22$ & $780 \pm 96$ & 3.4 \\
\hline Parker & & 316710 & $7 / 5$ & 1 & $812 \pm 37$ & $819 \pm 65$ & 0.9 \\
\hline Parker & $1.364 \times 0.070$ & 316104 & $4 / 3$ & 1 & $683 \pm 26$ & $736 \pm 12$ & 7.8 \\
\hline Parker & & 317403 & $7 / 8$ & 1 & $639 \pm 18$ & $675 \pm 32$ & 5.6 \\
\hline Parker & $7.688 \times 0.070$ & 316104 & $5 / 5$ & 3 & $896 \pm 31$ & $860 \pm 58$ & -4.0 \\
\hline Parker & & 317851 & $8 / 7$ & 3 & $489 \pm 29$ & $586 \pm 19$ & 19.8 \\
\hline Parker & $16.339 \times 0.103$ & 316104 & $8 / 8$ & 3 & $868 \pm 7$ & $906 \pm 32$ & 4.4 \\
\hline Parker & & 316710 & $8 / 8$ & 3 & $819 \pm 9$ & $842 \pm 28$ & 2.8 \\
\hline RD & $0.301 \times 0.054$ & 15107 & $8 / 8$ & 1 & $447 \pm 29$ & $493 \pm 27$ & 10.3 \\
\hline $\mathrm{RD}$ & $0.551 \times 0.070$ & 14810 & $7 / 8$ & 1 & $358 \pm 16$ & $403 \pm 13$ & 12.6 \\
\hline RD & & 15107 & $8 / 6$ & 1 & $367 \pm 15$ & $414 \pm 24$ & 12.8 \\
\hline RD & $1.114 \times 0.070$ & 14810 & $7 / 8$ & 1 & $369 \pm 14$ & $387 \pm 25$ & 4.9 \\
\hline RD & & 15107 & $7 / 8$ & 1 & $389 \pm 25$ & $431 \pm 22$ & 10.8 \\
\hline RD & $7.185 \times 0.103$ & 14810 & $7 / 8$ & 3 & $418 \pm 17$ & $435 \pm 24$ & 4.1 \\
\hline RD & & 15107 & $8 / 8$ & 3 & $507 \pm 30$ & $553 \pm 22$ & 9.1 \\
\hline RD & $11.196 \times 0.103$ & 14936 & $7 / 7$ & 3 & $465 \pm 22$ & $496 \pm 31$ & 6.7 \\
\hline $\mathrm{RD}$ & & 15107 & $7 / 8$ & 3 & $477 \pm 26$ & $560 \pm 21$ & 17.4 \\
\hline Precision & $0.301 \times 0.054$ & 19052 & $7 / 7$ & 1 & $554 \pm 38$ & $628 \pm 24$ & 13.4 \\
\hline Precision & & 19895 & $8 / 8$ & 1 & $516 \pm 16$ & $642 \pm 22$ & 24.4 \\
\hline Precision & $1.364 \times 0.070$ & 17405 & $6 / 8$ & 1 & $577 \pm 17$ & $658 \pm 18$ & 14.0 \\
\hline Precision & & 19895 & $8 / 7$ & 1 & $585 \pm 27$ & $623 \pm 46$ & 6.5 \\
\hline Precision & $7.739 \times 0.070$ & 19052 & $8 / 8$ & 3 & $788 \pm 50$ & $919 \pm 37$ & 16.6 \\
\hline Precision & & 19921 & $6 / 6$ & 3 & $760 \pm 21$ & $834 \pm 18$ & 9.7 \\
\hline Precision & $16.955 \times 0.139$ & 19422 & $8 / 8$ & 3 & $576 \pm 10$ & $660 \pm 12$ & 14.6 \\
\hline Precision & & 19895 & $8 / 8$ & 3 & $614 \pm 10$ & $729 \pm 29$ & 18.7 \\
\hline
\end{tabular}


Table 1-8. Linear Tensile Modulus (0-25\% elongation) Data for RD Rubber O-Rings, Batch 15107 Cure Study

\begin{tabular}{|c|c|c|c|c|c|c|c|c|c|c|c|}
\hline \multicolumn{3}{|c|}{$0.301 \times 0.054$} & \multirow{2}{*}{$\begin{array}{l}\text { RD } 15107 \\
\text { Aged }\end{array}$} & \multicolumn{2}{|c|}{$\begin{array}{l}0.301 \times 0.054 \\
(4 \mathrm{~min} . \text { cure })\end{array}$} & \multicolumn{2}{|r|}{ RD 15107} & \multicolumn{2}{|c|}{$\begin{array}{l}0.301 \times 0.054 \\
(3 \mathrm{~min} . \text { cure })\end{array}$} & \multirow[b]{2}{*}{ Ring } & \multirow{2}{*}{$\begin{array}{l}\text { RD } 15107 \\
\text { Aged }\end{array}$} \\
\hline Ring & Initial & Ring & & Ring & Initial & Ring & Aged & Ring & Initial & & \\
\hline 1 & 451 & 9 & 448 & 1 & 442 & 9 & 503 & 1 & 521 & 9 & 500 \\
\hline 2 & 448 & 10 & 486 & 2 & 427 & 10 & 446 & 2 & $N / A$ & 10 & 529 \\
\hline 3 & 481 & 11 & 500 & 3 & 452 & 11 & 442 & 3 & 467 & 11 & 523 \\
\hline 4 & 481 & 12 & 523 & 4 & 414 & 12 & 464 & 4 & 453 & 12 & 541 \\
\hline 5 & 42.1 & 13 & 502 & 5 & 443 & 13 & 472 & 5 & 456 & 13 & 544 \\
\hline 6 & 442 & 14 & 532 & 6 & 417 & 14 & 480 & 6 & 444 & 14 & 526 \\
\hline 7 & 394 & 15 & 472 & 7 & 408 & 15 & 467 & 7 & 475 & 15 & 554 \\
\hline 8 & $\underline{456}$ & 16 & 479 & 8 & $\underline{439}$ & 16 & 487 & 8 & $\underline{437}$ & 16 & $\underline{547}$ \\
\hline Avg: & $447 \pm 29$ & & $493 \pm 27$ & Avg: & $430 \pm 16$ & & $470 \pm 20$ & Avg: & $465 \pm 28$ & & $533 \pm 17$ \\
\hline \multicolumn{3}{|c|}{ Modulus Change: } & $10 \%$ & \multicolumn{3}{|c|}{ Modulus Change: } & $9 \%$ & \multicolumn{3}{|c|}{ Modulus Change: } & $15 \%$ \\
\hline \multicolumn{3}{|c|}{$1.114 \times 0.070$} & RD 15107 & \multicolumn{2}{|c|}{$\begin{array}{l}1.114 \times 0.070 \\
(4 \mathrm{~min} . \text { cure })\end{array}$} & & RD 15107 & \multicolumn{2}{|c|}{$\begin{array}{l}1.114 \times 0.070 \\
(3 \mathrm{~min} . \text { cure })\end{array}$} & & RD 15107 \\
\hline Ring & Initial & Ring & Aged & Ring & Initial & Ring & Aged & Ring & Initial & Ring & Aged \\
\hline 1 & 383 & 9 & 431 & 1 & 378 & 9 & $\overline{499}$ & 1 & $\overline{378}$ & 9 & 483 \\
\hline 2 & 373 & 10 & 415 & 2 & 400 & 10 & 458 & 2 & 363 & 10 & 466 \\
\hline 3 & 423 & 11 & 408 & 3 & 413 & 11 & 469 & 3 & 382 & 11 & 451 \\
\hline 4 & 400 & 12 & 421 & 4 & 353 & 12 & 415 & 4 & 408 & 12 & 388 \\
\hline 5 & 376 & 13 & 427 & 5 & 373 & 13 & 487 & 5 & 407 & 13 & 426 \\
\hline 6 & 353 & 14 & 475 & 6 & 384 & 14 & 482 & 6 & 378 & 14 & 470 \\
\hline 7 & N/A & 15 & 418 & 7 & 416 & 15 & 445 & 7 & 349 & 15 & 505 \\
\hline 8 & $\underline{416}$ & 16 & $\underline{454}$ & 8 & $\underline{406}$ & 16 & $\underline{417}$ & 8 & $\underline{400}$ & 16 & $\underline{474}$ \\
\hline Avg: & $389 \pm 25$ & & $431 \pm 22$ & Avg: & $390+22$ & & $459 \pm 31$ & Avg: & $383 \pm 21$ & & $458 \pm 36$ \\
\hline \multicolumn{3}{|c|}{ Modulus Change: } & $11 \%$ & \multicolumn{3}{|c|}{ Modulus Change: } & $19 \%$ & \multicolumn{3}{|c|}{ Modulus Change: } & $19 \%$ \\
\hline \multicolumn{3}{|c|}{$7.185 \times 0.103$} & RD 15107 & \multicolumn{2}{|c|}{$\begin{array}{l}7.185 \times 0.103 \\
(4 \mathrm{~min} . \text { cure })\end{array}$} & & RD 15107 & \multicolumn{2}{|c|}{$\begin{array}{l}7.185 \times 0.103 \\
\text { (3 min. cure) }\end{array}$} & & RD 15107 \\
\hline Ring & Initial & Ring & Aged & Ring & Initial & Bing & Aged & Ring & Initial & Ring & Aged \\
\hline 1 & 544 & 9 & 537 & 1 & 489 & 9 & $\overline{623}$ & 1 & 511 & 9 & 578 \\
\hline 2 & 451 & 10 & 561 & 2 & 501 & 10 & 562 & 2 & 544 & 10 & 655 \\
\hline 3 & 491 & 11 & 547 & 3 & 492 & 11 & 607 & 3 & 569 & 11 & 634 \\
\hline 4 & 495 & 12 & 603 & 4 & 495 & 12 & 542 & 4 & 517 & 12 & 584 \\
\hline 5 & 532 & 13 & 544 & 5 & 492 & 13 & 587 & 5 & 529 & 13 & 567 \\
\hline 6 & 534 & 14 & 554 & 6 & 489 & 14 & 537 & 6 & 495 & 14 & 666 \\
\hline 7 & 507 & 15 & 533 & 7 & 504 & 15 & 557 & 7 & 504 & 15 & 588 \\
\hline 8 & $\underline{499}$ & 16 & $\underline{545}$ & 8 & $\underline{468}$ & 16 & $\underline{582}$ & 8 & $\underline{551}$ & 16 & $\underline{587}$ \\
\hline Avg: & $507 \pm 30$ & & $553 \pm 22$ & Avg: & $491 \pm 11$ & & $575 \pm 31$ & Avg: & $527 \pm 25$ & & $607 \pm 38$ \\
\hline Modul & Change: & & $12 \%$ & Modu & Change: & & $17 \%$ & Modul & Change: & & $15 \%$ \\
\hline 11.196 & 0.103 & & RD 15107 & $\begin{array}{l}11.19 \\
(4 \mathrm{mi}\end{array}$ & $\begin{array}{l}0.103 \\
\text { cure) }\end{array}$ & & RD 15107 & $\begin{array}{l}11.19 \\
(3 \mathrm{mir}\end{array}$ & $\begin{array}{l}0.103 \\
\text { cure) }\end{array}$ & & RD 15107 \\
\hline Ring & Initial & Ring & Aged & Ring & Initial & Ring & Aged & Ring & Initial & Ring & Aged \\
\hline 1 & 525 & 9 & 601 & 1 & 433 & 9 & 526 & 1 & 445 & 9 & 552 \\
\hline 2 & 490 & 10 & 552 & 2 & 433 & 10 & 526 & 2 & 445 & 10 & 531 \\
\hline 3 & 486 & 11 & 560 & 3 & 436 & 11 & 526 & 3 & 443 & 11 & 582 \\
\hline 4 & 460 & 12 & 541 & 4 & 418 & 12 & 542 & 4 & 443 & 12 & 613 \\
\hline 5 & N/A & 13 & 566 & 5 & 433 & 13 & 542 & 5 & 433 & 13 & 557 \\
\hline 6 & 448 & 14 & 558 & 6 & 436 & 14 & 542 & 6 & 439 & 14 & 577 \\
\hline 7 & 460 & 15 & 531 & 7 & 436 & 15 & 542 & 7 & 439 & 15 & 567 \\
\hline 8 & $\underline{468}$ & 16 & $\underline{571}$ & 8 & 427 & 16 & $\underline{562}$ & 8 & $\underline{449}$ & 16 & $\underline{582}$ \\
\hline Avg: & $477 \pm 26$ & & $560 \pm 21$ & Avg: & $\overline{432 \pm 6}$ & & $538 \pm 12$ & Avg: & $\widetilde{442 \pm 5}$ & & $5 \longdiv { 5 0 \pm 2 5 }$ \\
\hline Modul & Change: & & $18 \%$ & Modu & Change: & & $25 \%$ & Modu & Change: & & $29 \%$ \\
\hline
\end{tabular}


Table 1-9. Linear Tensile Modulus (0-25\% elongation) Data for RD Rubber O-Rings, Various Batches and Sizes

\begin{tabular}{|c|c|c|c|c|c|c|c|c|c|c|c|}
\hline \multicolumn{2}{|c|}{$0.551 \times 0.070$} & \multicolumn{2}{|r|}{ RD 14810} & \multicolumn{2}{|c|}{$0.551 \times 0.070$} & \multicolumn{2}{|c|}{ RD 15107} & \multicolumn{2}{|c|}{$1.114 \times 0.070$} & \multicolumn{2}{|c|}{ RD 14810} \\
\hline Ring & Initial & Ring & Aged & Ring & Initial & Ring & Aged & Bing & Initial & Ring & Aged \\
\hline 1 & 361 & 9 & 380 & 1 & 359 & 9 & 442 & 1 & 352 & 9 & 372 \\
\hline 2 & 372 & 10 & 413 & 2 & 372 & 10 & 401 & 2 & 368 & 10 & 355 \\
\hline 3 & 339 & 11 & 413 & 3 & 347 & 11 & 447 & 3 & 364 & 11 & 386 \\
\hline 4 & N/A & 12 & 409 & 4 & 357 & 12 & 401 & 4 & 364 & 12 & 424 \\
\hline 5 & 373 & 13 & 397 & 5 & 377 & 13 & 396 & 5 & N/A & 13 & 380 \\
\hline 6 & 340 & 14 & 403 & 6 & 392 & 14 & N/A & 6 & 398 & 14 & 415 \\
\hline 7 & 373 & 15 & 417 & 7 & 356 & 15 & N/A & 7 & 368 & 15 & 405 \\
\hline 8 & $\underline{347}$ & 16 & $\underline{392}$ & 8 & $\underline{376}$ & 16 & $\underline{396}$ & 8 & 372 & 16 & 359 \\
\hline Avg: & $358 \pm 16$ & & $403 \pm 13$ & Avg: & $367 \pm 15$ & & $414 \pm 24$ & Avg: & $369 \pm 14$ & & $387 \pm 25$ \\
\hline \multicolumn{2}{|c|}{ Modulus Change: } & & $13 \%$ & \multicolumn{2}{|c|}{ Modulus Change: } & & $13 \%$ & \multicolumn{2}{|c|}{ Modulus Change: } & & $5 \%$ \\
\hline \multicolumn{2}{|c|}{$7.185 \times 0.103$} & \multicolumn{2}{|r|}{ RD 14810} & \multicolumn{2}{|c|}{$11.196 \times 0.103$} & \multicolumn{2}{|c|}{ RD 14936} & & & & \\
\hline Ring & Initial & Ring & Aged & Ring & Initial & Ring & Aged & & & & \\
\hline 1 & 396 & 9 & 488 & 1 & 459 & 9 & 478 & & & & \\
\hline 2 & 435 & 10 & 439 & 2 & 443 & 10 & 489 & & & & \\
\hline 3 & 406 & 11 & 426 & 3 & 438 & 11 & 523 & & & & \\
\hline 4 & 407 & 12 & 442 & 4 & 504 & 12 & 465 & & & & \\
\hline 5 & 442 & 13 & 420 & 5 & 464 & 13 & 461 & & & & \\
\hline 6 & N/A & 14 & 434 & 6 & 473 & 14 & N/A & & & & \\
\hline 7 & 425 & 15 & 419 & 7 & 475 & 15 & 519 & & & & \\
\hline 8 & 413 & 16 & 410 & 8 & N/A & 16 & $\underline{540}$ & & & & \\
\hline Avg: & $418 \pm 17$ & & $435 \pm 24$ & Avg: & $465 \pm 22$ & & $496 \pm 31$ & & & & \\
\hline \multicolumn{2}{|c|}{ Modulus Change: } & & $4 \%$ & \multicolumn{2}{|c|}{ Modulus Change: } & & $7 \%$ & & & & \\
\hline
\end{tabular}




\section{$0.116 \times 0.038$ Parker 318466}

$\begin{array}{cccc}\text { Ring } & \frac{\text { Initial }}{479} & \frac{\text { Ring }}{9} & \frac{\text { Aged }}{564} \\ 2 & 544 & 10 & 565 \\ 3 & 587 & 11 & 586 \\ 4 & 487 & 12 & 602 \\ 5 & 488 & 13 & 629 \\ 6 & 535 & 14 & 557 \\ 7 & 532 & 15 & 606 \\ 8 & \underline{566} & 16 & \underline{536} \\ \text { Avg: } & 527 \pm 39 & & 581 \pm 31 \\ \text { Modulus Change: } & & 10 \%\end{array}$

\section{$0.301 \times 0.054 \quad$ Parker 316104}

Ring Initial Ring Aged

\begin{tabular}{|c|c|c|}
\hline 1 & 727 & 6 \\
\hline 2 & 750 & 7 \\
\hline 3 & 746 & 8 \\
\hline 4 & 789 & 9 \\
\hline 5 & 757 & 10 \\
\hline
\end{tabular}

Avg: $\overline{754 \pm 22} \quad \overline{780 \pm 96}$

Modulus Change:

$3 \%$

\begin{tabular}{cccc}
$7.688 \times 0.070$ & \multicolumn{2}{c}{ Parker 316104} \\
Ring & $\frac{\text { Initial }}{1}$ & Ring & Aged \\
1 & 901 & 6 & 812 \\
2 & 872 & 7 & 789 \\
3 & 915 & 8 & 871 \\
4 & 858 & 9 & 918 \\
5 & 934 & 10 & 911
\end{tabular}

Avg: $\quad \overline{896 \pm 31}$ Modulus Change:

\begin{tabular}{|c|c|c|c|}
\hline \multicolumn{2}{|c|}{$0.301 \times 0.054$} & \multicolumn{2}{|c|}{ Parker 316710} \\
\hline Ring & Initial & Ring & Aged \\
\hline 1 & $N / A$ & 9 & 706 \\
\hline 2 & 811 & 10 & N/A \\
\hline 3 & 829 & 11 & 839 \\
\hline 4 & 783 & 12 & N/A \\
\hline 5 & 841 & 13 & 857 \\
\hline 6 & 746 & 14 & 825 \\
\hline 7 & 853 & 15 & 865 \\
\hline 8 & $\underline{823}$ & 16 & $\underline{N / A}$ \\
\hline Avg: & $8 \overline{12 \pm 37}$ & & $819 \pm 65$ \\
\hline
\end{tabular}

Modulus Change:

\section{$7.688 \times 0.070$}

Ring Initial

1466

2448

3506

$4 \quad 483$

$5 \quad 472$

$\begin{array}{ll}6 & 540 \\ 7 & 512\end{array}$

$8 \quad 488$

Avg: $\quad 489 \pm 29$

Modulus Change:

\begin{tabular}{|c|c|c|c|}
\hline \multicolumn{2}{|c|}{$1.364 \times 0.070$} & \multicolumn{2}{|c|}{ Parker 31610} \\
\hline Bing & Initial & Ring & Aged \\
\hline 1 & 672 & 6 & 724 \\
\hline 2 & 652 & 7 & N/A \\
\hline 3 & 711 & 8 & 748 \\
\hline 4 & N/A & 9 & 735 \\
\hline 5 & 696 & 10 & N/A \\
\hline Avg: & $683 \pm 26$ & & $736 \pm 12$ \\
\hline Modu & & & $8 \%$ \\
\hline
\end{tabular}

\subsection{9x0.103 Parker 316104}

Ring Initial Ring Aged

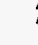

3

$\sqrt{2}+2$

5

7

\begin{tabular}{llll}
7 & 858 & 15 & 934 \\
\hline
\end{tabular}

$\begin{array}{cccc}8 & \underline{861} & 16 & \underline{895} \\ \text { Avg: } & 868 \pm 7 & & 906 \pm 32\end{array}$

Modulus Change:

\section{$1.364 \times 0.070$}

Ring Initial

1621

2652

$3 \quad 621$

$4 \quad$ N/A

$5 \quad 631$

$6 \quad 649$

7668

$\begin{array}{rr}8 & \underline{628} \\ \text { Avg: } & 639 \pm 18\end{array}$

Modulus Change:

\section{$16.339 \times 0.103$}

Bing Initial

1826

2836

$3 \quad 815$

$4 \quad 821$

$5 \quad 811$

$6 \quad 825$

$7 \quad 807$

$\begin{array}{rr}8 & \frac{813}{819} \\ \text { Avg: } & 819 \pm 9\end{array}$

Modulus Change:
Parker 317403

Ring Aged

9661

$10 \quad 662$

$11 \quad 645$

$12 \quad 665$

$13 \quad 636$

$14 \quad 707$

$15 \quad 698$

$16 \quad \underline{728}$

$675 \pm 32$

$6 \%$

Parker 316710

Ring Aged

$9 \quad 909$

$10 \quad 821$

$11 \quad 844$

$12 \quad 832$

$13 \quad 844$

$14 \quad 826$

$15 \quad 831$

$16 \quad 830$

$842 \pm 28$ 
Table 1-11. Linear Tensile Modulus (0-25\% elongation) Data for Precision O-Rings

\begin{tabular}{|c|c|c|c|c|c|c|c|c|c|c|c|c|c|c|c|}
\hline \multicolumn{2}{|c|}{$0.301 \times 0.054$} & \multicolumn{2}{|c|}{ Precision 19052} & \multicolumn{2}{|c|}{$0.301 \times 0.054$} & \multicolumn{2}{|c|}{ Precision 19895} & \multicolumn{2}{|c|}{$1.364 \times 0.070$} & \multicolumn{2}{|c|}{ Precision 17405} & \multicolumn{2}{|c|}{$1.364 \times 0.070$} & \multicolumn{2}{|c|}{ Precision 19895} \\
\hline Ring & Initial & Ring & Aged & Ring & Initial & Ring & Aged & Ring & Initial & Ring & Aged & Ring & Initial & Ring & Aged \\
\hline 1 & 553 & 9 & N/A & 1 & 496 & 9 & 637 & 1 & 547 & 9 & 620 & 1 & 574 & 9 & 545 \\
\hline 2 & 504 & 10 & 587 & 2 & 531 & 10 & 675 & 2 & 572 & 10 & 661 & 2 & 565 & 10 & 614 \\
\hline 3 & 582 & 11 & 669 & 3 & 517 & 11 & 609 & 3 & $N / A$ & 11 & 653 & 3 & 594 & 11 & 627 \\
\hline 4 & N/A & 12 & 625 & 4 & 531 & 12 & 615 & 4 & 588 & 12 & 653 & 4 & 570 & 12 & 655 \\
\hline 5 & 586 & 13 & 619 & 5 & 503 & 13 & 657 & 5 & N/A & 13 & 678 & 5 & 569 & 13 & $N / A$ \\
\hline 6 & 594 & 14 & 628 & 6 & 517 & 14 & 635 & 6 & 572 & 14 & 674 & 6 & 590 & 14 & 598 \\
\hline 7 & 560 & 15 & 637 & 7 & 538 & 15 & 649 & 7 & 588 & 15 & 670 & 7 & 569 & 15 & 631 \\
\hline 8 & $\underline{502}$ & 16 & $\underline{634}$ & 8 & 496 & 16 & $\underline{657}$ & 8 & $\underline{592}$ & 16 & $\underline{657}$ & 8 & $\underline{647}$ & 16 & $\underline{693}$ \\
\hline Avg: & $554 \pm 38$ & & $628 \pm 24$ & Avg: & $516 \pm 16$ & & $642 \pm 22$ & Avg: & $577 \pm 17$ & & $658 \pm 18$ & Avg: & $585 \pm 27$ & & $623 \pm 46$ \\
\hline \multicolumn{3}{|c|}{ Modulus Change: } & $13 \%$ & \multicolumn{3}{|c|}{ Modulus Change: } & $24 \%$ & \multicolumn{3}{|c|}{ Modulus Change: } & $14 \%$ & \multicolumn{2}{|c|}{ Modulus Change: } & & $7 \%$ \\
\hline \multicolumn{2}{|c|}{$7.739 \times 0.070$} & \multicolumn{2}{|c|}{ Precision 19052} & \multicolumn{2}{|c|}{$7.739 \times 0.070$} & \multicolumn{2}{|c|}{ Precision 19921} & \multicolumn{2}{|c|}{$16.955 \times 0.139$} & \multicolumn{2}{|c|}{ Precision 19422} & \multicolumn{2}{|c|}{$16.955 \times 0.139$} & \multicolumn{2}{|c|}{ Precision 19895} \\
\hline Ring & Initial & Bing & Aged & Bing & Initial & Bing & Aged & Ring & Initial & Bing & Aged & Ring & Initial & Ring & Aged \\
\hline 1 & 799 & 9 & 859 & 1 & 786 & 7 & 850 & 1 & 568 & 9 & 669 & 1 & 617 & 9 & 752 \\
\hline 2 & 705 & 10 & 945 & 2 & 786 & 8 & 830 & 2 & 565 & 10 & 643 & 2 & 605 & 10 & 702 \\
\hline 3 & 863 & 11 & 958 & 3 & 752 & 9 & 859 & 3 & 572 & 11 & 663 & 3 & 614 & 11 & 727 \\
\hline 4 & 739 & 12 & 957 & 4 & 740 & 10 & 819 & 4 & 571 & 12 & 658 & 4 & 625 & 12 & 671 \\
\hline 5 & 793 & 13 & 923 & 5 & 752 & 11 & 812 & 5 & 566 & 13 & 643 & 5 & 628 & 13 & 743 \\
\hline 6 & 819 & 14 & 876 & 6 & 740 & 12 & 832 & 6 & 588 & 14 & 665 & 6 & 597 & 14 & 757 \\
\hline 7 & 767 & 15 & 900 & & & & & 7 & 590 & 15 & 680 & 7 & 616 & 15 & 736 \\
\hline 8 & $\underline{819}$ & 16 & 932 & & & & & 8 & $\underline{585}$ & 16 & $\underline{655}$ & 8 & $\underline{608}$ & 16 & $\underline{744}$ \\
\hline Avg: & $788 \pm 50$ & & $919 \pm 37$ & Avg: & $760 \pm 21$ & & $834 \pm 18$ & Avg: & $576 \pm 10$ & & $660 \pm 12$ & Avg: & $614 \pm 10$ & & $729 \pm 29$ \\
\hline \multicolumn{3}{|c|}{ Modulus Change: } & $17 \%$ & \multicolumn{3}{|c|}{ Modulus Change: } & $10 \%$ & \multicolumn{3}{|c|}{ Modulus Change: } & $15 \%$ & \multicolumn{2}{|c|}{ Modulus Change: } & & $19 \%$ \\
\hline
\end{tabular}


Table 1-12. Linear Tensile Modulus (0-25\% elongation) Data for Test Slabs

\begin{tabular}{|c|c|c|}
\hline \multicolumn{3}{|c|}{ Parker 316104} \\
\hline Site & Initial & Aged \\
\hline 1 & 876 & $\overline{1202}$ \\
\hline 2 & 894 & 1037 \\
\hline 3 & 872 & 1134 \\
\hline 4 & 400 & 1105 \\
\hline Avg: & $761 \pm 240$ & $1120 \pm 68$ \\
\hline
\end{tabular}

Modulus Change: $\quad 47 \%$

\section{RD 14810}

Site Initial Aged

$1 \quad 581 \quad 562$

$2 \quad 551 \quad 596$

$3 \quad 570 \quad 613$

$4 \quad \underline{613} \quad \underline{583}$

Avg: $\quad 579 \pm 26 \quad 589 \pm 21$

Modulus Change: $\quad 2 \%$

Precision 19052A

$\begin{array}{ccc}\frac{\text { Site }}{1} & \frac{\text { Initial }}{758} & \frac{\text { Aged }}{765} \\ 2 & 735 & 840 \\ 3 & 714 & 863 \\ 4 & \underline{716} & \underline{824} \\ \text { Avg: } & 731 \pm 20 & 823 \pm 42\end{array}$

Modulus Change: $\quad 13 \%$

$\begin{array}{ccc}\begin{array}{l}\text { Parker } \\ \text { Site }\end{array} & \frac{16710}{\text { Initial }} & \text { Aged } \\ 1 & 1001 & 910 \\ 2 & 965 & 954 \\ 3 & 1058 & 960 \\ 4 & \underline{902} & \underline{1002} \\ \text { Avg: } & 981 \pm 65 & 956 \pm 37\end{array}$

Modulus Change: $\quad-3 \%$

\section{RD 15107}

Site Initial

$\begin{array}{ll}1 & 629 \\ 2 & 633\end{array}$

3679

$4 \quad 621$

Avg: $\quad 641 \pm 26$

Modulus Change:

Aged
684
678
688
$\frac{614}{666 \pm 35}$
$4 \%$

Precision 19895A

\begin{tabular}{|c|c|c|}
\hline$\underline{\text { Site }}$ & Initial & Aged \\
\hline 1 & 777 & 771 \\
\hline 2 & 792 & 793 \\
\hline 3 & 754 & 825 \\
\hline 4 & $\underline{743}$ & 822 \\
\hline Avg: & $766 \pm 22$ & $803 \pm 26$ \\
\hline Modu & s Change: & $5 \%$ \\
\hline
\end{tabular}

\section{Parker 317403}

Site Initial

11941

$\frac{\text { Aged }}{992}$

Parker 317851

Site Initial

1970

2958

$3 \quad 1007$

$4 \quad \underline{958}$

Avg: $\quad 973 \pm 23$

Modulus Change:

$\frac{\text { Aged }}{1002}$
943
904
$\underline{983}$
$958 \pm 43$

Modulus Change:

$056 \pm 70$

\section{RD 15107 (4 min. cure)}

Site Initial

$$
\text { Aged }
$$

RD 15107 (3 min. cure)

Site Initial Aged

$\begin{array}{llllll}1 & 600 & 654 & 1 & 674 & 721 \\ 2 & 612 & \text { N/A } & 2 & 621 & 681\end{array}$

$\begin{array}{llllll}3 & 583 & 682 & 3 & 633 & 659\end{array}$

$4 \quad \underline{536} \quad \underline{739} \quad 4 \quad \underline{638} \quad \underline{641}$

Avg: $583 \pm 34 \quad 692 \pm 43$ Avg: $642 \pm 23 \quad 676 \pm 35$

Modulus Change: $\quad 19 \% \quad$ Modulus Change: $\quad 5 \%$

$\begin{array}{ccc}\begin{array}{c}\text { Parker } 318466 \\ \text { Site }\end{array} & \frac{\text { Initial }}{574} & \frac{\text { Aged }}{545} \\ 2 & 651 & 610 \\ 3 & 592 & 659 \\ 4 & \underline{458} & \text { N/A } \\ \text { Avg: } & 569 \pm 81 & 604 \pm 57 \\ \text { Modulus Change: } & 6 \%\end{array}$

$6 \%$ 


\section{Appendix J: Properties vs. Cure Cycle Data}

Contents:

Table J-1. Hardness and Compression Set of Materials with Different Cures

Table J-2. Tensile Strength and Elongation of Materials with Different Cures

Table J-3. Tensile Modulus (all elongation ranges) of Materials with Different Cures

Table J-4. Tensile Modulus Plus Averages of Materials with Different Cures

Table J-5. Tensile Work (0-20\% elongation) of Materials with Different Cures

Plot J-6. Modulus vs. Percent Elongation Range of Unaged Materials with Different Cures

Plot J-7. Modulus vs. Percent Elongation Range of Aged Materials with Different Cures

Detailed ring and test slab data is contained in Tables in the preceding appendices. 
Table J-1. Hardness and Compression Set Data on RD Rubber Materials With Differing Cure Schedules

All rings prepared from RD Rubber Batch No. 15107.

$3 \min .12$ sec. $=45 \%$ cure. $\quad 4$ min. 18 sec. $=70 \%$ cure. $\quad 10 \mathrm{~min} .=95 \%$ cure

\begin{tabular}{|c|c|c|c|c|c|c|c|}
\hline Ring Size & Cure Time & $\begin{array}{c}\text { Initial } \\
\text { Hardness }\end{array}$ & $\begin{array}{c}\text { Hardness } \\
\text { after Aging } 1\end{array}$ & $\begin{array}{l}\text { Change in } \\
\text { Hardness }\end{array}$ & Initial Thickness & $\begin{array}{c}\text { Thickness after } \\
\text { Aging }^{2}\end{array}$ & $\begin{array}{c}\text { Compression } \\
\text { Set }(\%)\end{array}$ \\
\hline $0.301 \times 0.054$ & $\begin{array}{c}3 \mathrm{~min} .12 \mathrm{sec} . \\
4 \mathrm{~min} .18 \mathrm{sec} . \\
10 \mathrm{~min} .\end{array}$ & $\begin{array}{l}75.9 \pm 1.1 \\
75.6 \pm 1.0 \\
76.1 \pm 0.4\end{array}$ & $\begin{array}{l}80.8 \pm 0.8 \\
80.1 \pm 0.6 \\
79.3 \pm 0.6\end{array}$ & $\begin{array}{l}+4.9 \\
+4.5 \\
+3.2\end{array}$ & $\begin{array}{l}0.05552 \pm 0.00057 \\
0.05490 \pm 0.00033 \\
0.05524 \pm 0.00044\end{array}$ & $\begin{array}{l}0.05433 \pm 0.00069 \\
0.05389 \pm 0.00031 \\
0.05429 \pm 0.00041\end{array}$ & $\begin{array}{l}7.9 \\
7.0 \\
6.5\end{array}$ \\
\hline $1.114 \times 0.070$ & $\begin{array}{l}3 \mathrm{~min} .12 \mathrm{sec} . \\
4 \mathrm{~min} .18 \mathrm{sec} . \\
10 \mathrm{~min} .\end{array}$ & $\begin{array}{l}73.3 \pm 1.2 \\
72.9 \pm 0.8 \\
75.2 \pm 0.8\end{array}$ & $\begin{array}{l}80.0 \pm 0.3 \\
77.2 \pm 0.5 \\
76.8 \pm 0.6\end{array}$ & $\begin{array}{l}+6.7 \\
+4.3 \\
+1.6\end{array}$ & $\begin{array}{l}0.06967 \pm 0.00033 \\
0.06951 \pm 0.00025 \\
0.06930 \pm 0.00022\end{array}$ & $\begin{array}{l}0.06782 \pm 0.00013 \\
0.06839 \pm 0.00028 \\
0.06811 \pm 0.00019\end{array}$ & $\begin{array}{l}10.8 \\
6.6 \\
7.1\end{array}$ \\
\hline $7.185 \times 0.103$ & $\begin{array}{c}3 \mathrm{~min} .12 \mathrm{sec} . \\
4 \mathrm{~min} .18 \mathrm{sec} . \\
10 \mathrm{~min} .\end{array}$ & $\begin{array}{l}72.8 \pm 1.5 \\
73.1 \pm 0.5 \\
74.2 \pm 0.8\end{array}$ & $\begin{array}{l}76.9 \pm 0.9 \\
77.7 \pm 0.3 \\
76.1 \pm 0.7\end{array}$ & $\begin{array}{l}+4.1 \\
+4.6 \\
+1.9\end{array}$ & $\begin{array}{l}0.10432 \pm 0.00038 \\
0.10538 \pm 0.00072 \\
0.10473 \pm 0.00064\end{array}$ & $\begin{array}{l}0.10164 \pm 0.00030 \\
0.10126 \pm 0.00080 \\
0.10318 \pm 0.00058\end{array}$ & $\begin{array}{c}9.8 \\
14.5 \\
5.6\end{array}$ \\
\hline $11.196 \times 0.103$ & $\begin{array}{c}3 \mathrm{~min} .12 \mathrm{sec} . \\
4 \mathrm{~min} .18 \mathrm{sec} . \\
10 \mathrm{~min} .\end{array}$ & $\begin{array}{l}72.3 \pm 1.7 \\
73.6 \pm 0.6 \\
72.8 \pm 0.9\end{array}$ & $\begin{array}{l}76.9 \pm 0.9 \\
76.6 \pm 0.7 \\
75.4 \pm 1.4\end{array}$ & $\begin{array}{l}+4.6 \\
+3.0 \\
+2.6\end{array}$ & $\begin{array}{l}0.10468 \pm 0.00051 \\
0.10386 \pm 0.00042 \\
0.10685 \pm 0.00078\end{array}$ & $\begin{array}{l}0.10246 \pm 0.00034 \\
0.10206 \pm 0.00033 \\
0.10540 \pm 0.00069\end{array}$ & $\begin{array}{l}8.0 \\
6.7 \\
4.9\end{array}$ \\
\hline Test Slabs & $\begin{array}{c}3 \mathrm{~min} .12 \mathrm{sec} . \\
4 \mathrm{~min} .18 \mathrm{sec} . \\
10 \mathrm{~min} .\end{array}$ & $\begin{array}{l}67.3 \pm 0.8 \\
66.8 \pm 0.8 \\
65.5 \pm 0.5\end{array}$ & $\begin{array}{l}69.8 \pm 0.8 \\
70.0 \pm 1.2 \\
64.8 \pm 0.4\end{array}$ & $\begin{array}{l}+2.5 \\
+3.2 \\
-0.7\end{array}$ & $\begin{array}{l}0.3530 \pm 0.0016 \\
0.3358 \pm 0.0003 \\
0.3308 \pm 0.0011\end{array}$ & $\begin{array}{l}0.3411 \pm 0.0006 \\
0.3275 \pm 0.0003 \\
0.3188 \pm 0.0009\end{array}$ & $\begin{array}{l}13.5 \\
10.8 \\
12.6\end{array}$ \\
\hline
\end{tabular}

1. 70 hours at $212^{\circ} \mathrm{F}$ plus 24 hours at room temperature.

2. 22 hours compression set aging at $25 \%$ compression and $158^{\circ} \mathrm{F}$ plus $30 \mathrm{~min}$. at room temperature. 
Table J-2. Tensile Strength and Elongation Data on RD Rubber Materials With Differing Cure Schedules

All rings prepared from RD Rubber Batch No. 15107.

3 min. 12 sec. $=45 \%$ cure.

4 min. 18 sec. $=70 \%$ cure.

$10 \mathrm{~min} .=95 \%$ cure

\begin{tabular}{|c|c|c|c|c|c|c|c|}
\hline Ring Size & Cure Time & $\begin{array}{c}\text { Initial Tensile } \\
\text { Strength }\end{array}$ & $\begin{array}{c}\text { Ten. Strength } \\
\text { after Aging }\end{array}$ & $\begin{array}{l}\text { Percent } \\
\text { Change }\end{array}$ & | Initial Elongation & $\begin{array}{c}\text { Elongation after } \\
\text { Aging }\end{array}$ & $\begin{array}{l}\text { Percent } \\
\text { Change } \\
\end{array}$ \\
\hline \multirow[t]{3}{*}{$0.301 \times 0.054$} & $3 \mathrm{~min} .12 \mathrm{sec}$. & $2429 \pm 133$ & $2556 \pm 136$ & 5 & $340 \pm 20$ & $276 \pm 12$ & -18 \\
\hline & $4 \mathrm{~min} .18 \mathrm{sec}$. & $2374 \pm 76$ & $2369 \pm 153$ & 0 & $334 \pm 15$ & $284 \pm 15$ & -15 \\
\hline & $10 \mathrm{~min}$. & $2236 \pm 406$ & $2423 \pm 122$ & 8 & $308 \pm 46$ & $303 \pm 13$ & -2 \\
\hline \multirow[t]{3}{*}{$1.114 \times 0.070$} & $3 \mathrm{~min} .12 \mathrm{sec}$. & $2177 \pm 262$ & $2089 \pm 171$ & -4 & $319 \pm 43$ & $223 \pm 34$ & -30 \\
\hline & $4 \mathrm{~min} .18 \mathrm{sec}$. & $2119 \pm 230$ & $2099 \pm 771$ & -1 & $291 \pm 35$ & $258 \pm 24$ & -11 \\
\hline & $10 \mathrm{~min}$. & $2039 \pm 236$ & $2153 \pm 107$ & 6 & $296 \pm 49$ & $300 \pm 23$ & 2 \\
\hline \multirow[t]{3}{*}{$7.185 \times 0.103$} & $3 \mathrm{~min} .12 \mathrm{sec}$. & $1879 \pm 249$ & $1751 \pm 157$ & -7 & $218 \pm 22$ & $155 \pm 10$ & -29 \\
\hline & $4 \mathrm{~min} .18 \mathrm{sec}$. & $1170 \pm 332$ & $1641 \pm 251$ & 40 & $153 \pm 26$ & $159 \pm 13$ & 4 \\
\hline & $10 \mathrm{~min}$. & $1579 \pm 302$ & $1255 \pm 384$ & -20 & $215 \pm 30$ & $171 \pm 39$ & -21 \\
\hline \multirow[t]{3}{*}{$11.196 \times 0.103$} & $3 \mathrm{~min} .12 \mathrm{sec}$ & $1746 \pm 201$ & $1902 \pm 252$ & 9 & $228 \pm 23$ & $184 \pm 25$ & -20 \\
\hline & $4 \mathrm{~min} .18 \mathrm{sec}$. & $1380 \pm 296$ & $1869 \pm 224$ & 35 & $190 \pm 29$ & $194 \pm 20$ & 2 \\
\hline & $10 \mathrm{~min}$ & $1436 \pm 355$ & $1396 \pm 451$ & -3 & $175 \pm 29$ & $152 \pm 30$ & -13 \\
\hline \multirow[t]{3}{*}{ Test Slabs } & $3 \mathrm{~min} .12 \mathrm{sec}$. & $2116 \pm 153$ & $2034 \pm 91$ & -4 & $221 \pm 9$ & $189 \pm 16$ & -14 \\
\hline & $4 \mathrm{~min} .18 \mathrm{sec}$ & $2092 \pm 42$ & $1950 \pm 144$ & -7 & $247 \pm 9$ & $179 \pm 13$ & -28 \\
\hline & $10 \mathrm{~min}$ & $2123 \pm 55$ & $2010 \pm 137$ & -5 & $243 \pm 16$ & $220 \pm 12$ & -9 \\
\hline
\end{tabular}

Aging conditions: 70 hours at $212^{\circ} \mathrm{F}$ plus 24 hours at room temperature. 
Table J-3. Tensile Modulus Data on RD Rubber Materials With Differing Cure Schedules

All rings prepared from RD Rubber Batch No. 15107.

$3 \min .12$ sec. $=45 \%$ cure.

$4 \min .18$ sec. $=70 \%$ cure.

10 min. $=95 \%$ cure

\begin{tabular}{|c|c|c|c|c|c|c|c|c|c|c|c|c|c|c|c|c|}
\hline Ring Size & Cure Time & & $\begin{array}{l}\text { odulus } \\
-10 \% \\
\end{array}$ & & & $\begin{array}{l}\text { odulus } \\
0-15 \% \\
\end{array}$ & & & $\begin{array}{l}\text { odulus } \\
-15 \% \\
\end{array}$ & & & $\begin{array}{l}\text { odulus } \\
0-20 \% \\
\end{array}$ & & & $\begin{array}{l}\text { odulus } \\
-25 \% \\
\end{array}$ & \\
\hline & & unaged & aged & $\Delta \%$ & unaged & aged & $\Delta \%$ & unaged & aged & $\Delta \%$ & unaged & aged & $\Delta \%$ & unaged & aged & $\Delta \%$ \\
\hline $0.301 \times 0.054$ & 3 min. $12 \mathrm{sec}$. & $616 \pm 79$ & $604 \pm 78$ & -2 & $410 \pm 77$ & $537 \pm 74$ & 31 & $471 \pm 31$ & $558 \pm 46$ & 18 & $432 \pm 71$ & $566 \pm 32$ & 31 & $469 \pm 31$ & $547 \pm 24$ & 17 \\
\hline & $4 \mathrm{~min} .18 \mathrm{sec}$. & $511 \pm 47$ & $525 \pm 30$ & 3 & $370 \pm 47$ & $468 \pm 35$ & 26 & $444 \pm 27$ & $479 \pm 20$ & 8 & $384 \pm 25$ & $479 \pm 22$ & 25 & $433 \pm 19$ & $471 \pm 6$ & 9 \\
\hline & $10 \mathrm{~min}$. & $544 \pm 67$ & $517 \pm 53$ & -5 & $315 \pm 46$ & $479 \pm 60$ & 52 & $414 \pm 15$ & $490 \pm 44$ & 18 & $381 \pm 31$ & $504 \pm 27$ & 32 & $427 \pm 17$ & $494 \pm 24$ & 16 \\
\hline $1.114 \times 0.070$ & $3 \mathrm{~min} .12 \mathrm{sec}$. & $451 \pm 34$ & $508 \pm 42$ & 13 & $391 \pm 23$ & $450 \pm 49$ & 15 & $425 \pm 22$ & $499 \pm 38$ & 17 & $346 \pm 20$ & $467 \pm 49$ & 35 & $390 \pm 17$ & $479 \pm 39$ & 23 \\
\hline & $4 \mathrm{~min} .18 \mathrm{sec}$. & $465 \pm 22$ & $548 \pm 42$ & 18 & $400 \pm 21$ & $461 \pm 29$ & 15 & $431 \pm 19$ & $509 \pm 21$ & 18 & $356 \pm 15$ & $426 \pm 22$ & 20 & $391 \pm 17$ & $464 \pm 24$ & 19 \\
\hline & $10 \mathrm{~min}$. & $412 \pm 71$ & $484 \pm 35$ & 17 & $379 \pm 54$ & $398 \pm 54$ & 5 & $419 \pm 27$ & $457 \pm 14$ & 9 & $341 \pm 38$ & $376 \pm 26$ & 10 & $390 \pm 26$ & $428 \pm 19$ & 10 \\
\hline $7.185 \times 0.103$ & $3 \mathrm{~min} .12 \mathrm{sec}$. & $558 \pm 28$ & $643 \pm 34$ & 15 & $503 \pm 24$ & $572 \pm 42$ & 14 & $532 \pm 20$ & $612 \pm 37$ & 15 & $477 \pm 27$ & $541 \pm 24$ & 13 & $513 \pm 21$ & $588 \pm 33$ & 15 \\
\hline & $4 \mathrm{~min} .18 \mathrm{sec}$. & $533 \pm 8$ & $617 \pm 41$ & 16 & $450 \pm 21$ & $531 \pm 32$ & 18 & $497 \pm 9$ & $579 \pm 25$ & 16 & $435 \pm 15$ & $510 \pm 20$ & 17 & $479 \pm 11$ & $556 \pm 25$ & 16 \\
\hline & $10 \mathrm{~min}$. & $471 \pm 23$ & $519 \pm 17$ & 10 & $400 \pm 15$ & $443 \pm 16$ & 11 & $424 \pm 11$ & $467 \pm 11$ & 10 & $366 \pm 12$ & $420 \pm 21$ & 15 & $424 \pm 18$ & $474 \pm 17$ & 12 \\
\hline $11.196 \times 0.103$ & 3 min. $12 \mathrm{sec}$. & $486 \pm 11$ & $646 \pm 35$ & 33 & $401 \pm 9$ & $524 \pm 34$ & 31 & $449 \pm 8$ & $585 \pm 26$ & 30 & $379 \pm 6$ & $500 \pm 25$ & 32 & $421 \pm 4$ & $546 \pm 24$ & 30 \\
\hline & $4 \mathrm{~min} .18 \mathrm{sec}$. & $470 \pm 13$ & $619 \pm 25$ & 32 & $391 \pm 11$ & $478 \pm 11$ & 22 & $441 \pm 1.0$ & $553 \pm 11$ & 25 & $365 \pm 9$ & $463 \pm 8$ & 27 & $411 \pm 7$ & $514 \pm 9$ & 25 \\
\hline & $10 \mathrm{~min}$. & $452 \pm 30$ & $529 \pm 25$ & 17 & $373 \pm 16$ & $476 \pm 32$ & 28 & $409 \pm 8$ & $396 \pm 20$ & -3 & $385 \pm 25$ & $477 \pm 25$ & 24 & $423 \pm 21$ & $508 \pm 18$ & 20 \\
\hline Test Slabs & $3 \mathrm{~min} .12 \mathrm{sec}$. & $785 \pm 89$ & $793 \pm 28$ & 1 & $556 \pm 35$ & $580 \pm 93$ & 4 & $656 \pm 31$ & $651 \pm 55$ & -1 & $501 \pm 14$ & $512 \pm 77$ & 2 & $613 \pm 16$ & $635 \pm 43$ & 4 \\
\hline & 4 min. $18 \mathrm{sec}$. & $587 \pm 42$ & $698 \pm 30$ & 19 & $556 \pm 82$ & $568 \pm 57$ & 2 & $552 \pm 54$ & $636 \pm 30$ & 15 & $482 \pm 77$ & $526 \pm 41$ & 9 & $536 \pm 38$ & $640 \pm 28$ & 19 \\
\hline & $10 \mathrm{~min}$. & $578 \pm 152$ & $|744 \pm 85|$ & 29 & $499 \pm 98$ & $|528 \pm 54|$ & 6 & $528 \pm 11$ & $633 \pm 39$ & 20 & $493 \pm 58$ & $493 \pm 30$ & 0 & $584 \pm 27$ & $|625 \pm 16|$ & 7 \\
\hline
\end{tabular}

Aging conditions: 70 hours at $212^{\circ} \mathrm{F}$ plus 24 hours at room temperature. 
Table J-4. Tensile Modulus Data and Averages on RD Rubber Materials With Differing Cure Schedules

All rings prepared from RD Rubber Batch No. 15107.

$3 \mathrm{~min} .12$ sec. $=45 \%$ cure. $\quad 4 \mathrm{~min} .18 \mathrm{sec} .=70 \%$ cure. $\quad 10 \mathrm{~min} .=95 \%$ cure

\begin{tabular}{|c|c|c|c|c|c|c|c|c|c|c|c|c|c|c|}
\hline & Ring Size & Cure Time & $\begin{array}{r}\text { Mod } \\
5-1 \\
\end{array}$ & $\begin{array}{l}\text { lous } \\
0 \%\end{array}$ & $\begin{array}{l}\text { Modt } \\
10-1\end{array}$ & $\begin{array}{l}\text { Ius } \\
5 \%\end{array}$ & $\begin{array}{r}\text { Mod } \\
5-1 \\
\end{array}$ & $\begin{array}{l}\text { lus } \\
\%\end{array}$ & $\begin{array}{l}\text { Mod } \\
10-2\end{array}$ & $\begin{array}{l}\text { lus } \\
0 \% \\
\end{array}$ & $\begin{array}{r}\text { Mod } \\
0-2 \\
\end{array}$ & $\begin{array}{l}\text { lus } \\
; \% \\
\%\end{array}$ & $\begin{array}{l}\text { Ave } \\
\text { Mod }\end{array}$ & $\begin{array}{l}\text { age } \\
\text { lus }\end{array}$ \\
\hline & & & unaged & aged & unaged & aged & unaged & aged & unaged & aged & unaged & aged & unaged & aged \\
\hline & $0.301 \times 0.054$ & 3 min. 12 sec. & 616 & 604 & 410 & 537 & 471 & 558 & 432 & 566 & 469 & 547 & 480 & 562 \\
\hline & & $4 \mathrm{~min} .18 \mathrm{sec}$. & 511 & 525 & 370 & 468 & 444 & 479 & 384 & 479 & 433 & 471 & 428 & 484 \\
\hline & & $10 \mathrm{~min}$. & 544 & 517 & 315 & 479 & 414 & 490 & 381 & 504 & 427 & 494 & 416 & 497 \\
\hline & $1.114 \times 0.070$ & $3 \mathrm{~min} .12 \mathrm{sec}$. & 451 & 508 & 391 & 450 & 425 & 499 & 346 & 467 & 390 & 479 & 401 & 481 \\
\hline & & $4 \mathrm{~min} .18 \mathrm{sec}$. & 465 & 548 & 400 & 461 & 431 & 509 & 356 & 426 & 391 & 464 & 409 & 482 \\
\hline & & 10 min. & 412 & 484 & 379 & 398 & 419 & 457 & 341 & 376 & 390 & 428 & 388 & 429 \\
\hline & $7.185 \times 0.103$ & $3 \mathrm{~min} .12 \mathrm{sec}$. & 558 & 643 & 503 & 572 & 532 & 612 & 477 & 541 & 513 & 588 & 517 & 591 \\
\hline & & $4 \mathrm{~min} .18 \mathrm{sec}$. & 533 & 617 & 450 & 531 & 497 & 579 & 435 & 510 & 479 & 556 & 479 & 559 \\
\hline & & $10 \mathrm{~min}$. & 471 & 519 & 400 & 443 & 424 & 467 & 366 & 420 & 424 & 474 & 417 & 465 \\
\hline & $11.196 \times 0.103$ & $3 \mathrm{~min} .12 \mathrm{sec}$. & 486 & 646 & 401 & 524 & 449 & 585 & 379 & 500 & 421 & 546 & 427 & 560 \\
\hline & & $4 \mathrm{~min} .18 \mathrm{sec}$. & 470 & 619 & 391 & 478 & 441 & 553 & 365 & 463 & 411 & 514 & 416 & 525 \\
\hline & & $10 \mathrm{~min}$. & 452 & 529 & 373 & 476 & 409 & 396 & 385 & 477 & 423 & 508 & 408 & 477 \\
\hline & Test Slabs & $3 \mathrm{~min} .12 \mathrm{sec}$. & 785 & 793 & 556 & 580 & 656 & 651 & 501 & 512 & 613 & 635 & 622 & 634 \\
\hline & & $4 \mathrm{~min} .18 \mathrm{sec}$. & 587 & 698 & 556 & 568 & 552 & 636 & 482 & 526 & 536 & 640 & 543 & 614 \\
\hline & & $10 \mathrm{~min}$. & 578 & 744 & 499 & 528 & 528 & 633 & 493 & 493 & 584 & 625 & 536 & 605 \\
\hline
\end{tabular}

Aging conditions: 70 hours at $212^{\circ} \mathrm{F}$ plus 24 hours at room temperature. 
Table J-5. Tensile Work (0-20\% elongation) Data on RD Rubber Materials With Differing Cure Schedules

All rings prepared from RD Rubber Batch No. 15107.

$3 \min .12$ sec. $=45 \%$ cure

4 min. 18 sec. $=70 \%$ cure.

$10 \mathrm{~min} .=95 \%$ cure

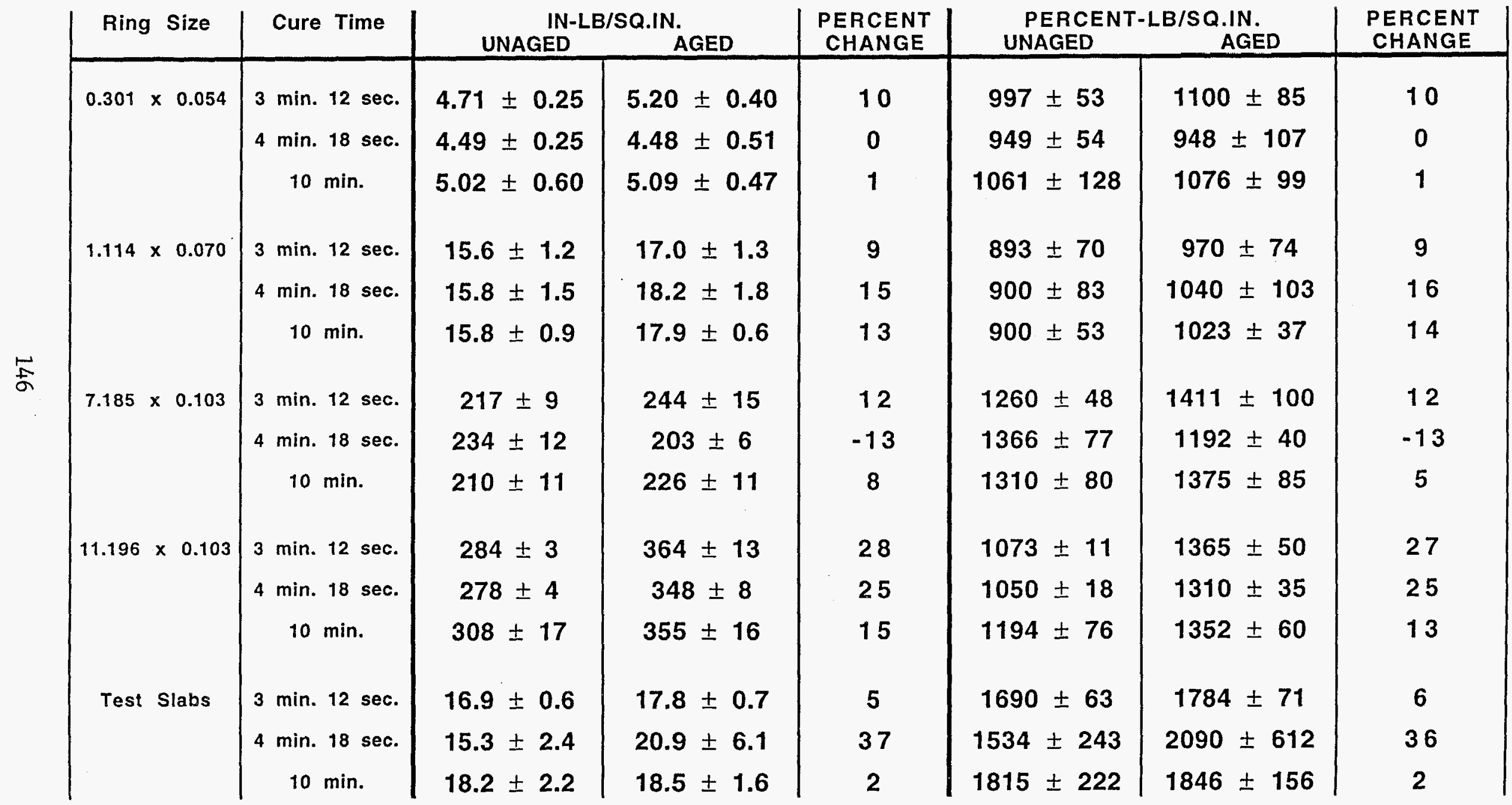

Aging conditions: 70 hours at $212^{\circ} \mathrm{F}$ plus 24 hours at room temperature. 


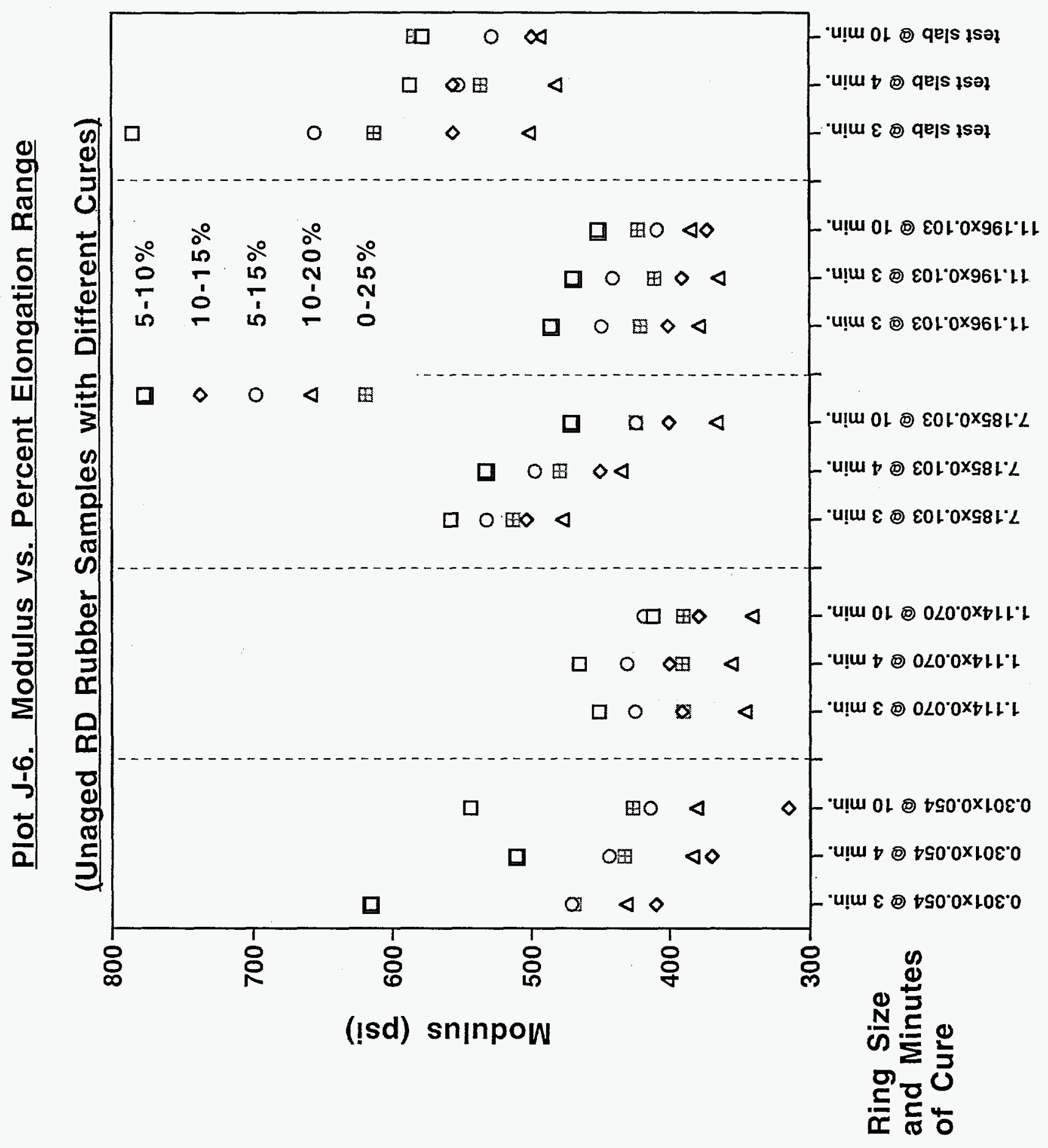




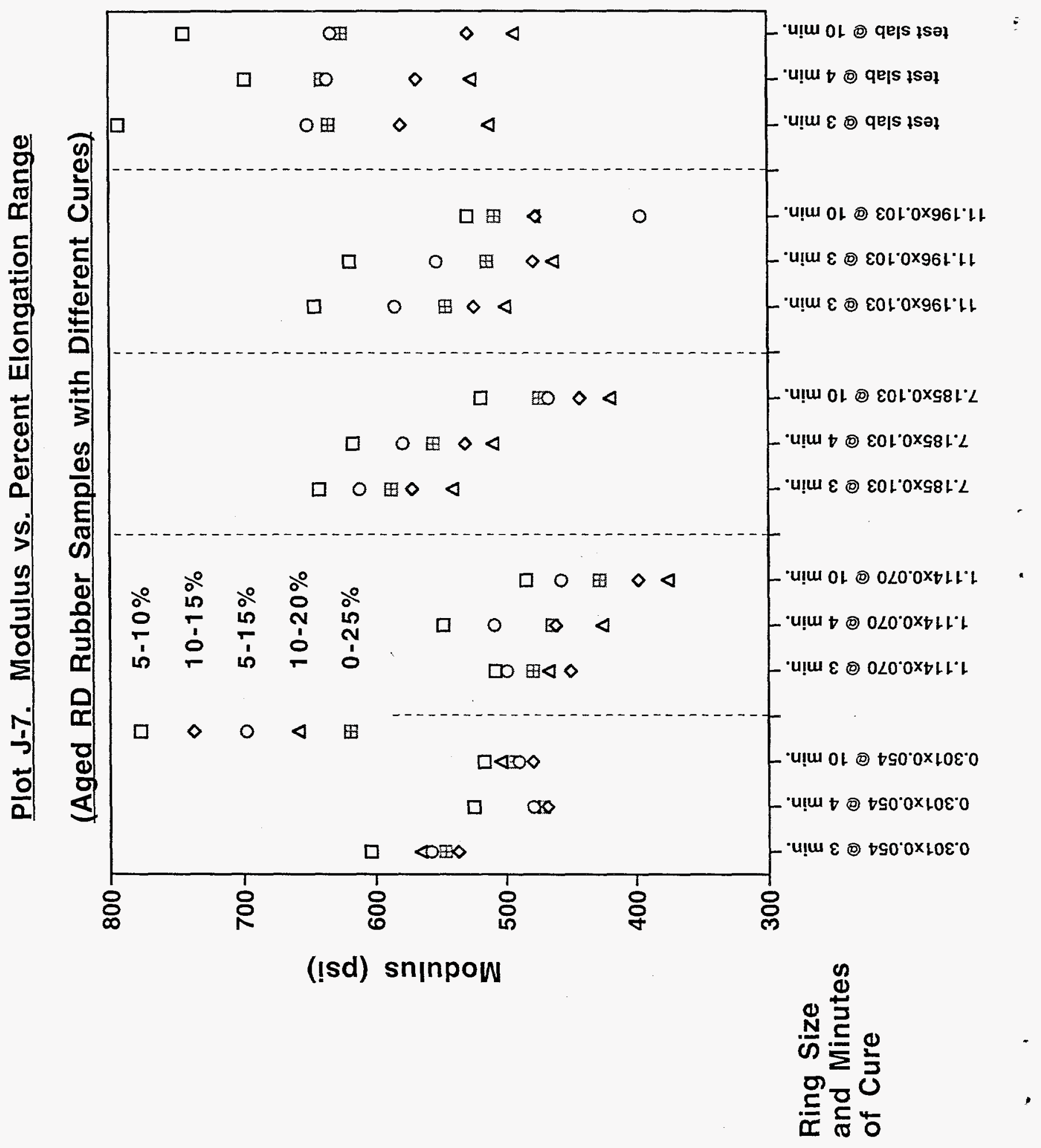


Appendix K: DSC Scans on Rubber Materials

\section{Contents:}

Figure K-1. DSC Scans on O-Rings and Slabs from Different Vendors

Figure K-2. DSC Scans on Stockpile Aged W76 and W87 Butyl Rubber O-Rings 


\section{Figure K-1. DSC Scans of Butyl Rubber Materials from Different Vendors}

(endotherms are positive, exotherms are negative)

Parker O-Rings and Test Slab, Batch 316104

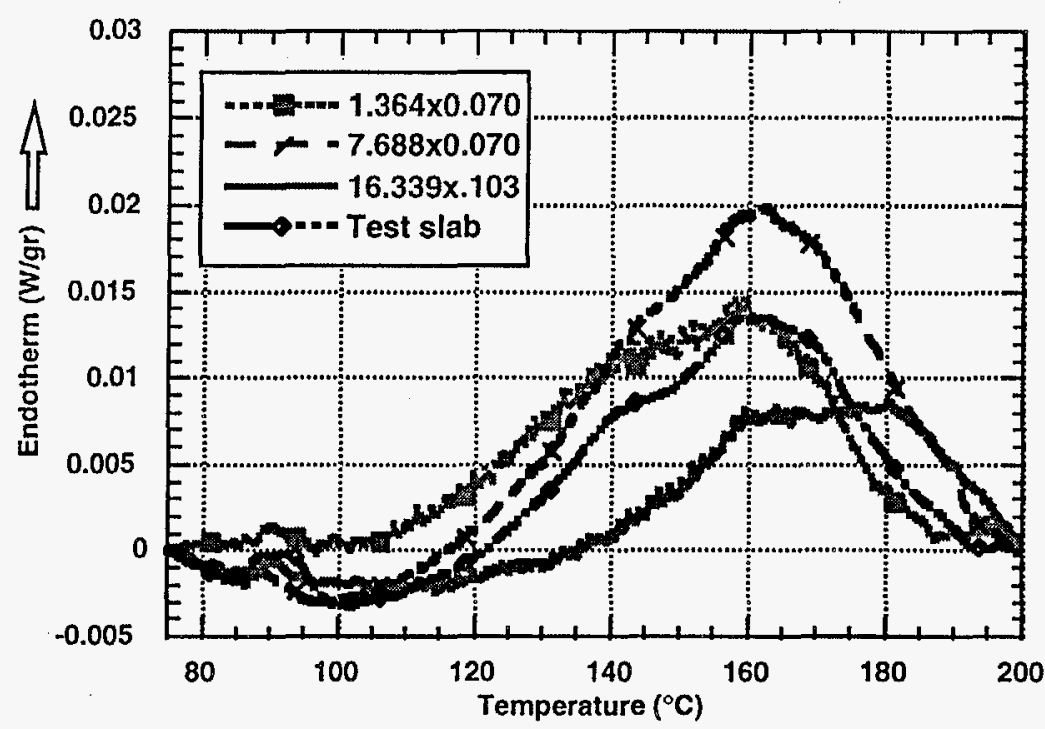

RD Rubber O-Rings and Test Slab, Batch 14810

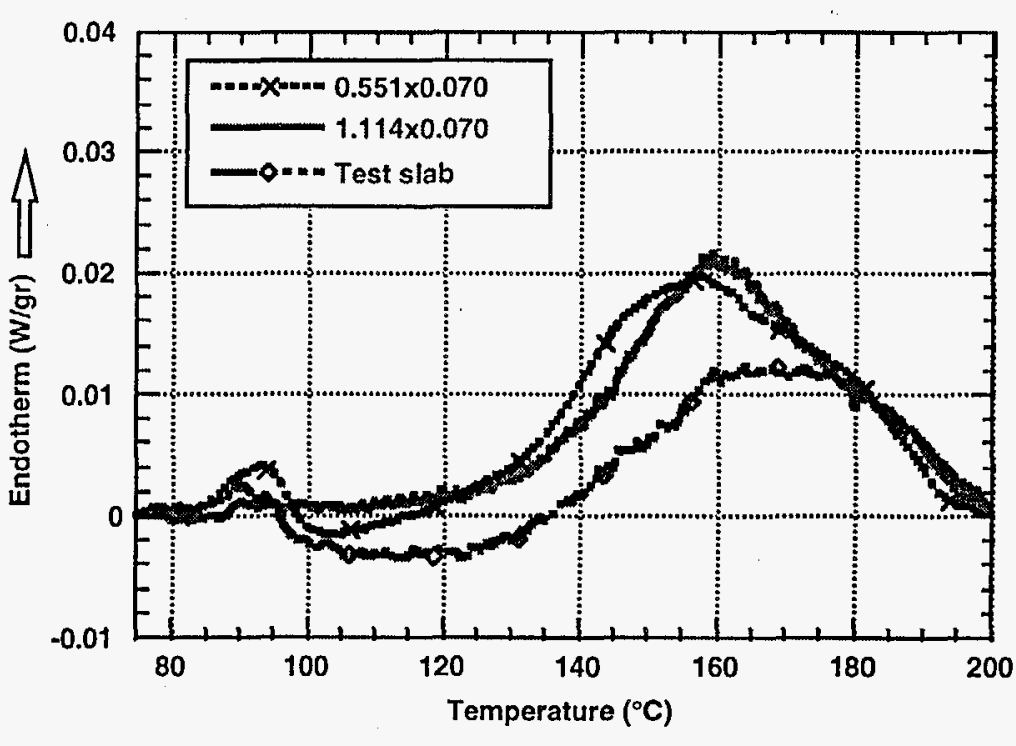

Precision O-Rings and Test Slabs, Batch 19895

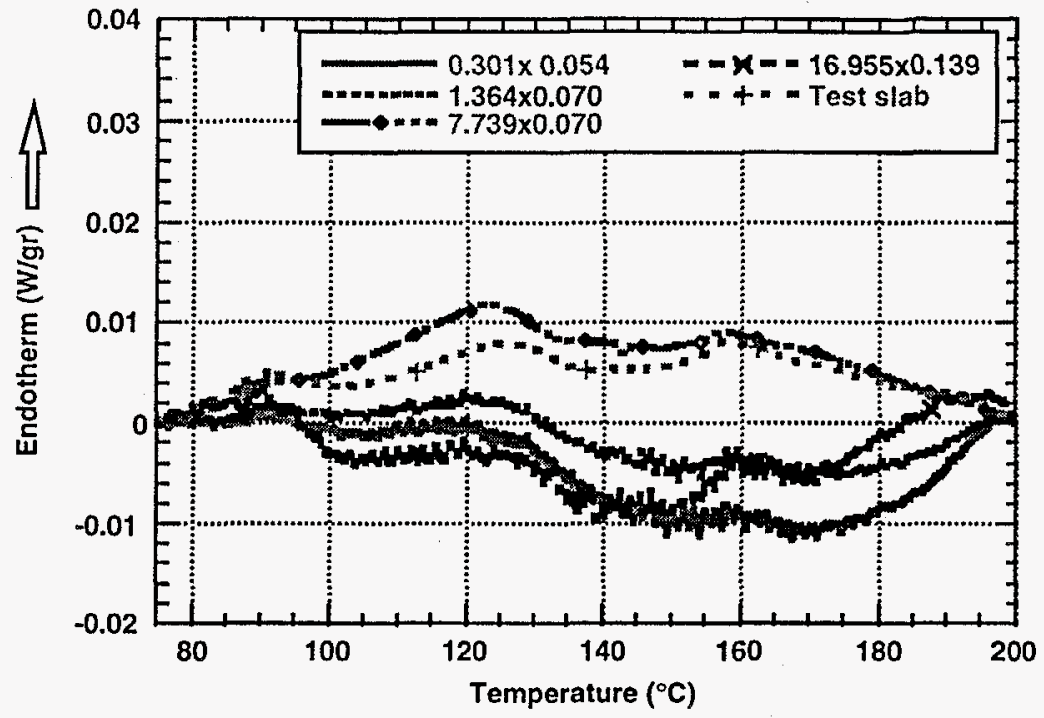

RD Rubber O-Rings and Test Slab, Batch 15107

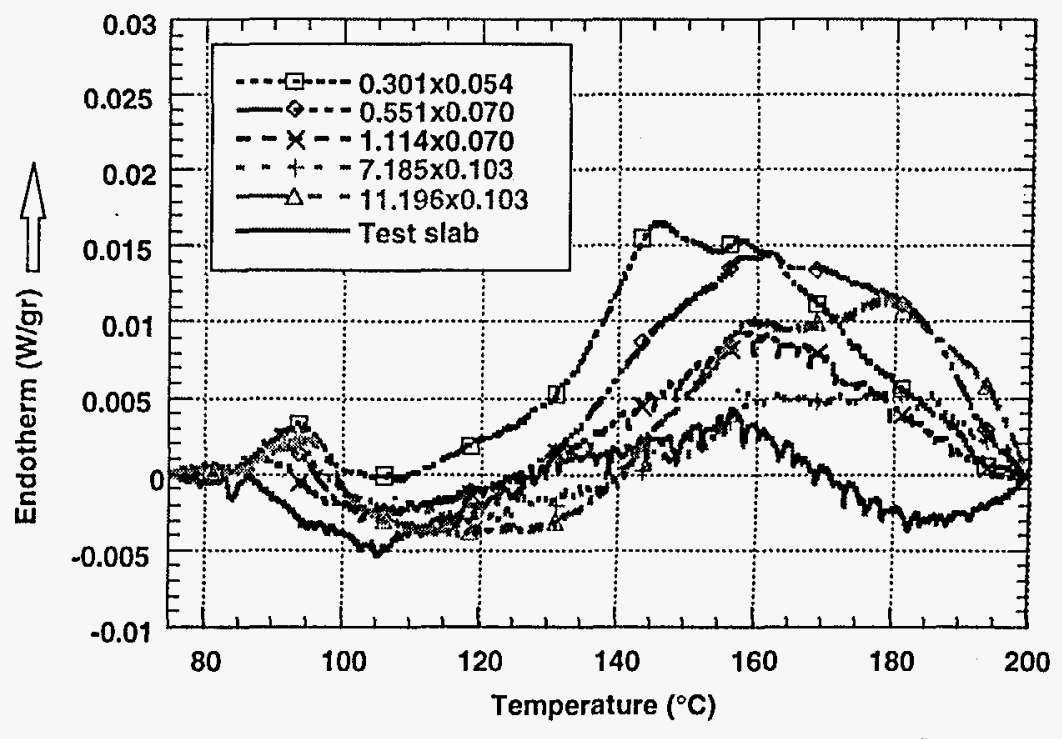



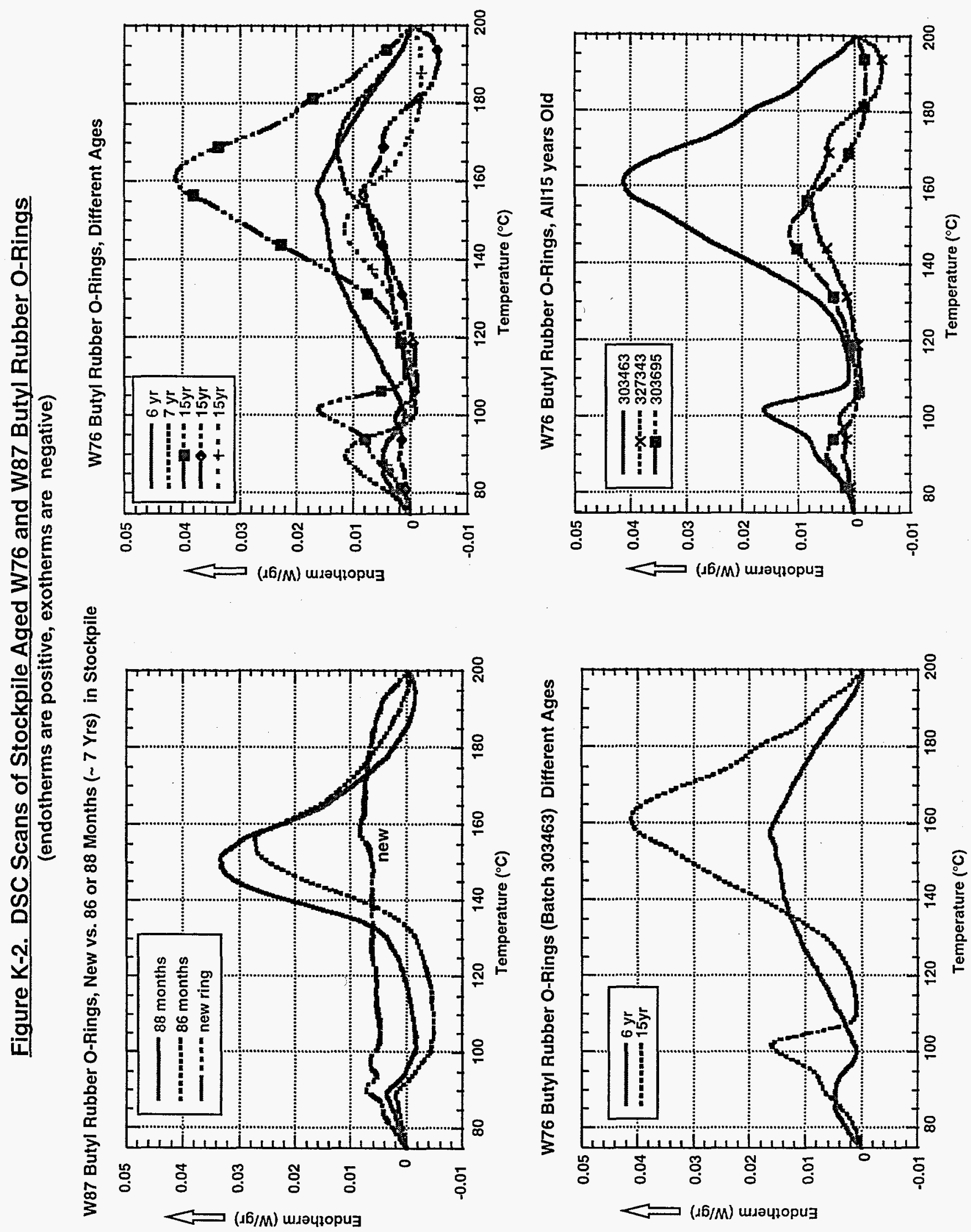


\section{Appendix L: Drawings for Tensile Test Fixtures}

\section{Contents:}

1) Angle Mount Drawing

2) 0.038 inch cross section Mount Insert Drawing

3) $\quad 0.054$ inch cross section Mount Insert Drawing

4) $\quad 0.070$ inch cross section Mount Insert Drawing

5) $\quad 0.103$ inch cross section Mount Insert Drawing

6) 0.139 inch cross section Mount Insert Drawing

All aluminum except No. 2. 


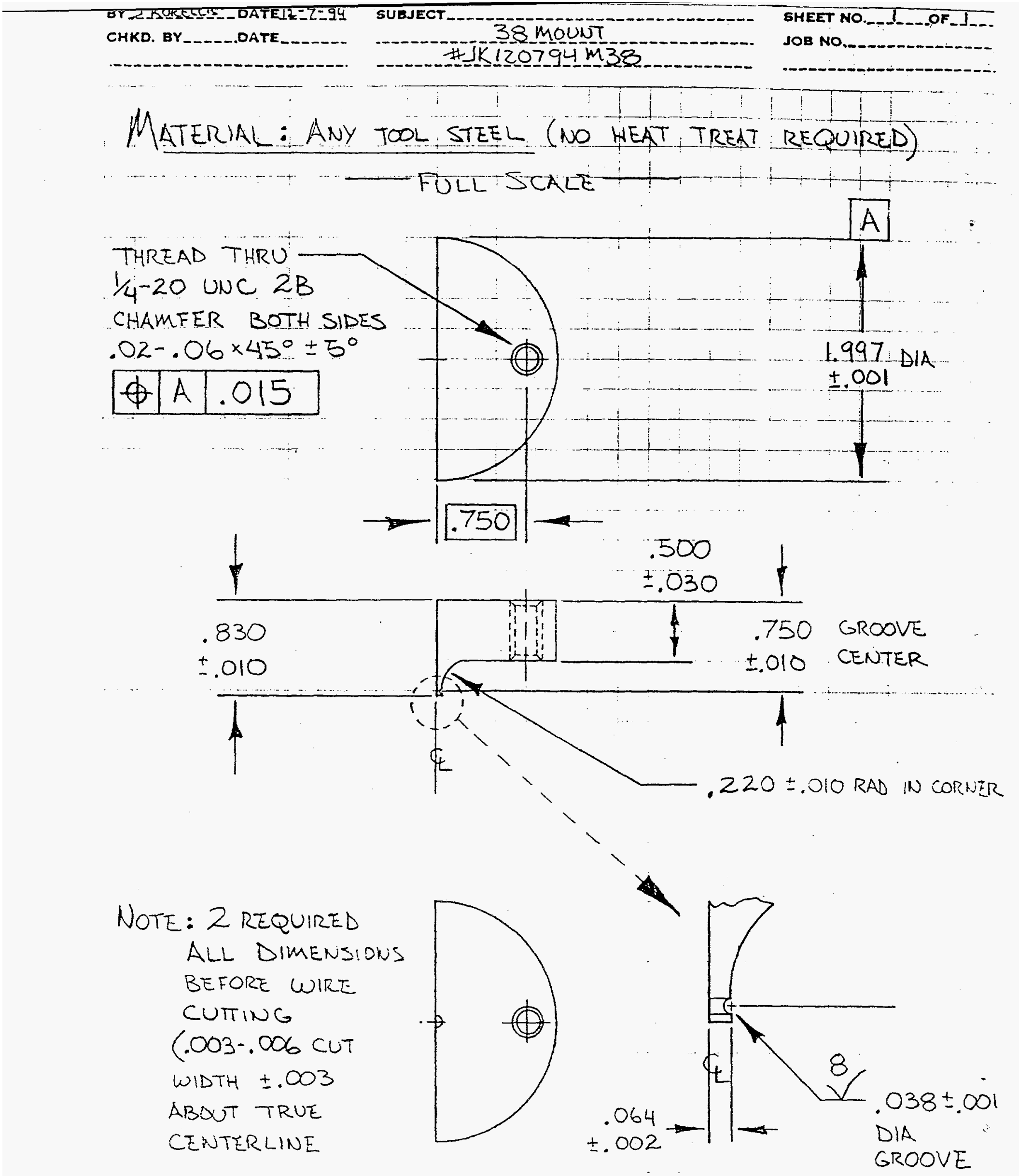


BY_KKOREJLIS DATE $3=7=94$

SUBJECT

54 MOUNT SHEET NO _LL OF -J CHKD. BY_._. DATE \# J $120794 \mathrm{M} 54$ JOB NO.

MATERIAL: 6061-T651 ALuminum FULL SCALE =-

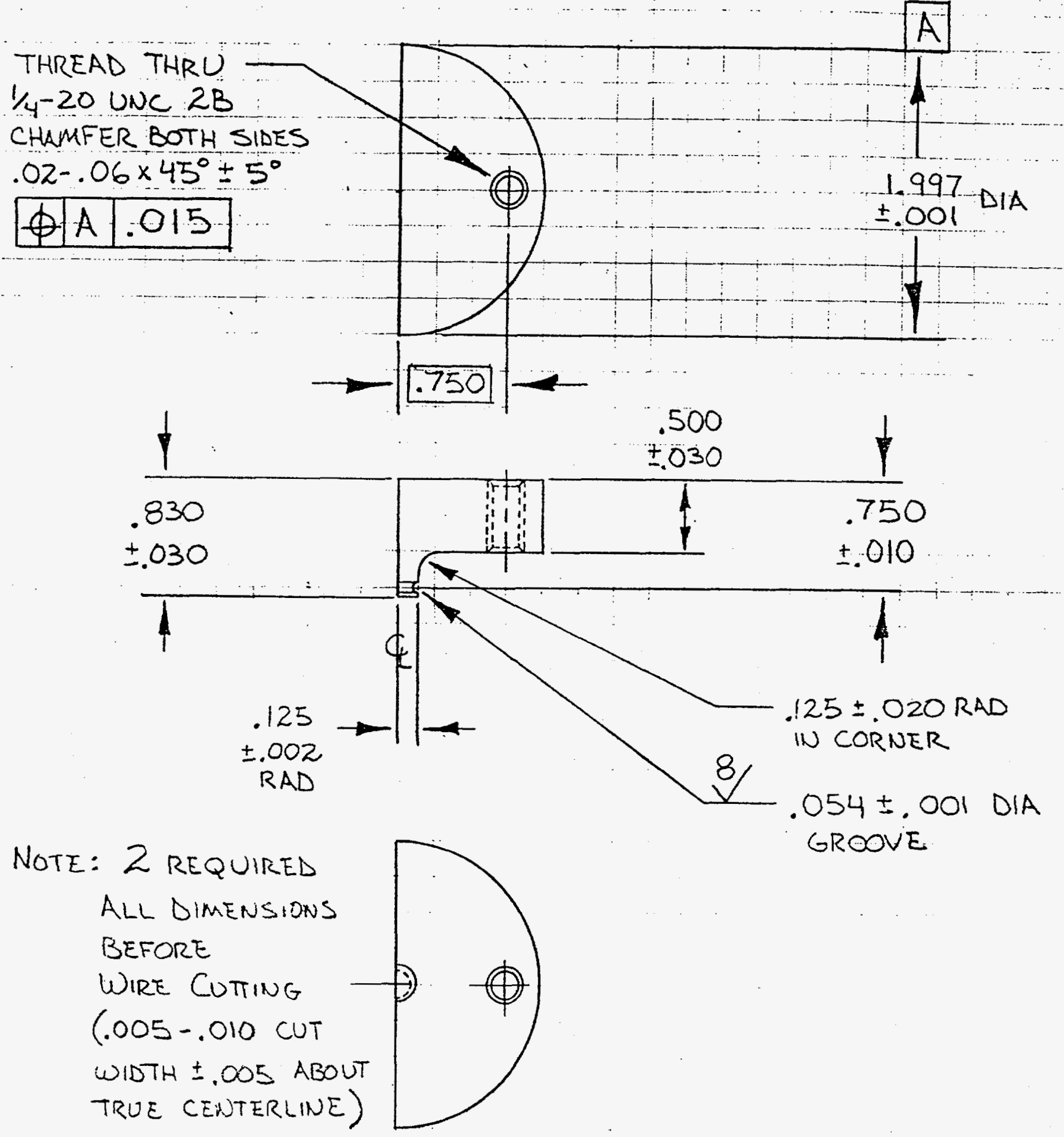

155 


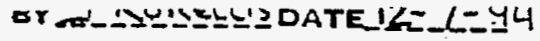

CHKO. BY.
DATE
TOMOUNT

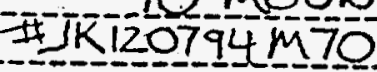

SHEET NO._._L__.OF_..J

JOB NO.

MATERIAL: $6061-7651$ ALUMINUM

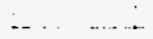

-..

THREAD THRU $1 / 4-20$ UNC:2B CHAMFER BOTH SIDES $.02-.06 \times 45^{\circ} \pm 5^{\circ}$ \begin{tabular}{|l|l|l|}
\hline$\oplus$. & .015 \\
\hline
\end{tabular} $-1 \perp+1$ $+F u$ SCALE
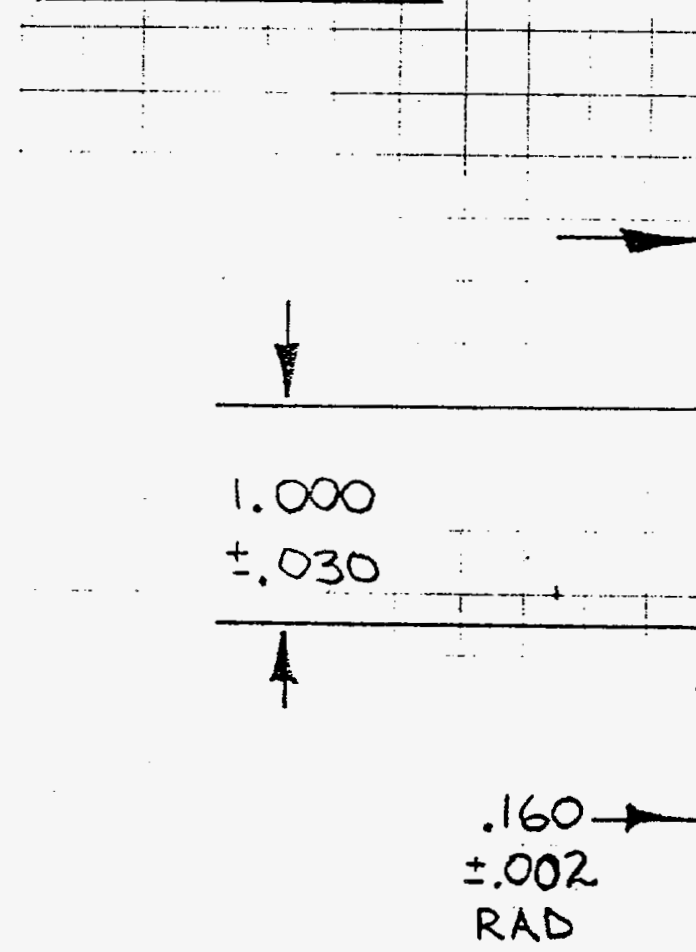

NOTE: 2 REQUIRED All DIMENSIONS BEFORE WIRE CUTTING (.005-.010. CUT WIDTH \pm .005 ABOUT true (ENTERLINE) 
BY 1 KORELLLS_DATE12-6-94 SUBJECT

CHKD. BY. DATE

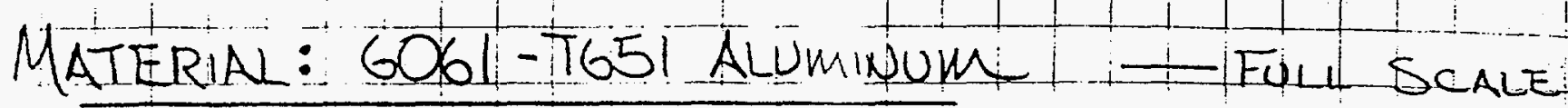

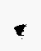

THREAD THRU $1 / 4-20$ ONC $2 B$ CHAMFER BOTH SIDES $.02-.06 \times 45^{\circ} \pm 5^{\circ}$

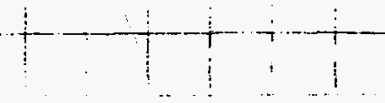
由.A.015

\section{……}

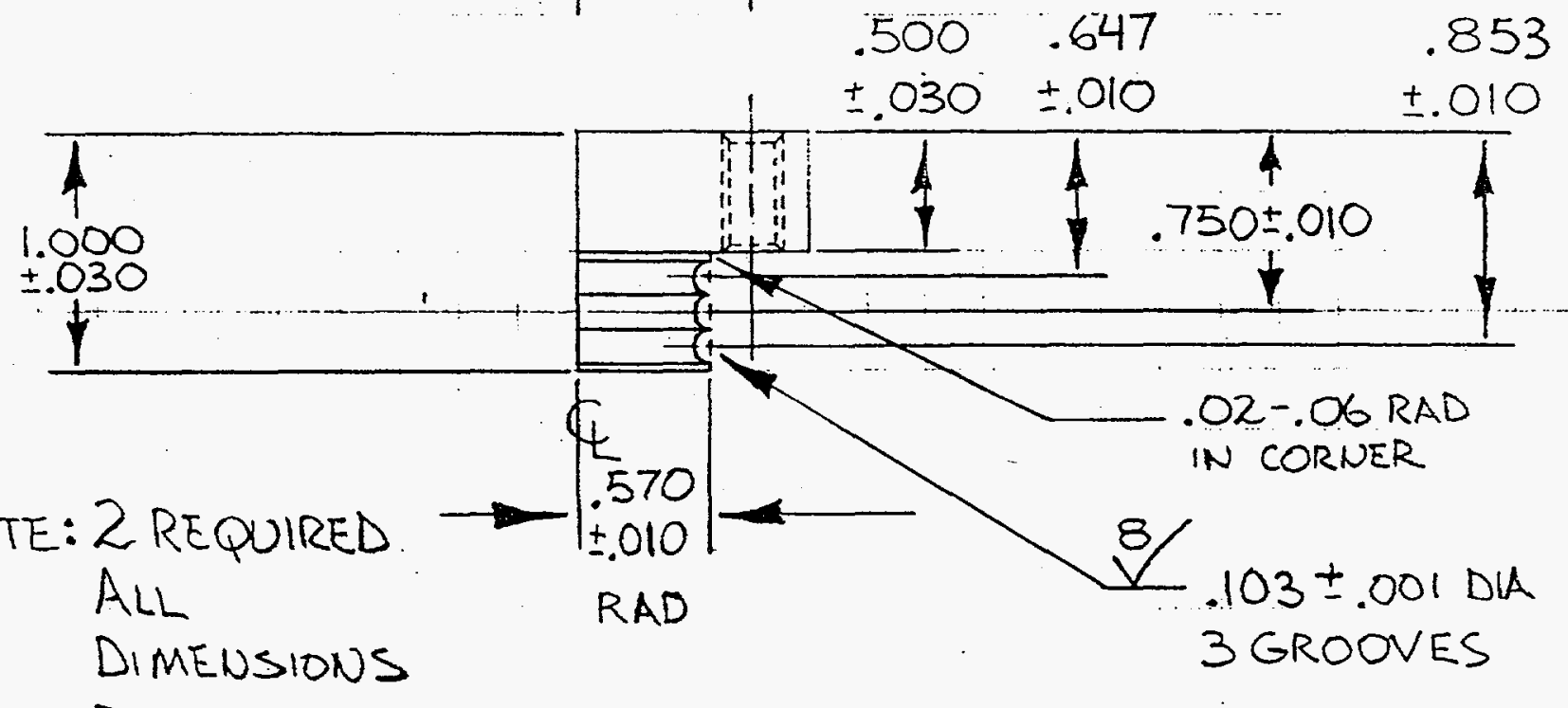

NOTE: 2 REQUIRED ALL BEFORE WIRE CUTING (.005-.012 CUT WIDTH \pm .005 ABOUT TRUE CENTERLINE)

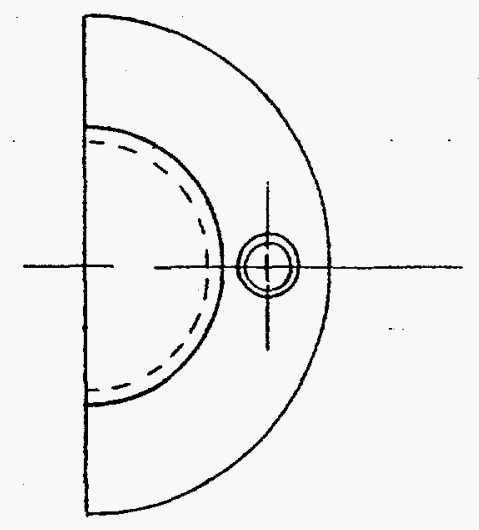


BY_J_KORELLSSDATE12=6-94

CHKD. BY

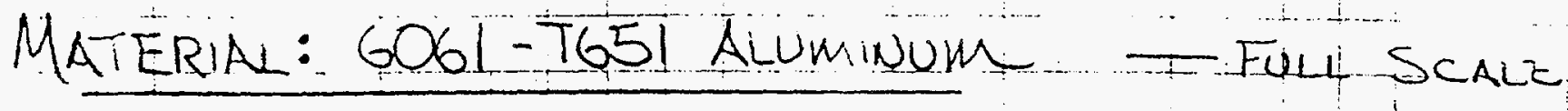

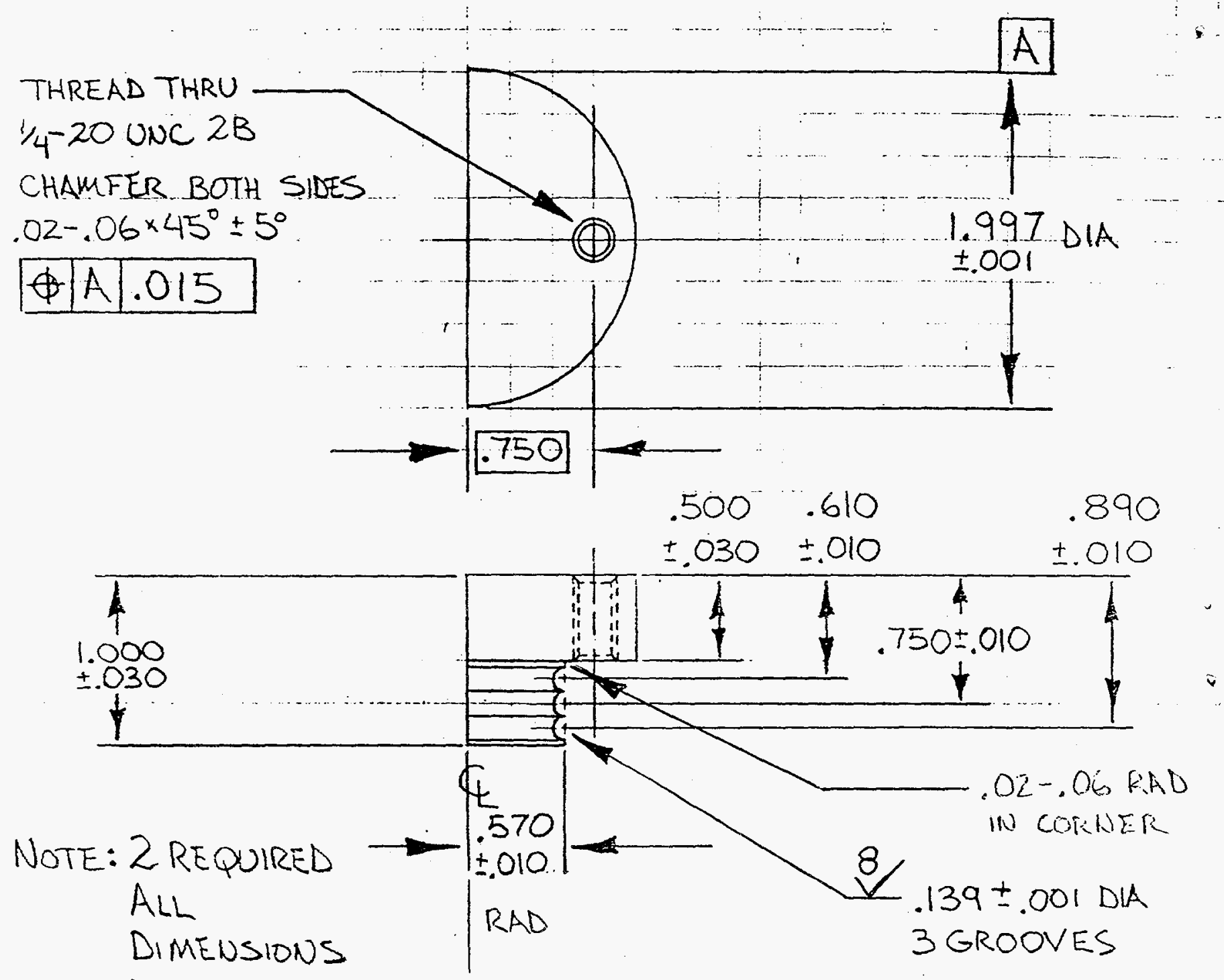

BEFORE

WIRE CUTING

(.005-.012 CUT

WIDTH \pm .005

ABOUT TRUE

CENTERLINE)

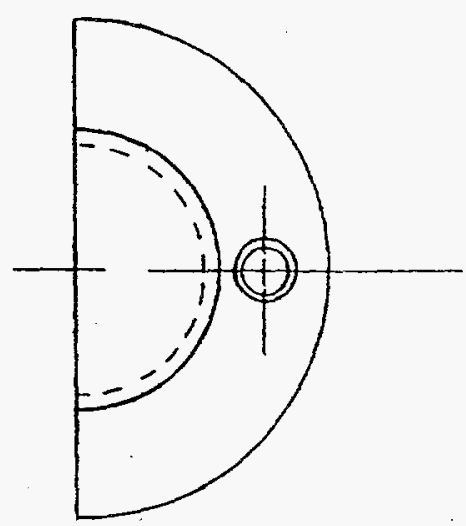




\section{UNLIMITED RELEASE}

\section{INITIAL DISTRIBUTION:}

Allied Signal, Inc.

Federal Manufacturing \& Technologies Division (FM\&T)

Attn: Ed Kibalo

Tommy Snider

Julie A. Stuckey, Dept. ME1-8, MS 2B37

P. O. Box 419159

Mark H. Wilson, Dept. MB4-2C43, MS 2C43

Kansas City, MO 64141-6159

\begin{tabular}{|c|c|}
\hline MS0333 & D. B. Adolf, 1841 \\
\hline MS0333 & J. Curro, 1870 \\
\hline MS0342 & D. Salzbrenner, 1805 \\
\hline MS0443 & R. S. Chambers, 9117 \\
\hline MS0439 & D. J. Segalman, 9234 \\
\hline MS0961 & J. A. Sayre, 1403 \\
\hline MS1407 & R. Clough, 1811 \\
\hline MS 1407 & K. T. Gillen, 1811 \\
\hline MS9001 & T. O. Hunter, 8000 \\
\hline MS9002 & Attn: $\quad$ P. N. Smith, 8200 \\
\hline MS9003 & D. L. Crawford, 8900 \\
\hline MS9004 & M. E. John, 8100 \\
\hline MS9005 & J. B. Wright, 2200 \\
\hline MS9006 & E. E. Ives, 5200 \\
\hline MS9007 & R. C. Wayne, 8400 \\
\hline MS9054 & W. J. McLean, 8300 \\
\hline MS9141 & P. E. Brewer, 8800 \\
\hline MS9405 & T. M. Dyer, 8700 \\
\hline MS9420 & L. A. West, 8200 \\
\hline MS9013 & D. Bozman, 2266 \\
\hline MS9013 & R. Clark, 2266 \\
\hline MS9013 & W. Delameter, 2266 \\
\hline MS9013 & R. G. Miller, 2266 \\
\hline MS9013 & R. Sauls, 2266 \\
\hline MS9013 & D. Walker, 2266 \\
\hline MS9014 & R. B. Anderson, 2271 \\
\hline MS9042 & W. A. Kawahara, 8746 \\
\hline MS9141 & K. Lee, 8746 \\
\hline MS9141 & D. Mosher, 8746 \\
\hline MS9042 & L. I. Weingarten, 8742 \\
\hline MS9141 & J. Korellis, 8746 \\
\hline MS9141 & J. Totten, 8970 \\
\hline MS9402 & M. W. Perra, 8711 \\
\hline MS9403 & S. H. Goods, 8712 \\
\hline MS9403 & D. E. Meeker, 8713 \\
\hline MS9403 & B. E. Mills, 8713 \\
\hline MS9403 & B. C. Odegard, 8712 \\
\hline MS9403 & J. E. Smugeresky, 8712 \\
\hline MS9403 & J. C. F. Wang, 8713 \\
\hline MS9403 & J. L. Yio, 8713 \\
\hline
\end{tabular}




$\begin{array}{ll}\text { MS9405 } & \text { L. A. Domeier, 8230 (10) } \\ \text { MS9405 } & \text { C. C. Henderson, 8230 } \\ \text { MS9405 } & \text { J. M. Hruby, 8230 } \\ \text { MS9405 } & \text { P. N. Keifer, 8230 } \\ \text { MS9405 } & \text { D.M. Skala, 8230 } \\ \text { MS9405 } & \text { K. Wagter, 8230 } \\ & \\ \text { MS9420 } & \text { L. A. West, 8200 } \\ \text { MS9040 } & \text { Attn: B. E. Affeldt, 8210 } \\ \text { MS9405 } & \text { R. E. Stoltz, 8202 } \\ \text { MS9409 } & \text { R. H. Stulen, 8250 } \\ \text { MS9420 } & \text { R. H. Rogers, 8220 } \\ \text { MS9430 } & \text { A. J. West, 8240 } \\ \text { MS9430 } & \text { L. N. Tallerico, 8204 } \\ \text { MS9021 } & \text { Technical Communications Department, 8815, for OSTI (10) } \\ \text { MS9021 } & \text { Technical Communications Department, 8815/Technical Library, MS0899, } \\ \text { MS0899 } & \text { 4414 } \\ \text { MS9018 } & \text { Central Technical Files, 8940-2 (3) }\end{array}$

